\title{
Short-chain fatty acids
}

Citation for published version (APA):

Canfora, E. E. (2016). Short-chain fatty acids: the link between gut microbiota and metabolic health .

[Doctoral Thesis, Maastricht University]. Proefschriftmaken.nl || Uitgeverij BOXPress.

https://doi.org/10.26481/dis.20160923ec

Document status and date:

Published: 01/01/2016

DOI:

$10.26481 /$ dis.20160923ec

Document Version:

Publisher's PDF, also known as Version of record

\section{Please check the document version of this publication:}

- A submitted manuscript is the version of the article upon submission and before peer-review. There can be important differences between the submitted version and the official published version of record.

People interested in the research are advised to contact the author for the final version of the publication, or visit the DOI to the publisher's website.

- The final author version and the galley proof are versions of the publication after peer review.

- The final published version features the final layout of the paper including the volume, issue and page numbers.

Link to publication

\footnotetext{
General rights rights.

- You may freely distribute the URL identifying the publication in the public portal. please follow below link for the End User Agreement:

www.umlib.nl/taverne-license

Take down policy

If you believe that this document breaches copyright please contact us at:

repository@maastrichtuniversity.nl

providing details and we will investigate your claim.
}

Copyright and moral rights for the publications made accessible in the public portal are retained by the authors and/or other copyright owners and it is a condition of accessing publications that users recognise and abide by the legal requirements associated with these

- Users may download and print one copy of any publication from the public portal for the purpose of private study or research.

- You may not further distribute the material or use it for any profit-making activity or commercial gain

If the publication is distributed under the terms of Article $25 \mathrm{fa}$ of the Dutch Copyright Act, indicated by the "Taverne" license above, 
SHORT-CHAIN FATTY ACIDS:

THE LINK BETWEEN GUT MICROBIOTA AND

METABOLIC HEALTH 
(C) Emanuel Canfora, Maastricht 2016

Cover design: Daniel Canfora

Layout: Emanuel Canfora

Printed by: Proefschriftmaken.nl / Uitgeverij BOXPress 


\title{
SHORT-CHAIN FATTY ACIDS: \\ THE LINK BETWEEN GUT MICROBIOTA AND \\ METABOLIC HEALTH
}

\author{
PROEFSCHRIFT \\ Ter verkrijging van de graad van doctor \\ aan de Universiteit Maastricht \\ op gezag van de Rector Magnificus Prof. dr. L.L.G. Soete, \\ volgens het besluit van het College van Decanen, \\ in het openbaar te verdedigen \\ op vrijdag 23 september 2016 om 12.00 uur.
}

door

Emanuel E. Canfora

Geboren te Bietigheim-Bissingen, op 19 mei 1983 
Promotor

Prof. dr. E.E. Blaak

\section{Co-promotores}

Dr. J.W. Jocken

Dr. K. Lenaerts

\section{Beoordelingscommissie}

Prof. dr. W.H.M. Saris (voorzitter)

Prof. dr. N. Delzenne (Université catholique de Louvain, Brussels, België)

Prof. dr. A.K. Groen (Academisch Medisch Centrum Amsterdam)

Dr. D.M.A.E. Jonkers

Prof. Dr. J. Plat 
The studies presented in this thesis were performed within the framework of TI Food and Nutrition and within NUTRIM School of Nutrition and Translational Research in Metabolism, which participates in the Graduate School VLAG (Food Technology, Agrobiotechnology, Nutrition and Healthy Sciences), accredited by the Royal Netherlands Academy of Arts and Sciences.
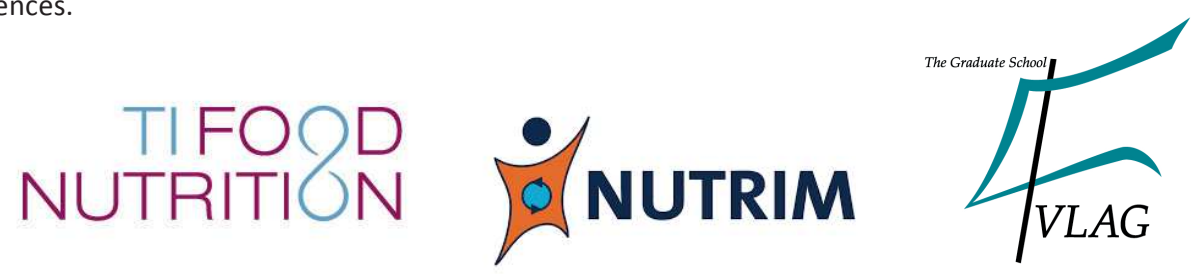

Financial support by the Netherlands Association for the Study of Obesity (NASO) for the publication of this thesis is gratefully acknowledged.

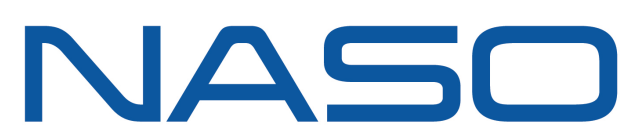





\section{TABLE OF CONTENTS}

Chapter 1. General introduction

Chapter 2. Short-chain fatty acids in control of body weight and insulin sensitivity

Chapter 3. Distal, not proximal, colonic acetate infusions promote fat oxidation and improve metabolic markers in overweight men

Chapter 4. Colonic infusions of short-chain fatty acid mixtures promote energy metabolism in overweight men

Chapter 5. Short-chain fatty acids differentially affect intracellular lipolysis in a human white adipocyte model

Chapter 6. Twelve-week supplementation of galacto-oligosaccharides Increased bifidobacteria in obese prediabetic adults, whereas insulin sensitivity and energy metabolism were not changed

Chapter 7. The role of polydextrose in body weight control and glucose regulation

Chapter 8. General discussion

Appendices. Summary

Zusammenfassung

Valorization

Acknowledgements, Dankwoord, Danksagung

Curriculum Vitae

List of Publications 



\section{CHAPTER 1}

General introduction 


\section{Obesity - The $21^{\text {st }}$ century pandemic}

The worldwide prevalence of obesity has grown enormously in the last decades. ${ }^{1,2}$ Driven by the easy access to energy-dense foods and the increasing sedentary lifestyle, obesity is one of the major health problems of the $21^{\text {st }}$ century and contributes to a wide spectrum of comorbididities. ${ }^{3-5}$ Body mass index (BMI) is a simple calculation (defined as weight in kilograms divided by the square of height in meters $\left.\left(\mathrm{kg} / \mathrm{m}^{2}\right)\right)$ that is commonly used in classifying overweight and obesity in adult populations and individuals. $\mathrm{A} B M \mathrm{BI} \geq 25 \mathrm{~kg} / \mathrm{m}^{2}$ indicates overweight and a $\mathrm{BMI} \geq 30$ $\mathrm{kg} / \mathrm{m}^{2}$ is referred to as obesity, ${ }^{1}$ but the classification of the metabolic and cardiovascular risk of overweight and obesity goes beyond BMI.

Overweight and obesity have reached worldwide epidemic proportions with more than $39 \%$ overweight ( $>1.9$ billion adults, $>60 \%$ in Europe) and $13 \%$ (>600 million) clinically obese adults. ${ }^{1}$ Of great concern is that more than 42 million children under the age of 5 were overweight or obese in 2013 and number are on the rise. ${ }^{1}$ Worldwide, more people die as a consequence of being overweight/obese (>2.8 million adults) than being underweight. Overweight/obesity is thereby the fifth leading cause of death. ${ }^{1}$ While being one of the major public health issues and one of the most important risk factors for cardiovascular disease, type 2 diabetes mellitus, fatty liver disease, mental disorders (i.e. depression) and certain types of cancers, the increasing prevalence has besides public health issues also major socioeconomic consequences. ${ }^{3-6}$

Even though obesity treatment strategies such as increasing physical activity, caloric restriction, behavioural modifications and bariatric surgery are improved in the last decades; the long-term success of these interventions is limited.

Indeed, the expectation is that the obesity pandemic, as well as obesityrelated diseases will increase dramatically in the upcoming years. ${ }^{1}$ Hence, improved and novel strategies are urgently needed. Therefore, additional nutritional and nutraceutical approaches that beneficially impact body weight control and subsequently reduce the obesity-related health complications are crucial for future prevention and treatment of obesity and associated disorders.

A putative strategy to improve control of body weight and obesity-associated insulin resistance is the supplementation of short-chain fatty acids (SCFA). SCFA are formed via the fermentation of indigestible dietary components by the gut microbiota. Animal and in vitro studies increasingly indicate an important role of SCFA as metabolic targets to prevent and treat obesity and obesity-induced insulin resistance. ${ }^{7}$ However, human intervention and mechanistic studies are scarce and 
the importance of SCFA in human energy and substrate metabolism remains to be established.

\section{Interorgan crosstalk in obesity and insulin resistance}

The human energy and substrate metabolism is regulated by a tight interplay between different organs such as the gastrointestinal tract, the liver, adipose tissue, skeletal muscle and pancreas. Derangements in functionality in these organs may cause or contribute to the development of disturbance in glucose and insulin homeostasis (figure 1).

Obesity is a chronic metabolic disorder resulting from an energy imbalance, in which a long-term surplus of energy intake over energy expenditure (that is, positive energy balance) leads to the storage of excess energy as body fat, mainly as triglycerides (TAG) in the adipose tissue. This chronic excessive energy intake leads to a nutritional overload and the adipose tissue and cells will expand to accommodate extra energy in form of TAG. As a result, enlargement (hypertrophy) of existing adipocytes develops. ${ }^{8,9}$ Hypertrophic adipocytes are associated with impairments in the lipid buffering capacity. ${ }^{10}$ This is mainly caused by disturbances in lipoprotein lipase (LPL)-mediated uptake of lipids into adipocytes, ${ }^{11}$ a reduced adipose tissue blood flow (less delivery of TAG and lipoproteins to the adipose tissue) and hypoxia, ${ }^{12,13}$ as well as an reduced lipid turnover (hydrolysation of stored TAG to fatty acids and glycerol and subsequent oxidation). ${ }^{14,15}$ The exceeded lipid buffering capacity in the adipose tissue results in lipid spillover into the systemic and portal circulation leading to an increased lipid supply to other tissues such as the liver, skeletal muscle and pancreas. This subsequently enhances the storage of lipids and lipid metabolites in these tissues, also called ectopic lipid accumulation. An altered storage, localization or composition of bioactive lipid metabolites (i.e. diglycerides, ceramides, long chain acyl-CoA, and acylcarnitines) might result in metabolic derangements via lipid-induced toxicity (lipotoxicity), which interferes with insulin signalling and promotes the development of insulin resistance. ${ }^{16-20}$ In addition, when adipose tissue expands, inflammation develops, which is accompanied by an increased production and secretion of proinflammatory cytokines, chemokines and adipokines, such as tumour necrosis factor (TNF), interleukin 6 (IL-6), IL-1 $\beta$, leptin and monocyte chemoattractant protein-1 (MCP-1). ${ }^{21}$,

${ }^{22}$ An increased MCP-1 expression attracts macrophages to the adipose tissue, which might polarize from anti-inflammatory $\mathrm{M} 2$ to proinflammatory cytokine producing 
M1 macrophages, although this distinction is mainly derived from animal studies and is less pronounced in humans. ${ }^{23,24}$ The increased local inflammation might cause systemic low-grade inflammation, which leads to impairments of insulin signalling and contributes to the development of insulin resistance in hepatocytes, muscle cells, adipocytes and endothelial cells. ${ }^{22,25}$

The skeletal muscle is recognized as one of the most important organs in peripheral insulin resistance, since it is responsible for almost $80 \%$ of insulinstimulated glucose disposal. ${ }^{26}$ Besides the increased supply of lipids to the skeletal muscle, intrinsic disturbances in muscle lipid turnover might be responsible for the impairments in skeletal muscle insulin action. A reduced capacity to oxidize fatty acids is often observed in the skeletal muscle of obese, insulin resistant individuals, ${ }^{27}$ which is partly related to an impaired fatty acid uptake, a disturbed intramuscular lipolysis and impairments in the mitochondrial capacity. ${ }^{28,}{ }^{29}$ Consequently, the muscle cannot process the excess supply of fatty acids, caused by the impaired adipose tissue lipid buffering capacity. This imbalance of lipid uptake and utilization might contribute to increased accumulation of lipid metabolites such as ceramides, diglycerides and acylcarnitines, which leads to lipotoxicity and insulin resistance by interfering with insulin signalling and by stimulating inflammatory pathways. ${ }^{27,}$ 29-31

The gastrointestinal tract is the first organ to encounter dietary nutrients after oral ingestion. Hence, its primary task is to digest and absorb food components to yield energy and serve as building block for larger biomolecules, essential for whole-body homeostasis. Importantly, the intestine is also a major endocrine organ, responsible for the secretion of satiety hormones, incretins and inflammatory factors, which have a great influence on energy and substrate metabolism. Disturbances in this secretory function, i.e. due to high-fat diet induced intestinal inflammation and impaired endocrine function, might contribute to obesity and insulin resistance. ${ }^{32}$ Furthermore, disturbances in intestinal macronutrient handling, i.e. a disturbed intestinal fat oxidation or absorption, might contribute to the imbalance in energy homeostasis. ${ }^{33}$ However, not only the intestine itself but also its residents, the gut microbiota and its products, seem to be highly involved in the aetiology of obesity and obesity-induced insulin resistance, as discussed in the next section. 


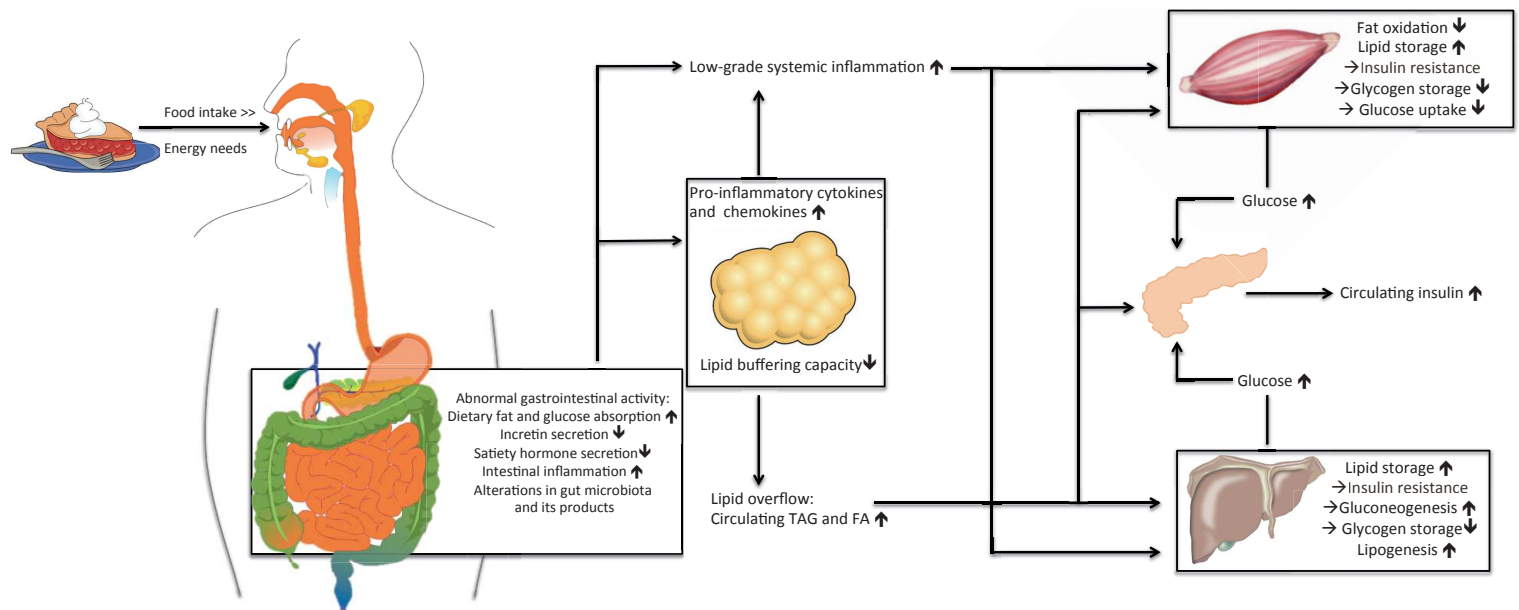

Figure 1. Interorgan crosstalk in relation to obesity-induced insulin resistance. Under conditions of chronic positive energy balance (intake>>expenditure), adipose tissue exceeds its buffering capacity to store all excess energy in the form of TAG resulting in lipid overflow into the circulation. This increased supply of lipids to non-adipose tissues such as the liver, skeletal muscle and pancreas results in ectopic fat storage and the development of insulin resistance. Together with a reduced lipid buffering capacity, adipose tissue inflammation develops, which is accompanied with an increased production and secretion of proinflammatory cytokines and chemokines. In addition, abnormalities in the gastrointestinal activity and the gut microbiome might contribute to the disturbed adipose tissue function and low-grade inflammation. Consequently, disturbances in tissue/organ function contribute to the development of peripheral insulin resistance and a disturbed glucose homeostasis.

\section{Gut microbiota in obesity and insulin resistance}

In recent years, the gut microbiota has emerged as regulator of the energy and substrate metabolism, and an important contributor to the aetiology of obesity and insulin resistance. ${ }^{34-36}$ The dominant phyla of the microbiota in the distal gut are Bacteroidetes ( 20-25\%), Firmicutes ( 60-65\%), Proteobacteria ( 5-10\%) and Actinobacteria ( 3 \%). ${ }^{37,38}$ Phylum-level and even family-level grouping of microbes are, however, too global to make a functionally significant separation, since different species within one phylum might greatly vary in their function. Nevertheless, most preliminary conclusions, which link the human gut microbiota to obesity and comorbidities are, so far, limited to ratios or abundance of microbial at phylum-level. A number of studies have shown that obese compared to lean humans differ in microbial diversity, gene enrichment, and have an increased fractional proportion of Firmicutes relative to Bacteroidetes, ${ }^{37,39-43}$ but, with respect to the latter, other studies also report contradictory findings. ${ }^{44-46}$ However, on genus-like taxonomic 
level some bacteria such as Faecalibacterium prausnitzii, Bifidobacterium and Akkermansia muciniphila have been identified as putative beneficial contributors to host inflammation, glucose and insulin homeostasis. ${ }^{47-50}$

Overall, the human gut microbiota consists of up to 100 trillion microbes and carries more than 150 times more genes than are present in the human genome. ${ }^{51}$ Significant efforts have been invested in studying the impact of our human genome in putative personalized dietary effects and health. However, within individuals our genomes are nearly identical (up to $99.9 \%$ ), whereas our gut microbiome might show only $10 \%$ similarity from one individual to another. ${ }^{51}$ Therefore, studies on personalized nutrition, and health based on one individuals' genetic makeup might have been on the wrong track, since the dominant factor in variation may lie within our microbiome rather than our genome. Intriguingly, in a large-scale study including 893 human heterogenic subjects, a strong association between the gut microbiota composition and variations in $\mathrm{BMI}$ and blood lipids independent of age, gender and host genome has been observed. ${ }^{52}$ In addition, a study in over 800 people revealed a strong relationship between the gut microbiome and individual blood glucose levels. Based on extensive gut microbiome analysis and metabolic data sets of the individuals including continuous glucose monitoring, the authors developed machine-learning models. A personalized dietary intervention based on this algorithm clearly demonstrated the importance of our gut microbial composition on postprandial glucose response and host metabolic heath. ${ }^{53}$

In addition, recent human studies have shown that gut microbiota manipulation could impact host physiology and health. Faecal transplantation transferring intestinal microbiota from lean to obese individuals improved peripheral insulin sensitivity, hereby suggesting a direct role of the gut microbiota on host metabolism. ${ }^{54}$ Next, oral antibiotic treatment with vancomycin against gram-positive gut bacteria decreased peripheral insulin sensitivity in obese male subjects, which illustrates that intestinal microbiota, particularly of the Firmicutes phylum might contribute to glucose metabolism in humans. ${ }^{55}$ Nevertheless, other studies in humans did not confirm this antibiotic-induced effect of the gut microbiota on host insulin and glucose homeostasis. ${ }^{56,57}$

Besides the important abilities of the gut microbiota to interact with the host immune system, ${ }^{58}$ de novo synthesis and supply of vitamins, ${ }^{59}$ and bile acid metabolism, ${ }^{60}$ the effect of intestinal microbiota on host metabolism is mediated to a large extent via an enzyme-regulated hydrolysation of indigestible foods, such as dietary fibres and resistant starch. ${ }^{61-63}$ Of note, the gut microbiota of lean and obese 
individuals differ in their ability to ferment complex indigestible foods and to use the fermentation products as an energy source. ${ }^{61,64}$ Furthermore, both animal and human studies demonstrated that changes in macronutrient composition and the intake of specific dietary compounds could rapidly alter microbial composition. ${ }^{53,65-}$ 67 These data suggest that dietary interventions targeting gut microbiota composition might be an effective method to prevent and treat metabolic disorders.

\section{Short-chain fatty acids and metabolic health}

The above described microbial fermentation process ends up in the production of several important metabolites such as SCFA. These SCFA are in part further metabolized and converted by the local microbiota, they provide energy to the cells of the colonic epithelium, and they might act as important substrate and signalling molecules between the gut and host immune system and metabolism.

Increasing evidence supports that these gut-derived SCFA, including acetate, propionate and butyrate play a key role in host substrate and energy metabolism. ${ }^{7,68}$ SCFA might not only exert local colonic health effects but might also induce the secretion of gut-derived signalling hormones such as glucagon-like peptide 1 (GLP-1), peptide YY (PYY) and angiopoetin-like peptide 4 (ANGPTL4). ${ }^{7}$ Interestingly, SCFA can also enter the bloodstream, ${ }^{69}$ thereby acting as important signalling molecules between the gut microbiota and host physiology. ${ }^{7,35,70}$ Furthermore, SCFA might affect body weight control via regulation of energy intake, energy harvesting and host peripheral substrate and energy metabolism, thereby having a key role in the pathophysiology of obesity. ${ }^{71-77}$

Several mechanisms that link SCFA to insulin and glucose metabolism and the development of type 2 diabetes mellitus have been proposed, including production of incretins affecting satiety, glycaemic response and gastro-intestinal transit, effects on adipose tissue fat storage, liver and skeletal muscle substrate metabolism and the development of chronic low-grade-inflammation. ${ }^{76,78,79}$ The suggested mechanisms are mainly based on animal studies and are extensively reviewed in Chapter $\mathbf{2}$ of this thesis. 
General introduction

\section{Dietary fibre in body weight and glucose control}

Dietary fibres are indigestible carbohydrates such as oligosaccharides, lignin and polysaccharides. Dietary fibres can be classified by solubility, fermentation ability by gut microbes and viscosity. In the last years, nutritional and obesity research has focused on the study of putative prebiotic fibres, as they might beneficially alter the gut microbial composition. These fibres are proposed to be beneficial with respect to control of body weight and glucose homeostasis, as are extensively discussed in Chapter $\mathbf{2}$ and $\mathbf{7}$ of this thesis. However, data on the longerterm effects of fibres in humans are limited and controversial, and mechanisms are not completely understood. Proposed mechanisms are impacts on orocaecal transit time, nutrient absorption, immune response and gut hormone production, as well as interactions with the gut microbiota and their fermentation by the gut microbiota, which delivers important metabolites, such as SCFA.

\section{Aim and outline of the thesis}

This thesis focuses on the role of the short-chain fatty acids (SCFA) acetate, propionate and butyrate in human substrate and energy metabolism.

Chapter 2 provides a comprehensive review of current state of the art on the role of SCFA in body weight control and insulin sensitivity. The systemic literature review provides data on SCFA production and absorption rates and on circulating SCFA concentrations. Furthermore, the controversial role of SCFA in energy homeostasis and adipose tissue, skeletal muscle and liver function related to insulin sensitivity is discussed in depth. Finally, a detailed overview is given on human studies investigating the effect of acute and long-term SCFA administration and dietary fibre(s) in relation to glucose homeostasis. So far, most data on the role of SCFA in host metabolism are based on animal studies.

The main goal of the current thesis was to elucidate the role of gut-derived SCFA in human substrate and energy metabolism by combing acute and long-term human clinical studies and in vitro studies directed at understanding fundamental molecular mechanisms. Therefore, in Chapter 3, a unique technique that enabled us to administer SCFA in both the proximal and distal part of the human colon was developed. This design allowed us to examine which route of administration of the SCFA acetate, either proximal or distal, induces the most pronounced effects on fat oxidation, energy expenditure and several circulating metabolic parameters in 
overweight men. As a follow-up, in Chapter 4, an acute clinical study is described. In this study, physiologically relevant SCFA mixtures, that can be achieved by dietary fibre intake, were infused in the distal part of the colon and the effects on fat oxidation, energy expenditure and metabolic profile were studied in overweight men. In Chapter 5, we used an in vitro human white adipocyte model, the human multipotent adipose-derived stem (hMADS) cells to evaluate mechanisms involved in the SCFA-mediated inhibition of lipolysis.

Based on the outcome of the studies outlined in Chapter $\mathbf{3}$ and Chapter $\mathbf{4}$ and available in vitro fermentation data, a dietary acetogenic fibre was selected for a longer-term clinical study. This fibre was hypothesized to lead to a healthy SCFA profile and improved peripheral insulin sensitivity. This proof-of-concept study is presented in Chapter 6. In this randomized placebo-controlled trial, we assessed the effects of 12 week supplementation with the prebiotic galacto-oligosaccharides (GOS) on changes in peripheral insulin sensitivity, substrate oxidation, energy expenditure, body composition, circulating metabolites, gut microbiota composition, and in faecal/plasma SCFA concentrations in overweight/obese subjects with impaired glucose metabolism. Chapter 7 reviews the current literature on the effects of putative prebiotic fibre polydextrose (PDX) on body weight control and glucose metabolism. Recent human intervention studies and the mechanisms involved in the PDX effects are discussed, including effects on gut transit time, intestinal macronutrient absorption, gut microbiota composition and SCFA production.

To its end, in Chapter 8, the main findings from the studies described in this thesis are integrated and discussed in a broader perspective and suggestions for future research directions are provided. 


\section{References}

1. Organization WHO. http://www.who.int/mediacentre/factsheets/fs311/en/, 2015.

2. $\mathrm{Ng} \mathrm{M}$, Fleming $\mathrm{T}$, Robinson $\mathrm{M}$, et al. Global, regional, and national prevalence of overweight and obesity in children and adults during 1980-2013: a systematic analysis for the Global Burden of Disease Study 2013. The Lancet 2014;384:766-781.

3. Bhaskaran $\mathrm{K}$, Douglas I, Forbes $\mathrm{H}$, et al. Body-mass index and risk of 22 specific cancers: a population-based cohort study of $5 \cdot 24$ million UK adults. The Lancet 2014;384:755-765.

4. Preiss K, Brennan L, Clarke D. A systematic review of variables associated with the relationship between obesity and depression. Obesity Reviews 2013;14:906-918.

5. Kahn SE, Hull RL, Utzschneider KM. Mechanisms linking obesity to insulin resistance and type 2 diabetes. Nature 2006;444:840-846.

6. Wormser D, Kaptoge S, Di Angelantonio E, et al. Separate and combined associations of body-mass index and abdominal adiposity with cardiovascular disease: collaborative analysis of 58 prospective studies. The Lancet 2011;377:1085-1095.

7. Canfora EE, Jocken JW, Blaak EE. Short-chain fatty acids in control of body weight and insulin sensitivity. Nat Rev Endocrinol 2015;11:577-591.

8. Krotkiewski M, Björntorp P, Sjöström L, et al. Impact of obesity on metabolism in men and women. Importance of regional adipose tissue distribution. Journal of Clinical Investigation 1983;72:1150.

9. Srdic B, Ukropina ESAKM, Breberlna KVM. Morphological Characteristics of Abdominal Adipose Tissue in Normal-Weight and Obese Women of Different Metabolic Profiles. 2010.

10. Lundgren $\mathrm{M}$, Svensson $\mathrm{M}$, Lindmark $\mathrm{S}$, et al. Fat cell enlargement is an independent marker of insulin resistance and 'hyperleptinaemia'. Diabetologia 2007;50:625-633.

11. Potts JL, Coppack SW, Fisher RM, et al. Impaired postprandial clearance of triacylglycerol-rich lipoproteins in adipose tissue in obese subjects. American Journal of Physiology-Endocrinology And Metabolism 1995;268:E588-E594.

12. Blaak $E$, Van Baak $M$, Kemerink $G$, et al. $\beta$-adrenergic stimulation and abdominal subcutaneous fat blood flow in lean, obese, and reduced-obese subjects. Metabolism 1995;44:183-187.

13. Goossens GH, Bizzarri A, Venteclef N, et al. Increased adipose tissue oxygen tension in obese compared with lean men is accompanied by insulin resistance, impaired adipose tissue capillarization, and inflammation. Circulation 2011;124:67-76.

14. Nellemann B, Gormsen LC, Sørensen LP, et al. Impaired Insulin-Mediated Antilipolysis and Lactate Release in Adipose Tissue of Upper-Body Obese Women. Obesity 2012;20:57-64.

15. Jocken J, Goossens G, van Hees A, et al. Effect of beta-adrenergic stimulation on whole-body and abdominal subcutaneous adipose tissue lipolysis in lean and obese men. Diabetologia 2008;51:320-327.

16. Machann J, Häring $\mathrm{H}$, Schick $\mathrm{F}$, et al. Intramyocellular lipids and insulin resistance. Diabetes, Obesity and Metabolism 2004;6:239-248.

17. Perry RJ, Samuel VT, Petersen KF, et al. The role of hepatic lipids in hepatic insulin resistance and type 2 diabetes. Nature 2014;510:84.

18. Glass CK, Olefsky JM. Inflammation and lipid signaling in the etiology of insulin resistance. Cell metabolism 2012;15:635-645.

19. Aguer C, McCoin CS, Knotts TA, et al. Acylcarnitines: potential implications for skeletal muscle insulin resistance. The FASEB Journal 2015;29:336-345.

20. Seiler S, Koves T, Gooding J, et al. Carnitine Acetyltransferase Mitigates Metabolic Inertia and Muscle Fatigue during Exercise. Cell metabolism 2015;22:65. 
21. Hotamisligil GS, Shargill NS, Spiegelman BM. Adipose expression of tumor necrosis factor-alpha: direct role in obesity-linked insulin resistance. Science 1993;259:87-91.

22. Makki K, Froguel P, Wolowczuk I. Adipose Tissue in Obesity-Related Inflammation and Insulin Resistance: Cells, Cytokines, and Chemokines. ISRN inflammation $2013 ; 2013$.

23. Wynn TA, Chawla A, Pollard JW. Macrophage biology in development, homeostasis and disease. Nature 2013;496:445-455.

24. Mraz M, Haluzik M. The role of adipose tissue immune cells in obesity and low-grade inflammation. Journal of Endocrinology 2014;222:R113-R127.

25. Goossens GH, Blaak EE, Theunissen R, et al. Expression of NLRP3 inflammasome and $T$ cell population markers in adipose tissue are associated with insulin resistance and impaired glucose metabolism in humans. Molecular immunology 2012;50:142-149.

26. Defronzo $R$, Jacot $E$, Jequier $E$, et al. The effect of insulin on the disposal of intravenous glucose: results from indirect calorimetry and hepatic and femoral venous catheterization. Diabetes 1981;30:1000-1007.

27. Blaak EE, Hul G, Verdich C, et al. Fat oxidation before and after a high fat load in the obese insulin-resistant state. The Journal of Clinical Endocrinology \& Metabolism 2006;91:1462-1469.

28. Hulver MW, Berggren JR, Carper MJ, et al. Elevated stearoyl-CoA desaturase-1 expression in skeletal muscle contributes to abnormal fatty acid partitioning in obese humans. Cell metabolism 2005;2:251-261.

29. Koves TR, Ussher JR, Noland RC, et al. Mitochondrial overload and incomplete fatty acid oxidation contribute to skeletal muscle insulin resistance. Cell metabolism 2008;7:45-56.

30. Corpeleijn E, Saris W, Blaak E. Metabolic flexibility in the development of insulin resistance and type 2 diabetes: effects of lifestyle. obesity reviews 2009;10:178-193.

31. Blaak EE, Wagenmakers AJ, Glatz JF, et al. Plasma FFA utilization and fatty acidbinding protein content are diminished in type 2 diabetic muscle. American Journal of Physiology-Endocrinology And Metabolism 2000;279:E146-E154.

32. Ding S, Lund PK. Role of intestinal inflammation as an early event in obesity and insulin resistance. Current opinion in clinical nutrition and metabolic care 2011;14:328.

33. Warnakula S, Hsieh J, Adeli K, et al. New insights into how the intestine can regulate lipid homeostasis and impact vascular disease: frontiers for new pharmaceutical therapies to lower cardiovascular disease risk. Canadian Journal of Cardiology 2011;27:183-191.

34. Murphy KG, Dhillo WS, Bloom SR. Gut peptides in the regulation of food intake and energy homeostasis. Endocr Rev 2006;27:719-27.

35. Diamant M, Blaak EE, de Vos WM. Do nutrient-gut-microbiota interactions play a role in human obesity, insulin resistance and type 2 diabetes? Obes Rev 2011;12:272-81.

36. Delzenne NM, Cani PD, Everard A, et al. Gut microorganisms as promising targets for the management of type 2 diabetes. Diabetologia 2015;58:2206-2217.

37. Turnbaugh PJ, Hamady M, Yatsunenko T, et al. A core gut microbiome in obese and lean twins. nature 2008;457:480-484.

38. Consortium HMP. Structure, function and diversity of the healthy human microbiome. Nature 2012;486:207-214.

39. Walters WA, Xu Z, Knight R. Meta-analyses of human gut microbes associated with obesity and IBD. FEBS letters 2014;588:4223-4233.

40. Ley RE, Turnbaugh PJ, Klein S, et al. Microbial ecology: human gut microbes associated with obesity. Nature 2006;444:1022-1023. 
41. Schwiertz A, Taras D, Schäfer K, et al. Microbiota and SCFA in lean and overweight healthy subjects. Obesity (Silver Spring, Md.) 2010;18:190-195.

42. Arumugam M, Raes J, Pelletier E, et al. Enterotypes of the human gut microbiome. nature 2011;473:174-180.

43. Le Chatelier E, Nielsen T, Qin J, et al. Richness of human gut microbiome correlates with metabolic markers. Nature 2013;500:541-546.

44. Zhao L. The gut microbiota and obesity: from correlation to causality. Nature Reviews Microbiology 2013;11:639-647.

45. Hartstra AV, Bouter KE, Bäckhed F, et al. Insights Into the Role of the Microbiome in Obesity and Type 2 Diabetes. Diabetes care 2015;38:159-165.

46. Wu GD, Chen J, Hoffmann C, et al. Linking long-term dietary patterns with gut microbial enterotypes. Science 2011;334:105-108.

47. Qin J, Li Y, Cai Z, et al. A metagenome-wide association study of gut microbiota in type 2 diabetes. Nature 2012;490:55-60.

48. Karlsson FH, Tremaroli V, Nookaew I, et al. Gut metagenome in European women with normal, impaired and diabetic glucose control. Nature 2013;498:99-103.

49. Santacruz A, Marcos A, Wärnberg J, et al. Interplay Between Weight Loss and Gut Microbiota Composition in Overweight Adolescents. Obesity 2009;17:1906.

50. Dewulf E, Cani P, Claus S, et al. Insight into the prebiotic concept: lessons from an exploratory, double blind intervention study with inulin-type fructans in obese women. Gut 2013;62:1112-1121.

51. Ursell LK, Haiser HJ, Van Treuren W, et al. The intestinal metabolome: an intersection between microbiota and host. Gastroenterology 2014;146:1470-1476.

52. Fu J, Bonder MJ, Cenit MC, et al. The Gut Microbiome Contributes to a Substantial Proportion of the Variation in Blood Lipids. Circulation research 2015;117:817-824.

53. Zeevi D, Korem T, Zmora N, et al. Personalized Nutrition by Prediction of Glycemic Responses. Cell 2015;163:1079-1094.

54. Vrieze A, Van Nood E, Holleman F, et al. Transfer of intestinal microbiota from lean donors increases insulin sensitivity in individuals with metabolic syndrome. Gastroenterology 2012;143:913-6 e7.

55. Vrieze A, Out C, Fuentes S, et al. Impact of oral vancomycin on gut microbiota, bile acid metabolism, and insulin sensitivity. Journal of hepatology 2014;60:824-831.

56. Mikkelsen KH, Frost M, Bahl MI, et al. Effect of Antibiotics on Gut Microbiota, Gut Hormones and Glucose Metabolism. PloS one 2015;10:e0142352.

57. Reijnders D, Goossens GH, Neis EP, et al. Effects of gut microbiota manipulation by antibiotics on host metabolism in obese humans. Obesity Facts 2015;T1/T2:OS1.1.

58. Everard A, Geurts L, Caesar R, et al. Intestinal epithelial MyD88 is a sensor switching host metabolism towards obesity according to nutritional status. Nature communications 2014;5.

59. LeBlanc JG, Milani C, de Giori GS, et al. Bacteria as vitamin suppliers to their host: a gut microbiota perspective. Current opinion in biotechnology 2013;24:160-168.

60. Kuipers F, Bloks VW, Groen AK. Beyond intestinal soap - bile acids in metabolic control. Nat Rev Endocrinol 2014;10:488-498.

61. Ridaura VK, Faith JJ, Rey FE, et al. Gut microbiota from twins discordant for obesity modulate metabolism in mice. Science 2013;341:1241214.

62. Gill SR, Pop M, DeBoy RT, et al. Metagenomic analysis of the human distal gut microbiome. science 2006;312:1355-1359.

63. Delzenne NM, Neyrinck AM, Bäckhed F, et al. Targeting gut microbiota in obesity: effects of prebiotics and probiotics. Nature Reviews Endocrinology 2011;7:639-646.

64. Turnbaugh PJ, Ley RE, Mahowald MA, et al. An obesity-associated gut microbiome with increased capacity for energy harvest. Nature 2006;444:1027-131. 
65. Ley RE, Backhed F, Turnbaugh P, et al. Obesity alters gut microbial ecology. Proc Natl Acad Sci U S A 2005;102:11070-5.

66. Walker AW, Ince J, Duncan SH, et al. Dominant and diet-responsive groups of bacteria within the human colonic microbiota. ISME J 2011;5:220-30.

67. Korem T, Zeevi D, Suez J, et al. Growth dynamics of gut microbiota in health and disease inferred from single metagenomic samples. Science 2015;349:1101-1106.

68. Canfora EE, Blaak EE. The role of polydextrose in body weight control and glucose regulation. Current Opinion in Clinical Nutrition \& Metabolic Care 2015;18:395-400.

69. Bloemen JG, Venema K, van de Poll MC, et al. Short chain fatty acids exchange across the gut and liver in humans measured at surgery. Clinical nutrition 2009;28:657-661.

70. den Besten G, van Eunen K, Groen AK, et al. The role of short-chain fatty acids in the interplay between diet, gut microbiota and host energy metabolism. Journal of lipid research 2013.

71. De Vadder F, Kovatcheva-Datchary P, Goncalves D, et al. Microbiota-generated metabolites promote metabolic benefits via gut-brain neural circuits. Cell 2014;156:84-96.

72. Gao Z, Yin J, Zhang J, et al. Butyrate improves insulin sensitivity and increases energy expenditure in mice. Diabetes 2009;58:1509.

73. Lin HV, Frassetto A, Kowalik Jr EJ, et al. Butyrate and Propionate Protect against Diet-Induced Obesity and Regulate Gut Hormones via Free Fatty Acid Receptor 3Independent Mechanisms. PLoS ONE 2012;7:e35240.

74. Frost $G$, Sleeth ML, Sahuri-Arisoylu M, et al. The short-chain fatty acid acetate reduces appetite via a central homeostatic mechanism. Nature communications 2014;5.

75. Freeland KR, Wolever T. Acute effects of intravenous and rectal acetate on glucagonlike peptide-1, peptide YY, ghrelin, adiponectin and tumour necrosis factor-alpha. British Journal of Nutrition 2010;103:460-466.

76. den Besten G, Bleeker A, Gerding A, et al. Short-Chain Fatty Acids protect against High-Fat Diet-Induced Obesity via a PPAR $\gamma$-dependent switch from lipogenesis to fat oxidation. Diabetes 2015:db141213.

77. Murphy $E$, Cotter $P$, Healy $S$, et al. Composition and energy harvesting capacity of the gut microbiota: relationship to diet, obesity and time in mouse models. Gut 2010;59:1635-1642.

78. Al-Lahham Sa, Roelofsen $\mathrm{H}$, Rezaee F, et al. Propionic acid affects immune status and metabolism in adipose tissue from overweight subjects. European journal of clinical investigation 2012;42:357-364.

79. Al-Lahham SaH, Roelofsen $\mathrm{H}$, Priebe $\mathrm{M}$, et al. Regulation of adipokine production in human adipose tissue by propionic acid. European journal of clinical investigation 2010;40:401-407. 



\section{CHAPTER 2}

Short-chain fatty acids in control of body weight and insulin sensitivity

Running title: SCFA in body weight control and insulin sensitivity

Emanuel E. Canfora, Johan W. Jocken, and Ellen E. Blaak

Nature Reviews Endocrinology (2015) 11, 577-591 


\section{Abstract}

The connection between the gut microbiota and the aetiology of obesity and cardiometabolic disorders is increasingly being recognized by clinicians. Our gut microbiota might affect the cardiometabolic phenotype by fermenting indigestible dietary components thereby producing short-chain fatty acids (SCFA). These SCFA are not only of importance in gut health and as signalling molecules, but they might also enter the systemic circulation and directly affect metabolism and the function of peripheral tissues. In this Review, we discuss the effects of three SCFA (acetate, propionate and butyrate) on energy homeostasis and metabolism, as well as how these SCFA can beneficially modulate adipose tissue, skeletal muscle and liver tissue function. As a result, these SCFA contribute to improved glucose homeostasis and insulin sensitivity. Furthermore, we also summarize the increasing evidence for a potential role of SCFA as a metabolic target to prevent and counteract obesity and its associated disorders in glucose metabolism and insulin resistance. However, most data are derived from animal and in vitro studies, and consequently the importance of SCFA and differential SCFA availability in human energy and substrate metabolism remains to be fully established. Well-controlled human intervention studies investigating the role of SCFA on cardiometabolic health are, therefore, eagerly awaited. 


\section{Key Points}

- Short-chain fatty acids (SCFA), which are derived from gut microbial fermentation of indigestible foods, have important metabolic functions and are crucial for intestinal health

- The discovery of SCFA receptors in many different tissues highlights that SCFAs are involved in the crosstalk between the gut and peripheral tissues

- In addition to their role in gut health and as signalling molecules, SCFA might enter the systemic circulation and directly affect substrate metabolism and function of peripheral tissues

- SCFA might increase intestinal energy harvesting and promote the development of obesity, but could also increase energy expenditure and anorexic hormone production, as well as improving appetite regulation

- Increasing evidence supports a beneficial role of SCFA on adipose tissue, skeletal muscle and liver substrate metabolism and function, thereby contributing to improved insulin sensitivity

- Well-controlled human intervention studies investigating the role of SCFA and differential SCFA availability on gut and systemic metabolic health are eagerly awaited 


\section{Introduction}

Obesity is becoming one of the major health-care problems of the $21^{\text {st }}$ century and is associated with a wide spectrum of pathological disturbances in metabolic organs predisposed towards insulin resistance, as well as type 2 diabetes mellitus (T2DM) and cardiovascular disease. ${ }^{1-3} \mathrm{~A}$ tight interplay between different insulin-sensitive organs regulates energy and substrate metabolism in the human body. Functional disturbances in either of these organs can, therefore, theoretically cause or contribute to the development of disturbances in glucose metabolism, insulin resistance and cardiometabolic disease. A growing body of evidence suggests that our gut and its resident microbiota have a crucial role in the regulation of energy and substrate metabolism and the development of cardiometabolic diseases in rodent models ${ }^{4-7}$ and humans. ${ }^{8,9}$ In humans with obesity, 7 days of treatment with vancomycin, an antibiotic against gram-positive bacteria, can modulate gut microbiota composition and decrease peripheral insulin sensitivity. ${ }^{8}$ Furthermore, transfer of intestinal microbiota from lean donors to individuals with the metabolic syndrome can improve insulin sensitivity and increase intestinal butyrate-producing microbiota and faecal short-chain fatty acids (SCFA). ${ }^{9}$

Our gut microbiota ferment dietary components that are incompletely hydrolysed due to the lack of the appropriate enzymes, which results in the production of SCFA: including acetate, butyrate and propionate. ${ }^{10}$ These SCFA have key functional roles in the pathophysiology of obesity and related disorders by affecting body weight control via regulation of energy intake, energy harvesting and host energy and substrate metabolism. ${ }^{11-17}$ In addition, several mechanisms that associate SCFA to insulin sensitivity and the development of T2DM have been proposed, including the interorgan effects on adipose tissue function and lipid storage capacity, inflammatory profile, and liver and skeletal muscle substrate metabolism (Figure 1). ${ }^{16,18,19}$

In this Review, we discuss the current knowledge regarding the role of the major gut-derived SCFA - acetate, propionate and butyrate. We provide an overview of luminal SCFA production, metabolism and absorption rates and also discuss the putative effects of SCFA on energy homeostasis and body weight control. The effect of SCFA and nondigestible fiber on adipose tissue, skeletal muscle and liver tissue metabolism and function in relation to insulin sensitivity will also be discussed. 


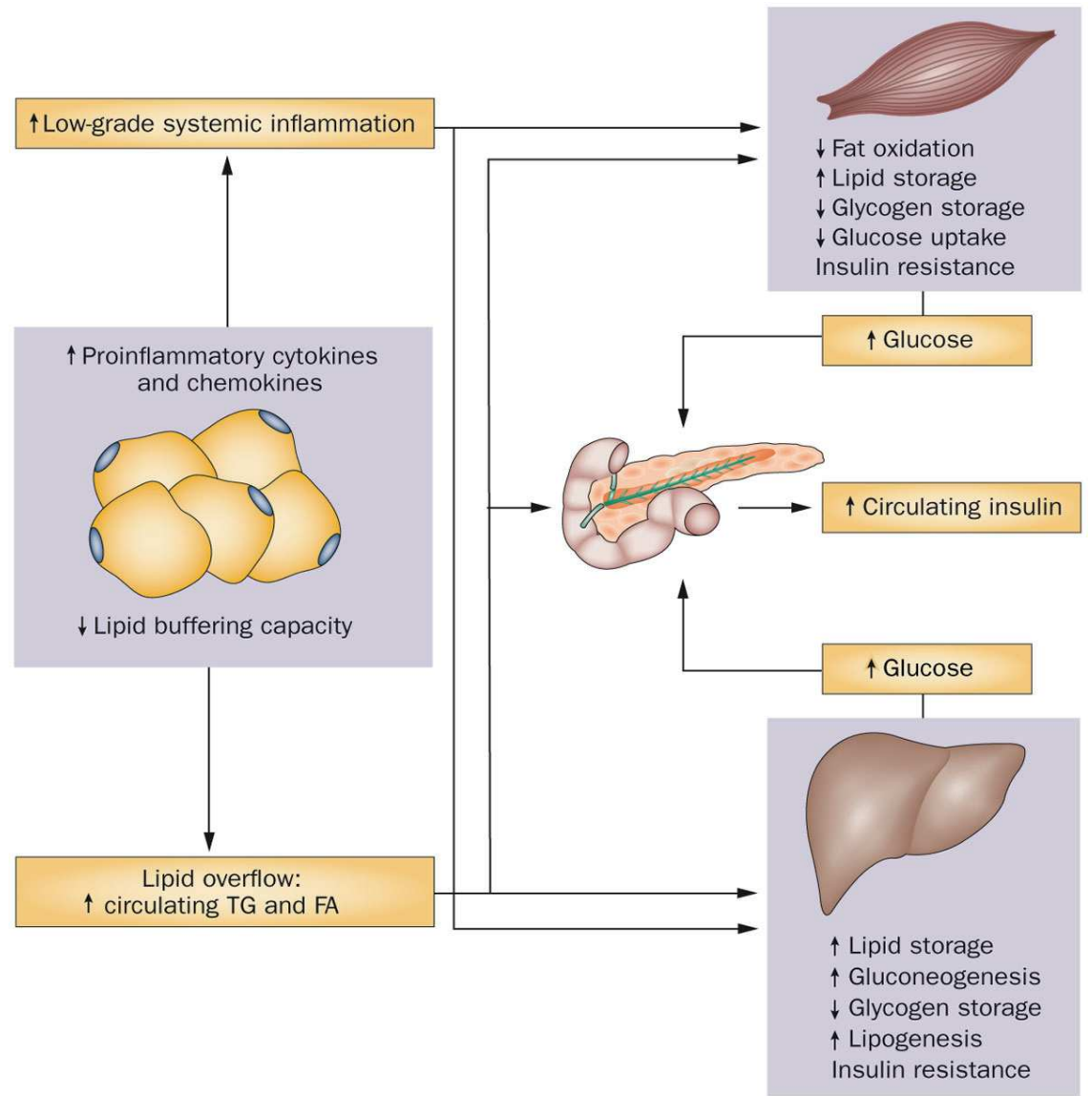

Nature Reviews | Endocrinology

Figure 1 | Inter-organ crosstalk and obesity-induced insulin resistance. Under conditions of chronic positive energy balance (that is energy intake is much greater expenditure), adipose tissue exceeds its buffering capacity to store all excess energy in the form of TG resulting in overflow of lipids into the circulation. This increased lipid supply to nonadipose tissues such as the liver, skeletal muscle and pancreas results in ectopic fat storage in these tissues and the development of insulin resistance. Together with a reduced lipid buffering capacity, adipose tissue becomes inflamed and results in an increased production and secretion of proinflammatory cytokines and adipokines, such as tumour necrosis factor, IL-6 and monocyte chemoattractant protein-1, which might also contribute to the development of peripheral insulin resistance and a disturbed glucose homeostasis. Abbreviations: FA, fatty acids; TG, triglyceride. 
SCFA in body weight control and insulin sensitivity

\section{Production and absorption of SCFA}

\section{SCFA in the human gut}

SCFA are end products of the intestinal microbial fermentation of indigestible foods and complex carbohydrates, like resistant starch or dietary fiber, are main substrates for SCFA production. ${ }^{20}$ The most abundant SCFA in the gut are acetate, propionate and butyrate (which constitute $>95 \%$ of the SCFA content), while formate, valerate and caproate are present in substantially lower amounts and make up the remaining $<5 \% .{ }^{21}$ Nondigested proteins or peptides might also be substrates for microbial production of SCFA. ${ }^{22-24}$ However, microbial protein fermentation yields a greater diversity of metabolites, including branched-chain fatty acids, amines, phenols, indoles and thiols, many of which might have negative consequences on epithelial cell metabolism and barrier function and affect host's gut and metabolic health. ${ }^{20,24-26}$

Most SCFA production occurs in the caecum and proximal colon. ${ }^{27}$ The concentrations of faecal acetate, propionate and butyrate are found in a molar ratio of approximately $3: 1: 1{ }^{28,29}$ Data from individuals who suddenly died showed that the SCFA concentrations are approximately 10-fold higher in the caecum (131 $\mathrm{mmol} / \mathrm{kg}$ of luminal content) than in the ileum (13 mmol/ $\mathrm{kg})$. In the colon, SCFA concentrations were $123 \mathrm{mmol} / \mathrm{kg}, 117 \mathrm{mmol} / \mathrm{kg}, 80 \mathrm{mmol} / \mathrm{kg}$ and $100 \mathrm{mmol} / \mathrm{kg}$ luminal content in the ascending, transverse, descending and sigmoid colon, respectively. ${ }^{21}$ The SCFA molar ratio was comparable in samples from the caecum, the colonic regions, and faecal samples. ${ }^{21}$

A daily amount of $\sim 400-800$ mmol SCFA can theoretically be produced with a high fibre diet, assuming that $10 \mathrm{~g}$ of dietary fiber fermentation yield $\sim 100 \mathrm{mmol}$ SCFA. ${ }^{30,31}$ These estimates agree with the results on in vitro fermentation of ileal effluents from patients with an ileostomy, which produced $120-420 \mathrm{mmol}$ acetate and 45-148 mmol propionate per day, depending upon the type and amount of complex carbohydrates in their diet. Fermentation of oat bran, which contains high amounts $\beta$-glucan, and kidney beans, containing high amounts of resistant starch and $\alpha$-galactosides, yielded the highest production of major SCFA. ${ }^{32}$ Other factors, including the specific species of microbiota, diversity and absolute amount of host's intestinal microbiota and gut transit time of food, also have an important role in the production of SCFA. ${ }^{27,33,34}$ During increased speed of transit through the colon, substrates available for microbial fermentation are diminished, which might lead to reduced SCFA production. ${ }^{10,35-39}$ Furthermore, differences in substrate availability, 
due to altered gut transit times could shift microbial composition and concentrations, which might lead to alterations in microbial SCFA production. ${ }^{10,35-39}$ Consistent with this observation, a cisapride-induced reduction in gut transit time in humans was associated with an increased in vitro production of the major SCFA, as measured by the ability of individuals faecal inoculum to ferment dietary fibres in vitro. $^{39}$

\section{SCFA absorption and systemic concentrations}

Colonic SCFA absorption is efficient and rapid with only 5-10\% of the SCFA excreted in the faeces. ${ }^{27}$ SCFA can be absorbed through the apical membrane of colonic epithelial cells via four putative mechanisms: non-ionic diffusion of protonated SCFA; ${ }^{40}$ exchange with bicarbonate in a ratio of $1: 1 ;^{41}$ via hydrogencoupled monocarboxylate transporter 1 (MCT1), МCT2 and MCT4; ${ }^{42,43}$ and via the sodium-coupled monocarboxylate transporter $1 .^{43}$

SCFA absorbed in the caecum, colon ascendens or colon transversum are transported into the superior mesenteric vein, whilst SCFA absorbed in the colon descendens and sigmoid enter the inferior mesenteric vein, which both drain into the portal vein and liver. ${ }^{44,45}$ Interestingly, SCFA absorbed in the sigmoid and anus region can also bypass the liver via the pelvic plexus, which drains into the vena cava inferior, thereby reaching the systemic circulation directly. ${ }^{45}$ In the available human studies in which SCFA dynamics have been measured during major upper abdominal surgery, acetate is absorbed in the highest amount in the liver and reaches the highest peripheral concentrations (19-160 $\mu \mathrm{mol} / \mathrm{l})$ compared with propionate (1$13 \mu \mathrm{mol} / \mathrm{l})$ and butyrate $(1-12 \mu \mathrm{mol} / \mathrm{l}) .{ }^{44,46}$ Systemic concentrations of SCFA depend on both the production and absorption rates in the gut, which in turn relate to the dietary pattern. For example, in a 4-week human intervention study, supplementation of resistant starch ( $30 \mathrm{~g}$ per day), increased postprandial systemic acetate and propionate concentrations up to $280 \mu \mathrm{mol} / \mathrm{l}$ and $13 \mu \mathrm{mol} / \mathrm{l}$, respectively. ${ }^{47}$

\section{SCFA receptors}

Butyrate is the major intestinal fuel, ${ }^{48}$ supplying $~ 60-70 \%$ of the energy needs of isolated colonocytes ${ }^{49}, 50$ Moreover, acetate, propionate and butyrate stimulate epithelial cell proliferation and differentiation in rats. ${ }^{51}$ SCFA might affect gut and host metabolism via the activation of G-protein coupled cell surface receptors, G-protein coupled receptor 41 (GPR41, also known as free fatty acid 
receptor 3) and GPR43 (also known as free fatty acid receptor 2). ${ }^{52,53}$ GPR41 is primarily activated by propionate followed by butyrate and acetate, GPR43 is similarly activated by all three SCFA. ${ }^{52,53}$ GPR41 and GPR43 protein and mRNA has been found in human colonic tissue. ${ }^{54,55}$ Notably, both receptors are also expressed in human white adipose tissue, ${ }^{19,52,53}$ skeletal muscle and liver, ${ }^{52}$ which indicates that SCFA might also affect substrate and energy metabolism directly in peripheral tissues. Furthermore, GPR109a (also known as hydroxycarboxylic acid receptor 2), which is expressed in gut epithelial cells, adipocytes and immune cells, has been found to respond to butyrate, but not acetate or propionate. ${ }^{56-59}$ In addition, acetate and propionate can also modulate blood pressure via olfactory receptor $51 \mathrm{E} 2$, which is expressed in kidney and vascular smooth muscle cells. ${ }^{60}$ 


\section{SCFA and body weight control}

\section{SCFA and energy harvesting}

The gut microbiota in the colon can enable the host to gain extra energy, mainly through the production of SCFA from otherwise indigestible carbohydrates. Since the 1940s, in vitro ${ }^{61-64}$ and in vivo animal ${ }^{65-68}$ and human ${ }^{69-72}$ data have been published, in which the role of SCFA in adiposity has been studied. ${ }^{61-72}$ Until the 1990s, characterization of the gut microbiota was laborious and time-consuming because bacteriological culture was the only technique available to specifically characterize its composition. ${ }^{73}$ Since 1993, advances in culture-independent techniques to analyse genetic diversity of complex microbial compositions have provided a more direct link between composition of the gut microbiota, SCFA production and obesity. ${ }^{73,74}$ In mice with genetically induced obesity, an increased ratio of Firmicutes to Bacteroidetes (the two dominant microbial phyla that can generate SCFA), was associated with increased concentrations of caecal concentrations of acetate and butyrate ${ }^{5}$ or acetate and propionate, ${ }^{17}$ respectively, when compared with lean control mice.

Data from humans also supports a relationship between the gut microbiota, SCFA and markers of obesity. ${ }^{28,29,75-77}$ An increase in faecal concentrations of SCFA (in particular propionate) and a decreased ratio of Bacteroidetes to Firmicutes has been reported in individuals with obesity, as compared to lean individuals. ${ }^{28,} 29$ However, human data are inconsistent and can variably show increased, similar or decreased Bacteroidetes to Firmicutes ratios. ${ }^{29,75,76}$ Furthermore, when comparing the gut microbiota of monozygotic twins and dizygotic twins who are discordant for obesity, the gut microbiome in the twin with obesity was associated with a dominant abundance of Firmicutes, reduced microbial diversity and enrichment of genes involved in carbohydrate fermentation. ${ }^{77}$ Taken together, these data suggest that gut and faecal SCFA might be increased in human obesity.

By contrast, the data from several animal studies indicate that treatment with SCFA can reduce or reverse body weight gain and adiposity. ${ }^{11-14,16,78}$ In obese mice, oral administration of sodium butyrate elicits body weight loss, via an increased energy expenditure and fat oxidation. ${ }^{12}$ In addition, oral acetate, propionate and butyrate administration to high-fat fed mice reduced body weight and improved insulin sensitivity without changing food intake or physical activity. ${ }^{16}$ Furthermore, faecal microbiota transplantation from human twins discordant for obesity to germ-free mice increased adiposity, reduced caecal SCFA and increased 
monosaccharide and disaccharide concentrations after a diet rich in plant polysaccharides in mice receiving the obese microbiota as compared to those receiving the lean co-twin microbiota. ${ }^{79}$ These data suggest that the microbiota from patients with obesity has a lower capacity to completely ferment and breakdown complex carbohydrates as compared with microbiota from lean individuals.

In humans, the beneficial metabolic effects of faecal transplantation from lean donors to men with obesity have been associated with an increased content of butyrate-producing bacteria. ${ }^{9}$ Further data also provide evidence that dietary fibres, such as resistant starch, inulin, oligofructose, polydextrose and galactooligosaccharides are associated with improved weight control and insulin sensitivity. This effect might be triggered via SCFA actions on the ability to store energy and respond to energy intake via differential mechanisms, such as the production of anorexic hormones, increased energy expenditure and improved metabolic function of peripheral tissues such as skeletal muscle and adipose tissue. $^{47,80-89}$

These data suggest that gut or faecal SCFA are increased in the obesityassociated gut microbiome, and might indicate an increased capacity to extract calories from otherwise indigestible foods in these individuals. Nevertheless, the data are controversial and the evidence that SCFA production by fermentation accounts for $5-10 \%$ of the daily human energy intake is only circumstantial. ${ }^{90}$ Taken together, the significance of energy harvesting from indigestible carbohydrates is largely unknown.

\section{SCFA as a regulator of energy intake}

The results from dietary intervention studies in humans indicate that SCFA might be used to regulate energy intake and body weight. In an acute crossover trial with healthy volunteers, an intake of $10 \mathrm{~g}$ of inulin propionate ester increased satiety and reduced appetite, as measured via visual analogue scales for hunger and satiety, compared with inulin alone. ${ }^{91}$ Furthermore, in humans with obesity, inulin propionate ester intake ( $10 \mathrm{~g}$ per day) versus inulin alone ( $10 \mathrm{~g}$ per day) for 24 weeks prevented gains in body weight (percentage of patients who gained $\geq 5 \%$ of their baseline body weight: $17 \%$ vs. $0 \%$, respectively, $P<0.05) .{ }^{92}$ Finally, patients with obesity who consumed acetate in $500 \mathrm{ml}$ beverages every day for 12 weeks experienced reduced body weight $(74.2 \pm 11.0 \mathrm{~kg}$ and $74.6 \pm 11.3 \mathrm{~kg}$ versus $73.1 \pm$ $8.6 \mathrm{~kg}$ and $71.2 \pm 8.3 \mathrm{~kg}$, for $0 \mathrm{~g}$ and $1.5 \mathrm{~g}$ acetate, respectively; $P<0.05)$. In this study, total body fat percentage $(1.0 \%$ versus $-3.5 \% ; P<0.05)$, and visceral fat percentage 
(4.4\% versus $-4.9 \% ; P<0.05)$ were also reduced following consumption of $1.5 \mathrm{~g}$ of acetate. $^{93}$

\section{SCFA control energy intake via gut-brain axis}

One of the mechanisms underlying the effect of SCFA on food intake and satiety might relate to the release of gut-derived satiety hormones, in particular glucagon-like peptide-1 (GLP-1) and peptide YY (PYY). These proteins are secreted by intestinal enteroendocrine L-cells, which are found at the highest density in the ileal and colonic epithelium. ${ }^{94,95}$ PYY affects appetite and satiety by suppressing neuropeptide $Y$ (NPY) and activating propiomelanocortin (POMC) neurons in the hypothalic arcuate nucleus (ARC), or by delaying gastric emptying. ${ }^{96,97}$ In addition to its role as an incretin, GLP-1 also regulates appetite via effects on POMC and NPY neurons in hypothalamic ARC and is known to inhibit gastric emptying and gastric acid secretion. ${ }^{98-100}$

In several in vitro studies using intestinal cell lines from rodents ${ }^{101,102}$ and humans, ${ }^{92,103,104}$ SCFA stimulated the secretion of PYY and GLP-1 from L- cells in a GPR41 and GPR43 dependent manner. ${ }^{101,102,105}$ Additionally, the use of rodent knockout models has highlighted the importance of the SCFA receptor GPR43 in GLP1 and PYY secretion. Knock out of GPR43 in mice lowers in vivo basal levels of active GLP-1 by $\sim 43 \% \quad(P<0.01)$ and blunts GLP-1 levels after glucose gavage by $\sim 47 \%$ $(P<0.01)$, compared with wild-type littermates. ${ }^{101}$ GPR43 deficiency in mice also reduces portal vein levels of PYY and GLP-1 following intra-colonic propionate administration (180 mmol/l) compared with wild-type littermates. ${ }^{102}$

Furthermore, in in vivo animal studies, diets containing fermentable carbohydrates (such as oligofructose, inulin and resistant starch) can increase PYY and GLP-1 secretion. ${ }^{106-108}$ Such diets can also increase expression of PYY and proglucagon, (a precursor of glucagon and several other hormones including GLP-1) in the caecum and colon, ${ }^{108,109}$ and promote L-cell differentiation in the proximal colon. $^{110}$

These findings, and the potent anorectic influence of gut hormones, led to an increased number of human studies on the effects of fermentable polysaccharides and the release of PYY and GLP-1 in relation to control of body weight. For example, in one study, supplementation of oligofructose (16 g per day for 2 weeks) lowered subjective hunger ratings $(P<0.01)$, as measured by visual analogue scales, which was associated with increased postprandial plasma levels of PYY and GLP-1 in healthy 
adults. ${ }^{84}$ Moreover, oligofructose intake for 12 weeks ( $21 \mathrm{~g}$ per day) led to a moderate but significant weight loss $(1.03 \pm 0.43 \mathrm{~kg}, P<0.01)$ compared with maltodextrin, which was associated with an enhanced PYY release and reduced energy intake of by $29 \%(P<0.01)$, in overweight volunteers $\left(\mathrm{BMI}>25 \mathrm{~kg} / \mathrm{m}^{2}\right){ }^{89}$ Interestingly, an elegant 5-week dose-escalation study in healthy human volunteers highlighted that intake of at least $35 \mathrm{~g}$ per day oligofructose was needed to significantly elevate $8 \mathrm{~h}$ postprandial PYY concentrations (oligofructose: 17,846 \pm $2,537 \mathrm{pmol} \mathrm{min} / \mathrm{I}$ versus $22,349 \pm 2,527 \mathrm{pmol} \mathrm{min} / \mathrm{I}$ for $0 \mathrm{~g}$ versus $35 \mathrm{~g}$ oligofructose respectively; $P<0.01)^{111}$

Although these data provide evidence that SCFA have a role in energy intake via the gut-derived satiety hormones PYY and GLP-1, germ-free mice (which lack microbial SCFA production), have increased rather than decreased basal plasma GLP1 levels and delayed intestinal transit compared with conventionally raised control mice. ${ }^{112}$ These results suggest that an adaptive mechanism to inadequate energy availability in the colon delays gut transit and enables increased nutrient absorption. ${ }^{112}$ Consequently, further human studies on the effects of physiologically relevant SCFA mixtures on the secretion of GLP-1 and PYY and their metabolic consequences should be performed.

\section{Acetate and appetite regulation}

In an elegant study in mice using PET-CT, intravenously and colonically administered ${ }^{11} \mathrm{C}$-acetate can cross the blood-brain barrier to be taken up in the hypothalamus. ${ }^{14}$ This uptake resulted in decreased food intake through appetite suppression accompanied by an increased production of lactate and $\gamma$-aminobutyric acid. ${ }^{14}$ Furthermore, in humans, acetate can also cross the blood-brain barrier and be metabolized in the brain. ${ }^{113}$ Enhancing circulating concentrations of acetate using specific dietary fibres could, therefore, affect central appetite regulation and subsequent body weight control. However, further research is required to investigate whether acetate elicits a central hypothalamic effect in humans.

\section{SCFA control energy intake via leptin}

SCFA might stimulate the secretion of the satiety hormone leptin (which is derived from adipose tissue), as shown in mice ${ }^{114}$ and bovine adipocytes in vitro. ${ }^{115}$ Additionally, $24 \mathrm{~h}$ incubation of human subcutaneous and omental adipocytes with supraphysiological concentrations of propionate $(3 \mathrm{mmol} / \mathrm{l})$ can stimulate expression of leptin mRNA and the hormone's secretion. ${ }^{19}$ Furthermore, oral or intravenous 
administration of propionate can induce leptin mRNA expression by $45 \%(P<0.05)$ in sheep subcutaneous adipose tissue. ${ }^{116}$ Consequently, in addition to PYY and GLP-1, and the direct effects of acetate on the central nervous system, the secretion of leptin might partly explain the putative satiety-inducing effects of SCFA. Nevertheless, usually obesity is characterized by both increased leptin concentrations and by reduced action of the hormone (that is, leptin resistance). ${ }^{117-}$ ${ }^{119}$ Whether an SCFA induced increase in leptin secretion might have the ability to overcome leptin resistance, and thereby affect satiety, remains to be determined.

\section{SCFA as a regulator of energy use}

SCFA might also beneficially affect body weight control by influencing energy expenditure. In obese mice, oral administration of sodium butyrate leads to body weight loss, via an increased energy expenditure and fat oxidation. ${ }^{12}$ This effect might in part be related to the increased gene and protein expression of two thermogenesis-related genes, peroxisome proliferator-activated receptor $\gamma$ coactivator $1 \alpha$ and uncoupling protein 1 , in brown adipose tissue. ${ }^{12}$ In addition, oral acetate administration to mice fed a high-fat diet can decrease total body fat content and hepatic fat accumulation without changing food intake, ${ }^{120}$ which has been linked to an increased expression of thermogenesis-related proteins (peroxisomal acyl-coenzyme A oxidase 1 [also know as AOX], carnitine Opalimtoyltransferase 1 , liver isoform and mitochondrial uncoupling protein-2) in the liver. ${ }^{120}$ Whether these effects also translate into the human condition remains to be determined.

Furthermore, SCFA potentially regulate body weight by modulating sympathetic activity and intestinal gluconeogenesis. Administration of propionate can increase energy expenditure and heart rate in wild-type mice, whereas these effects were blunted when a $\beta$-adrenergic receptor blocker was administered. ${ }^{121}$ Additionally, propionate can induce the secretion of norepinephrine from sympathetic neurons, which indicates that propionate increases sympathetic activity at the ganglion level. ${ }^{121}$

In an interesting study using mice, the beneficial metabolic effects of a diet rich in propionate and butyrate, including improved glucose tolerance, insulin sensitivity and body weight, were completely abolished in mice deficient in intestinal gluconeogenesis. ${ }^{11}$ The investigators suggested that intestinal gluconeogenesis induction promotes glucose release in the portal vein (acting as an agonist for low- 
affinity sodium-glucose co-transporter 3), which resulted in decreased hepatic glucose production and increased satiety and energy expenditure through a brainrelated mechanism. ${ }^{11,}{ }^{122}$ Human in vivo intervention studies are, therefore, warranted to examine if these animal data can be translated to humans.

In summary, gut microbiota have been implicated in energy harvesting and the development of obesity. The currently available data are controversial and evidence in human is circumstantial. However, observational and intervention studies both provide evidence for beneficial effects of SCFA on body weight control by increasing energy expenditure and stimulating the secretion of anorexic hormones. In addition, acetate might directly affect satiety via a central mechanism in the central nervous system; whereas propionate might influence body weight control via sympathetic nervous system activity and induction of intestinal gluconeogenesis (as summarized in Figure 2). Longer-term human dietary intervention studies are warranted to examine the chronic effect of SCFA supplementation on control of body weight. 


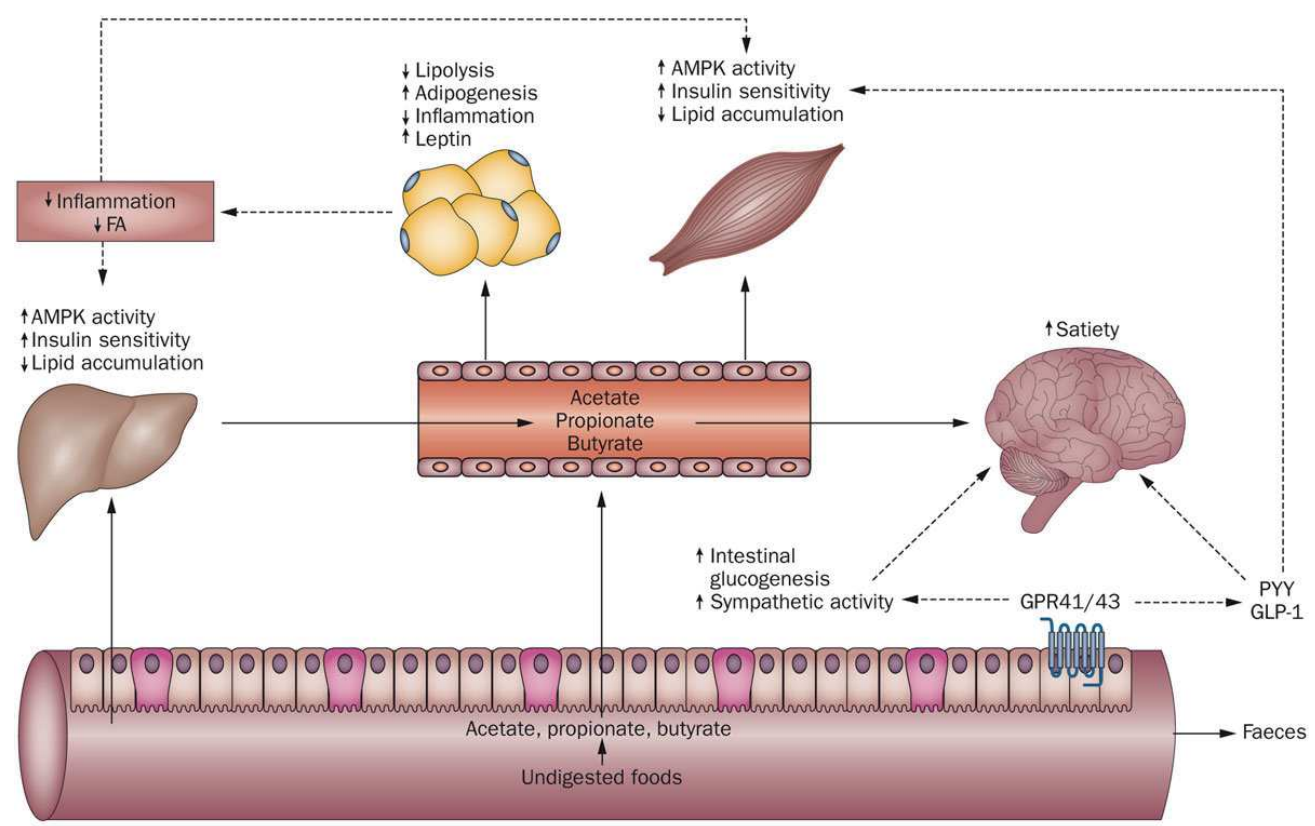

Nature Reviews | Endocrinology

Figure 2 | SCFA and interorgan crosstalk. Fermentation of indigestible foods in the distal intestine results in the production of SCFA. The ration of acetate to propionate to butyrate in the ileum, caecum and colon is 3:1:1. Butyrate and propionate are generally metabolized in the colon and liver and, therefore, mainly affect local gut and liver function. In the distal gut, SCFA bind to GPR41 and GPR43, which leads to the production of the gut hormones PYY and GLP-1 and affects satiety and glucose homeostasis. Furthermore, propionate and butyrate might induce intestinal gluconeogenesis and sympathetic activity, thereby improving glucose and energy homeostasis. Small amounts of propionate and butyrate and high amounts of acetate reach the circulation and can also directly affect peripheral adipose tissue, liver and muscle substrate metabolism and function. In addition, circulating acetate might be taken up by the brain and regulate satiety via a central homeostatic mechanism. Whether metabolic effects are mainly explained by direct effects of SCFA or indirectly via gut-derived signalling molecules still remain unclear. Solid lines indicate direct SCFA effects and dashed lines indirect SCFA effects. Abbreviations: SCFA, short-chain fatty acids; AMPK, adenosine monophosphate-activated protein kinase; FA, fatty acid; GLP-1, glucagon-like peptide-1; GPR, G-protein coupled receptor; PYY, peptide YY. 


\section{SCFA and adipose tissue function}

\section{Lipolysis}

In the late 1960s, the putative antilipolytic effect of acetate was recognized in a cross-over study in humans, in which orally administered sodium acetate significantly decreased plasma free fatty acids (FFA) concentrations by $25 \%$ $(P<0.01) .{ }^{69}$ Two decades later, acute rectal administration of acetate $(180 \mathrm{mmol} / \mathrm{l})$ plus propionate $(60 \mathrm{mmol} / \mathrm{l})$ resulted in a $40 \%$ fall in serum FFA $(P<0.05)$ in healthy humans. ${ }^{72}$ The latter finding and the observation that in humans SCFA receptors (GPR41 and GPR43) are expressed at higher levels in subcutaneous than in omental adipose tissue has led to renewed interest in the lipolytic properties of SCFA. ${ }^{19,52}$ In a 2008 study, treatment of differentiated murine 3T3-L1 adipocytes with acetate and propionate $(0.1-0.3 \mathrm{mmol} / \mathrm{l})$ reduced intracellular lipolytic activity up to $50 \%$ via activation of GPR43. ${ }^{123} \mathrm{~A}$ decreased hormone-sensitive lipase phosphorylation at Ser563 might underlie this antilipolytic effect, as shown in mature 3T3-L1 adipocytes treated with supraphysiological acetate concentrations $(4 \mathrm{mmol} / \mathrm{l}) .{ }^{124}$

By contrast, incubation of 3T3-L1 adipocytes with supraphysiological concentrations of butyrate $(5 \mathrm{mmol} / \mathrm{l})$ and propionate $(20 \mathrm{mmol} / \mathrm{l})$ resulted in an enhanced glycerol release, indicating an elevated lipolytic response. ${ }^{125}$ These results indicate a potent role of SCFA on lipolytic activity in murine 3T3-L1 adipocytes. However, whether these findings extend to human adipocytes, in which both GPR41 and GPR43 are expressed (in contrast to 3T3-L1 adipocytes that only express GPR43), remains to be determined. ${ }^{126-130}$

In addition to intracellular (that is, endogenous) lipolysis, extracellular lipolysis mediated by lipoprotein lipase (LPL) might also be affected by SCFA in adipose tissue. Incubation of omental adipose tissue explants from overweight humans with propionate $(3 \mathrm{mmol} / \mathrm{l}$ for $24 \mathrm{~h}$ ) resulted in an increased LPL mRNA expression. ${ }^{18,131}$ Consistent with this observation, short-term (30 $\mathrm{min}$ ) intravenous infusions of $1.2 \mathrm{~mol} / \mathrm{l}$ propionate at a rate of $64 \mu \mathrm{mol} / \mathrm{min}$ per $\mathrm{kg}$ body weight in sheep increased adipose tissue LPL expression by approximately five-fold as compared to saline $(P<0.05) .{ }^{116}$ Interestingly, expression and activation of angiopoietin-like protein 4 (encoded by ANGPTL4), which inhibits LPL activity, were also enhanced in intestinal and hepatic cancer cell lines, when treated with propionate and butyrate, but not when treated with acetate. ${ }^{132}$ However, the actual effect of SCFA on adipocyte and adipose tissue ANGPTL4 expression and activity is currently unknown. 
In summary, acetate and propionate might both inhibit intracellular lipolysis, while propionate can also increase the lipid buffering capacity of adipose tissue by increasing LPL-mediated triglyceride extraction. This effect results in reduced lipid overflow and decreased ectopic accumulation of fat, thereby positively affecting insulin sensitivity. However, the role of SCFA on LPL or angiopoietin-like protein 4 signalling and the impact of SCFA on lipolysis in human adipose tissue cells needs to be investigated in detail.

\section{Adipogenesis}

In vitro treatment of murine and porcine preadipocytes with sodium acetate, butyrate and propionate enhances adipocyte differentiation, which suggests that SCFA have proadipogenic properties. ${ }^{133,134}$ In addition, 3T3-L1 preadipocytes treated with acetate $(0.1 \mu \mathrm{mol} / \mathrm{l})$ and propionate $(0.1 \mu \mathrm{mol} / \mathrm{l})$ for 7 days enhanced adipocyte differentiation as measured by Oil red O staining, via increased expression of GPR43 and peroxisome proliferator-activated receptor $\gamma$ (PPAR $\gamma)$, a transcription factor involved in early adipogenic differentiation. ${ }^{126}$ These effects were completely abolished when GPR43 expression was blocked using siRNA, ${ }^{126}$ which indicates that the GPR43 receptor is a major mediator of the SCFA adipogenic potential. In addition, in mice fed a high-fat diet, adipogenesis was increased in subcutaneous adipose tissue, which was associated with an overexpression of GPR43 and PPARY target genes, namely those that encode CD36 and LPL mRNA. ${ }^{135}$ By contrast, in vitro differentiation of human omental preadipocytes with acetate and propionate did not modulate the expression of PPARy target genes, namely those that encode GPR43 and aP2 mRNA, known as late marker of adipocyte differentiation, suggesting that adipocyte differentiation in humans is not mediated by GPR43. ${ }^{136}$

These data derived from rodent models indicate that acetate, propionate and butyrate might be involved in adipogenic differentiation. However, further mechanistic research is required to confirm these outcomes in humans.

\section{Adipose tissue inflammation}

Systemic inflammation, characterized by increased systemic concentrations and tissue infiltration of immune cells, is strongly associated with insulin resistance and T2DM. ${ }^{137,138}$ Although the stimulus for persistent immune activation remains unclear, adipose tissue is increasingly recognized as a major source of proinflammatory adipocytokines that affect cardiometabolic function. ${ }^{1}{ }^{139}$ To what extent the host metabolism is controlled by the intestinal immune system in close 
interaction with our gut microbiota and microbial products is currently unknown. However, several SCFA-dependent mechanisms could be proposed.

Regulatory $T$ cells ( $T_{\text {REG }}$ cells) are central regulators of antimicrobial immunity and tissue inflammation, and their numbers are decreased in visceral adipose tissue from people with obesity. ${ }^{140}$ Disturbances in balance between proinflammatory Thelper 1 cells $\left(T_{H} 1, C D 4+\right)$ cells and cytotoxic $T$ cells $(C D 8+)$ versus antiinflammatory $T_{\text {REG }}$ cells are thought to be central in obesity-associated macrophage recruitment and adipose tissue and systemic inflammation. ${ }^{141,}{ }^{142}$ Interestingly, treatment of mice with all three SCFA (acetate, propionate and butyrate) alone or in combination for 3 weeks augmented the number and suppressive function of colonic anti-inflammatory $T_{\text {REG }}$ cells, which was dependent on GPR43. ${ }^{143}$ Consistent with this finding, butyrate induced the differentiation of colonic $T_{R E G}$ cells both in vivo and in vitro in mice. ${ }^{144}$ Furthermore, butyrate and propionate in drinking water (but not acetate) accelerated extrathymic peripheral differentiation of anti-inflammatory $T_{\text {REG }}$ cells in mice treated with antibiotics. ${ }^{144}$ In vitro incubation of naïve $\mathrm{CD} 4^{+} \mathrm{T}_{\mathrm{REG}}$ cells and dendritic cells with butyrate support these outcomes, ${ }^{145}$ suggesting that SCFA have a direct role in the regulation of T cells in both the gut and peripheral tissues. However, the role of SCFA in humans on systemic and adipose tissue T cell number and activity is currently unknown.

SCFA might also enhance intestinal barrier function, giving further support for their anti-inflammatory potential. In several studies using intestinal cell lines, SCFA (particularly butyrate), improve epithelial barrier function and gut permeability, by modulating expression of tight junction protein and mucins. ${ }^{146-149}$ Moreover, in a mouse study, a diet high in dietary fibres (SF11-029), including guar gum and cellulose, induced the NLRP3 inflammasome and led to the cleavage pro-IL18 into IL18 in colonic epithelial cells, via the activation of SCFA receptor GPR43 and the butyrate receptor GPR109a, thereby preventing disruption in epithelial integrity and dysbiosis. ${ }^{150}$ An improved gut barrier function is important to prevent leakage of toxic compounds produced by pathogenic bacteria into the circulation. Metabolic endotoxemia, particularly an increase in circulating lipopolysaccharide, is associated with chronic low-grade inflammation, adipose inflammation and dysfunction, weight gain and insulin resistance. ${ }^{151-155}$

SCFA might also directly counteract lipopolysaccharide-induced inflammation. In vitro, acetate and butyrate decrease lipopolysaccharide-stimulated release of tumour necrosis factor (TNF) from human neutrophils by $\sim 33 \%$ and $~ 75 \%$, respectively $(P<0.05),{ }^{156}$ and inhibit lipopolysaccharide-induced nuclear factor $\kappa \mathrm{B}$ 
(NF-KB) in lipopolysaccharide-stimulated murine macrophage cell lines. ${ }^{157}$ In addition, in another in vitro study using human peripheral blood mononuclear cells, overnight incubation with acetate, propionate and butyrate in concentrations of 0.2-100 mmol/I inhibit lipopolysaccharide-induced production of TNF and interferon $\gamma($ IFN- $\gamma)$; and showed that production levels decreased with increased SCFA concentrations. ${ }^{158}$ Moreover, in vivo data showed that acute rectal and intravenous administration of sodium acetate (compared with saline) decreased TNF plasma levels in women with obesity. ${ }^{15}$

Few studies have been conducted to assess the direct effects of SCFA on adipose tissue inflammation. Propionate treatment $(3 \mathrm{mmol} / \mathrm{l})$ reduced levels of the mRNA, but not the protein expression, of the proinflammatory cytokine resistin in human omental and subcutaneous adipose tissue cells. ${ }^{19}$ In addition, $24 \mathrm{~h}$ incubation of human adipose tissue explants with $3 \mathrm{mmol} / \mathrm{l}$ propionate resulted in a reduced mRNA expression and secretion of the proinflammatory cytokines IL-4, IL-10 and TNF, as well as several chemokines. ${ }^{18}$ Finally, co-incubation of murine 3T3-L1 adipocytes with RAW264.7 macrophages and butyrate $(0.2-1 \mathrm{mmol} / \mathrm{l})$ for $24 \mathrm{~h}$, reduced TNF, MCP1 and IL-6 concentrations dose-dependently. ${ }^{159}$

In summary, the currently available data indicate that SCFA might increase the lipid buffering capacity of adipose tissue by inhibiting intracellular lipolysis, increasing LPL-mediated triglyceride extraction and increasing adipogenic differentiation. Acetate, propionate and butyrate might all prevent chronic lowgrade inflammation by upregulating anti-inflammatory $T_{R E G}$ cells, decreasing metabolic endotoxemia and reducing production of proinflammatory adipocytokines and chemokines. These effects will thereby influence the recruitment and accumulation of monocytes in the adipose tissue (Figure 3). Currently, most of the evidence for these functions is derived from in vitro studies using animal-derived cell models, which do not directly recapitulate the situations in human disease. Consequently, future investigations should focus on human SCFA metabolism using human in vivo and cell models. 


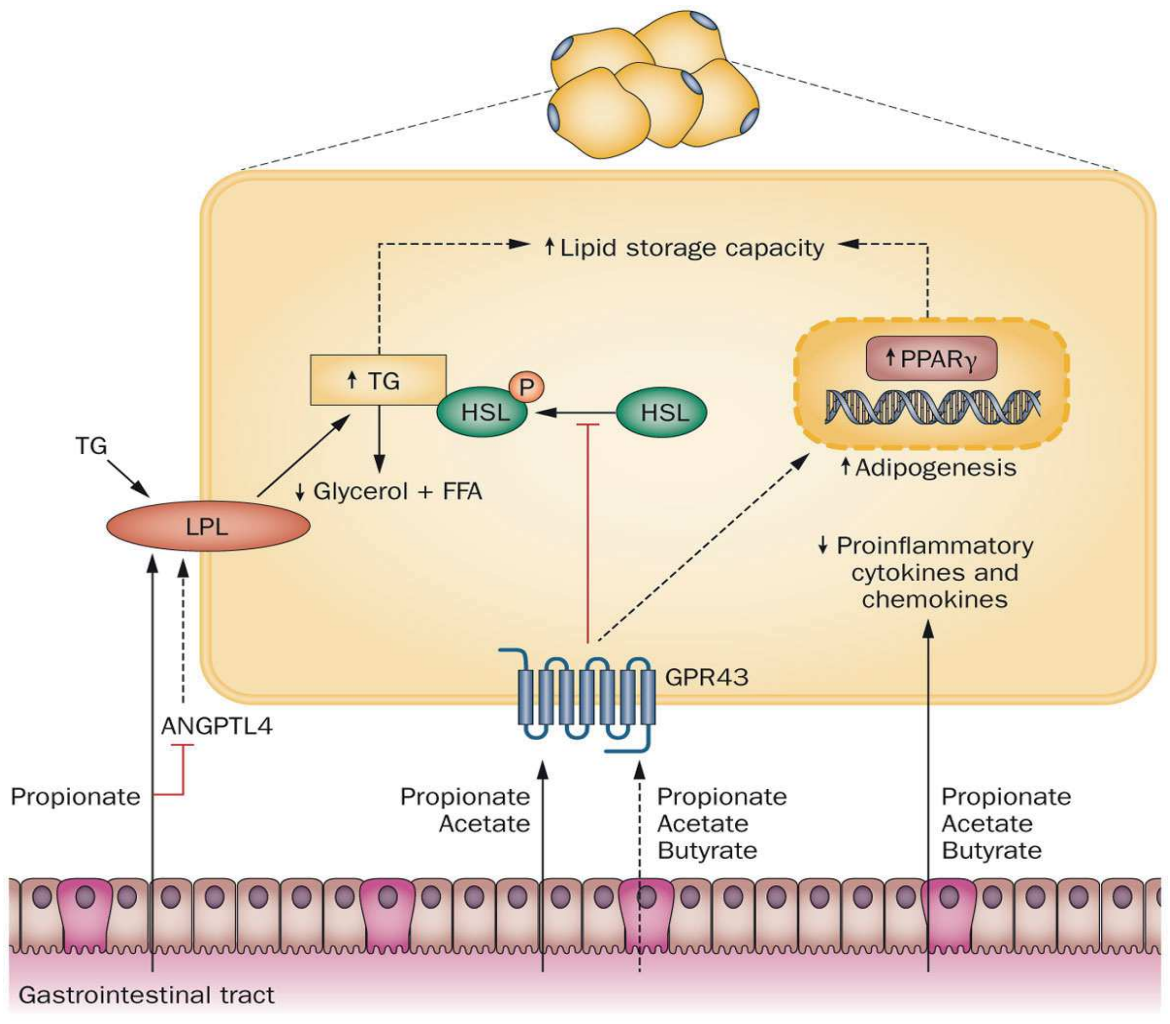

Nature Reviews | Endocrinology

Figure 3 | The effect of SCFA on adipose tissue function. Propionate might increase FFA uptake, possibly by affecting the LPL inhibitor ANGPTL4. Acetate and propionate might also attenuate intracellular lipolysis via decreased HSL phosphorylation, via GPR43. In addition, acetate, propionate and butyrate might increase PPARY-mediated adipogenesis, putatively regulated by a GPR43-related mechanism. Together these effects might contribute to increased adipose tissue storage of TG and a reduced systemic FFA release. Acetate, and especially propionate and butyrate might reduce the secretion of proinflammatory cytokines and chemokines, thereby possibly reducing local macrophage infiltration. The solid lines indicate this evidence is consistent between in vitro and in vivo data. The dashed lines indicate inconsistent or hypothetical evidence. Abbreviations: ANGPTL4, angiopoietin-like 4; FFA, free fatty acid; GPR43, G-protein coupled receptor 43; HSL, hormone sensitive lipase; $\mathrm{LPL}$, lipoprotein lipase; P, phosphate; PPARY, peroxisome proliferator-activated receptor $\gamma$; TG, triglyceride. 


\section{SCFA and skeletal muscle function}

The decline in circulating lipid concentrations might contribute to a decline in ectopic fat storage, lipotoxicity and an improvement in liver and skeletal muscle insulin sensitivity. In addition to an increased lipid supply, the inability to adjust lipid oxidation to supply might contribute to accumulation of bioactive lipid metabolites in the muscle, which is associated with insulin resistance. ${ }^{160,161}$

Only a few studies have examined the direct effects of SCFA on muscle fat oxidation, glucose uptake and insulin sensitivity. In obese rats, 6 months of acetate injections $(5.2 \mathrm{mg} / \mathrm{kg}$ of body weight) improved expression of genes involved in oxidative and glucose metabolism (such as, $M b$ [which encodes myoglobin] and glucose transporter Glut4) and increased muscle adenosine monophosphateactivated protein kinase (AMPK) activity in skeletal muscle. ${ }^{162}$ Dietary acetate supplementation for 6 days in rats increased glycogen storage and decreased glycolysis in the gastrocnemius muscle compared with chow fed rats. ${ }^{163}$ In dietinduced obese C57BL/6J mice, 16 weeks of a sodium butyrate enriched high-fat diet increased the proportion of type 1 oxidative muscle fibres and PPAR $\delta$ expression, which resulted in enhanced mitochondrial fat oxidation compared with control mice on a high-fat diet. ${ }^{12}$ Taken together, these data suggest that acetate and butyrate can improve skeletal muscle glucose and oxidative metabolism and might increase muscle lipid turnover, which in turn will improve insulin sensitivity. Part of the SCFAinduced effects on skeletal muscle substrate oxidation might be mediated via SCFA receptor signalling as GPR41 and GPR43 are both expressed in human skeletal muscle. ${ }^{52,164}$ Future investigations should also focus on skeletal muscle SCFA uptake and their contribution to muscle oxidative metabolism in humans, in addition to the role of these receptors.

SCFA might also indirectly affect muscle insulin sensitivity and glucose metabolism through gut-derived GLP-1 secretion and modulate muscle microvascular blood volume and flow, which is associated with augmented muscle insulin action and increased muscle glucose utilization. ${ }^{165}$ SCFA-stimulated secretion of gut-derived PYY might also improve insulin-mediated glucose uptake in skeletal muscle and increase whole-body fat oxidation, as shown in animal studies. ${ }^{166-168}$ Manipulating intestinal SCFA concentrations and ratios might, therefore, beneficially affect glucose homeostasis by triggering the release of gut-derived incretins and increase skeletal muscle insulin action (Figure 4). To date, no human intervention study on the direct association between gut-derived SCFA and skeletal muscle function has been performed. 


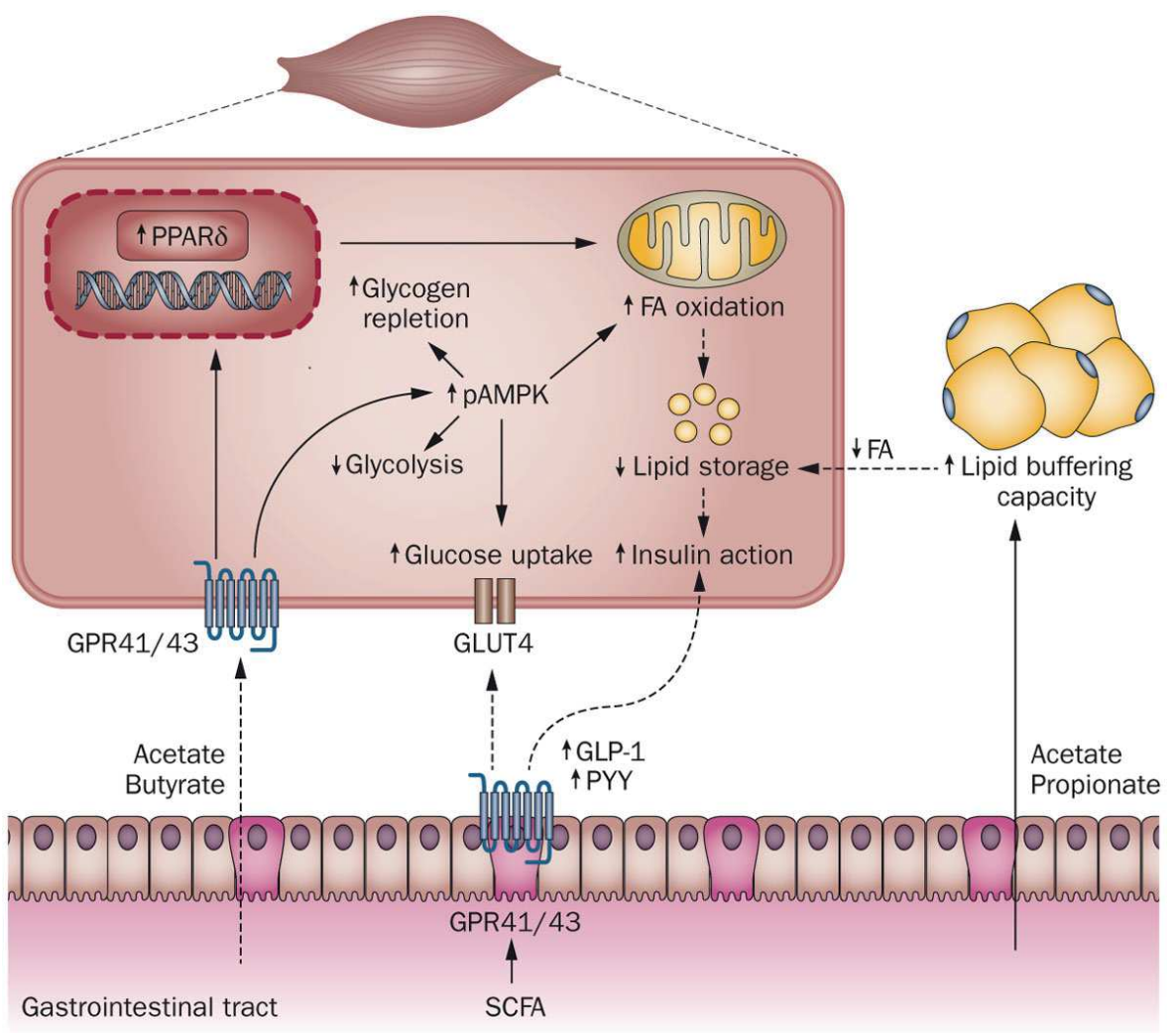

Nature Reviews | Endocrinology

Figure 4 | SCFA and skeletal muscle substrate metabolism. Acetate and propionate might reduce ectopic lipid storage in skeletal muscle, due to a decreased lipid supply. Acetate and butyrate increase muscle FA oxidation, possibly mediated via increased activation of AMPK and a PPARס-dependent mechanism. In addition, acetate and butyrate might influence skeletal muscle glucose metabolism in an AMPK dependent manner, which might increase glucose uptake (via GLUT4) and glycogen storage possibly via a GPR41/GPR43-mediated mechanism. SCFA might also indirectly affect muscle insulin sensitivity and glucose metabolism via increase systemic levels of gut-derived PYY and GLP-1, thereby affecting skeletal muscle insulin action and glucose uptake, contributing to improved muscle insulin sensitivity and glucose handling. The solid lines indicate that evidence is consistent between in vitro and in vivo data. The dashed lines indicate inconsistent or hypothetical mechanisms. Abbreviations: AMPK, adenosine monophosphate-activated protein kinase; FA, fatty acid; GLP-1, glucagon-like peptide-1; GLUT4, glucose transporter 4; GPR, G-protein coupled receptor; PAMPK, phosphorylated AMPK; PPARס, peroxisome proliferator-activated receptor $\delta$; PYY, peptide YY; SCFA, short-chain fatty acids. 


\section{SCFA and liver function}

Obesity-induced hepatic fat accumulation and chronic low-grade inflammation are strongly associated with insulin resistance. Consequently, factors that improve hepatic substrate metabolism might be used to prevent or treat insulin resistance and T2DM.

In a study in which radiolabelled ${ }^{13}$ C-SCFA was directly infused in the caecum of mice, acetate and butyrate were found to be highly involved in liver palmitate and cholesterol synthesis. ${ }^{169}$ However, a large part of the infused propionate was used for de novo gluconeogenesis, and not lipogenesis. ${ }^{169}$ Consistent with this observation, in isolated rat hepatocytes, acetate acts as a lipogenic substrate whilst propionate suppresses lipogenesis through a decreased expression of fatty acid synthase. $^{170}$

Additionally, SCFA might affect hepatic glucose and lipid metabolism through an AMPK-dependent mechanism. ${ }^{171,172}$ Bovine hepatocytes, cultured with acetate in concentrations of $1.8-7.2 \mathrm{mmol} / \mathrm{l}$ for $3 \mathrm{~h}$ increased the AMP to ATP ratio and subsequent AMPK phosphorylation, increasing the expression of PPAR $\alpha$ target genes involved in lipid oxidation. ${ }^{173}$ Moreover, oral and intravenous administration of acetate, $^{16,120,174,175}$ butyrate $^{16}$ and propionate ${ }^{16}$ in animal models of obesity and T2DM can decrease the accumulation of lipids in the liver and improved glucose tolerance. This mechanism functioned via increased hepatic AMPK phosphorylation, and expression of PPAR $\alpha$ target genes involved in FFA oxidation, glycogen storage, thermogenesis, gluconeogenesis and lipogenesis. Taken together, these data suggest a potential role for SCFA in hepatic lipid and glucose handling. Furthermore, treatment of rats with butyrate-producing bacteria can prevent the progression of diet-induced non-alcoholic fatty liver disease, improve insulin resistance and triglyceride content, which is possibly mediated by increased activation of liver AMPK. ${ }^{176}$ These SCFA effects on liver glucose and lipid metabolism might be mediated in part by GPR41 and GPR43, which are expressed in human hepatic cells. ${ }^{52,164}$

In summary, propionate might be a direct substrate for liver gluconeogenesis and acetate and butyrate for lipogenesis. Furthermore, acetate and butyrate in particular might indirectly affect liver function and metabolism in an AMPKdependent manner (Figure 5). However, studies in humans that investigate the effect of SCFA effects on parameters of liver metabolism are currently lacking. 


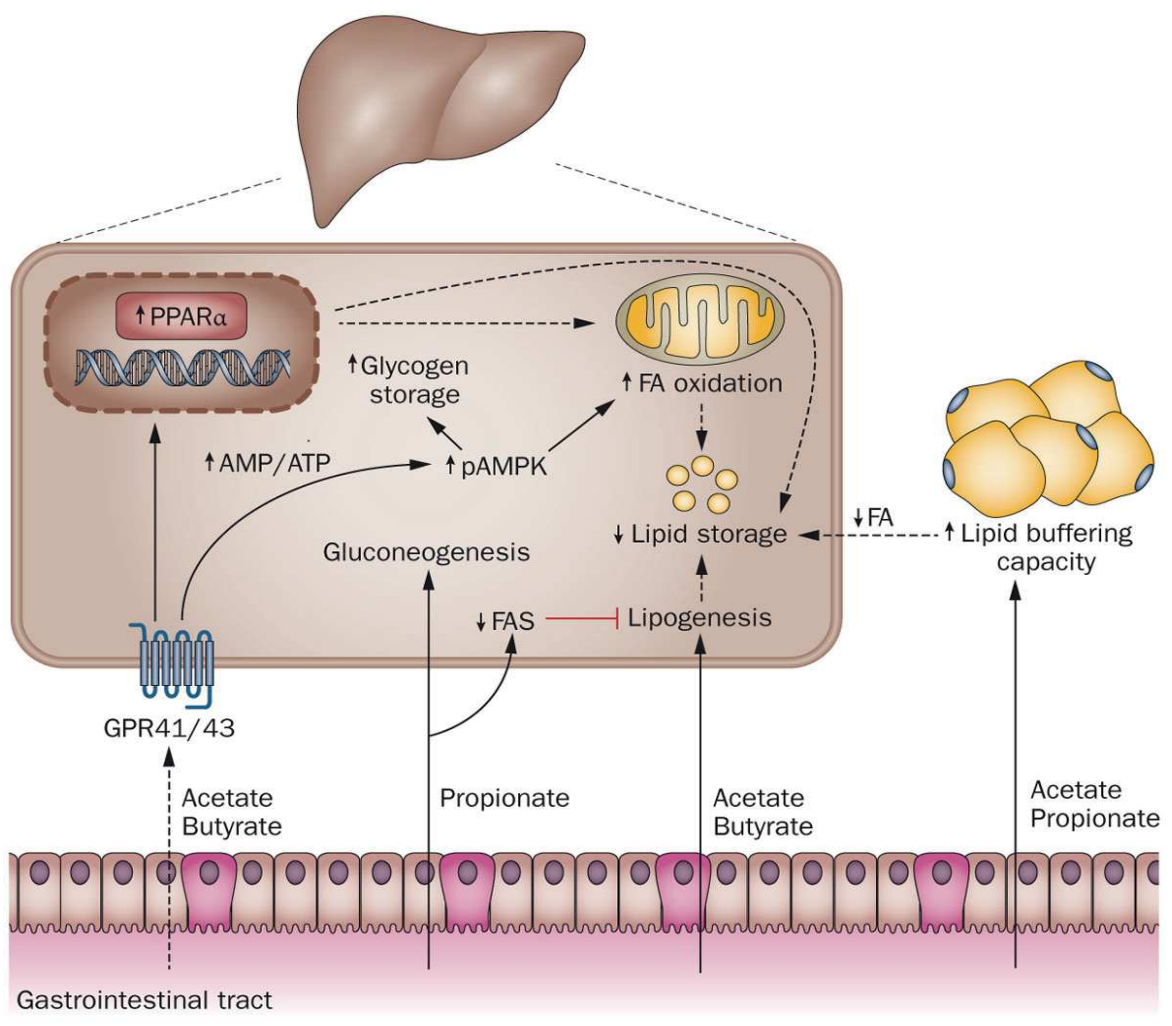

Nature Reviews | Endocrinology

Figure 5 | SCFA and liver function. SCFA might act as substrates for glucose and de novo lipogenesis. Propionate acts in the liver as a precursor for de novo gluconeogenesis and attenuates lipogenesis via inhibition of FAS expression. Acetate and butyrate are involved in liver lipogenesis. Moreover, acetate and butyrate might directly increase hepatic AMPK phosphorylation and activity, via an increase in the AMP to ATP ratio, and the upregulation of PPAR $\alpha$ target genes, thereby increasing FA oxidation and glycogen storage, possibly mediated via GPR41/GPR43-dependent mechanism. The solid lines indicate that evidence is consistent between in vitro and in vivo data. The dashed lines indicate inconsistent or hypothetical evidence. Abbreviations: AMPK, adenosine monophosphate-activated protein kinase; FA, fatty acid; FAS, fatty acid synthase; GPR, G-protein coupled receptor; PAMPK, phosphorylated AMPK; PPAR $\alpha$, peroxisome proliferator-activated receptor $\alpha$. 


\section{SCFA and glucose homeostasis in humans}

The putative direct and indirect effects of SCFA on function of peripheral tissues (Figure 2) suggest that SCFA might be strongly involved in glucose regulation in humans. Several studies have focused on the acute effects of SCFA administration on parameters of glucose and insulin metabolism (Table 1). Blood glucose and insulin levels are unaffected after rectal administration of acetate and propionate within 30 minutes; but in this investigations, both SCFA decreased circulating concentrations of FFA. ${ }^{72}$ However, in a subsequent study, acute rectal acetate infusions increased circulating levels of glucagon and decreased circulating FFA, but did not affect blood glucose or insulin levels. ${ }^{177}$ Rectal propionate infusions increased glucose and glucagon levels, but did not affect FFA or insulin concentrations, which suggests that gut-derived propionate might be a substrate for gluconeogenesis (Table 1). ${ }^{177}$

However, other investigators have found no effects on glucose metabolism after a $3 \mathrm{~h}$ gastric infusions of acetate and/or propionate, although these infusions reduced circulating concentrations of FFA. ${ }^{178}$ No effects of acute intravenously and rectally infused sodium acetate have been observed on glucose and insulin levels, whilst intravenous and rectal acetate infusions lowered plasma TNF and rectal acetate infusions increased PYY levels. ${ }^{15}$ Finally, no differences have been seen in the clearance of intravenously-administered acetate in adults who were healthy or had hyperinsulinaemia. ${ }^{179}$ However, in both groups FFA levels fall after acetate administration and a greater FFA fall and rebound was observed in the healthy adults compared with those with hyperinsulinaemia. ${ }^{179}$ FFA fall and rebound were both negatively correlated with insulin resistance indices (HOMA and Insulinogenic Index), and indicated an association between acetate-induced decrease in lipolysis and improved insulin resistance (Table 1). ${ }^{179}$ Data on the long-term administration of SCFA are limited (Table 1). In one study, propionate supplementation for 7 weeks led to decreased fasting glucose levels and maximum insulin increments during an oral glucose tolerance test in healthy women. ${ }^{180}$ Daily propionate supplementation in bread for 1 week decreases 2-h postprandial glucose levels after consumption of the bread in the morning on day 8, compared to consumption of a propionate-free bread. ${ }^{71}$ However, the glucose lowering effects were related to decreased digestion of the bread-derived starch, as a higher faecal bulk was found in the propionatetreated group than in the control group. ${ }^{71}$ 
Table 1 | SCFA intervention studies in humans

\begin{tabular}{|c|c|c|c|c|}
\hline Participants & SCFA & Design & Effects on glucose homeostasis & Study \\
\hline $\begin{array}{l}9 \text { healthy and } \\
9 \text { adults with } \\
\text { hyperinsulinaemia }\end{array}$ & $\begin{array}{l}\text { Intravenous sodium acetate } \\
(140 \mathrm{mmol} / \mathrm{l} \text { in } 90 \mathrm{~min})\end{array}$ & $\begin{array}{l}\text { Acute comparison } \\
\text { of healthy versus } \\
\text { hyperinsulinaemia }\end{array}$ & $\begin{array}{l}\text { Acetate-induced FFA response was } \\
\sim 14 \% \text { and FFA rebound } \sim 30 \% \text { greater } \\
\text { in healthy adults compared with } \\
\text { patients who were hyperinsulinaemic } \\
(P<0.01)\end{array}$ & $\begin{array}{l}\text { Fernandes et } \\
\text { al. }(2012)^{179}\end{array}$ \\
\hline $\begin{array}{l}6 \text { overweight or } \\
\text { obese }(\mathrm{BMI}>25 \\
\left.\mathrm{kg} / \mathrm{m}^{2}\right) \text {, } \\
\text { hyperinsulinaemic } \\
\text { women }\end{array}$ & $\begin{array}{l}\text { Sodium acetate } \\
60 \mathrm{mmol} \text { in } 300 \mathrm{ml} \text { water; } 200 \\
\mathrm{mmol} / \mathrm{l} \text { (rectally), } \\
\text { Intravenous } 20 \mathrm{mmol} \text { in } 100 \mathrm{ml} \\
\text { water in } 5 \mathrm{~min}\end{array}$ & $\begin{array}{l}\text { Acute; placebo } \\
\text { controlled } \\
\text { (saline) }\end{array}$ & $\begin{array}{l}\text { No significant changes in glucose and } \\
\text { insulin levels } \\
\text { Increase in PYY and decrease in TNF }\end{array}$ & $\begin{array}{l}\text { Freeland et al. } \\
(2010)^{15}\end{array}$ \\
\hline 6 healthy adults & $\begin{array}{l}\text { Acetate }(12 \mathrm{mmol} / \mathrm{h}) \text {, or } \\
\text { propionate }(4 \mathrm{mmol} / \mathrm{h}) \text {, or } \\
\text { acetate + propionate } \\
(12 \mathrm{mmol} / \mathrm{h}+4 \mathrm{mmol} / \mathrm{h}) \text { for } 3 \mathrm{~h} \\
\text { (gastric) }\end{array}$ & $\begin{array}{l}\text { Acute; placebo } \\
\text { controlled } \\
\text { (saline) }\end{array}$ & $\begin{array}{l}\text { No changes in blood glucose, plasma } \\
\text { insulin concentrations or hepatic } \\
\text { glucose production } \\
\text { Decreased circulating FFA after all } \\
\text { SCFA infusions }\end{array}$ & $\begin{array}{l}\text { Laurent et al. } \\
(1995)^{178}\end{array}$ \\
\hline 6 healthy adults & $\begin{array}{l}\text { Oral sodium propionate } \\
(9.9 \mathrm{~g} \text { per day) in white bread } \\
\text { for } 1 \text { week }\end{array}$ & $\begin{array}{l}\text { Chronic, placebo } \\
\text { controlled (standard } \\
\text { white bread) }\end{array}$ & $\begin{array}{l}38 \% \text { lowered } 2 \mathrm{~h} \text { glucose area under } \\
\text { the curve } \\
\text { values }(P<0.05) \text { and a lower glucose } \\
\text { peak }\end{array}$ & $\begin{array}{l}\text { Todesco et al. } \\
(1991)^{71}\end{array}$ \\
\hline 6 healthy adults & $\begin{array}{l}800 \mathrm{ml} \text { rectal infusions with } \\
180 \mathrm{mmol} \text { acetate alone, } \\
180 \mathrm{mmol} \text { propionate alone or } \\
\text { a combination of both } \\
\text { (180 mmol acetate }+60 \mathrm{mmol} \\
\text { propionate) }\end{array}$ & $\begin{array}{l}\text { Acute; placebo } \\
\text { controlled } \\
\text { (saline) }\end{array}$ & $\begin{array}{l}\text { Acetate alone increased serum } \\
\text { glucagon by } \sim 26 \%(P<0.05) \text { and } \\
\text { decreased FFA levels by } \sim 22 \% \\
(P<0.05) \text {, but did not affect glucose or } \\
\text { insulin levels } \\
\text { Propionate alone increased glucose by } \\
\sim 8 \%(P<0.05) \text {, and glucagon by } \sim 13 \% \text {, } \\
\text { but no effects on insulin levels were } \\
\text { observed }\end{array}$ & $\begin{array}{l}\text { Wolever et al. } \\
(1991)^{177}\end{array}$ \\
\hline $\begin{array}{l}20 \text { healthy female } \\
\text { adults }\end{array}$ & $\begin{array}{l}\text { Oral sodium propionate }(7.5 \mathrm{~g} \\
\text { capsules daily) for } 7 \text { weeks }\end{array}$ & $\begin{array}{l}\text { Chronic; placebo } \\
\text { controlled } \\
\text { (calcium phosphate) }\end{array}$ & $\begin{array}{l}\text { Reduced fasting blood glucose and } \\
\text { insulin response }(P<0.05)\end{array}$ & $\begin{array}{l}\text { Venter et al. } \\
(1990)^{180}\end{array}$ \\
\hline 6 healthy adults & $\begin{array}{l}800 \mathrm{ml} \text { rectal infusions with } 90 \\
\mathrm{mmol} \text { acetate }+30 \mathrm{mmol} \\
\text { propionate }(90 \mathrm{mmol} / \mathrm{l}, \\
\text { isotonic) or } 180 \mathrm{mmol} \text { acetate + } \\
60 \mathrm{mmol} \text { propionate } \\
(180 \mathrm{mmol} / \mathrm{l} \text {, hypertonic) within } \\
30 \mathrm{~min}\end{array}$ & $\begin{array}{l}\text { Acute; placebo } \\
\text { controlled } \\
\text { (saline) }\end{array}$ & $\begin{array}{l}\text { No effects on circulating glucose or } \\
\text { insulin } \\
40 \% \text { decreased serum FFA after } 180 \\
\text { mmol/I SCFA infusion }(P<0.05)\end{array}$ & $\begin{array}{l}\text { Wolever et al. } \\
(1989)^{72}\end{array}$ \\
\hline
\end{tabular}

Abbreviations: AUC, area under the curve; FFA, free fatty acid; PYY, protein YY; SCFA, short-chain fatty acids; TNF, tumour necrosis factor. 
Further indications for a beneficial effect of SCFA on insulin sensitivity and glucose homeostasis are derived from human dietary intervention studies using fermentable polysaccharides (Table 2). A daily dose of $30 \mathrm{~g}$ resistant starch supplementation for 4 weeks can enhance whole-body and skeletal muscle insulin sensitivity in healthy individuals, which was accompanied by increased systemic acetate and propionate levels and an increase in adipose tissue and skeletal muscle acetate uptake. ${ }^{47}$ A 2-week treatment with oligofructose (16 g per day) decreases postprandial glucose levels, which was associated with increased plasma GLP-1 levels and an increased breath-hydrogen excretion (increased microbial fermentation) in healthy adults. ${ }^{84}$ Consistent with these observations, reduced postprandial glucose and insulin levels and increased PYY levels have been observed after oligofructose $\left(21 \mathrm{~g} /\right.$ day) intake for 12 weeks in overweight adults. ${ }^{89}$ In addition, a 12-week supplementation of a galactooligosaccharide mixture in overweight patients increased faecal Bifidobacterium spp., and decreased fasting insulin and TAG concentrations. ${ }^{86}$ In another elegant study, other investigators found an improved postprandial glucose response, and a shift towards a butyrate-producing gut microbiota composition after 3 months intake of an inulin/oligofructose mixture (16 g/day) in women with obesity. ${ }^{88}$ However, no effects were found on $\mathrm{HbA}_{1 \mathrm{c}}$, HOMA and fasting levels of insulin and glucose in this study (Table 2 ). ${ }^{88}$

These data provide direct and indirect evidence for a role of SCFA in glucose control and insulin sensitizing. However, well-controlled long-term studies using fermentable dietary fibres failed to demonstrate any beneficial effects on glucose homeostasis. ${ }^{87,111}$ These conflicting outcomes indicate that an urgent need exists for human SCFA intervention studies to properly investigate the effects on glucose homeostasis and insulin sensitivity. 
Table 2 | Long-term dietary intervention studies with effects on glucose homeostasis and insulin sensitivity

\begin{tabular}{lllll}
\hline Participants & Nondigestible carbohydrate & Design & Effects on glucose homeostasis & Study \\
\hline 10 healthy & 30 g resistant starch $(10 \mathrm{~g}$ & 4 weeks; placebo & Improved whole-body insulin sensitivity & Robertson et al. \\
adults & three times per day $)$ & controlled $(20 \mathrm{~g}$ & (euglycemic-hyperinsulinaemic clamp) & $(2005)^{47}$
\end{tabular}

\begin{tabular}{|c|c|c|c|c|}
\hline $\begin{array}{l}10 \text { healthy } \\
\text { adults }\end{array}$ & $\begin{array}{l}16 \text { g oligofructose ( } 8 \mathrm{~g} \text { twice } \\
\text { per day) }\end{array}$ & $\begin{array}{l}2 \text { weeks; placebo- } \\
\text { controlled (16 g } \\
\text { dextrin maltose) }\end{array}$ & $\begin{array}{l}\text { 2h postprandial glucose AUC was } \\
\text { reduced by } \sim 17 \%(P<0.05) \text {. Increased } \\
\text { plasma GLP-1 and PYY levels and } \\
\text { increased breath-hydrogen excretion }\end{array}$ & $\begin{array}{l}\text { Cani et al. } \\
(2009)^{84}\end{array}$ \\
\hline $\begin{array}{l}48 \text { overweight } \\
\text { or obese adults } \\
\left(\mathrm{BMI}>25 \mathrm{~kg} / \mathrm{m}^{2}\right)\end{array}$ & $\begin{array}{l}21 \mathrm{~g} \text { oligofructose ( } 7 \mathrm{~g} \text { three } \\
\text { times per day) }\end{array}$ & $\begin{array}{l}12 \text { weeks, placebo- } \\
\text { controlled ( } 7.89 \mathrm{~g} \\
\text { isocaloric } \\
\text { maltodextrin) }\end{array}$ & $\begin{array}{l}\text { Absolute } 6 \text { h postprandial plasma glucose } \\
\text { and insulin concentrations were reduced } \\
\text { by } 5 \%(P<0.01) \sim 10 \%(P<0.01) \text {, } \\
\text { respectively }\end{array}$ & $\begin{array}{l}\text { Parnell et al. } \\
(2009)^{89}\end{array}$ \\
\hline $\begin{array}{l}30 \text { women with } \\
\text { obesity (BMI > } \\
\left.30 \mathrm{~kg} / \mathrm{m}^{2}\right)\end{array}$ & $\begin{array}{l}16 \mathrm{~g} \text { inulin/oligofructose mix } \\
\text { (8 g twice per day) }\end{array}$ & $\begin{array}{l}3 \text { months; placebo- } \\
\text { controlled (16 g } \\
\text { maltodextrin) }\end{array}$ & $\begin{array}{l}\text { Reduced post-OGTT glucose response } \\
(7 \%(P<0.01)) \text {. No effects on HOMA, } \\
\text { fasting glucose and insulin and HbA1c }\end{array}$ & $\begin{array}{l}\text { Dewulf et al. } \\
(2013)^{88}\end{array}$ \\
\hline $\begin{array}{l}45 \text { overweight } \\
\text { or obese adults } \\
\left(\mathrm{BMI}>25 \mathrm{~kg} / \mathrm{m}^{2}\right)\end{array}$ & $\begin{array}{l}5.5 \text { g galactooligosaccharide } \\
\text { mixture once a day }\end{array}$ & $\begin{array}{l}12 \text { weeks; placebo- } \\
\text { controlled } \\
\text { (5.5 g } \\
\text { maltodextrin) }\end{array}$ & $\begin{array}{l}\text { Decreased fasting insulin }(\sim 14 \% \\
(P<0.01)) \text {, triglyceride and C-reactive } \\
\text { protein plasma concentrations }\end{array}$ & $\begin{array}{l}\text { Vulevic et al. } \\
(2013)^{86}\end{array}$ \\
\hline $\begin{array}{l}12 \text { healthy } \\
\text { adults }\end{array}$ & $\begin{array}{l}15,25,35,45-55 \mathrm{~g} \\
\text { oligofructose daily (increased } \\
\text { per week) }\end{array}$ & $\begin{array}{l}5 \text { weeks; dose- } \\
\text { escalating pilot }\end{array}$ & $\begin{array}{l}\text { No effects on fasting or postprandial } \\
\text { glucose and insulin }\end{array}$ & $\begin{array}{l}\text { Pedersen et al. } \\
(2013)^{111}\end{array}$ \\
\hline $\begin{array}{l}22 \text { overweight } \\
\text { or obese adults } \\
(\mathrm{BMI} 25-35 \\
\left.\mathrm{kg} / \mathrm{m}^{2}\right)\end{array}$ & $\begin{array}{l}30 \mathrm{~g} \text { oligofructose ( } 10 \mathrm{~g} \times 3 \\
\text { times per day) }\end{array}$ & $\begin{array}{l}6 \text { weeks; } 30 \mathrm{~g} \\
\text { cellulose as control }\end{array}$ & $\begin{array}{l}\text { No effects on fasting or postprandial } \\
\text { glucose and insulin (neither between } \\
\text { treatments nor within group) }\end{array}$ & $\begin{array}{l}\text { Daud et al. } \\
(2014)^{87}\end{array}$ \\
\hline
\end{tabular}




\section{Conclusions}

The impact of SCFA on energy homeostasis is ambiguous. The results of animal studies suggest that SCFA might be involved in an increased energy harvesting, and thereby contribute to development of obesity. Conversely, SCFA might increase energy expenditure, stimulate the production of satiety hormones and acetate itself might enhance central appetite regulation, preventing rather than promoting obesity. Additionally, SCFA, and the microbiota that produce them, have been associated with improved insulin sensitivity and metabolic health in, albeit a limited number of, human intervention studies.

Several different mechanisms might be responsible for the putative positive effects of SCFA on insulin sensitivity. SCFA, especially acetate and propionate, might improve the lipid buffering capacity of adipose tissue via attenuation of intracellular lipolysis and increased adipogenesis. SCFA, in particular butyrate can regulate obesity-induced chronic low-grade inflammation, by activating anti-inflammatory $\mathrm{T}_{\mathrm{REG}}$ cells and suppress pathways involved in proinflammatory cytokine and chemokine production. In addition, acetate, propionate and butyrate might directly decrease secretion of adipose tissue-derived proinflammatory cytokines and chemokines. An improved SCFA-related adipose tissue function might decrease systemic lipid overflow and inflammation, and thereby reduce ectopic fat storage in non-adipose tissues such as the skeletal muscle and liver. Furthermore, acetate and butyrate might improve local muscle fat oxidation in an AMPK-dependent manner or by changing the oxidative state of muscle fibres, and thereby improve the capacity to utilize and switch between the major fuels lipids and carbohydrates (that is, enhance metabolic flexibility). In the liver, acetate and butyrate can directly act as a substrate for lipogenesis, whereas propionate is mainly a substrate for gluconeogenesis. Moreover, acetate and butyrate can regulate hepatic substrate metabolism in an AMPK-dependent manner. Taken together, these effects might contribute to an improved hepatic and peripheral insulin sensitivity and glucose homeostasis.

The evidence for a potential role of SCFA as a metabolic tool to prevent and counteract obesity and associated cardiometabolic risk factors such as insulin resistance is increasing. Nevertheless, most data are derived from animal and in vitro studies and the clinical significance and metabolic impact in humans remain to be established. Concluding that modulation of the SCFA production by microbiota via intake of complex carbohydrates is a useful tool to prevent obesity and obesityrelated disturbances in glucose metabolism and insulin resistance is probably 
premature. Long-term human intervention studies that are well controlled are needed to clarify the role of SCFA on control of body weight and insulin sensitivity.

\section{Review Criteria}

PubMed was searched for relevant topics, using the search terms "shortchain fatty acids", "acetate", "butyrate", "propionate" or "dietary fiber" in combination with "obesity", "weight", "satiety", "type 2 diabetes", "glycemic control", "glucose-lowering mechanisms", "energy metabolism", "FFAR2", "FFAR3", "inflammation", "treg", "microbiota", "fermentation", "intestinal homeostasis", "cardiovascular disease" and "metabolic control", without time constraints on publication. References cited in this article include primarily English-language original research and in some specific cases reviews by experts in the field. 


\section{References}

1. Shulman GI. Ectopic Fat in Insulin Resistance, Dyslipidemia, and Cardiometabolic Disease. New England Journal of Medicine 2014;371:1131-1141.

2. Grundy SM. Obesity, metabolic syndrome, and cardiovascular disease. The Journal of Clinical Endocrinology \& Metabolism 2004;89:2595-2600.

3. Kahn SE, Hull RL, Utzschneider KM. Mechanisms linking obesity to insulin resistance and type 2 diabetes. Nature 2006;444:840-846.

4. Backhed F, Ding $\mathrm{H}$, Wang $\mathrm{T}$, et al. The gut microbiota as an environmental factor that regulates fat storage. Proc Natl Acad Sci U S A 2004;101:15718-23.

5. Turnbaugh PJ, Ley RE, Mahowald MA, et al. An obesity-associated gut microbiome with increased capacity for energy harvest. Nature 2006;444:1027-1031.

6. Membrez $M$, Blancher $F$, Jaquet $M$, et al. Gut microbiota modulation with norfloxacin and ampicillin enhances glucose tolerance in mice. Faseb Journal 2008;22:2416-2426.

7. Andersson U, Branning C, Ahrne S, et al. Probiotics lower plasma glucose in the highfat fed C57BL/6J mouse. Beneficial Microbes 2010;1:189-196.

8. Vrieze A, Out C, Fuentes $S$, et al. Impact of oral vancomycin on gut microbiota, bile acid metabolism, and insulin sensitivity. Journal of hepatology 2014;60:824-831.

9. Vrieze A, Van Nood E, Holleman F, et al. Transfer of intestinal microbiota from lean donors increases insulin sensitivity in individuals with metabolic syndrome. Gastroenterology 2012;143:913-916. e7.

10. Topping DL, Clifton PM. Short-chain fatty acids and human colonic function: roles of resistant starch and nonstarch polysaccharides. Physiological reviews 2001;81:10311064.

11. De Vadder F, Kovatcheva-Datchary P, Goncalves D, et al. Microbiota-generated metabolites promote metabolic benefits via gut-brain neural circuits. Cell 2014;156:84-96.

12. Gao Z, Yin J, Zhang J, et al. Butyrate improves insulin sensitivity and increases energy expenditure in mice. Diabetes 2009;58:1509.

13. Lin HV, Frassetto A, Kowalik Jr EJ, et al. Butyrate and Propionate Protect against Diet-Induced Obesity and Regulate Gut Hormones via Free Fatty Acid Receptor 3Independent Mechanisms. PLoS ONE 2012;7:e35240.

14. Frost $G$, Sleeth ML, Sahuri-Arisoylu M, et al. The short-chain fatty acid acetate reduces appetite via a central homeostatic mechanism. Nature communications 2014;5.

15. Freeland KR, Wolever T. Acute effects of intravenous and rectal acetate on glucagonlike peptide-1, peptide YY, ghrelin, adiponectin and tumour necrosis factor-alpha. British Journal of Nutrition 2010;103:460-466.

16. den Besten G, Bleeker A, Gerding A, et al. Short-Chain Fatty Acids protect against High-Fat Diet-Induced Obesity via a PPARy-dependent switch from lipogenesis to fat oxidation. Diabetes 2015:db141213.

17. Murphy $E$, Cotter $P$, Healy $S$, et al. Composition and energy harvesting capacity of the gut microbiota: relationship to diet, obesity and time in mouse models. Gut 2010;59:1635-1642.

18. Al-Lahham Sa, Roelofsen $\mathrm{H}$, Rezaee $\mathrm{F}$, et al. Propionic acid affects immune status and metabolism in adipose tissue from overweight subjects. European journal of clinical investigation 2012;42:357-364.

19. Al-Lahham SaH, Roelofsen $\mathrm{H}$, Priebe $\mathrm{M}$, et al. Regulation of adipokine production in human adipose tissue by propionic acid. European journal of clinical investigation 2010;40:401-407. 
20. Macfarlane GT, Macfarlane S. Bacteria, colonic fermentation, and gastrointestinal health. Journal of AOAC International 2012;95:50-60.

21. Cummings J, Pomare E, Branch W, et al. Short chain fatty acids in human large intestine, portal, hepatic and venous blood. Gut 1987;28:1221.

22. Blachier F, Mariotti F, Huneau J, et al. Effects of amino acid-derived luminal metabolites on the colonic epithelium and physiopathological consequences. Amino acids 2007;33:547-562.

23. Geypens B, Claus D, Evenepoel P, et al. Influence of dietary protein supplements on the formation of bacterial metabolites in the colon. Gut 1997;41:70-76.

24. Macfarlane G, Gibson G, Beatty E, et al. Estimation of short-chain fatty acid production from protein by human intestinal bacteria based on branched-chain fatty acid measurements. FEMS Microbiology Letters 1992;101:81-88.

25. Corpet DE, Yin Y, Zhang XM, et al. Colonic protein fermentation and promotion of colon carcinogenesis by thermolyzed casein. 1995.

26. Windey K, De Preter V, Verbeke K. Relevance of protein fermentation to gut health. Molecular nutrition \& food research 2012;56:184-196.

27. Wong JM, de Souza R, Kendall CW, et al. Colonic health: fermentation and short chain fatty acids. Journal of clinical gastroenterology 2006;40:235-243.

28. Schwiertz A, Taras D, SchV§fer K, et al. Microbiota and SCFA in lean and overweight healthy subjects. Obesity 2009;18:190-195.

29. Fernandes J, Su W, Rahat-Rozenbloom S, et al. Adiposity, gut microbiota and faecal short chain fatty acids are linked in adult humans. Nutrition \& diabetes 2014;4:e121.

30. Cummings JH, Macfarlane GT. Colonic microflora: nutrition and health. Nutrition (Burbank, Los Angeles County, Calif.) 1997;13:476.

31. MCBURNEY MI, THOMPSON LU. In vitro fermentabilities of purified fiber supplements. Journal of Food Science 1989;54:347-350.

32. McBurney M, Thompson L, Cuff D, et al. Comparison of ileal effluents, dietary fibers, and whole foods in predicting the physiological importance of colonic fermentation. The American journal of gastroenterology 1988;83:536.

33. Venema K. Microbial metabolites produced by the colonic microbiota as drivers for immunomodulation in the host. The FASEB Journal 2013;27:643.12.

34. Pylkas A, Juneja L, Slavin J. Comparison of different fibers for in vitro production of short chain fatty acids by intestinal microflora. Journal of medicinal food 2005;8:113.

35. Lampe J, Fredstrom S, Slavin J, et al. Sex differences in colonic function: a randomised trial. Gut 1993;34:531-536.

36. Lampe J, Wetsch R, Thompson W, et al. Gastrointestinal effects of sugarbeet fiber and wheat bran in healthy men. European journal of clinical nutrition 1993;47:543548.

37. Owens F, Isaacson H. Ruminal microbial yields: factors influencing synthesis and bypass, In Federation proceedings, 1977.

38. Lewis S, Heaton K. Increasing butyrate concentration in the distal colon by accelerating intestinal transit. Gut 1997;41:245-251.

39. El Oufir L, Barry J, Flourie B, et al. Relationships between transit time in man and in vitro fermentation of dietary fiber by fecal bacteria. European journal of clinical nutrition 2000;54:603-609.

40. Ruppin H, Bar-Meir S, Soergel K, et al. Absorption of short-chain fatty acids by the colon. Gastroenterology 1980;78:1500-1507.

41. Titus E, Ahearn GA. Short-chain fatty acid transport in the intestine of a herbivorous teleost. Journal of experimental biology 1988;135:77-94. 
42. Ritzhaupt A, Wood IS, Ellis A, et al. Identification and characterization of a monocarboxylate transporter (MCT1) in pig and human colon: its potential to transport L-lactate as well as butyrate. The Journal of physiology 1998;513:719-732.

43. Moschen I, Bröer A, Galić S, et al. Significance of short chain fatty acid transport by members of the monocarboxylate transporter family (MCT). Neurochemical research 2012;37:2562-2568.

44. Bloemen JG, Venema K, van de Poll MC, et al. Short chain fatty acids exchange across the gut and liver in humans measured at surgery. Clinical nutrition 2009;28:657-661.

45. Bailey HR, Billingham RP, Stamos MJ, et al. Colorectal Surgery: Elsevier Health Sciences, 2012.

46. Bloemen JG, Damink SWO, Venema K, et al. Short chain fatty acids exchange: Is the cirrhotic, dysfunctional liver still able to clear them? Clinical Nutrition 2010;29:365369.

47. Robertson MD, Bickerton AS, Dennis AL, et al. Insulin-sensitizing effects of dietary resistant starch and effects on skeletal muscle and adipose tissue metabolism. The American journal of clinical nutrition 2005;82:559-567.

48. Roediger W. Role of anaerobic bacteria in the metabolic welfare of the colonic mucosa in man. Gut 1980;21:793-798.

49. Roediger W. The place of short chain fatty acids in colonocyte metabolism in health and in ulcerative colitis: the impaired colonocyte barrier. 1995.

50. Ardawi M, Newsholme E. Fuel utilization in colonocytes of the rat. Biochemical journal 1985;231:713.

51. Frankel W, Zhang W, Singh A, et al. Mediation of the trophic effects of short-chain fatty acids on the rat jejunum and colon. Gastroenterology 1994;106:375.

52. Brown AJ, Goldsworthy SM, Barnes AA, et al. The Orphan G protein-coupled receptors GPR41 and GPR43 are activated by propionate and other short chain carboxylic acids. Journal of Biological Chemistry 2003;278:11312-11319.

53. Le Poul E, Loison C, Struyf S, et al. Functional characterization of human receptors for short chain fatty acids and their role in polymorphonuclear cell activation. Journal of Biological Chemistry 2003;278:25481-25489.

54. Karaki S-i, Tazoe $\mathrm{H}$, Hayashi $\mathrm{H}$, et al. Expression of the short-chain fatty acid receptor, GPR43, in the human colon. Journal of molecular histology 2008;39:135142.

55. Tazoe H, Otomo Y, Karaki S-i, et al. Expression of short-chain fatty acid receptor GPR41 in the human colon. Biomedical Research 2009;30:149-156.

56. Thangaraju M, Cresci GA, Liu K, et al. GPR109A is a G-protein-coupled receptor for the bacterial fermentation product butyrate and functions as a tumor suppressor in colon. Cancer research 2009;69:2826-2832.

57. Liu F, Fu Y, Wei C, et al. The Expression of GPR109A, NF-kB and IL-1 $\beta$ in Peripheral Blood Leukocytes from Patients with Type 2 Diabetes. Annals of Clinical \& Laboratory Science 2014;44:443-448.

58. Taggart AK, Kero J, Gan X, et al. (D)- $\beta$-hydroxybutyrate inhibits adipocyte lipolysis via the nicotinic acid receptor PUMA-G. Journal of Biological Chemistry 2005;280:26649-26652.

59. Tunaru S, Kero J, Schaub A, et al. PUMA-G and HM74 are receptors for nicotinic acid and mediate its anti-lipolytic effect. Nature medicine 2003;9:352-355.

60. Pluznick JL, Protzko RJ, Gevorgyan H, et al. Olfactory receptor responding to gut microbiota-derived signals plays a role in renin secretion and blood pressure regulation. Proceedings of the National Academy of Sciences 2013;110:4410-4415. 
61. Hellman B, Larsson S, Westman S. Acetate Metabolism in Isolated Epididymal Adipose Tissue from Obese-Hyperglycemic Mice of Different Ages. Acta Physiologica Scandinavica 1962;56:189-198.

62. VILLEE C. The effect of insulin on the incorporation of C14-labeled pyruvate and acetate into lipid and protein. The Anatomical record 1948;101:680-680.

63. Feller D. METABOLISM OF ADIPOSE TISSUE I. INCORPORATION OF ACETATE CARBON INTO LIPIDES BY SLICES OF ADIPOSE TISSUE. Journal of Biological Chemistry 1954;206:171-180.

64. Elwood J, Marcó A, Van Bruggen J. Lipid Metabolism in the Diabetic Rat IV. METABOLISM OF ACETATE, ACETOACETATE, BUTYRATE, AND MEVALONATE IN VITRO. Journal of Biological Chemistry 1960;235:573-577.

65. Wong RK, Van Bruggen J. Lipid metabolism in the diabetic rat. 1. Acetate metabolism and lipid synthesis in vivo. Journal of Biological Chemistry 1960;235:26-29.

66. Reshef L, Niv J, Shapiro B. Effect of propionate on lipogenesis in adipose tissue. Journal of lipid research 1967;8:682-687.

67. Sakata T. Effects of indigestible dietary bulk and short chain fatty acids on the tissue weight and epithelial cell proliferation rate of the digestive tract in rats. Journal of nutritional science and vitaminology 1986;32:355.

68. Boillot J, Alamowitch C, Berger A-M, et al. Effects of dietary propionate on hepatic glucose production, whole-body glucose utilization, carbohydrate and lipid metabolism in normal rats. British Journal of Nutrition 1995;73:241-251.

69. Crouse JR, Gerson CD, DeCarli LM, et al. Role of acetate in the reduction of plasma free fatty acids produced by ethanol in man. Journal of lipid research 1968;9:509512.

70. BJÖRNTORP P, HOOD B. Studies on Adipose Tissue from Obese Patients with or without Diabetes Mellitus. Acta Medica Scandinavica 1966;179:221-227.

71. Todesco T, Rao AV, Bosello O, et al. Propionate lowers blood glucose and alters lipid metabolism in healthy subjects. The American journal of clinical nutrition 1991;54:860-865.

72. Wolever T, Brighenti F, Royall D, et al. Effect of rectal infusion of short chain fatty acids in human subjects. The American journal of gastroenterology 1989;84:1027.

73. Zoetendal EG, Collier CT, Koike S, et al. Molecular ecological analysis of the gastrointestinal microbiota: a review. The Journal of nutrition 2004;134:465-472.

74. Muyzer G, De Waal EC, Uitterlinden AG. Profiling of complex microbial populations by denaturing gradient gel electrophoresis analysis of polymerase chain reactionamplified genes coding for $16 \mathrm{~S}$ rRNA. Applied and environmental microbiology 1993;59:695-700.

75. Zhao L. The gut microbiota and obesity: from correlation to causality. Nature Reviews Microbiology 2013;11:639-647.

76. Hartstra AV, Bouter KE, Bäckhed F, et al. Insights Into the Role of the Microbiome in Obesity and Type 2 Diabetes. Diabetes care 2015;38:159-165.

77. Turnbaugh PJ, Hamady M, Yatsunenko T, et al. A core gut microbiome in obese and lean twins. nature 2008;457:480-484.

78. Pedersen MH, Lauritzen L, Hellgren LI. Fish oil combined with SCFA synergistically prevent tissue accumulation of NEFA during weight loss in obese mice. British Journal of Nutrition 2011;106:1449-1456.

79. Ridaura VK, Faith JJ, Rey FE, et al. Gut microbiota from twins discordant for obesity modulate metabolism in mice. Science 2013;341:1241214.

80. Fujii $\mathrm{H}$, Iwase $\mathrm{M}$, Ohkuma $\mathrm{T}$, et al. Impact of dietary fiber intake on glycemic control, cardiovascular risk factors and chronic kidney disease in Japanese patients with type 2 diabetes mellitus: the Fukuoka Diabetes Registry. Nutrition journal 2013;12:159. 
81. Konings E, Schoffelen PF, Stegen J, et al. Effect of polydextrose and soluble maize fibre on energy metabolism, metabolic profile and appetite control in overweight men and women. British Journal of Nutrition 2014;111:111-121.

82. Reichert RG, Lyon MR, Kacinik V, et al. Decreasing cardiovascular risk factors in obese individuals using a combination of $\mathrm{PGX}^{\circledR}$ meal replacements and $\mathrm{PGX}{ }^{\circledR}$ granules in a 12-week clinical weight modification program. Journal of Complementary and Integrative Medicine 2013;10:135-142.

83. Hashizume C, Kishimoto $\mathrm{Y}$, Kanahori $\mathrm{S}$, et al. Improvement effect of resistant maltodextrin in humans with metabolic syndrome by continuous administration. Journal of nutritional science and vitaminology 2012;58:423-430.

84. Cani PD, Lecourt E, Dewulf EM, et al. Gut microbiota fermentation of prebiotics increases satietogenic and incretin gut peptide production with consequences for appetite sensation and glucose response after a meal. The American journal of clinical nutrition 2009;90:1236-1243.

85. Cani PD, Joly E, Horsmans $\mathrm{Y}$, et al. Oligofructose promotes satiety in healthy human: a pilot study. European journal of clinical nutrition 2006;60:567-572.

86. Vulevic J, Juric A, Tzortzis $G$, et al. A mixture of trans-galactooligosaccharides reduces markers of metabolic syndrome and modulates the fecal microbiota and immune function of overweight adults. The Journal of nutrition 2013;143:324-331.

87. Daud NM, Ismail NA, Thomas EL, et al. The impact of oligofructose on stimulation of gut hormones, appetite regulation and adiposity. Obesity 2014;22:1430-1438.

88. Dewulf $\mathrm{E}$, Cani $\mathrm{P}$, Claus $\mathrm{S}$, et al. Insight into the prebiotic concept: lessons from an exploratory, double blind intervention study with inulin-type fructans in obese women. Gut 2013;62:1112-1121.

89. Parnell JA, Reimer RA. Weight loss during oligofructose supplementation is associated with decreased ghrelin and increased peptide $Y Y$ in overweight and obese adults. The American journal of clinical nutrition 2009;89:1751-1759.

90. Royall D, Wolever T, Jeejeebhoy KN. Clinical significance of colonic fermentation. The American journal of gastroenterology 1990;85:1307-1312.

91. Alhabeeb $\mathrm{H}, \mathrm{Chambers} \mathrm{E}$, Frost $\mathrm{G}$, et al. Inulin propionate ester increases satiety and decreases appetite but does not affect gastric emptying in healthy humans. Proceedings of the Nutrition Society 2014;73:E21.

92. Chambers ES, Viardot A, Psichas A, et al. Effects of targeted delivery of propionate to the human colon on appetite regulation, body weight maintenance and adiposity in overweight adults. Gut 2014:gutjnl-2014-307913.

93. Kondo $\mathrm{T}$, Kishi $\mathrm{M}$, Fushimi $\mathrm{T}$, et al. Vinegar intake reduces body weight, body fat mass, and serum triglyceride levels in obese Japanese subjects. Bioscience, biotechnology, and biochemistry 2009;73:1837-1843.

94. Theodorakis MJ, Carlson O, Michopoulos S, et al. Human duodenal enteroendocrine cells: source of both incretin peptides, GLP-1 and GIP. American Journal of Physiology-Endocrinology and Metabolism 2006;290:E550-E559.

95. Roberge JN, Brubaker PL. Regulation of intestinal proglucagon-derived peptide secretion by glucose-dependent insulinotropic peptide in a novel enteroendocrine loop. Endocrinology 1993;133:233-240.

96. De Silva A, Bloom SR. Gut hormones and appetite control: a focus on PYY and GLP-1 as therapeutic targets in obesity. Gut and liver 2012;6:10-20.

97. Savage A, Adrian T, Carolan G, et al. Effects of peptide YY (PYY) on mouth to caecum intestinal transit time and on the rate of gastric emptying in healthy volunteers. Gut 1987;28:166-170.

98. Murphy KG, Bloom SR. Gut hormones and the regulation of energy homeostasis. Nature 2006;444:854-859. 
99. Näslund E, Bogefors J, Skogar S, et al. GLP-1 slows solid gastric emptying and inhibits insulin, glucagon, and PYY release in humans. American Journal of PhysiologyRegulatory, Integrative and Comparative Physiology 1999;277:R910-R916.

100. Schjoldager B, Mortensen P, Christiansen J, et al. GLP-1 (glucagon-like peptide 1) and truncated GLP-1, fragments of human proglucagon, inhibit gastric acid secretion in humans. Digestive diseases and sciences 1989;34:703-708.

101. Tolhurst G, Heffron H, Lam YS, et al. Short-chain fatty acids stimulate glucagon-like peptide-1 secretion via the G-protein-coupled receptor FFAR2. Diabetes 2012;61:364-371.

102. Psichas A, Sleeth M, Murphy K, et al. The short chain fatty acid propionate stimulates GLP-1 and PYY secretion via free fatty acid receptor 2 in rodents. International Journal of Obesity 2014.

103. Reimer RA, Darimont C, Gremlich S, et al. A human cellular model for studying the regulation of glucagon-like peptide-1 secretion. Endocrinology 2001;142:4522-4528.

104. Psichas A, Zac-Varghese S, Murphy K, et al. Short chain fatty acids stimulate the release of gut hormone peptide $Y Y$ from human primary enteroendocrine $L$ cells, In Proceedings of The Physiological Society, 27, PC331, 2012.

105. Karaki S, Mitsui R, Hayashi $H$, et al. Short-chain fatty acid receptor, GPR43, is expressed by enteroendocrine cells and mucosal mast cells in rat intestine. Cell and tissue research 2006;324:353-360.

106. Cani PD, Dewever C, Delzenne NM. Inulin-type fructans modulate gastrointestinal peptides involved in appetite regulation (glucagon-like peptide-1 and ghrelin) in rats. British Journal of Nutrition 2004;92:521-526.

107. Zhou J, Martin RJ, Tulley RT, et al. Dietary resistant starch upregulates total GLP-1 and PYY in a sustained day-long manner through fermentation in rodents. American Journal of Physiology-Endocrinology and Metabolism 2008;295:E1160-E1166.

108. Cani PD, Neyrinck AM, Maton N, et al. Oligofructose Promotes Satiety in Rats Fed a High-Fat Diet: Involvement of Glucagon-Like Peptide-1. Obesity research 2005;13:1000-1007.

109. Zhou J, Hegsted M, McCutcheon KL, et al. Peptide $\mathrm{YY}$ and proglucagon mRNA expression patterns and regulation in the gut. Obesity 2006;14:683-689.

110. Cani PD, Hoste S, Guiot Y, et al. Dietary non-digestible carbohydrates promote L-cell differentiation in the proximal colon of rats. British Journal of Nutrition 2007;98:3237.

111. Pedersen C, Lefevre S, Peters V, et al. Gut hormone release and appetite regulation in healthy non-obese participants following oligofructose intake. A dose-escalation study. Appetite 2013;66:44-53.

112. Wichmann A, Allahyar A, Greiner TU, et al. Microbial modulation of energy availability in the colon regulates intestinal transit. Cell host \& microbe 2013;14:582590.

113. Jiang L, Gulanski BI, De Feyter HM, et al. Increased brain uptake and oxidation of acetate in heavy drinkers. The Journal of clinical investigation 2013;123:1605-1614.

114. Xiong Y, Miyamoto N, Shibata K, et al. Short-chain fatty acids stimulate leptin production in adipocytes through the $G$ protein-coupled receptor GPR41. Proceedings of the National Academy of Sciences of the United States of America 2004;101:1045.

115. Soliman M, Kimura K, Ahmed M, et al. Inverse regulation of leptin mRNA expression by short-and long-chain fatty acids in cultured bovine adipocytes. Domestic animal endocrinology 2007;33:400-409.

116. Lee $\mathrm{S}$, Hossner K. Coordinate regulation of ovine adipose tissue gene expression by propionate. Journal of animal science 2002;80:2840. 
117. Ioffe $E$, Moon B, Connolly E, et al. Abnormal regulation of the leptin gene in the pathogenesis of obesity. Proceedings of the National Academy of Sciences 1998;95:11852-11857.

118. Maffei $M$, Halaas J, Ravussin E, et al. Leptin levels in human and rodent: measurement of plasma leptin and ob RNA in obese and weight-reduced subjects. Nature medicine 1995:1155-61.

119. Frederich RC, Hamann A, Anderson S, et al. Leptin levels reflect body lipid content in mice: evidence for diet-induced resistance to leptin action. Nature medicine 1995;1:1311-1314.

120. Kondo T, Kishi M, Fushimi T, et al. Acetic acid upregulates the expression of genes for fatty acid oxidation enzymes in liver to suppress body fat accumulation. Journal of agricultural and food chemistry 2009;57:5982-5986.

121. Kimura I, Inoue D, Maeda T, et al. Short-chain fatty acids and ketones directly regulate sympathetic nervous system via $\mathrm{G}$ protein-coupled receptor 41 (GPR41). Proceedings of the National Academy of Sciences 2011;108:8030-8035.

122. Mithieux G, Gautier-Stein A. Intestinal glucose metabolism revisited. Diabetes research and clinical practice 2014.

123. Ge H, Li X, Weiszmann J, et al. Activation of $\mathrm{G}$ protein-coupled receptor 43 in adipocytes leads to inhibition of lipolysis and suppression of plasma free fatty acids. Endocrinology 2008;149:4519.

124. Aberdein N, Schweizer M, Ball D. Sodium acetate decreases phosphorylation of hormone sensitive lipase in isoproterenol-stimulated 3T3-L1 mature adipocytes. Adipocyte 2014;3:121.

125. Rumberger J, Arch J, Green A. Butyrate and other short-chain fatty acids increase the rate of lipolysis in 3T3-L1 adipocytes. PeerJ 2013;2:e611-e611.

126. Hong $\mathrm{YH}$, Nishimura $\mathrm{Y}$, Hishikawa $\mathrm{D}$, et al. Acetate and propionate short chain fatty acids stimulate adipogenesis via GPCR43. Endocrinology 2005;146:5092.

127. Kimura I, Ozawa K, Inoue D, et al. The gut microbiota suppresses insulin-mediated fat accumulation via the short-chain fatty acid receptor GPR43. Nature communications 2013;4:1829.

128. Inoue D, Tsujimoto G, Kimura I. Regulation of energy homeostasis by GPR41. Frontiers in Endocrinology 2014;5.

129. Zaibi MS, Stocker CJ, O'Dowd J, et al. Roles of GPR41 and GPR43 in leptin secretory responses of murine adipocytes to short chain fatty acids. FEBS letters 2010;584:2381-2386.

130. Frost G, Cai Z, Raven M, et al. Effect of short chain fatty acids on the expression of free fatty acid receptor 2 (Ffar2), Ffar3 and early-stage adipogenesis. Nutrition \& diabetes 2014;4:e128.

131. Merkel M, Eckel RH, Goldberg IJ. Lipoprotein lipase genetics, lipid uptake, and regulation. Journal of lipid research 2002;43:1997-2006.

132. Grootaert C, Van de Wiele T, Van Roosbroeck I, et al. Bacterial monocultures, propionate, butyrate and $\mathrm{H} 2 \mathrm{O} 2$ modulate the expression, secretion and structure of the fasting induced adipose factor in gut epithelial cell lines. Environmental microbiology 2011;13:1778-1789.

133. Haberland M, Carrer M, Mokalled MH, et al. Redundant control of adipogenesis by histone deacetylases 1 and 2. Journal of Biological Chemistry 2010;285:1466314670.

134. Li G, Yao W, Jiang H. Short-Chain Fatty Acids Enhance Adipocyte Differentiation in the Stromal Vascular Fraction of Porcine Adipose Tissue. The Journal of nutrition 2014:jn. 114.198531. 
135. Dewulf EM, Cani PD, Neyrinck AM, et al. Inulin-type fructans with prebiotic properties counteract GPR43 overexpression and PPARy-related adipogenesis in the white adipose tissue of high-fat diet-fed mice. The Journal of nutritional biochemistry 2011;22:712-722.

136. Dewulf EM, Ge Q, Bindels LB, et al. Evaluation of the relationship between GPR43 and adiposity in human. Nutrition \& metabolism 2013;10:11.

137. Goossens GH. The role of adipose tissue dysfunction in the pathogenesis of obesityrelated insulin resistance. Physiology \& behavior 2008;94:206-218.

138. Tilg $\mathrm{H}$, Moschen AR. Adipocytokines: mediators linking adipose tissue, inflammation and immunity. Nature Reviews Immunology 2006;6:772-783.

139. Apovian CM, Bigornia S, Mott M, et al. Adipose macrophage infiltration is associated with insulin resistance and vascular endothelial dysfunction in obese subjects. Arteriosclerosis, thrombosis, and vascular biology 2008;28:1654-1659.

140. Chaudhry A, Rudensky AY. Control of inflammation by integration of environmental cues by regulatory T cells. The Journal of clinical investigation 2013;123:939-944.

141. Nishimura S, Manabe I, Nagasaki M, et al. CD8+ effector T cells contribute to macrophage recruitment and adipose tissue inflammation in obesity. Nature medicine 2009;15:914-920.

142. Mazurek T, Zhang L, Zalewski A, et al. Human epicardial adipose tissue is a source of inflammatory mediators. Circulation 2003;108:2460-2466.

143. Smith PM, Howitt MR, Panikov N, et al. The microbial metabolites, short-chain fatty acids, regulate colonic Treg cell homeostasis. Science 2013;341:569-573.

144. Furusawa Y, Obata Y, Fukuda S, et al. Commensal microbe-derived butyrate induces the differentiation of colonic regulatory T cells. Nature 2013;504:446-450.

145. Arpaia N, Campbell C, Fan X, et al. Metabolites produced by commensal bacteria promote peripheral regulatory T-cell generation. Nature 2013;504:451-455.

146. Mariadason JM, Barkla DH, Gibson PR. Effect of short-chain fatty acids on paracellular permeability in Caco-2 intestinal epithelium model. American Journal of Physiology-Gastrointestinal and Liver Physiology 1997;272:G705-G712.

147. Malago J, Koninkx J, Douma P, et al. Differential modulation of enterocyte-like Caco2 cells after exposure to short-chain fatty acids. Food Additives \& Contaminants 2003;20:427-437.

148. Suzuki T, Yoshida S, Hara H. Physiological concentrations of short-chain fatty acids immediately suppress colonic epithelial permeability. British journal of nutrition 2008;100:297-305.

149. Elamin EE, Masclee AA, Dekker J, et al. Short-chain fatty acids activate AMPactivated protein kinase and ameliorate ethanol-induced intestinal barrier dysfunction in Caco-2 cell monolayers. The Journal of nutrition 2013;143:1872-1881.

150. Macia L, Tan J, Vieira AT, et al. Metabolite-sensing receptors GPR43 and GPR109A facilitate dietary fibre-induced gut homeostasis through regulation of the inflammasome. Nature communications 2015;6.

151. Cani P, Neyrinck A, Fava F, et al. Selective increases of bifidobacteria in gut microflora improve high-fat-diet-induced diabetes in mice through a mechanism associated with endotoxaemia. Diabetologia 2007;50:2374-2383.

152. Cani PD, Amar J, Iglesias MA, et al. Metabolic endotoxemia initiates obesity and insulin resistance. Diabetes 2007;56:1761-1772.

153. Mehta NN, McGillicuddy FC, Anderson PD, et al. Experimental endotoxemia induces adipose inflammation and insulin resistance in humans. Diabetes 2010;59:172-181.

154. Vila IK, Badin P-M, Marques M-A, et al. Immune Cell Toll-like Receptor 4 Mediates the Development of Obesity-and Endotoxemia-Associated Adipose Tissue Fibrosis. Cell reports 2014;7:1116-1129. 
155. Muccioli GG, Naslain D, Bäckhed F, et al. The endocannabinoid system links gut microbiota to adipogenesis. Molecular systems biology 2010;6.

156. Tedelind S, Westberg $F$, Kjerrulf $M$, et al. Anti-inflammatory properties of the shortchain fatty acids acetate and propionate: a study with relevance to inflammatory bowel disease. World Journal of Gastroenterology 2007;13:2826.

157. Liu T, Li J, Liu Y, et al. Short-chain fatty acids suppress lipopolysaccharide-induced production of nitric oxide and proinflammatory cytokines through inhibition of NFKB pathway in RAW264. 7 cells. Inflammation 2012;35:1676-1684.

158. Cox MA, Jackson J, Stanton M, et al. Short-chain fatty acids act as antiinflammatory mediators by regulating prostaglandin E2 and cytokines. World journal of gastroenterology: WJG 2009;15:5549.

159. Ohira H, Fujioka Y, Katagiri C, et al. Butyrate Attenuates Inflammation and Lipolysis Generated by the Interaction of Adipocytes and Macrophages. Journal of atherosclerosis and thrombosis 2013.

160. Koves TR, Ussher JR, Noland RC, et al. Mitochondrial overload and incomplete fatty acid oxidation contribute to skeletal muscle insulin resistance. Cell metabolism 2008;7:45-56.

161. Corpeleijn E, Saris W, Blaak E. Metabolic flexibility in the development of insulin resistance and type 2 diabetes: effects of lifestyle. obesity reviews 2009;10:178-193.

162. Yamashita $\mathrm{H}$, Maruta $\mathrm{H}$, Jozuka $\mathrm{M}$, et al. Effects of acetate on lipid metabolism in muscles and adipose tissues of type 2 diabetic Otsuka Long-Evans Tokushima Fatty (OLETF) rats. Bioscience, biotechnology, and biochemistry 2009;73:570-576.

163. Fushimi T, Tayama K, Fukaya M, et al. Acetic acid feeding enhances glycogen repletion in liver and skeletal muscle of rats. The Journal of nutrition 2001;131:19731977.

164. Bonini JA, Anderson SM, Steiner DF. Molecular cloning and tissue expression of a novel orphan $\mathrm{G}$ protein-coupled receptor from rat lung. Biochemical and biophysical research communications 1997;234:190-193.

165. Chai W, Dong Z, Wang N, et al. Glucagon-like peptide 1 recruits microvasculature and increases glucose use in muscle via a nitric oxide-dependent mechanism. Diabetes 2012;61:888-896.

166. Cherbut C, Ferrier L, RozV $\subseteq$ C, et al. Short-chain fatty acids modify colonic motility through nerves and polypeptide $Y Y$ release in the rat. American Journal of Physiology-Gastrointestinal and Liver Physiology 1998;275:G1415-G1422.

167. Tazoe H, Otomo Y, Kaji I, et al. Roles of short-chain fatty acids receptors, GPR41 and GPR43 on colonic functions. J Physiol Pharmacol 2008;59:251-262.

168. Samuel BS, Shaito A, Motoike T, et al. Effects of the gut microbiota on host adiposity are modulated by the short-chain fatty-acid binding $G$ protein-coupled receptor, Gpr41. Proceedings of the National Academy of Sciences 2008;105:16767.

169. den Besten G, Lange K, Havinga R, et al. Gut-derived short-chain fatty acids are vividly assimilated into host carbohydrates and lipids. American Journal of Physiology-Gastrointestinal and Liver Physiology 2013;305:G900-G910.

170. Demigne C, Morand C, Levrat M, et al. Effect of propionate on fatty acid and cholesterol synthesis and on acetate metabolism in isolated rat hepatocytes. British Journal of Nutrition (United Kingdom) 1995.

171. Hardie D, Pan D. Regulation of fatty acid synthesis and oxidation by the AMPactivated protein kinase. Biochemical Society Transactions 2002;30:1064.

172. Zhang BB, Zhou G, Li C. AMPK: an emerging drug target for diabetes and the metabolic syndrome. Cell metabolism 2009;9:407-416. 
173. Li X, Chen H, Guan Y, et al. Acetic acid activates the AMP-activated protein kinase signaling pathway to regulate lipid metabolism in bovine hepatocytes. PloS one 2013;8:e67880.

174. Yamashita H, Fujisawa K, Ito E, et al. Improvement of obesity and glucose tolerance by acetate in type 2 diabetic Otsuka Long-Evans Tokushima Fatty (OLETF) rats. Bioscience, biotechnology, and biochemistry 2007;71:1236-1243.

175. Sakakibara S, Yamauchi T, Oshima Y, et al. Acetic acid activates hepatic AMPK and reduces hyperglycemia in diabetic KK-A (y) mice. Biochemical and biophysical research communications 2006;344:597-604.

176. Endo H, Niioka M, Kobayashi N, et al. Butyrate-Producing Probiotics Reduce Nonalcoholic Fatty Liver Disease Progression in Rats: New Insight into the Probiotics for the Gut-Liver Axis. PloS one 2013;8:e63388.

177. Wolever T, Spadafora P, Eshuis H. Interaction between colonic acetate and propionate in humans. The American journal of clinical nutrition 1991;53:681-687.

178. Laurent C, Simoneau C, Marks L, et al. Effect of acetate and propionate on fasting hepatic glucose production in humans. European journal of clinical nutrition 1995;49:484.

179. Fernandes J, Vogt J, Wolever TM. Intravenous acetate elicits a greater free fatty acid rebound in normal than hyperinsulinaemic humans. European journal of clinical nutrition 2012;66:1029-1034.

180. Venter CS, Vorster HH, Cummings JH. Effects of dietary propionate on carbohydrate and lipid metabolism in healthy volunteers. The American journal of gastroenterology 1990;85:549-553. 
CHAPTER 2 



\section{CHAPTER 3}

Distal, not proximal, colonic acetate infusions promote fat oxidation and improve metabolic markers in overweight men

Running title: Colonic acetate and human metabolism

Christina M van der Beek*, Emanuel E Canfora*, Kaatje Lenaerts, Freddy J Troost, Steven W M Olde Damink, Jens J Holst, Ad A M Masclee, Cornelis H C Dejong, Ellen E Blaak

*Shared first author

Clinical Science, in revision 


\section{Abstract}

Background and Objectives: Gut microbial-derived short-chain fatty acids (SCFA) are believed to affect host metabolism and cardiometabolic risk factors. The present study objective was to investigate the effects of proximal and distal colonic infusions with the SCFA sodium acetate on human fat oxidation and other metabolic parameters in overweight men.

Subjects and Methods: In this randomized, double blind crossover trial, six healthy overweight or obese men (BMI $\left.25-35 \mathrm{~kg} / \mathrm{m}^{2}\right)$ underwent two experimental periods: one with distal and one with proximal colonic acetate infusions. A feeding catheter was endoscopically positioned at the beginning of each period and remained in the colon for three consecutive days, enabling colonic sodium acetate $(100 \mathrm{mmol} / \mathrm{L}$ or 180 $\mathrm{mmol} / \mathrm{L}$ ) or placebo infusion during fasting conditions as well as after a oral glucose load (postprandial). Fat oxidation and energy expenditure were measured for $2 \mathrm{~h}$ using an open-circuit ventilated hood system during fasting as well as during postprandial conditions. In addition, blood samples were repeatedly collected for $2 \mathrm{~h}$ for analyses of metabolites, hormones and inflammatory markers.

Results: Distal colonic $180 \mathrm{mmol} / \mathrm{L}$ sodium acetate infusions increased fasting fat oxidation $\left(1.78 \pm 0.28\right.$ vs $-0.78 \pm 0.89 \mathrm{~g}$ fat $\left.2 \mathrm{~h}^{-1}, P=0.015\right)$, increased fasting peptide $Y Y$ (PYY, $P=0.009)$ and postprandial glucose and insulin concentrations $(P<0.05)$, and tended to increase concentrations of fasting plasma acetate $(P=0.069)$ compared with placebo. In addition, distal $100 \mathrm{mmol} / \mathrm{L}$ sodium acetate administration tended to decrease fasting tumour necrosis factor- $\alpha$ (TNF- $\alpha, P=0.067)$ compared with placebo. Proximal colonic acetate infusions showed no effects on energy and substrate metabolism, circulating hormones or inflammatory markers.

Conclusions: Distal colonic sodium acetate infusions affected whole-body substrate metabolism, with a pronounced increase in fasting fat oxidation and the gut-derived satiety-stimulating hormone PYY, and a slightly decrease in circulating TNF- $\alpha$. Modulating colonic acetate may be a nutritional target to treat or prevent obesity and related metabolic disorders. 


\section{Introduction}

Accumulating evidence suggests that the gut microbiota and its products may affect host metabolism, body weight, insulin sensitivity, and cardiometabolic risk factors, thereby contributing to the development of obesity and its adverse health consequences. ${ }^{1}$

Among the main products of gut microbiota metabolism are the short-chain fatty acids (SCFA) acetate, propionate, and butyrate, which are formed in the colon by fermentation of indigestible food components such as dietary fibres. ${ }^{2}$ SCFA may exert local colonic health effects by changing the $\mathrm{pH}$, regulating local inflammatory responses, and acting as an energy source for colonocytes. ${ }^{3}$ Interestingly, SCFA, mainly acetate, can enter the bloodstream, ${ }^{4}$ thereby affecting human whole-body energy and substrate metabolism. Additionally, SCFA might act as signalling molecules between gut microbiota and peripheral tissues, affecting fat oxidation, incretin responses, low-grade systemic inflammation, as well as adipose tissue fat storage; thereby influencing glucose and lipid homeostasis, and insulin sensitivity of the host. ${ }^{2}$

Several in vitro and animal studies indicated that the luminal and circulating most abundant SCFA acetate is an important mediator of substrate and energy metabolism. Rodent-derived data implied that acetate might improve satiety and appetite regulation via secretion of L-cells derived anorexic hormones such as glucagon-like peptide-1 (GLP-1) and peptide YY (PYY), and via central mechanisms. ${ }^{5-7}$ Furthermore, oral acetate administration to mice fed a high-fat diet reduced body weight and improved insulin sensitivity. ${ }^{8}$

Human studies supporting beneficial effects of acetate administration on substrate and energy metabolism are scarce. In hyperinsulinemic women, rectal and intravenous sodium acetate administration has been shown to increase PYY and to suppress the inflammatory marker tumour necrosis factor- $\alpha$ (TNF- $\alpha$ ) in plasma. ${ }^{9}$

Data on acute effects of colonic acetate administration on human fat oxidation and metabolic parameters are lacking. Moreover, it is of particular interest whether site of acetate delivery, i.e. proximal or distal colon, differentially affects substrate and energy metabolism. Interestingly, the proximal and distal colon differ in their microbial SCFA production rates, in distribution of the acetate receptor G-protein coupled receptor 43 (GPR43), and in their venous system, partly bypassing the liver when absorbed in the distal colon. ${ }^{10-13}$ Therefore, the primary aim of this study was to assess the effect of proximal versus distal colonic acetate infusions on fat oxidation and energy expenditure in overweight and obese healthy men during fasting and postprandial conditions. To this end, we used a unique endoscopic procedure, which 
Colonic acetate and human metabolism

allowed us to infuse acetate both proximally and distally in the colon. Secondary outcomes were carbohydrate oxidation, plasma SCFA, circulating metabolites (glucose, triacylglycerol (TAG), FFA, free glycerol) and hormones (insulin, PYY, GLP-1, leptin, angiopoietin-like protein 4 (ANGPTL4)) and inflammatory markers (TNF- $\alpha$, interleukin-6 (IL-6), interleukin-8 (IL-8), lipopolysaccharide binding protein (LBP)). 


\section{Material and Methods}

\section{Study participants}

Six healthy Caucasian normoglycaemic men between 20-50 years (BMI 25-35 $\mathrm{kg} / \mathrm{m}^{2}$ ) were recruited between May 2012 and January 2013 from the vicinity of Maastricht, the Netherlands. Exclusion criteria were: Diabetes mellitus (fasting plasma glucose $\geq 7.0 \mathrm{mmol} / \mathrm{L}$ ), gastroenterological diseases or prior abdominal surgery, cardiovascular diseases, cancer, liver or kidney malfunction, patients with a life expectancy shorter than 5 years, men following a hypocaloric diet, use of laxatives, or use of antibiotics, pre- or probiotics in the 3 months prior to start of the study or during the study period. The study was approved by the Medical Ethical Committee of Maastricht University Medical Centre+ (MUMC+) and conducted in accordance with the Declaration of Helsinki (revised version, October 2008, Seoul, South Korea). Written informed consent was obtained from all participants. All authors had access to the study data and reviewed and approved the final manuscript.

\section{Study design}

In this double blind, placebo-controlled, randomized, crossover study (Figure 1A), participants were studied during two experimental periods of 3 consecutive clinical investigation days (CID) with at least a 7-day washout period in between. During one period a feeding catheter was placed endoscopically in the proximal colon, and during the other period in the distal colon, the order of placement being randomized. In each period, the catheter remained in the colon for 3 consecutive CID during which sodium acetate $(100 \mathrm{mmol} / \mathrm{L}$ or $180 \mathrm{mmol} / \mathrm{L}$ dissolved in $120 \mathrm{~mL} 0.9 \% \mathrm{NaCl}$ ) or placebo (120 mL $0.9 \% \mathrm{NaCl}$ ) was instilled via the catheter on separate days in random order (Figure $1 \mathrm{~A}$ ). After an overnight fast, during each $\mathrm{CID}$, the participants received colonic infusions during fasting conditions and after an oral glucose load of 75 gram resembling the postprandial state. The order of sodium acetate/placebo solution administration was blinded for both the investigator and participants. The order of catheter placement was randomized but not blinded due to ethical reasons. An independent researcher performed permuted block randomization and assigned participants to interventions. The solutions were isotonic and manufactured by Basic Pharma Technologies B.V. (Geleen, The Netherlands) in accordance to standards of European Good Medical Practice requirements. 


\section{Catheter placement}

The day before colonic catheter placement, participants ingested 1 litre of the laxative sodium picosulfate/magnesium citrate (Ferring Pharmaceuticals, Hoofddorp, The Netherlands) combined with 20 mg Bisacodyl (Centrafarm, Etten-Leur, The Netherlands) to expel part of colonic content thereby allowing a safe introduction of the endoscope under inspection by the gastroenterologist the following day, but not washing out all microbiota. Participants were not allowed to consume anything after $20.00 \mathrm{~h}$ except for water. The next day, participants came to the hospital and a standard sigmoidoscopy or colonoscopy was performed at the Endoscopy Unit of MUMC+. A feeding catheter (Pur Tube Flocare, Nutricia Medical Devices BV, Schiphol Airport, The Netherlands) was placed either in the ascending colon for proximal infusion or in the descending colon or sigmoid for distal infusion. The catheter was clipped to the colonic mucosa using an endoclip fixation technique (Resolution clip 11 $\mathrm{mm}$, Boston Scientific, Galway, Ireland) to secure its position for three consecutive CID. During proximal placement, the participants received intravenous sedation with $2-2.5$ mg Midazolam (Actavis B.V., Baarn, The Netherlands) and the correct position of the catheter was confirmed by standard fluoroscopy.

\section{Three-day investigation period}

After positioning of the colonic catheter, the participants went to the Metabolic Research Unit of MUMC+ where they stayed for the three-day test period, including the nights. The three consecutive days after the day of catheter placement, the experiments were performed. A standardized diet was given during the entire period. The personalized standardized diets were based on the estimated daily energy expenditure calculated by the Harris Benedict Equation. ${ }^{14}$ The diet consisted of carbohydrates (55 en\%), fat (30 en\%) and protein (15 en\%). Participants consumed a meal directly after the test period, had snacks in between and consumed a warm evening meal before $19.30 \mathrm{~h}$. They were fasted overnight. After the third CID, a doctor removed the colonic catheter and participants went home (Figure $1 \mathrm{~A}$ ).

\section{Clinical investigation days (CID)}

Each CID consisted of two periods of each $2 \mathrm{~h}$ : a fasting period (t0 - t120) and a subsequent postprandial period (t180 - t300) (Figure 1B). Between the periods no measurements took place for $30 \mathrm{~min}$. Prior to the start of the fasting period a cannula was placed in an antecubital vein of the forearm to enable venous blood sampling. 
Each period was preceded by basal (at to for the fasting and at t180 for the postprandial period) venous blood sampling and measurements of energy expenditure and substrate oxidation for $30 \mathrm{~min}$ (from t-30 - t0 before the fasting period and from t150 - t180 before the postprandial period), using an open circuit ventilated hood system (Omnical, Maastricht University, The Netherlands). After baseline measurements colonic acetate or placebo infusion took place, followed by immediate ingestion of the oral glucose load in the postprandial period. The $120 \mathrm{~mL}$ test solutions were manually infused via the colonic catheter at a rate of $24 \mathrm{~mL}$ per min (within 5 min) using a syringe at to and 180 . Subsequently, in both periods, energy expenditure and substrate oxidation were measured during the complete $2 \mathrm{~h}$ period time frames. In addition, venous blood sampling was done at 15, 30, 60, 90 and 120 min after colonic infusions in both periods.

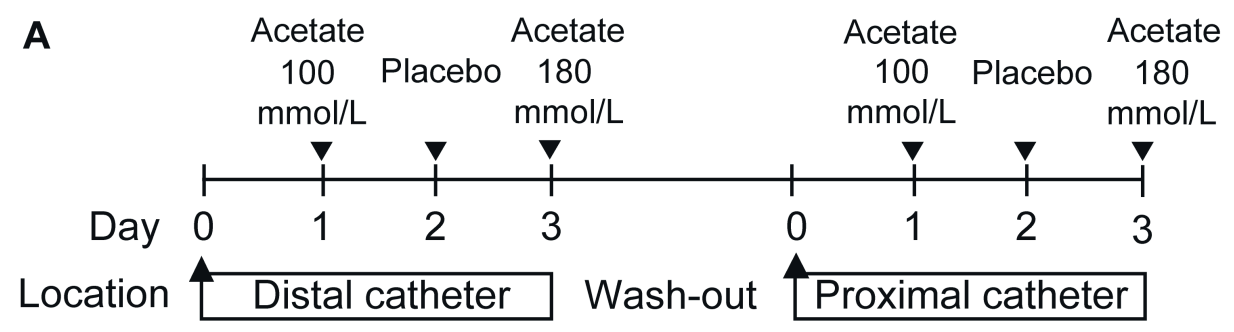

B

Time (min)
Colonic infusion
Glucose drink
Indirect calorimetry
Blood

VAS appetite
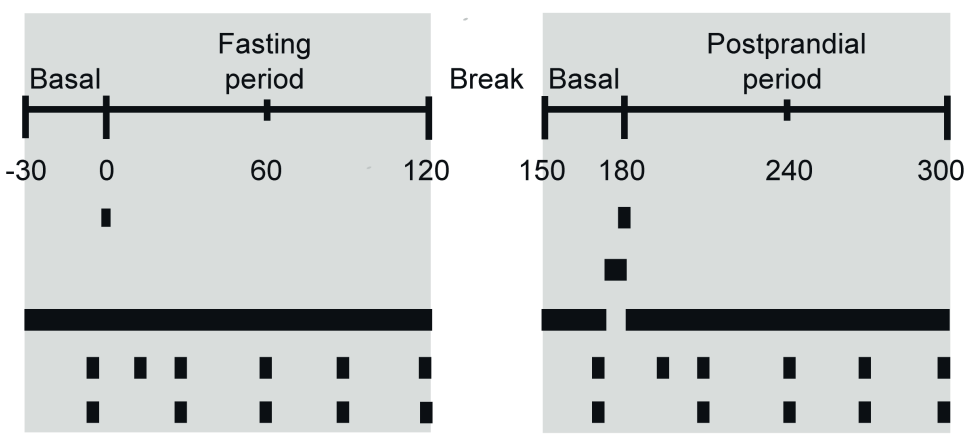

Figure 1. A: Example of study protocol B: Test day protocol 


\section{Outcomes}

Primary outcome was the effect of distal and proximal colonic acetate infusions on fat oxidation and energy expenditure during fasting and postprandial conditions measured via indirect calorimetry. The equations of Weir and Frayn ${ }^{15}$ were used to calculate total rate of substrate oxidation and energy expenditure.

Secondary outcomes were carbohydrate oxidation, plasma SCFA, circulating metabolites (glucose, TAG, FFA, free glycerol), hormones (insulin, active PYY, total GLP1, leptin, ANGPTL4) and inflammatory markers (TNF- $\alpha$, IL-6, IL-8, LBP).

For the metabolites, blood was collected into ice-cold EDTA tubes (0.2M EDTA (Sigma, Dorset, UK)). For GLP-1 analysis, blood was collected in a $2 \mathrm{~mL}$ EDTA tube containing $20 \mu \mathrm{L}$ of dipeptidyl peptidase-IV inhibitor (Millipore, Darmstadt, Germany). For PYY analysis, blood was collected in a $2 \mathrm{~mL}$ aprotinin tube containing $20 \mu \mathrm{L}$ of dipeptidyl peptidase-IV inhibitor. The samples were centrifuged at $3,500 \mathrm{~g}, 4{ }^{\circ} \mathrm{C}$ for 10 minutes, plasma was aliquoted and directly snap-frozen in liquid nitrogen and stored at $-80^{\circ} \mathrm{C}$ until analysis.

FFA, TAG and glucose were measured with enzymatic assays on an automated spectrophotometer (ABX Pentra 400 autoanalyser, Horiba ABX, Montpellier, France). Free glycerol was measured after precipitation with an enzymatic assay (Enzytec ${ }^{\mathrm{TM}}$ Glycerol, Roche Biopharm, Switzerland) automated on a Cobas Fara spectrophotometric autoanalyser (Roche Diagnostics, Basel, Switzerland). The concentrations of insulin, leptin and PYY were determined with radioimmunoassay (RIA) kits (Human Insulin specific RIA, Human Leptin RIA, Human PYY (3-36) RIA, Millipore Corporation, MA, USA). IL-6, IL-8 and TNF- $\alpha$ were determined with an enzyme-linked immunosorbent assay (ELISA) kit (Human Prolnflammatory II 4-Plex Ultra-Sensitive Kit, Meso Scale Diagnositics, MD, USA). The ANGPTL4 concentrations were determined with ELISA (Human ANGPTL4 ELISA Kit, RayBiotech, Norcross, USA). Samples were assayed for total GLP-1 immunoreactivity using an antiserum, which reacts equally with intact GLP-1 and the primary ( $\mathrm{N}$-terminally truncated) metabolite as previously described. ${ }^{16}$ For LBP detection, plates (Microlon 600 high binding, Greiner Bio-One, Alphen aan de Rijn, The Netherlands) were coated with polyclonal anti-human LBP. Diluted plasma samples (1:5000) and a standard dilution series with rLBP were added to the plate. Detection occurred with a biotinylated polyclonal rabbit antihuman LBP IgG, followed by peroxidase-conjugated streptavidin and substrate.

Deproteinization and preparation of plasma samples for SCFA analysis was performed as reported before, ${ }^{17}$ using a liquid chromatography system combined with mass spectrometry. 


\section{Power calculation}

To detect a $20 \%$ difference in the primary outcome parameter fat oxidation between the acetate treatments and placebo, the required samples size was 6 to achieve a power of $80 \%$ at a 2 -sided $\alpha$-level of 0.05 . Assuming a drop-out of $40 \%$ we totally included 10 subjects.

\section{Statistical analysis}

Values are expressed as mean \pm SEM. Responses after distal and proximal colonic administration during fasting (to - t120) and postprandial (t180 - t300) conditions are expressed as incremental area under the curve (iAUC), which were calculated by the trapezoid method and checked for normal distribution by a Kolmogorov-Smirnov test. Differences in fasting and postprandial iAUC between acetate and placebo infusions were analyzed using a linear mixed model for repeated measures. Intervention, period (catheter placement order) and subperiod (intervention order) were set as fixed factors and participants were set as random factor. Pairwise comparisons were performed with Fisher's Least Significant Difference (LSD) test. No carry-over effect was apparent to previous CID; therefore, previous intervention was not included in the model. iAUC not shown as values or figures did not present statistically significant differences. All statistics were performed using SPSS 22.0 for Mac (Chicago, IL, USA) and $P<0.05$ (two-sided $P$-value) was considered statistically significant. A $P$-value smaller than 0.10 was regarded as a trend. 


\section{Results}

Due to technical problems concerning the adherence of the mucosal clips, several catheters fell out of the colon directly after colonoscopy. Therefore, it was decided to increase the dropout rate of our sample size calculation to $40 \%$. This led to a total inclusion of 10 men, of which six completed all six experimental days and were included in the final analysis. After two failed attempts to clip the catheter to the colonic mucosa on two separate days, a participant was excluded from the study. Mean BMI of the participants was $31 \pm 1.5 \mathrm{~kg} / \mathrm{m}^{2}$ and they had a mean fasting glucose of $5.1 \pm$ $0.1 \mathrm{mmol} / \mathrm{L}$ (Table 1). No adverse events were reported.

Table 1. Study participants' characteristics $(n=6)$

\begin{tabular}{lc}
\hline Variable & Mean \pm SEM \\
\hline Age, years & $30.2 \pm 4.7$ \\
$\mathrm{BMI}, \mathrm{kg} / \mathrm{m}^{2}$ & $31.0 \pm 1.5$ \\
Waist circumference, $\mathrm{cm}$ & $108.0 \pm 4.9$ \\
Systolic blood pressure, $\mathrm{mmHg}$ & $126.3 \pm 3.5$ \\
Diastolic blood pressure, $\mathrm{mmHg}$ & $83.7 \pm 2.1$ \\
$\mathrm{HbA}_{1 \mathrm{c}} \%$ & $5.3 \pm 0.1$ \\
Fasting glucose, mmol/L & $5.1 \pm 0.1$ \\
\hline
\end{tabular}

Abbreviations: $\mathrm{BMI}$, body-mass-index; $\mathrm{HbA}_{1 c}$, Hemoglobin $\mathrm{A}_{1 \mathrm{c}}$.

\section{Fat oxidation, energy expenditure and carbohydrate oxidation}

Fasting fat oxidation was higher after distal $180 \mathrm{mmol} / \mathrm{L}$ acetate administration $\left(1.78 \pm 0.28\right.$ vs $-0.78 \pm 0.89 \mathrm{~g}$ fat $\left.2 \mathrm{~h}^{-1}, P=0.015\right)$ and tended to be higher after distal 100 $\mathrm{mmol} / \mathrm{L}$ acetate infusion $\left(0.88 \pm 0.45 \mathrm{vs}-0.78 \pm 0.89 \mathrm{~g}\right.$ fat $\left.2 \mathrm{~h}^{-1}, P=0.059\right)$ compared with placebo (Figure $2 \mathrm{~A}$ and $\mathrm{C}$ ). Fasting fat oxidation was not significantly different between interventions after proximal acetate infusion (Figure 2B). Postprandial fat oxidation decreased in all intervention groups. However, no significant differences between the groups neither after distal nor after proximal colonic infusions were detected.

Postprandial energy expenditure increased in all intervention groups. However, no significant differences between interventions in both fasting and postprandial conditions were observed (Figure 2D and E). 
No significant differences in fasting carbohydrate oxidation were observed after distal and proximal administration. Postprandial carbohydrate oxidation increased in all interventions without significant differences between the intervention groups neither after distal nor after proximal colonic infusions (Figure $2 \mathrm{~F}$ and $\mathrm{G}$ ).

\section{Plasma acetate, propionate and butyrate concentrations}

Fasting plasma acetate concentrations tended to be higher after distal 180 $\mathrm{mmol} / \mathrm{L}$ acetate administration, as compared to placebo (-833 \pm 663 vs $1344 \pm 1036$ $\mu \mathrm{mol} / \mathrm{L} 2 \mathrm{~h}^{-1}, P=0.069$; Figure $3 \mathrm{~A}$ and $\mathrm{C}$ ). No significant differences between interventions were found during the fasting and postprandial period after proximal colonic infusions (Figure 3C).

Plasma propionate and butyrate concentrations were not significantly affected after all intervention periods and administration sides (Supplemental Figure 1).

\section{Plasma concentrations of glucose and insulin}

Postprandial glucose concentrations were higher after $180 \mathrm{mmol} / \mathrm{L}$ acetate administration in the distal colon compared with placebo (303 $\pm 42 \mathrm{vs} 228 \pm 38 \mathrm{mmol} / \mathrm{L}$ $2 h^{-1}, P=0.004$; Figure 3D and F). In line, postprandial insulin concentrations were higher after distal administration of $180 \mathrm{mmol} / \mathrm{L}$ acetate as compared to placebo (6759 \pm 1281

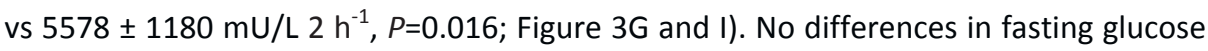
or insulin concentrations were observed when acetate was distally infused (Figure 3D and $G$ ). No effects of proximally infused acetate on circulating glucose and insulin concentrations were found (Figure $3 \mathrm{E}$ and $\mathrm{H}$ ). 

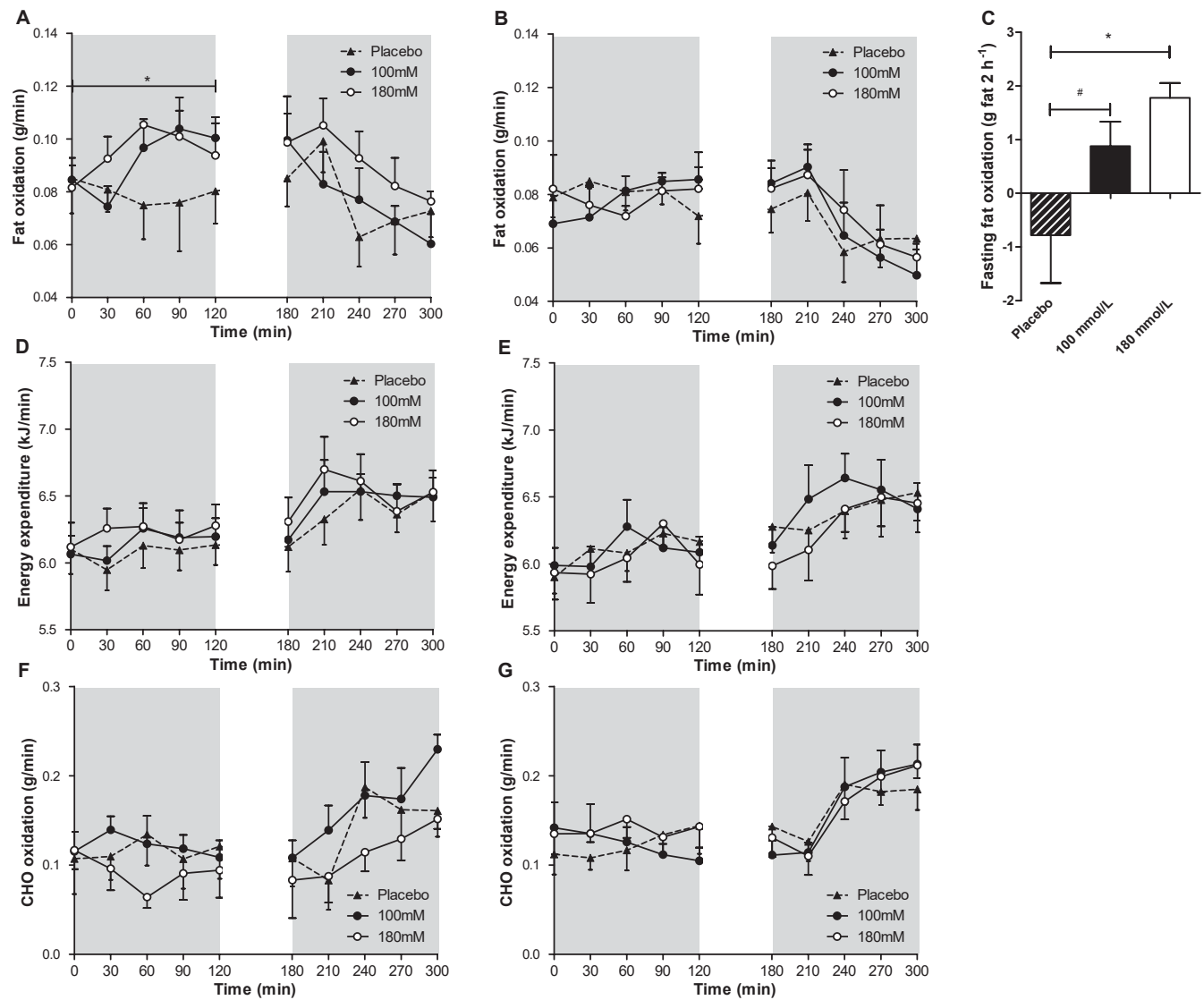

Figure 2. Energy expenditure and substrate oxidation

Fasting (t0 - t120) and postprandial ( $\mathrm{t} 180$ - t300) fat oxidation after distal (A) and proximal (B) colonic infusions. iAUC for fasting ( $\mathrm{t} 0$ - t120) fat oxidation following distal colonic acetate infusions (C). Overall intervention effect for fasting fat oxidation after distal acetate, $P=0.040$ (180 mmol/L vs placebo, $P=0.015 ; 100 \mathrm{mmol} / \mathrm{L}$ vs placebo, $P=0.059)$. Values are means $\pm \operatorname{SEMs}(\mathrm{n}=6) .{ }^{*} P<0.05$ and $\# P<0.1$.

Fasting (t0 - t120) and postprandial (t180 - t300) energy expenditure after distal (D) and proximal (E) colonic infusions. Values are means $\pm \operatorname{SEMs}(n=6)$. No significant differences between interventions.

Fasting ( $\mathrm{t} 0$ - t120) and postprandial ( $\mathrm{t} 180$ - t300) carbohydrate oxidation after distal (F) and proximal (G) colonic infusions. Values are means \pm SEMs $(n=6)$. No significant differences between interventions. 

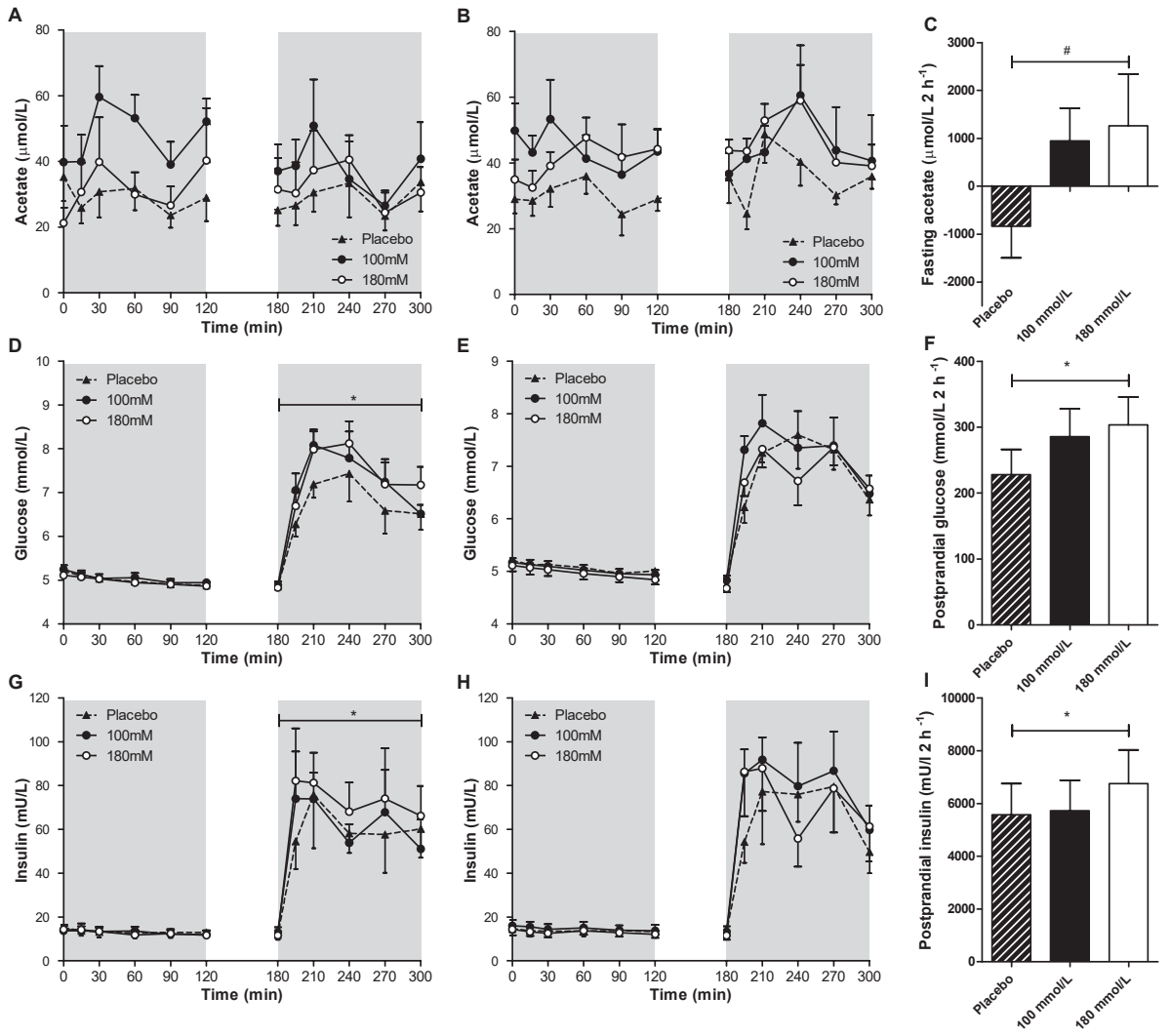

Figure 3. Plasma concentrations of acetate, glucose and insulin

Fasting (t0 - t120) and postprandial (t180 - t300) plasma acetate concentrations after distal (A) and proximal (B) colonic acetate infusions. iAUC for fasting (t0 - t120) plasma acetate following distal colonic infusion (C). Overall intervention effect for fasting plasma acetate after distal infusions $P=0.157$ (180 $\mathrm{mmol} / \mathrm{L}$ vs placebo, $P=0.069)$. Values are means $\pm \operatorname{SEMs}(\mathrm{n}=6) . \# P<0.1$.

Fasting (t0 - t120) and postprandial (t180 - t300) plasma glucose after distal (D) and proximal (E) colonic acetate infusions. iAUC for postprandial (t180 - t300) plasma glucose following distal colonic acetate infusion (F). Overall intervention effect for postprandial glucose after distal acetate, $P=0.010$ (180 $\mathrm{mmol} / \mathrm{L}$ vs placebo, $P=0.016)$. Values are means \pm SEMs $(\mathrm{n}=6) .{ }^{*} P<0.05$.

Fasting (t0 - t120) and postprandial (t180 - t300) plasma insulin after distal $(\mathrm{G})$ and proximal $(\mathrm{H})$ colonic acetate infusions. iAUC for postprandial (t180 - t300) plasma insulin following distal colonic acetate infusions (I). Overall intervention effect for postprandial insulin after distal acetate $P=0.028(180 \mathrm{mmol} / \mathrm{L}$ vs placebo, $P=0.016)$. Values are means \pm SEMs $(n=6) .{ }^{*} P<0.05$. 
Colonic acetate and human metabolism

\section{Plasma concentrations of PYY and GLP-1}

PYY was higher in the fasting period after distal $180 \mathrm{mmol} / \mathrm{L}$ acetate infusion as compared to placebo (1976 \pm 391 vs $0 \pm 535 \mathrm{ng} / \mathrm{L} 2 \mathrm{~h}^{-1}, P=0.009$; Figure $4 \mathrm{~A}$ and C). Proximally administered acetate did not significantly affect PYY plasma concentrations (Figure 4B).

Fasting GLP-1, as well as postprandial increase in GLP-1 concentrations, were not significantly affected by the administered acetate after proximal or distal colonic acetate infusions (Figure 4D and E).

\section{Plasma concentrations of inflammatory markers}

TNF- $\alpha$ plasma concentrations tended to be lower in the fasting state after distal administration of $100 \mathrm{mmol} / \mathrm{L}$ acetate when compared with placebo (-21.7 \pm 9.8 vs -2.1

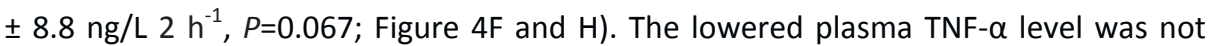
significantly different in the postprandial state. Proximal administration of acetate did not influence TNF- $\alpha$ levels (Figure 4G). Plasma IL-6, IL-8 and LBP concentrations were not significantly influenced by the administered acetate, neither after distal nor after proximal administration (Supplemental Figure 2).

\section{Plasma concentrations of TAG, FFA and free glycerol}

No significant differences in circulating TAG, FFA and free glycerol concentrations were observed between interventions neither in the fasting nor in the postprandial period. Postprandially, TAG, FFA, and free glycerol concentrations decreased in all intervention groups with no significant differences between groups (Supplemental Figure 3).

No significant differences in plasma leptin and ANGPTL4 concentrations were observed between interventions neither in the fasting nor in the postprandial period (Supplemental Figure 4). 

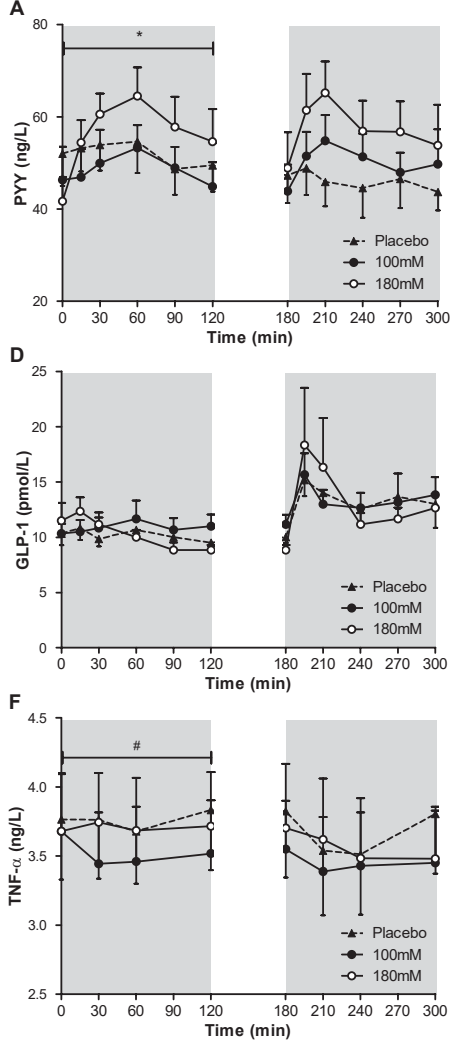

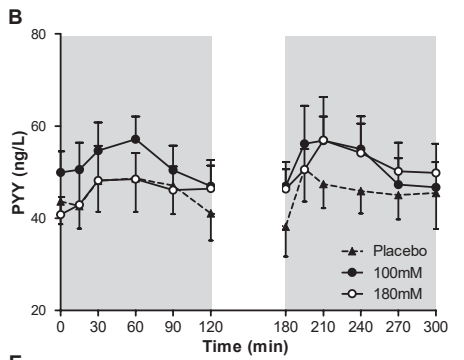

E
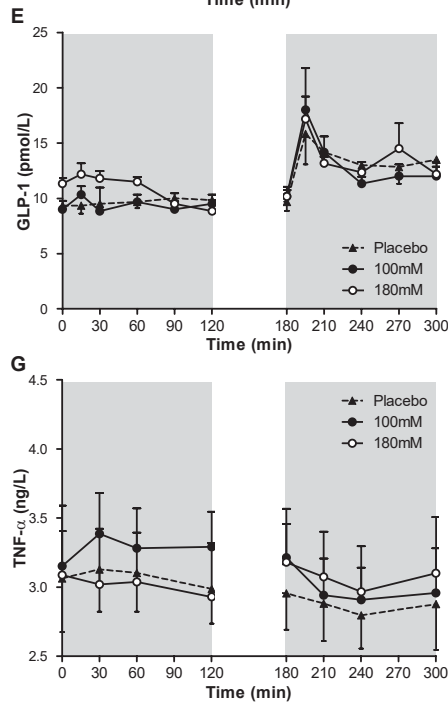
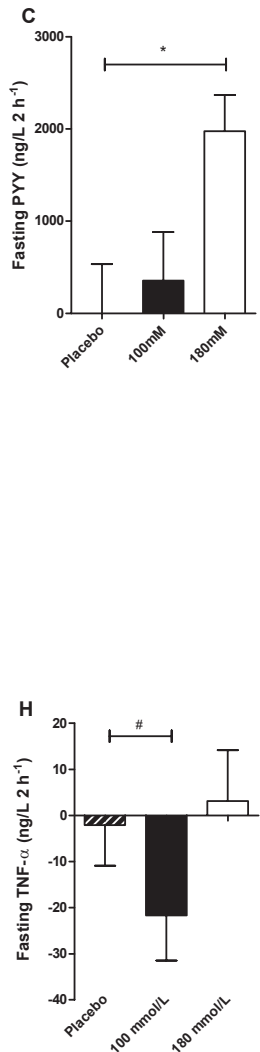

Figure 4. Plasma concentrations of PYY, GLP-1 and TNF- $\alpha$

Fasting (t0 - t120) and postprandial (t180 - t300) plasma PYY after distal (A) and proximal (B) colonic acetate infusions. iAUC for fasting ( $\mathrm{tO}-\mathrm{t} 120$ ) plasma PYY following distal colonic infusion (C). Overall intervention effect for fasting PYY after distal acetate, $P=0.019(180 \mathrm{mmol} / \mathrm{L}$ vs placebo, $P=0.009)$. Values are means \pm SEMs $(n=6) .{ }^{*} P<0.05$.

Fasting (t0 - t120) and postprandial (t180 - t300) plasma GLP-1 after distal (D) and proximal (E) colonic acetate infusions. Values are means $\pm \operatorname{SEMs}(n=6)$. No significant differences between interventions.

Fasting (t0 - t120) and postprandial (t180 - t300) plasma TNF- $\alpha$ after distal (F) and proximal (G) colonic acetate infusions. iAUC for fasting (t0 - t120) plasma TNF- $\alpha$ following distal colonic acetate infusions $(H)$. Overall intervention effect for fasting TNF- $\alpha$ after distal acetate $P=0.089(100 \mathrm{mmol} / \mathrm{L}$ vs placebo, $P=0.067)$. Values are means \pm SEMs $(n=6)$. $\# P<0.1$. 


\section{Discussion}

In the present randomized, placebo-controlled, double blind crossover study, we assessed the effect of sodium acetate $(180 \mathrm{mmol} / \mathrm{L}$ and $100 \mathrm{mmol} / \mathrm{L})$ and placebo infusions in the proximal and distal part of the colon on fat oxidation and metabolic parameters in overweight and obese normoglycaemic men. We demonstrated that distal colonic acetate infusions pronouncedly increased fasting fat oxidation with more than $25 \%$ (180 mmol/L vs placebo) and increased fasting plasma PYY concentrations. In addition, administration of distal colonic acetate slightly raised fasting circulating acetate, and postprandial glucose and insulin concentrations, as well as it slightly decreased TNF- $\alpha$ concentrations. Proximal colonic acetate instillation did not result in significant metabolic effects. This is the first human intervention study that compares acetate administration in different colonic regions and showed that putatively physiologically relevant distal colonic acetate concentrations ${ }^{18-20}$ promote fat oxidation and alter metabolic parameters in overweight volunteers.

The used amounts and concentrations of acetate in the present study can putatively be achieved ingesting a high fiber diet. The only human data available ${ }^{21}$ showed basal total SCFA concentrations of $123 \pm 12$ (mean \pm standard error) $\mathrm{mmol} / \mathrm{L}$ in the proximal and $100 \pm 30 \mathrm{mmol} / \mathrm{L}$ in the distal colon in sudden death victims. These data already showed that SCFA concentrations are highly variable. The productions rates of SCFA in the colon strongly depend on the nutritional status, amount of complex foods in the diet, gut microbial composition and colonic transit time. ${ }^{21-23}$ In vitro studies indicate that a daily amount of approximately $400-800 \mathrm{mmol}$ SCFA can be produced by ingesting a high-fiber diet, assuming that $10 \mathrm{~g}$ of dietary fiber fermentation yield $\sim 100$ mmol SCFA. ${ }^{22,24}$ These estimates agree with the results on in vitro fermentation of ileal effluents from patients with an ileostomy, which produced 120-420 mmol acetate per day, depending upon the type and amount of complex carbohydrates in their diet. ${ }^{24}$

Most SCFA production occurs in the proximal part of the colon, while a smaller amount of SCFA are produced in the distal colon. ${ }^{20}$ Interestingly, this study showed that metabolic effects were specifically found after distal acetate infusion, but not after proximal infusion. This could be explained by several factors. First, plasma acetate concentrations tended to be higher with distal, but not proximal, infusion (Figure 4AC). Therefore, distal acetate infusion is expected to have resulted in a higher systemic acetate appearance. In particular, since it can be speculated that peripheral acetate extraction was also higher with distal administration, in line with the more pronounced metabolic effects. Indeed, SCFA delivered in the proximal colon enter the superior 
mesenteric vein, which drains into the portal vein; whereas SCFA delivered in the distal colon partly bypass the liver, while the absorptive capacity is the same throughout the colon. ${ }^{10}$ Secondly, it is known that SCFA receptor distribution differs between the proximal and distal part of the colon. ${ }^{25}$ The SCFA receptor GPR43 is highly expressed in the sigmoid colon and to a lesser extent in the ascending colon, possibly contributing to the metabolic differences between proximal and distal infusions. Thirdly, microbiota composition and their activity may differ between proximal and distal colonic locations, ${ }^{26,27}$ which might have resulted in differences in the microbial utilization or conversation rate of the infused sodium acetate.

We demonstrated that distal colonic sodium acetate infusions enhanced fasting fat oxidation. However, acetate is a substrate and might be converted into acetyl-CoA, thereby delivering energy. Therefore, it can be questioned whether the found effect on fat oxidation is not due to the oxidation of sodium acetate per se, rather than the oxidation of endogenous lipids. However, when $100 \%$ of the colonically infused sodium acetate would have been oxidized, this would only explain 28 \% (calculated with a respiratory quotient $(\mathrm{RQ})$ of 0.5 representative for the oxidation of sodium acetate $\left.^{28}\right)$ of the found increase in fat oxidation $(180 \mathrm{mmol} / \mathrm{L}$ sodium acetate vs placebo, for calculation details see supplementary information). Moreover, at least 60 $\%$ of acetate absorption is by simple diffusion of protonated acetate, ${ }^{29}$ which would yield upon oxidation a RQ of 1.0 rather than $0.5 .^{30}$ Finally, a kinetic study showed that only $30-50 \%$ of rectally administered ${ }^{13} \mathrm{C}$-acetate is oxidized after $4 \mathrm{~h} .{ }^{31}$ This indicates that the estimated $28 \%$ is a large overestimation.

Hence, other mechanisms should explain the acetate-induced increase in fat oxidation. Firstly, it is known that acetate can activate adipose tissue and skeletal muscle AMPK, possibly mediated through an acetate-induced increased AMP/ATP ratio and upregulation of PPAR target genes, ${ }^{8,} 32,33$ which might stimulate the oxidative metabolism in these tissues. ${ }^{34}$ Secondly, we observed an elevation in fasting plasma PYY only after distal colonic infusion. Studies performed in mice and preliminary human data suggest that an increase in circulating PYY is responsible for a shift in substrate utilization towards fat oxidation. ${ }^{35,}{ }^{36}$ PY might also acutely increase glucose uptake from the gut, ${ }^{37}$ which might explain the slightly elevated postprandial plasma glucose and insulin after distal infusion.

TNF- $\alpha$, which tended to be reduced after distal acetate infusion in our study, has been linked to a state of low-grade inflammation in obesity and insulin resistance. ${ }^{38}$ Our data are consistent with a reduced TNF- $\alpha$ release from neutrophils after in vitro acetate treatment. ${ }^{39}$ Most cytokines, including TNF- $\alpha$, involved in inducing and/or maintaining inflammation are controlled by transcription factor NF-KB, and it can be 
hypothesized that suppressing NF-KB by acetate can cause suppression of these proinflammatory markers. ${ }^{40}$ Nevertheless, we only demonstrated a tendency towards decreased TNF- $\alpha$ concentrations after distal colonic acetate infusion with a 100 $\mathrm{mmol} / \mathrm{L}$, but not with the $180 \mathrm{mmol} / \mathrm{L}$. The reason for this is not entirely clear and the physiological relevance of this finding remains to be confirmed in future studies.

The increase in PYY and the decrease in TNF- $\alpha$ concentrations are in line with a human study in six obese hyperinsulinemic women. ${ }^{9}$ They showed that rectal infusions with acetate increased serum acetate and plasma PYY, and intravenous infusions of acetate decreased plasma TNF- $\alpha$ levels compared with saline infusions. ${ }^{9}$ Comparable to the present findings and other studies in humans ${ }^{41}, 42$ circulating acetate concentrations peaked between 30 - 60 min after distal colonic acetate administration. We extended previous data showing pronounced effects on human fat oxidation and the differential metabolic effect between proximal and distal colonic infusion. In addition, we investigated acetate-induced effects during fasting and postprandial conditions for a prolonged timeframe of $2 \mathrm{~h}$.

We are aware that the present study has limitations. Most are due to the complex study design and the invasive nature of the study using colonic catheters during prolonged periods.

First, inherent to the design, the use of laxation prior to colonoscopy is not ideal. It is possible that the microbiota changed after laxation. ${ }^{43}$ However, in vitro studies showed that the major groups of microbiota are stable at different transit times. ${ }^{44}$ Importantly, we tried to minimize this possible microbial change by using only $1 / 4^{\text {th }}$ of laxation product normally used for diagnostic colonoscopies. Due to the length and small width of the catheters, we were not able to sample faecal material during the periods.

Second, because the catheter stayed in the colon for three consecutive days, we had a washout period of about $16 \mathrm{~h}$ between test days. SCFA are, however, rapidly absorbed in the colon. ${ }^{45}$ Indeed, looking at our plasma results, we observed plasma SCFA levels returning to baseline at the beginning of the next test day, suggesting a normalization of SCFA concentrations. Third, due to the invasive protocol, we only included six volunteers in this study. We calculated, however, that this sample size is adequate for detecting differences on fat oxidation, our primary outcome.

This study has important clinical implications. The substantial increase in fat oxidation after colonic acetate supplementation may have great future potential if maintained during chronic treatment. An increase in fat oxidation can decrease fat storage in non-adipose tissue, such as skeletal muscle or liver tissue. A decrease in ectopic fat and bioactive lipid metabolites has been associated with improved insulin 
resistance, an important target in the treatment of metabolic diseases. ${ }^{46}$ Further studies should address which mixture of colonic SCFA is most beneficial for human health, and which fibres or prebiotics can be added to the diet to reach positive metabolic effects in the long term.

In conclusion, this study showed, for the first time, that distal, but not proximal, colonically administered acetate modulates whole-body substrate metabolism, with a pronounced increase in fasting fat oxidation and in the satiety-stimulating hormone PYY. This indicates that modulating colonic acetate via i.e. slow-fermentable acetogenic foods may be a nutritional or therapeutic target to treat or prevent chronic metabolic diseases. 


\section{References}

1. Diamant $M$, Blaak E, De Vos W. Do nutrient-gut-microbiota interactions play a role in human obesity, insulin resistance and type 2 diabetes? Obesity Reviews 2011;12:272-281.

2. Canfora EE, Jocken JW, Blaak EE. Short-chain fatty acids in control of body weight and insulin sensitivity. Nat Rev Endocrinol 2015;11:577-591.

3. Hamer HM, Jonkers D, Venema K, et al. Review article: the role of butyrate on colonic function. Aliment Pharmacol Ther 2008;27:104-19.

4. Bloemen JG, Venema K, van de Poll MC, et al. Short chain fatty acids exchange across the gut and liver in humans measured at surgery. Clinical nutrition 2009;28:657-661.

5. Frost G, Sleeth ML, Sahuri-Arisoylu M, et al. The short-chain fatty acid acetate reduces appetite via a central homeostatic mechanism. Nature communications 2014;5.

6. Tolhurst G, Heffron H, Lam YS, et al. Short-chain fatty acids stimulate glucagon-like peptide-1 secretion via the G-protein-coupled receptor FFAR2. Diabetes 2012;61:364-371.

7. Psichas A, Zac-Varghese S, Murphy K, et al. Short chain fatty acids stimulate the release of gut hormone peptide YY from human primary enteroendocrine L cells, In Proceedings of The Physiological Society, 27, PC331, 2012.

8. den Besten G, Bleeker A, Gerding A, et al. Short-Chain Fatty Acids protect against HighFat Diet-Induced Obesity via a PPARy-dependent switch from lipogenesis to fat oxidation. Diabetes 2015:db141213.

9. Freeland KR, Wolever T. Acute effects of intravenous and rectal acetate on glucagonlike peptide-1, peptide YY, ghrelin, adiponectin and tumour necrosis factor-alpha. British Journal of Nutrition 2010;103:460-466.

10. Moeinian M, Ghasemi-Niri SF, Mozaffari S, et al. Beneficial effect of butyrate, Lactobacillus casei and L-carnitine combination in preference to each in experimental colitis. World journal of gastroenterology 2014;20:10876-85.

11. Kaji I, Karaki S, Tanaka R, et al. Density distribution of free fatty acid receptor 2 (FFA2)expressing and GLP-1-producing enteroendocrine L cells in human and rat lower intestine, and increased cell numbers after ingestion of fructo-oligosaccharide. Journal of molecular histology 2011;42:27-38.

12. Alander M, De Smet I, Nollet L, et al. The effect of probiotic strains on the microbiota of the Simulator of the Human Intestinal Microbial Ecosystem (SHIME). International journal of food microbiology 1999;46:71-9.

13. Wang $\mathrm{M}$, Ahrne $\mathrm{S}$, Jeppsson $\mathrm{B}$, et al. Comparison of bacterial diversity along the human intestinal tract by direct cloning and sequencing of $16 \mathrm{~S}$ rRNA genes. FEMS microbiology ecology 2005;54:219-31.

14. Harris JA, Benedict FG. A biometric study of human basal metabolism. Proceedings of the National Academy of Sciences of the United States of America 1918;4:370.

15. Frayn K. Calculation of substrate oxidation rates in vivo from gaseous exchange. Journal of Applied Physiology 1983;55:628.

16. Orskov C, Rabenhoj L, Wettergren A, et al. Tissue and plasma concentrations of amidated and glycine-extended glucagon-like peptide I in humans. Diabetes 1994;43:535-9.

17. van Eijk HM, Bloemen JG, Dejong $\mathrm{CH}$. Application of liquid chromatography, Äimass spectrometry to measure short chain fatty acids in blood. Journal of Chromatography $B$ 2009;877:719-724.

18. Cummings JH, Macfarlane GT. Colonic microflora: nutrition and health. Nutrition 1997;13:476-8.

19. Andoh A, Tsujikawa T, Fujiyama Y. Role of dietary fiber and short-chain fatty acids in the colon. Curr Pharm Des 2003;9:347-58.

20. Cummings J, Pomare E, Branch W, et al. Short chain fatty acids in human large intestine, portal, hepatic and venous blood. Gut 1987;28:1221. 
21. Venema K. Microbial metabolites produced by the colonic microbiota as drivers for immunomodulation in the host. The FASEB Journal 2013;27:643.12.

22. Pylkas AM, Juneja LR, Slavin JL. Comparison of different fibers for in vitro production of short chain fatty acids by intestinal microflora. Journal of medicinal food 2005;8:113-116.

23. El Oufir L, Barry J, Flourie B, et al. Relationships between transit time in man and in vitro fermentation of dietary fiber by fecal bacteria. European journal of clinical nutrition 2000;54:603-609.

24. McBurney M, Thompson L, Cuff D, et al. Comparison of ileal effluents, dietary fibers, and whole foods in predicting the physiological importance of colonic fermentation. The American journal of gastroenterology 1988;83:536.

25. Kaji I, Karaki S, Tanaka R, et al. Density distribution of free fatty acid receptor 2 (FFA2)expressing and GLP-1-producing enteroendocrine $L$ cells in human and rat lower intestine, and increased cell numbers after ingestion of fructo-oligosaccharide. J Mol Histol 2011;42:27-38.

26. Alander M, De Smet I, Nollet L, et al. The effect of probiotic strains on the microbiota of the Simulator of the Human Intestinal Microbial Ecosystem (SHIME). Int J Food Microbiol 1999;46:71-9.

27. Wang $\mathrm{M}$, Ahrne $\mathrm{S}$, Jeppsson $\mathrm{B}$, et al. Comparison of bacterial diversity along the human intestinal tract by direct cloning and sequencing of $16 \mathrm{~S}$ rRNA genes. FEMS Microbiol Ecol 2005;54:219-31.

28. Akanji A, Bruce M, Frayn K. Effect of acetate infusion on energy expenditure and substrate oxidation rates in non-diabetic and diabetic subjects. European journal of clinical nutrition 1989;43:107-115.

29. Wong JM, de Souza R, Kendall CW, et al. Colonic health: fermentation and short chain fatty acids. Journal of clinical gastroenterology 2006;40:235-243.

30. Ritz P, Cloarec D, Beylot $M$, et al. Effects of colonic fermentation on respiratory gas exchanges following a glucose load in man. Metabolism 1993;42:347-352.

31. Lifschitz $\mathrm{CH}$, Irving $\mathrm{CS}$, Helge $\mathrm{H}$, et al. [13C] Acetate Oxidation in Infants After Oral Versus Rectal Administration: A Kinetic Model. Journal of pediatric gastroenterology and nutrition 1985;4:699-706.

32. Kondo T, Kishi M, Fushimi T, et al. Acetic acid upregulates the expression of genes for fatty acid oxidation enzymes in liver to suppress body fat accumulation. Journal of agricultural and food chemistry 2009;57:5982-5986.

33. Yamashita $\mathrm{H}$, Maruta $\mathrm{H}$, Jozuka $\mathrm{M}$, et al. Effects of acetate on lipid metabolism in muscles and adipose tissues of type 2 diabetic Otsuka Long-Evans Tokushima Fatty (OLETF) rats. Bioscience, biotechnology, and biochemistry 2009;73:570-576.

34. Hardie DG, Ross FA, Hawley SA. AMPK: a nutrient and energy sensor that maintains energy homeostasis. Nature reviews Molecular cell biology 2012;13:251-262.

35. van den Hoek AM, Heijboer AC, Voshol PJ, et al. Chronic PYY3-36 treatment promotes fat oxidation and ameliorates insulin resistance in C57BL6 mice. Am J Physiol Endocrinol Metab 2007;292:E238-45.

36. Sloth B, Holst JJ, Flint A, et al. Effects of PYY1-36 and PYY3-36 on appetite, energy intake, energy expenditure, glucose and fat metabolism in obese and lean subjects. American Journal of Physiology-Endocrinology and Metabolism 2007;292:E1062-E1068.

37. Bird AR, Croom WJ, Jr., Fan YK, et al. Peptide regulation of intestinal glucose absorption. J Anim Sci 1996;74:2523-40.

38. Dandona P, Weinstock $R$, Thusu K, et al. Tumor necrosis factor-alpha in sera of obese patients: fall with weight loss. J Clin Endocrinol Metab 1998;83:2907-10.

39. Tedelind S, Westberg F, Kjerrulf $M$, et al. Anti-inflammatory properties of the shortchain fatty acids acetate and propionate: a study with relevance to inflammatory bowel disease. World Journal of Gastroenterology 2007;13:2826. 
40. Liu T, Li J, Liu Y, et al. Short-chain fatty acids suppress lipopolysaccharide-induced production of nitric oxide and proinflammatory cytokines through inhibition of NF-KB pathway in RAW264. 7 cells. Inflammation 2012;35:1676-1684.

41. Wolever T, Brighenti F, Royall D, et al. Effect of rectal infusion of short chain fatty acids in human subjects. The American journal of gastroenterology 1989;84:1027.

42. Wolever T, Spadafora $\mathrm{P}$, Eshuis $\mathrm{H}$. Interaction between colonic acetate and propionate in humans. The American journal of clinical nutrition 1991;53:681.

43. Malago JJ, Sangu CL. Intraperitoneal administration of butyrate prevents the severity of acetic acid colitis in rats. Journal of Zhejiang University. Science. B 2015;16:224-34.

44. Child MW, Kennedy A, Walker AW, et al. Studies on the effect of system retention time on bacterial populations colonizing a three-stage continuous culture model of the human large gut using FISH techniques. FEMS Microbiol Ecol 2006;55:299-310.

45. van der Beek CM, Bloemen JG, van den Broek MA, et al. Hepatic Uptake of Rectally Administered Butyrate Prevents an Increase in Systemic Butyrate Concentrations in Humans. J Nutr 2015.

46. Blaak EE, Hul G, Verdich C, et al. Fat oxidation before and after a high fat load in the obese insulin-resistant state. J Clin Endocrinol Metab 2006;91:1462-9. 


\section{SUPPLEMENTAL RESULTS}

\section{Supplemental figure 1. Plasma butyrate and propionate}
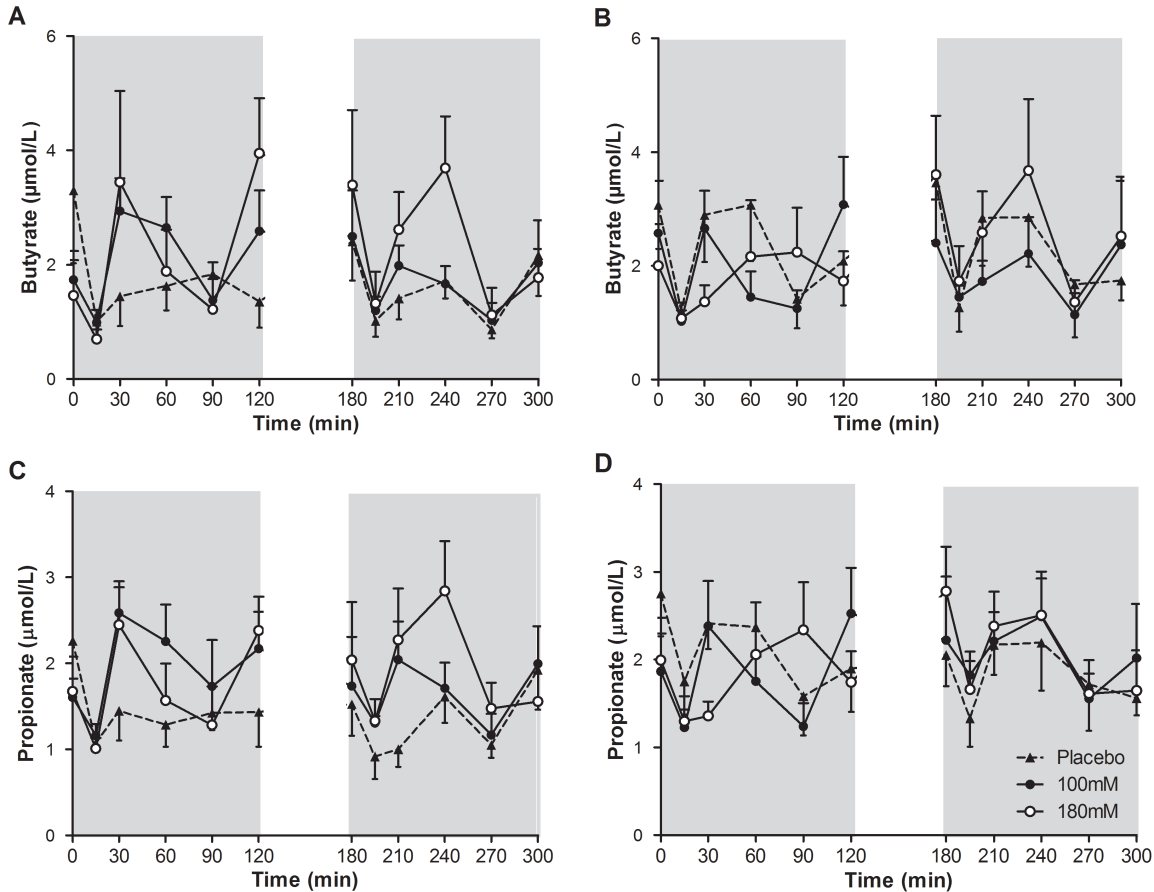

Fasting (t0 - t120) and postprandial (t180 - t300) plasma butyrate after distal (A) and proximal (B) colonic acetate infusions. Fasting ( $\mathrm{t} 0$ - t120) and postprandial ( $\mathrm{t} 180-\mathrm{t} 300)$ plasma propionate after distal (C) and proximal (D) colonic acetate infusions. Values are means \pm SEMs $(n=6)$. No significant differences. 


\section{Supplemental figure 2. Plasma inflammatory markers}

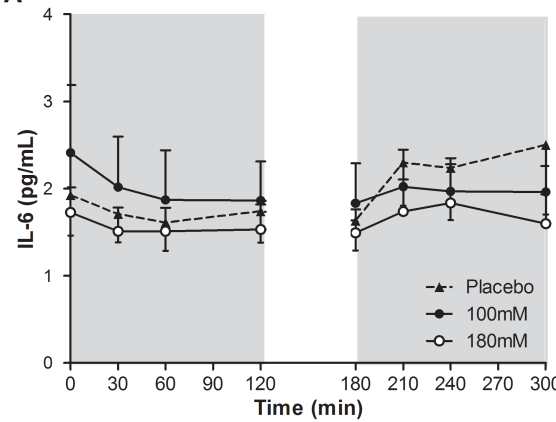

C

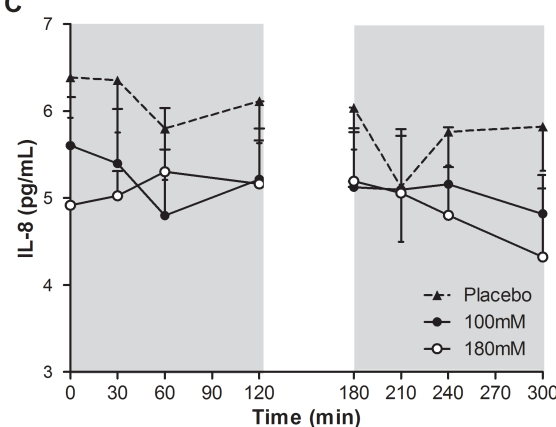

E

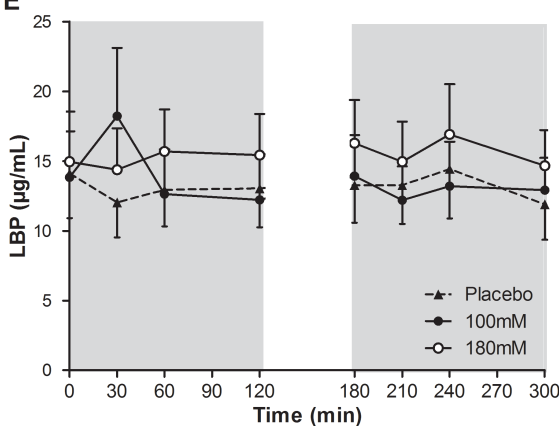

B

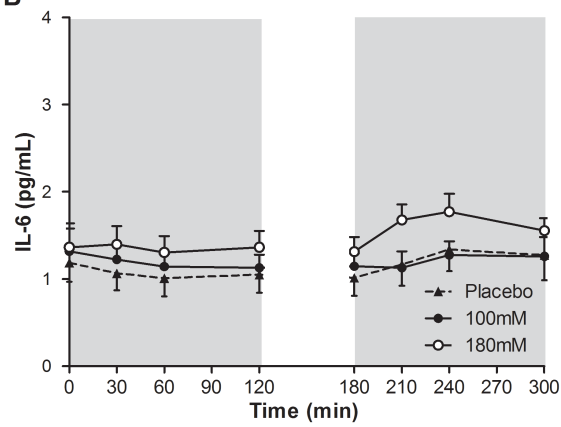

D

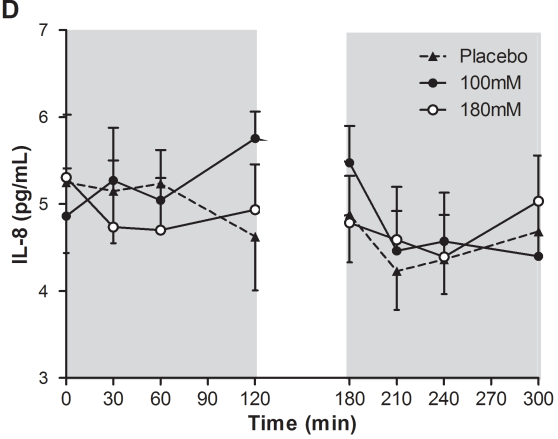

$\mathbf{F}$

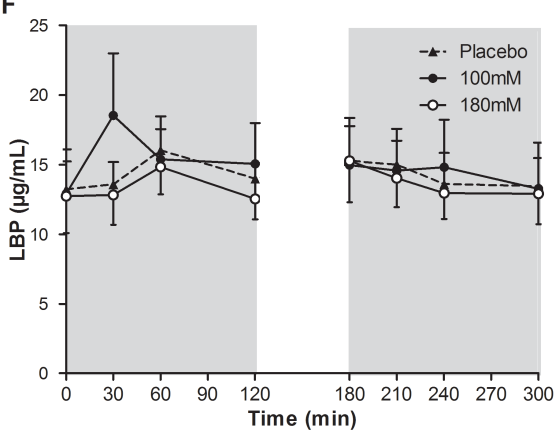

Fasting (t0 - t120) and postprandial (t180 - t300) plasma IL-6 after distal (A) and proximal (B) colonic acetate infusions. Fasting $(\mathrm{t} 0-\mathrm{t} 120)$ and postprandial $(\mathrm{t} 180-\mathrm{t} 300)$ plasma IL-8 after distal (C) and proximal (D) colonic acetate infusions. Fasting (t0 - t120) and postprandial (t180 - t300) plasma LBP after distal (E) and proximal (F) colonic acetate infusions. Values are means \pm SEMs $(n=6)$. No significant differences. 


\section{Supplemental figure 3. Plasma lipids}
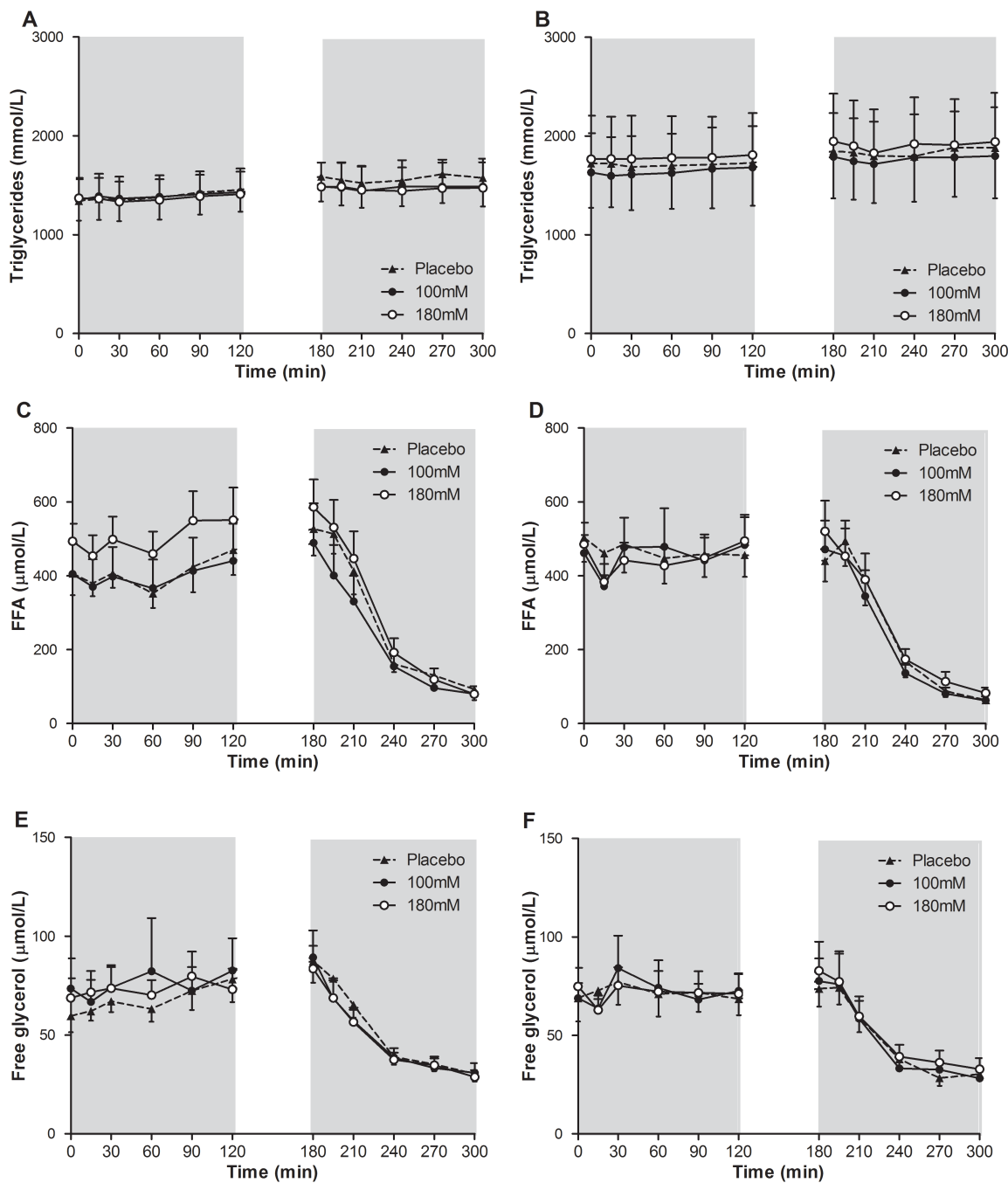

Fasting ( $\mathrm{t} 0$ - t120) and postprandial ( $\mathrm{t} 180$ - t300) plasma TAG after distal (A) and proximal (B) colonic acetate infusions. Fasting ( $\mathrm{t} 0-\mathrm{t} 120)$ and postprandial $(\mathrm{t} 180-\mathrm{t} 300)$ plasma FFA after distal (C) and proximal (D) colonic acetate infusions. Fasting (t0 - t120) and postprandial (t180 - t300) plasma free glycerol after distal (E) and proximal (F) colonic acetate infusions. Values are means \pm SEMs $(n=6)$. No significant differences. 


\section{Supplemental figure 4. Plasma leptin and ANGPTL4}
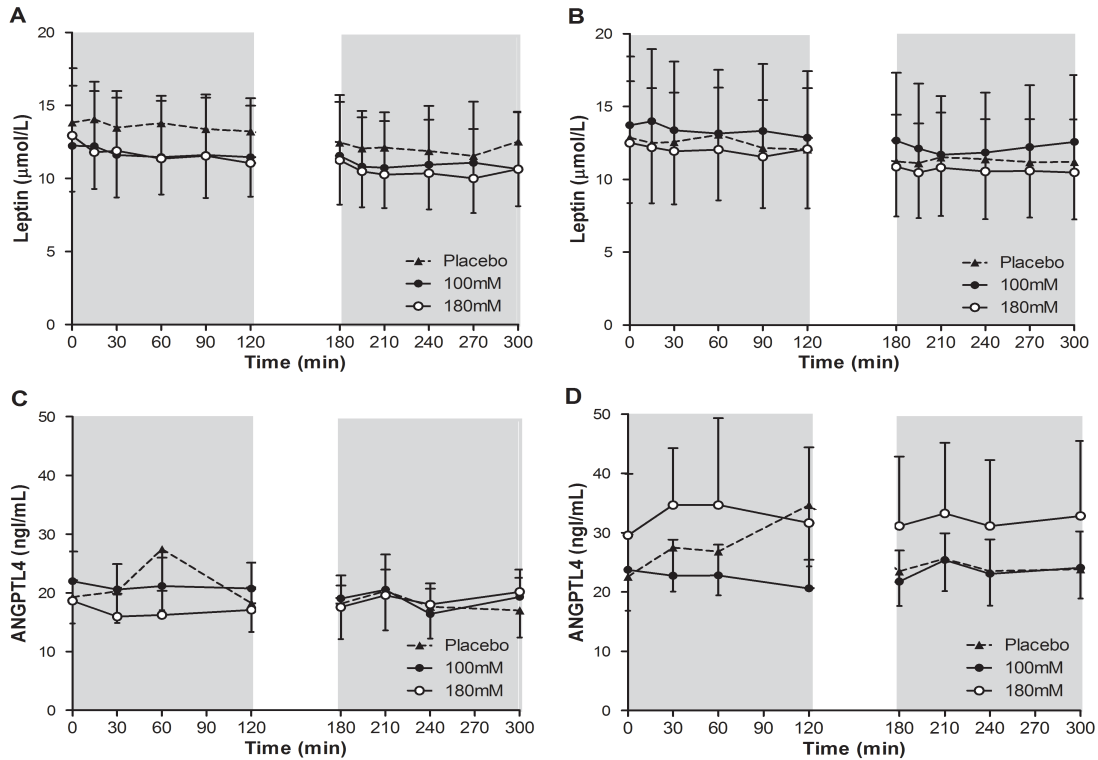

Fasting (t0 - t120) and postprandial (t180 - t300) plasma leptin after distal (A) and proximal (B) colonic acetate infusions. Fasting $(\mathrm{t} 0-\mathrm{t} 120)$ and postprandial $(\mathrm{t} 180-\mathrm{t} 300)$ plasma ANGPTL4 after distal (C) and proximal (D) colonic acetate infusions. Values are means \pm SEMs $(n=6)$. No significant differences. 


\section{SUPPLEMENTAL METHODS}

Supplementary information: Calculation of the percentage of increase in fat oxidation due to the oxidation of sodium acetate.

Whole-body fat oxidation rates were calculated according to Frayn et $a l^{1}{ }^{1}$, which is based on the $\mathrm{VO}_{2}$ and $\mathrm{VCO}_{2}$ values determined via the open-circuit ventilated hood system. We measured fat oxidation after the administration of the sodium acetate or placebo infusions for $2 \mathrm{~h}$. When we correct the determined $\mathrm{VO}_{2}$ and $\mathrm{VCO}_{2}$ values after the $180 \mathrm{mmol} / \mathrm{L}$ sodium acetate infusion for the oxidation of $100 \%$ infused sodium acetate ( $21.6 \mathrm{mmol} \mathrm{NaAc}$ in the $120 \mathrm{~mL}$ infused), this explains $28 \%$ of the $2 \mathrm{~h}$ increase in fasting fat oxidation ( $180 \mathrm{mmol} / \mathrm{L}$ acetate vs. placebo).

This is based on the calculations by Akanij et al. ${ }^{2}$. They assumed that the oxidation of $1 \mathrm{~mol}$ of sodium acetate consumes $2 \mathrm{~mol}$ of $\mathrm{O}_{2}(44.8 \mathrm{~L})$ and expires $1 \mathrm{~mol}$ of $\mathrm{CO}_{2}(22.4 \mathrm{~L})$, in our case that would mean:

\section{$21.6 \mathrm{mmol} \mathrm{NaAc}+967.7 \mathrm{~mL} \mathrm{O} \rightarrow 483.8 \mathrm{~mL} \mathrm{CO}_{2}+21.6 \mathrm{mmol} \mathrm{NaHCO} 3+19 \mathrm{~kJ}$}

The $\mathrm{NaHCO}_{3}$ produced is either increasing the bicarbonate pool size or is excreted in the urine, which causes an extrapulmonary loss of carbon dioxide. These calculated $\mathrm{VO}_{2}$ and $\mathrm{VCO}_{2}$ values for sodium acetate were then subtracted from the total $\mathrm{VO}_{2}$ and $\mathrm{VCO}_{2}$ during the $2 \mathrm{~h}$ period to calculate the nonacetate $\mathrm{VO}_{2}$ and $\mathrm{VCO}_{2}$. The nonacetate values were then used to calculate the fasting fat oxidation. The differences found account for $28.3 \%$ of increased fat oxidation during the $2 \mathrm{~h}$.

\section{References}

1. Frayn K. Calculation of substrate oxidation rates in vivo from gaseous exchange. Journal of Applied Physiology. 1983;55(2):628.

2. Akanji A, Bruce M, Frayn K. Effect of acetate infusion on energy expenditure and substrate oxidation rates in non-diabetic and diabetic subjects. European journal of clinical nutrition. 1989;43(2):107-15. 



\section{CHAPTER 4}

Colonic infusions of short-chain fatty acid mixtures promote energy metabolism in overweight men

Running title: SCFA mixtures and energy metabolism

Emanuel E. Canfora, Christina M. van der Beek, Johan W.E. Jocken, Gijs H. Goossens, Steven W. M. Olde Damink, Jens J. Holst, Kaatje Lenaerts, Cornelis H.C. Dejong, Ellen E. Blaak

To be submitted. 
SCFA mixtures and energy metabolism

\section{Abstract}

Background \& aims: Short-chain fatty acids (SCFA), formed by microbial fermentation of dietary fibre(s), are believed to be involved in the aetiology of obesity and diabetes. The study aim was to investigate the effects of colonic administration of physiologically relevant mixtures of the SCFA acetate, propionate and butyrate on human substrate and energy metabolism.

Methods: In this randomized, double-blind, placebo-controlled, crossover study, twelve normoglycaemic men (BMI $25-35 \mathrm{~kg} / \mathrm{m}^{2}$ ) underwent four investigational days, during which SCFA mixtures $(200 \mathrm{mmol} / \mathrm{L})$ high in either acetate (HA), propionate (HP), butyrate (HB) or placebo (PLA) were rectally administered during fasting and postprandial conditions (oral glucose load). Fat oxidation and energy expenditure (EE) were measured using an open-circuit ventilated-hood system. Blood samples were repeatedly collected for $2 \mathrm{~h}$ after colonic infusions to determine circulating metabolite and hormone concentrations.

Results: All three SCFA mixtures increased fasting fat oxidation $(P<.01)$, whilst resting EE increased after HA and HP compared with PLA $(P<.05)$. Interestingly, fasting fat oxidation and resting EE were positively associated with the increase in plasma acetate concentrations $(P<.05)$. In addition, all three SCFA mixtures increased fasting and postprandial plasma peptide YY concentrations, and attenuated fasting free glycerol concentrations versus PLA $(P<.05)$.

Conclusion: Colonic infusions of SCFA mixtures, in concentrations and ratios putatively reached after dietary fibre intake, beneficially modulated whole body energy metabolism, with a pronounced increase in fat oxidation, EE and the satietystimulating hormone peptide $\mathrm{YY}$, as well as a decreased whole-body lipolysis. Increasing colonic SCFA concentrations may provide a novel strategy to prevent and treat metabolic disorders. 


\section{Introduction}

A growing body of evidence suggests that the gut microbiota has a crucial role in the regulation of energy and substrate metabolism and, as such, in the aetiology of cardiometabolic disease. ${ }^{1-3}$ The gut microbiota ferment indigestible food components, such as dietary fibres, resulting in the production of important metabolites, including short-chain fatty acids (SCFA), which may affect host metabolism. ${ }^{4,5}$

Over the last decades, a number of studies have proposed that increased fibre content in our daily diet might prevent weight gain and disturbances in glucose and lipid metabolism. ${ }^{5-7}$ However, the underlying mechanisms involved are, so far, not completely understood.

Increasing evidence supports an important role of SCFA, including acetate, propionate and butyrate, in control of body weight and insulin sensitivity. ${ }^{5}$ These SCFA might have pronounced effects on host metabolism through the secretion of gut-derived signalling hormones ${ }^{8,9}$ or by entering the systemic circulation, ${ }^{10}$ thereby affecting peripheral energy and substrate metabolism. Indeed, several in vitro and animal studies have indicated that SCFA are important regulators of energy homeostasis and glucose metabolism. ${ }^{5,11}$ Cell culture studies showed that acetate, propionate and butyrate might alter adipose tissue function, by attenuating intracellular lipolysis, ${ }^{12,13}$ decreasing the production of proinflammatory molecules, ${ }^{13,14}$ as well as by stimulating adipogenesis. ${ }^{15}$ Furthermore, it has been shown that oral administration of butyrate affects control of body weight via enhanced energy expenditure and fat oxidation in obese mice. ${ }^{16}$ In addition, oral administration of acetate, propionate and butyrate to high-fat diet-fed mice all prevented gains in body weight and improved insulin sensitivity without changing energy intake and the amount of physical activity. ${ }^{11,17,18}$ Based on these rodent data, it is tempting to speculate that colonic administration of SCFA may also have beneficial effects on human substrate and energy metabolism. However, human data indicating in vivo effects of SCFA are scarce.

We have recently demonstrated that acute infusions of the most abundant SCFA acetate in the distal, but not in the proximal, part of the colon enhanced fat oxidation and circulating levels of the satiety-stimulating hormone peptide YY (PYY) in overweight men, indicating an improved metabolic profile. ${ }^{19}$ In the present study, we therefore, rectally administered SCFA mixtures, either high in acetate, propionate or butyrate, in concentrations and ratios putatively reached after dietary fibre intake, to elucidate the role of SCFA on fat oxidation and energy expenditure in 
SCFA mixtures and energy metabolism

normoglycaemic men with overweight or obesity during fasting and postprandial conditions. Secondary outcome parameters were effects of SCFA mixtures on carbohydrate oxidation, plasma SCFA concentrations, circulating (glucose, triacylglycerol (TAG), free fatty acids (FFA), free glycerol, lactate) and hormones (insulin, PYY, glucagon-like peptide 1 (GLP-1), angiopoietin-like protein 4 (ANGPTL4)), inflammatory markers (tumour necrosis factor alpha (TNF- $\alpha$ ), interleukin-1-beta (IL13), interleukin-6 (IL-6), interleukin-8 (IL-8)) and visual analogue scale (VAS)-scores for hunger and appetite. 


\section{Methods}

\section{Study participants}

Thirteen overweight and obese (BMI $25-35 \mathrm{~kg} / \mathrm{m}^{2}$ ), 20 - 50 years old normoglycaemic Caucasian men were recruited between August 2013 and January 2014 from the vicinity of Maastricht, the Netherlands. Exclusion criteria were the presence of diabetes mellitus (defined as fasting plasma glucose $\geq 7.0 \mathrm{mmol} / \mathrm{L}$ ), gastroenterological diseases or prior abdominal surgery, cardiovascular diseases, cancer, liver or kidney malfunction, a life expectancy shorter than 5 years, use of a hypocaloric diet, use of laxatives, or use of antibiotics, pre- or probiotics in the 3 months prior to the start of the study or during the study period. The study was approved by the Medical Ethical Committee of Maastricht University Medical Centre+ (MUMC+) and conducted in accordance with the Declaration of Helsinki (revised version, October 2008, Seoul, South Korea). Written informed consent was obtained from all participants.

\section{Study design and randomization}

This study was performed using a double-blind, placebo-controlled, randomized, crossover design. Participants were studied during four clinical investigation days (CID), each with at least a five-day washout period in between. During each CID the participants received either one of the three colonic SCFA mixtures infusions or a placebo infusion via enemas after an overnight fast of at least 12 hours. Three hours after the first rectal infusion, a second enema was administered after an oral glucose load of 75 gram, which resembled the postprandial state. The order of solution administration was blinded for both the investigator and participants. An independent researcher performed permuted block randomization and assigned participants to interventions.

\section{Investigational products}

In this study the participants received enemas containing three different SCFA mixtures high in either acetate (HA), or propionate (HP) or butyrate (HB) or they received placebo (PLA). The HA solution contained $24 \mathrm{mmol}$ sodium acetate (60 $\%), 8 \mathrm{mmol}$ sodium propionate (20\%), $8 \mathrm{mmol}$ sodium butyrate $(20 \%)$ dissolved in $200 \mathrm{~mL}$ sterile water (energy value: $15.8 \mathrm{kcal}$ ). The HP solution contained $18 \mathrm{mmol}$ sodium acetate (45\%), $14 \mathrm{mmol}$ sodium propionate (35\%), $8 \mathrm{mmol}$ sodium butyrate (20 \%) dissolved in $200 \mathrm{~mL}$ sterile water (energy value: $16.7 \mathrm{kcal}$ ). The HB solution 
SCFA mixtures and energy metabolism

contained $18 \mathrm{mmol}$ sodium acetate (45\%), $8 \mathrm{mmol}$ sodium propionate (20\%), 14 mmol sodium butyrate (35\%) dissolved in $200 \mathrm{~mL}$ sterile water (energy value: 17.9 kcal). As a PLA, $40 \mathrm{mmol}$ sodium chloride dissolved in $200 \mathrm{~mL}$ sterile water was administered. All solutions were isosmotic and equivalent in sodium content.

The SCFA mixtures and sodium chloride were provided pre-weighed in powder form by Basic Pharma Technologies B.V (Geleen, The Netherlands) and were freshly dissolved in the appropriate amount of sterile water (delivered with the SCFA) on the morning of the test days by an independent person. All solutions were produced in accordance with standards of European Good Medical Practice (GMP) requirements.

\section{Clinical investigation days (CID)}

Two days prior to the CID, participants were asked to refrain from intense physical activity and alcohol consumption. In the evening before each CID, the volunteers consumed a standardized low fibre meal (57 energy\% carbohydrate, 24 energy\% proteins and 29 energy\% fat). Participants came to the laboratory by car or bus in the morning after an overnight fast (12 hours). Each of the four CID consisted of two periods of each $2 \mathrm{~h}$ : a fasting period (t0 - t120 min) and a subsequent postprandial period (t180 - t300 min) (Figure 1). Between the fasting and postprandial periods, no measurements took place for 30 minutes. Prior to the start of each CID (after an overnight fast), a cannula was placed in an antecubital vein of the forearm to enable venous blood sampling. Each period was preceded by venous blood sampling (at t0 for the fasting and at t180 for the postprandial period), completion of a VAS recording for hunger and appetite and measurements of energy expenditure and substrate oxidation for 30 minutes (from t-30 - t0 before the fasting period and from t150 - t180 before the postprandial period), using an open circuit ventilated hood system (Omnical, MUMC+, The Netherlands ${ }^{20}$ ).

After baseline measurement, participants administered one of the SCFA mixtures or placebo via an enema, thereby lying on the left side. The enema was administered within $5 \mathrm{~min}$ at a rate of $40 \mathrm{~mL}$ per minute during fasting conditions (at $\mathrm{t}=0$ ), and immediately after the glucose load ( $\mathrm{at} t=180$ ) in the postprandial period. Subsequently, in both the fasting and postprandial period, energy expenditure and substrate oxidation were measured for the complete $2 \mathrm{~h}$ period. In addition, venous blood was sampled at 30, 60, 90 and 120 minutes after colonic SCFA infusions in both periods. Also, VAS-scores for hunger and appetite were completed 30, 60, 90 and 120 minutes after colonic administration. Primary outcome was the effect of 
colonic SCFA mixtures on fat oxidation and energy expenditure during fasting and postprandial conditions. Secondary outcomes were carbohydrate oxidation, circulating metabolites (glucose, TAG, FFA, free glycerol, lactate) and hormones (insulin, PYY, GLP-1, ANGPTL4), plasma SCFA, inflammatory markers (TNF- $\alpha$, IL-1, , IL6, IL-8) and VAS-scores for hunger and appetite.

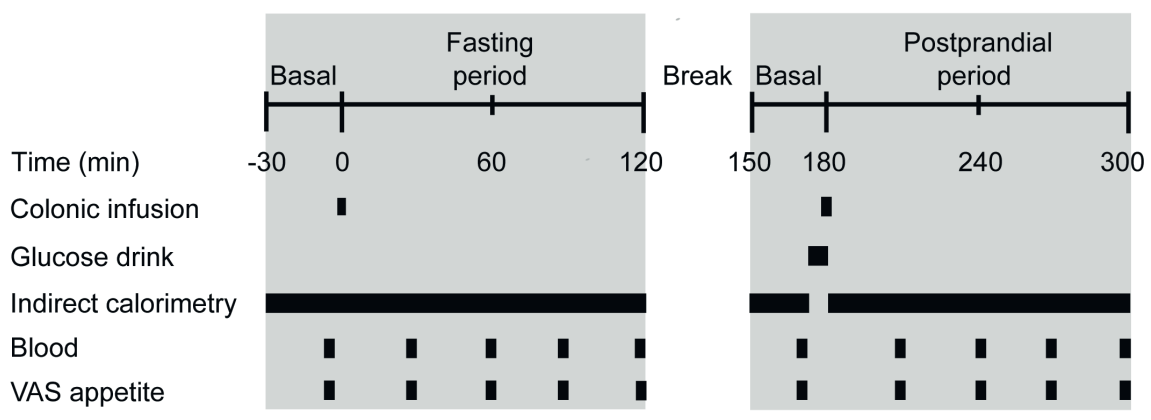

Figure 1. Clinical investigation day protocol

\section{Blood collection and storage}

Blood was collected into ice-cold EDTA tubes (0.2 M EDTA (Sigma, Dorset, UK)) for SCFA, insulin, glucose, lactate, FFA, TAG, free glycerol, ANGPTL4, TNF- $\alpha$, IL$1 \beta$, IL-6, and IL-8 analysis. For GLP-1 analysis, blood was collected in a $2 \mathrm{~mL}$ EDTA tube containing $20 \mu \mathrm{L}$ of dipeptidyl peptidase-IV inhibitor (Millipore, Darmstadt, Germany). For PYY analysis, blood was collected in a $2 \mathrm{~mL}$ aprotinin tube containing $20 \mu \mathrm{L}$ of dipeptidyl peptidase-IV inhibitor. The samples were centrifuged at 3,500 g, 4 ${ }^{\circ} \mathrm{C}$ for 10 minutes, plasma was aliquoted and directly snap-frozen in liquid nitrogen and stored at $-80^{\circ} \mathrm{C}$ until analysis.

\section{Plasma analysis}

Plasma FFA, TAG, and glucose were measured with enzymatic assays on an automated spectrophotometer (ABX Pentra 400 autoanalyser, Horiba ABX, Montpellier, France). Plasma free glycerol and lactate were measured after precipitation with an enzymatic assay automated on a Cobas Fara spectrophotometric autoanalyzer (Roche Diagnostics, Basel, Switzerland). Circulating insulin and PYY concentrations were determined with commercially available radioimmunoassay (RIA) kits (Human Insulin specific RIA, Human PYY (3-36) RIA, Millipore Corporation, MA, USA). IL-1 $\beta$, IL-6, IL- 8 and TNF- $\alpha$ were determined with 
an enzyme-linked immunosorbent assay (ELISA) kit (Human Prolnflammatory II 4Plex Ultra-Sensitive Kit, Meso Scale Diagnositics, MD, USA). Plasma ANGPTL4 was measured by ELISA as described by Kersten et $a{ }^{21}{ }^{21}$. Plasma samples were assayed for total GLP-1 immunoreactivity using an antiserum, which reacts equally with intact GLP-1 and the primary (N-terminally truncated) metabolite, as previously described. ${ }^{22}$ Deproteinisation and subsequent preparation of plasma samples for analysis of SCFA was performed as reported before. ${ }^{23}$ Analysis was performed using a liquid chromatography system combined with mass spectrometry (LC-MS). The detection limits for acetate, propionate and butyrate of this method were $0.1,0.05$ and $0.05 \mu \mathrm{mol} / \mathrm{L}$, respectively.

\section{Calculations}

The equations of Weir $^{24}$ and Frayn ${ }^{25}$ were used to calculate total rate of fat and carbohydrate oxidation and energy expenditure, assuming that protein oxidation represents $15 \%$ of total energy expenditure.

\section{Statistical analysis}

A power calculation was based on our recent crossover study with colonic infusions of acetate in overweight men. ${ }^{19}$ We calculated, using GPower (Version 3.1 for Mac, Parkville, Victoria, Australia), that 12 participants are sufficient to detect a $20 \%$ difference, with a standard deviation of $3 \%$, in our primary outcome parameter fat oxidation with a $80 \%$ power at an alpha level of $P=0.05$ and a two-tailed distribution. Considering a potential dropout rate of $20 \%$ during the protocol, the final number of participants that maximally could be recruited was $n=15$. Values are expressed as mean \pm SEM. Responses after rectal SCFA mixtures and PLA administration during fasting (t0 - t120) and postprandial (t180 - t300) conditions are expressed as incremental area under the curve (iAUC), which were calculated by the trapezoid method. Differences in fasting and postprandial iAUC between intervention groups were analysed using a linear mixed model for repeated measures. Intervention and period were set as fixed factors and participants were set as random factor. No carry-over effect was apparent due to a 5-day washout period; therefore, previous intervention was not included in the model. Association between plasma SCFA increments and increments of fat oxidation and energy expenditure were tested by linear regression. Statistics were done using SPSS 22.0 for MAC (Chicago, IL, USA) and $P<.05$ (two-sided $P$-value) was considered statistically significant. 


\section{Results}

Thirteen overweight or obese normoglycaemic men were included in this trial, of which 12 completed all four CID. One participant decided to withdraw from the study before the start of the first CID. Baseline characteristics of the 12 volunteers are presented in Table 1. No Adverse Events occurred.

Table 1. Participants' baseline characteristics

\begin{tabular}{lll}
\hline Variables & Mean & SEM \\
\hline Age, years & 36 & 3 \\
Weight, kg & 98.8 & 3.0 \\
BMI, kg/m & 30.3 & 0.8 \\
Waist circumference, cm & 108 & 3 \\
Hip circumference, cm & 110 & 2 \\
Systolic blood pressure, mmHg & 124 & 2 \\
Diastolic blood pressure, mmHg & 81 & 1 \\
HbA1c, \% & 5.2 & 0.1 \\
Fasting glucose, mmol/L & 5.1 & 0.1 \\
ALAT, U/L & 35 & 4 \\
Creatinine, $\mu$ mol/L & 90 & 3 \\
\hline $\mathrm{n}=12 ;$ Values are represented as mean \pm standard error of mean (SEM); BMI, body mass index; HbA1c, \\
haemoglobin 1Ac; ALAT, alanine-aminotransferase
\end{tabular}

\section{Energy expenditure and substrate oxidation}

Under fasting conditions, energy expenditure increased following HA and HP infusions as compared to PLA ( $P<.05$, Figure $2 \mathrm{~A}$ and $\mathrm{B})$. No significant differences in energy expenditure between interventions were observed during postprandial conditions (Figure 2A).

All SCFA mixtures (HA, HP and HB) increased fasting fat oxidation compared with PLA $(P<.01$, Figure $2 \mathrm{C}$ and $\mathrm{D})$, which was accompanied by a decreased carbohydrate oxidation ( $P<.01$, Figure $2 \mathrm{E}$ and $\mathrm{F}$ ). During the postprandial phase, fat and carbohydrate oxidation rates were not significantly different between interventions (Figure $2 \mathrm{C}$ and $\mathrm{E}$ ). 
A

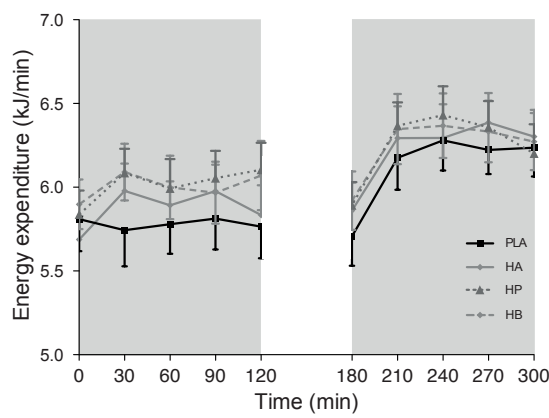

C

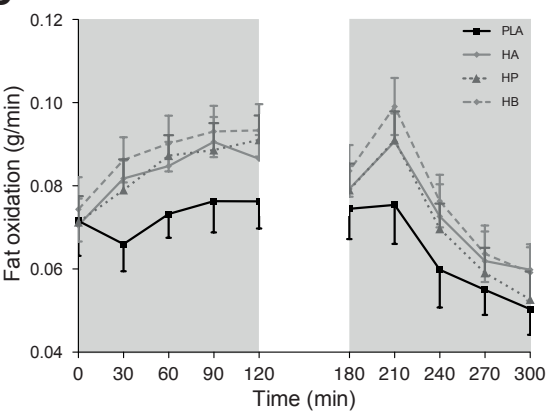

E

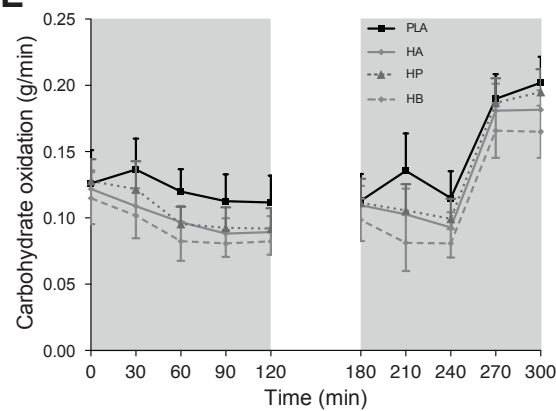

B

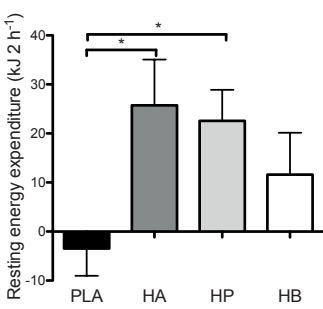

D

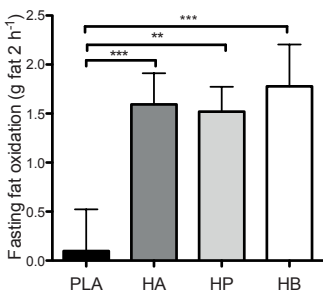

$\mathbf{F}$

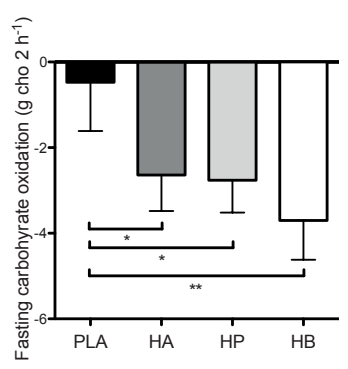

Figure 2. Effect of colonic administration of SCFA mixtures on resting and postprandial energy expenditure (A, B), fat oxidation (C, D), and carbohydrate oxidation (E, $F)$

A: Resting (t0 - t120 $\mathrm{min}$ ) and postprandial ( $\mathrm{t} 180-\mathrm{t} 300 \mathrm{~min}$ ) energy expenditure after colonic SCFA infusions. B: iAUC for resting (t0 - t120 min) energy expenditure following colonic SCFA infusions. Values are means \pm SEMs $(n=12)$. Overall treatment effect for resting energy expenditure $P=.049$.

C: Fasting (to - t120 min) and postprandial (t180 - t300 min) fat oxidation after colonic SCFA infusions. D: iAUC for fasting (t0 - t120 min) fat oxidation following colonic SCFA infusions. Overall treatment effect for fasting fat oxidation $P<.001$.

E: Fasting (t0 - t120 min) and postprandial (t180 - t300 min) carbohydrate oxidation after colonic SCFA infusions. F: iAUC for fasting (t0 - t120 min) carbohydrate oxidation following colonic SCFA infusions. Overall treatment effect for fasting carbohydrate oxidation $P=0.010$.

Values are means \pm SEMs $(n=12)$. Statistical significance indicated as asterisk $\left({ }^{*}\right)$ when ${ }^{* * *} P<.001$, ${ }^{* *} P<.01,{ }^{*} P<.05$. Abbreviations: HA, SCFA mixture high in acetate; HB, SCFA mixture high in butyrate; HP, SCFA mixture high in propionate; PLA, placebo 


\section{Plasma analysis}

Plasma short-chain fatty acids concentrations

HA and HP mixtures increased fasting plasma acetate concentrations compared with PLA $(P<.05$, Figure $3 A$ and $B)$. During the postprandial phase, acetate concentrations were not significantly different between treatments (Figure $3 \mathrm{~A}$ ).

No significant treatment effect was observed on circulating propionate concentrations in the fasting period (Figure $3 \mathrm{C}$ ). However, in the postprandial period plasma propionate concentrations were increased with HP treatment as compared to PLA ( $P=.008$, Figure $3 C$ and $D)$.

Under fasting conditions, plasma butyrate concentrations increased following administration of all SCFA mixtures, when compared to PLA $(P<.05$, Figure 3E and F). Postprandial circulating butyrate concentrations increased after $\mathrm{HA}$ and $\mathrm{HB}$ treatment, when compared to $\mathrm{PLA}(\mathrm{P}<.05$, Figure $3 \mathrm{E}$ and $\mathrm{G})$.

\section{Associations between plasma SCFA concentrations and energy and fat oxidation}

The increments of fasting plasma acetate concentrations were positively correlated with the increments of resting energy expenditure $(r=0.349, P=.0149$, supplementary data $1 \mathrm{~A})$ and fasting fat oxidation ( $\mathrm{r}=0.328, P=.0228$, supplementary data 1B). Changes in plasma propionate and butyrate concentrations did not correlate with changes in fat oxidation or resting energy expenditure, neither in the fasting nor in the postprandial period.

\section{Plasma glucose, insulin and lactate concentrations}

Fasting and postprandial plasma glucose concentrations did not differ between treatments. Although, postprandial plasma glucose and insulin concentrations were elevated following administration of all SCFA mixtures and PLA, no significant treatment effect was observed (Figure 4A and 4B).

Fasting plasma lactate concentrations did not differ between treatments (Figure 4C). However, postprandial lactate concentrations increased after HP mixture infusions as compared to HB and PLA $(P<.05$, Figure $4 C$ and $D)$. 
A
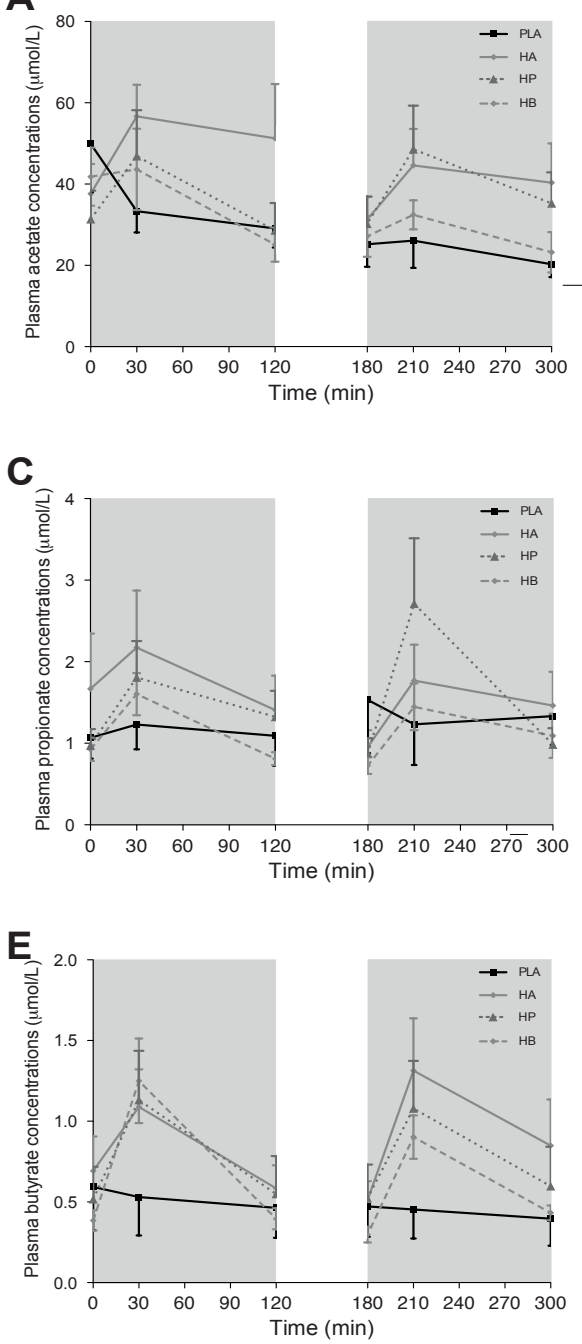

B

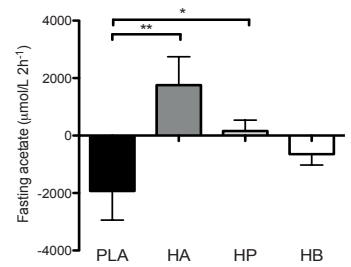

D

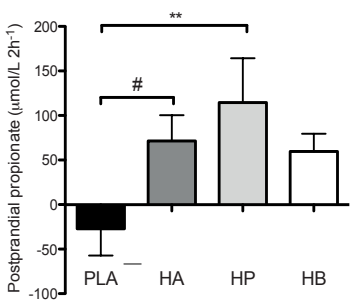

F

G
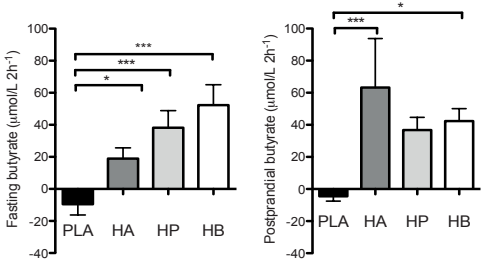

Figure 3. Effect of colonic administration of SCFA mixtures on fasting and postprandial plasma acetate $(A, B)$, propionate $(C, D)$, and butyrate $(E, F, G)$ concentrations

A: Fasting (t0 - t120 min) and postprandial (t180 - t300 min) plasma acetate concentrations after colonic SCFA infusions. B: iAUC for fasting (t0 - t120 min) plasma acetate following colonic SCFA infusions. Overall treatment effect for fasting plasma acetate $P=.029$.

C: Fasting (t0 - t120 min) and postprandial (t180 - t300 min) plasma propionate concentrations after colonic SCFA infusions. D: iAUC for postprandial (t180 - t300 min) plasma propionate following colonic SCFA infusions. Overall treatment effect for postprandial plasma propionate $P=.047$.

E: Fasting (t0 - t120 min) and postprandial (t180 - t300 min) plasma butyrate concentrations after colonic SCFA infusions. F: iAUC for fasting (t0 - t120 min) plasma butyrate following colonic SCFA infusions. Overall treatment effect for fasting plasma butyrate $P<.001$ G: iAUC for postprandial (t180 t300 $\mathrm{min}$ ) plasma butyrate following colonic SCFA infusions. Overall treatment effect for postprandial plasma butyrate $P=.032$.

Values are means \pm SEMs $(n=12)$. Statistical significance indicated as asterisk $\left({ }^{*}\right)$ when $* * * P<.001$, ${ }^{*} P<.01,{ }^{*} P<.05$ and as hashtag (\#) when $P<.10$. Abbreviations: HA, SCFA mixture high in acetate; HB, SCFA mixture high in butyrate; HP, SCFA mixture high in propionate; PLA, placebo 
A

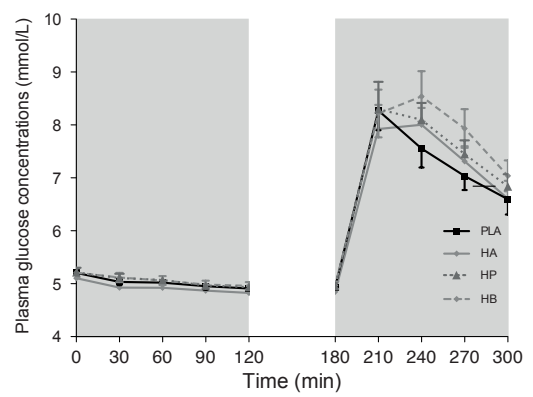

C

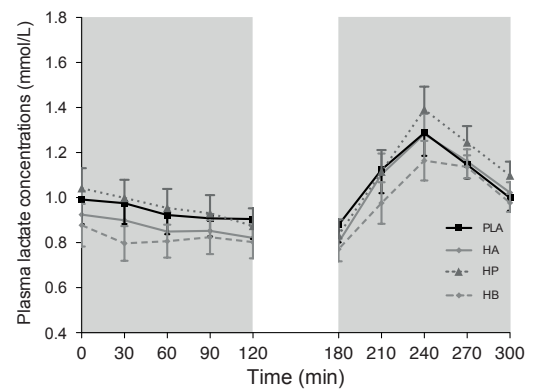

B

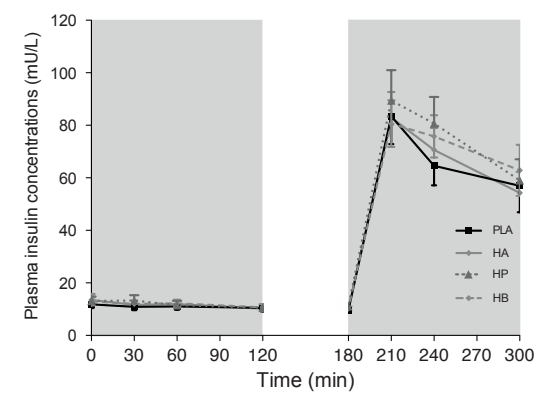

D

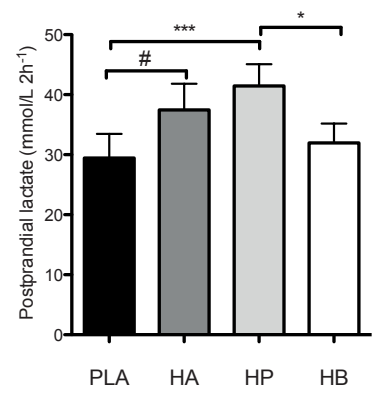

Figure 4. Effect of colonic administration of SCFA mixtures on fasting and postprandial plasma glucose (A), insulin (B) and lactate (C, D) concentrations

A: Fasting (t0 - t120 min) and postprandial (t180 - t300 min) plasma glucose concentrations after colonic SCFA infusions.

B: Fasting (t0 - t120 min) and postprandial (t180 - t300 min) plasma insulin concentrations after colonic SCFA infusions.

C: Fasting (t0 - t120 min) and postprandial (t180 - t300 min) plasma lactate concentrations after colonic SCFA infusions. D: iAUC for postprandial (t180 - t300 min) plasma lactate following colonic SCFA infusions. Overall treatment effect for postprandial plasma lactate $P<.022$.

Values are means \pm SEMs $(n=12)$. Statistical significance indicated as asterisk $\left({ }^{*}\right)$ when $* * * P<.001, * P$ $<.05$ and as hashtag (\#) when $P<.10$. Abbreviations: HA, SCFA mixture high in acetate; HB, SCFA mixture high in butyrate; HP, SCFA mixture high in propionate; PLA, placebo

\section{Plasma TAG, FFA, and free glycerol concentrations}

There were no significant differences in circulating plasma TAG concentrations between the interventions, neither in the fasting nor in the postprandial period (Figure 5A). No significant treatment effect was observed on circulating FFA concentrations in the fasting period. Postprandial FFA concentrations decreased in all treatment groups with no significant differences between the groups (Figure 5B). 
The administration of all three SCFA combinations (HA, HP and HB) significantly decreased circulating fasting free glycerol concentrations compared with PLA $(P<.05$, Figure $5 \mathrm{C}$ and $\mathrm{D})$. Postprandial free glycerol concentrations decreased in all intervention groups, with no significant differences between interventions (Figure 5C).

\section{Plasma PYY, GLP-1 and ANGPTL4 concentrations}

PYY was increased with all SCFA combinations (HA, HP and HB) both during fasting and postprandial conditions as compared to PLA $(P<.05$, Figure $6 \mathrm{~A}, \mathrm{~B}$ and $\mathrm{C})$.

Fasting GLP-1 levels showed no significant differences after infusion of SCFA mixtures. Postprandial GLP-1 concentrations increased following colonic administration of SCFA mixtures and PLA, without significant differences between groups (Figure 6D).

ANGPTL4 concentrations did not show statistically significant differences between treatments neither in the fasting nor in the postprandial period (Figure 6E).

\section{Plasma concentrations of inflammatory markers}

Fasting circulating levels of the proinflammatory cytokine IL-1 $\beta$ decreased with HA, when compared with HP $(P<.05$, Figure 7A and Figure B). Postprandial IL-1 $\beta$ levels did not differ between treatments (Figure 7A). Other proinflammatory cytokines including TNF- $\alpha$, IL- 6 and IL- 8 were not affected by SCFA infusion neither in the fasting nor in the postprandial period (Figure 7C, D and E).

\section{Hunger and appetite scores}

Overall, there were no significant differences in VAS-scores on hunger and appetite between interventions, neither in the fasting nor in the postprandial period (Supplementary data 2). 
A

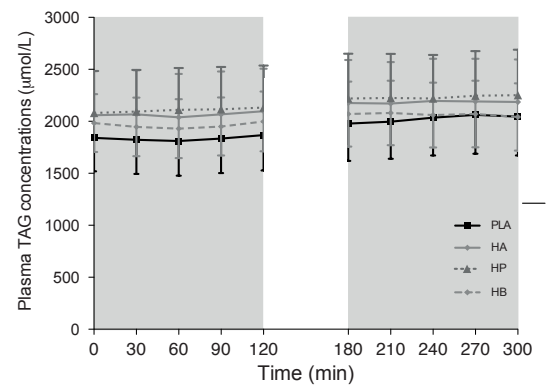

C

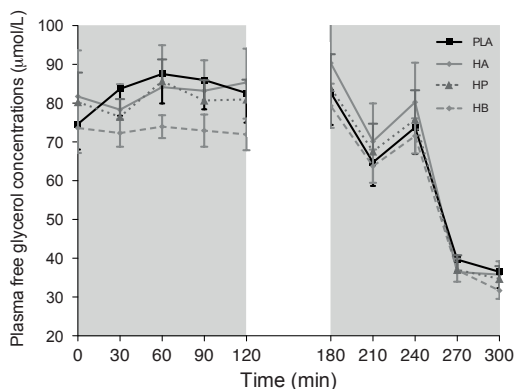

B

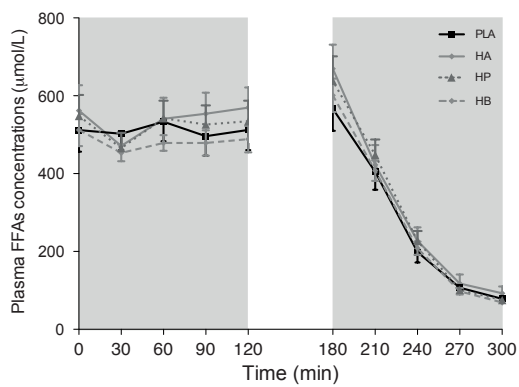

D

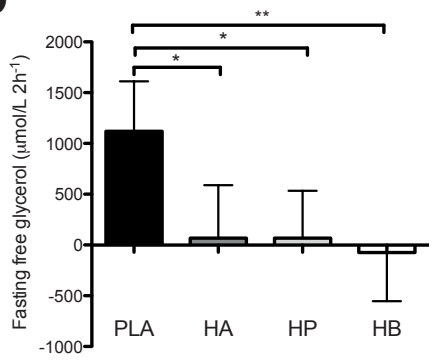

Figure 5. Effect of colonic administration of SCFA mixtures on fasting and postprandial plasma TAG (A), FFA (B) and free glycerol (C, D) concentrations

A: Fasting (t0 - t120 min) and postprandial (t180 - t300 min) plasma TAG concentrations after colonic SCFA infusions.

B: Fasting (t0 - t120 min) and postprandial (t180 - t300 min) plasma FFA concentrations after colonic SCFA infusions.

C: Fasting (t0 - t120 min) and postprandial (t180 - t300 min) plasma free glycerol concentrations after colonic SCFA infusions. D: iAUC for fasting (t0 - t120 min) plasma free glycerol following colonic SCFA infusion. Overall treatment effect for free glycerol $P=.030$.

Values are means \pm SEMs $(n=12)$. Statistical significance indicated as asterisk $\left({ }^{*}\right)$ when ${ }^{* *} P<.01$, ${ }^{*} P<.05$. Abbreviations: HA, SCFA mixture high in acetate; HB, SCFA mixture high in butyrate; HP, SCFA mixture high in propionate; PLA, placebo 
A

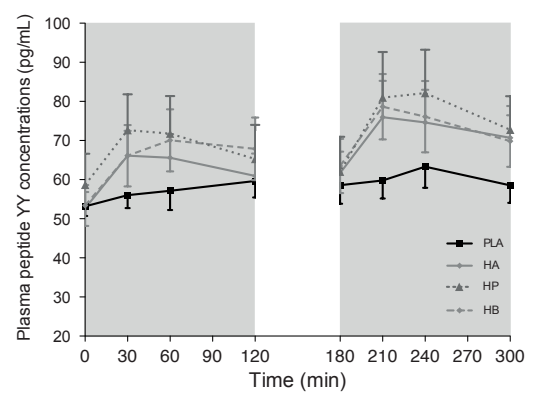

D

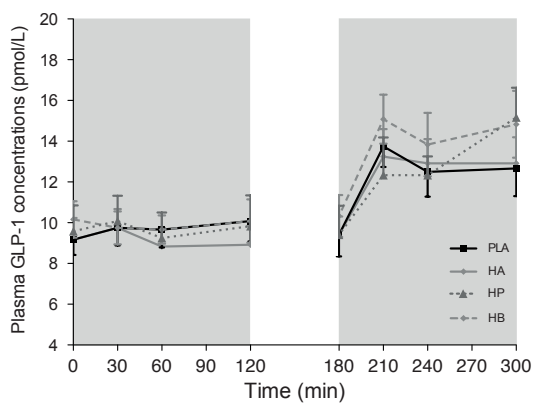

B
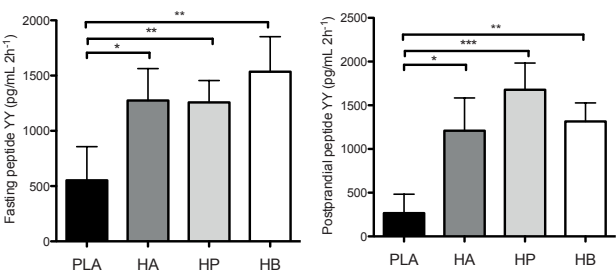

E

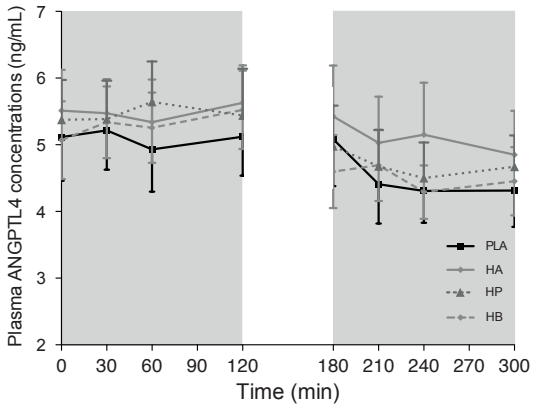

Figure 6. Effect of colonic administration of SCFA mixtures on fasting and postprandial plasma PYY (A, B, C), GLP1 (D) and ANGPTL4 (E)

A: Fasting (t0 - t120 min) and postprandial (t180 - t300 min) plasma PYY concentrations after colonic SCFA infusions. B: iAUC for fasting (t0 - t120 min) plasma PYY following colonic SCFA infusion. Overall treatment effect fasting PYY $P=.019$. C: iAUC for postprandial ( $\mathrm{t} 120-\mathrm{t} 300 \mathrm{~min}$ ) plasma PYY following colonic SCFA infusion. Overall treatment effect postprandial PYY $P<.001$.

D: Fasting (t0 - t120 min) and postprandial (t180 - t300 min) plasma GLP-1 concentrations after colonic SCFA infusions.

E: Fasting (t0 - t120 min) and postprandial (t180 - t300 min) plasma ANGTPL4 concentrations after colonic SCFA infusions.

Values are means \pm SEMs $(n=12)$. Statistical significance indicated as asterisk $\left({ }^{*}\right)$ when $*^{* *} P<.001$ and ${ }^{* *} P<.01$ and ${ }^{*} P<.05$. Abbreviations: HA, SCFA mixture high in acetate; HB, SCFA mixture high in butyrate; HP, SCFA mixture high in propionate; PLA, placebo 
A

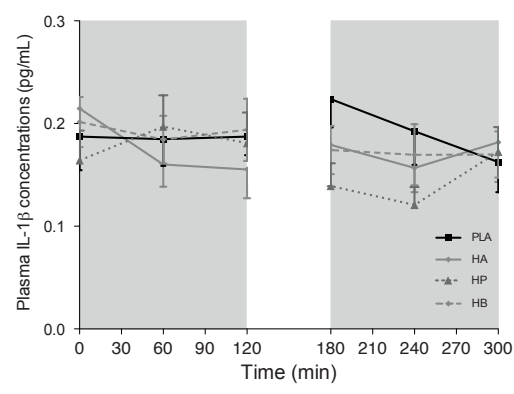

C

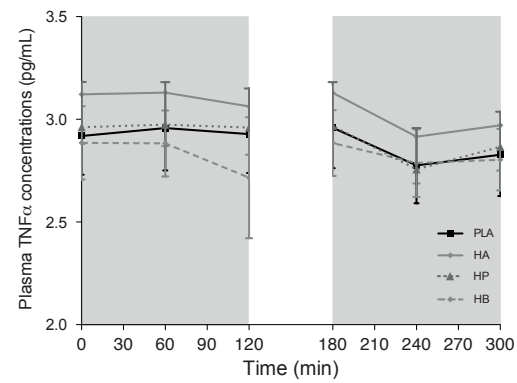

E

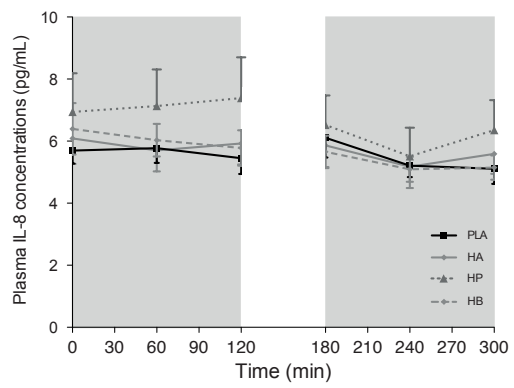

B

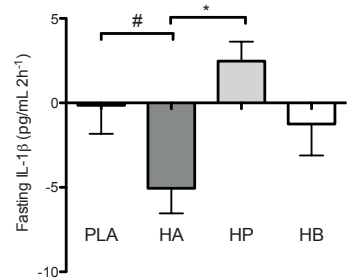

D

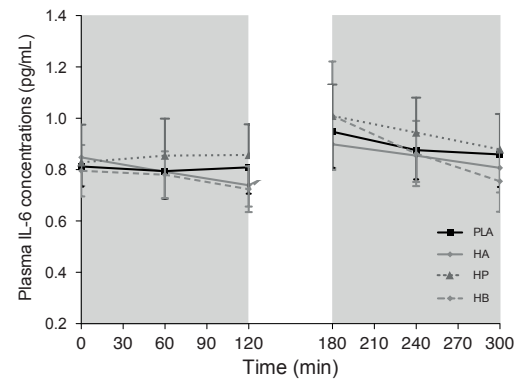

Figure 7. Effect of colonic administration of SCFA mixtures on fasting and postprandial plasma inflammatory cytokines

A: Fasting (t0 - t120 min) and postprandial (t180 - t300 min) plasma IL-1 $\beta$ concentrations after colonic SCFA infusions. B: iAUC for fasting (t0 - t120 min) plasma IL-1 $\beta$ following colonic SCFA infusion. Values are means $\pm \operatorname{SEMs}(\mathrm{n}=10$, for two volunteers $\mathrm{IL}-1 \beta$ concentrations were not detectable). Overall treatment effect for fasting IL-1 $\beta \quad<0.042$. Statistical significance indicated as asterisk $\left({ }^{*}\right)$ when ${ }^{*} P<.05$ and as hashtag when $\# P<.10$.

C: Fasting (t0 - t120 min) and postprandial (t180 - t300 min) plasma TNF- $\alpha$ after colonic SCFA infusions. Values are means \pm SEMs $(n=12)$.

D: Fasting (t0 - t120 min) and postprandial (t180 - t300 min) plasma IL-6 after colonic SCFA infusions. Values are means \pm SEMs ( $n=11$, for one participant IL- 6 concentrations were not detectable).

E: Fasting (t0 - t120 min) and postprandial (t180 - t300 min) plasma IL-8 after colonic SCFA infusions. Values are means \pm SEMs $(n=12)$.

Abbreviations: HA, SCFA mixture high in acetate; HB, SCFA mixture high in butyrate; HP, SCFA mixture high in propionate; PLA, placebo 


\section{Discussion}

In the present randomized, double-blind, placebo-controlled crossover study, the effects of administration of three different SCFA mixtures in the distal part of the colon on fat oxidation, energy expenditure and metabolic parameters were assessed in twelve overweight and obese, normoglycaemic men. We demonstrated that infusions of colonic SCFA mixtures markedly increase fasting fat oxidation and resting energy expenditure, which was accompanied by increased circulating acetate concentrations. In addition, these SCFA mixtures increased fasting and postprandial PYY concentrations, and attenuated whole-body lipolysis. This is the first human intervention study showing that colonic infusions of various SCFA mixtures significantly impact on human energy and lipid metabolism.

The ratios, absolute amounts and concentrations of SCFA used in this human in vivo study represent colonic physiological mixtures, which can be achieved in the colon by the intake of a diet rich in soluble dietary fibres. ${ }^{26-28}$ The human gut microbiota ferments orally ingested complex carbohydrates into a combination of

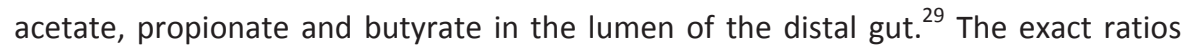
and amounts produced are dependent on many factors, including the type of fermented carbohydrate, the specific microbial species, diversity and absolute amount of host's gut microbiota, as well colonic transit time. ${ }^{26-30}$ Theoretically, the total amount of SCFA produced over the whole colon can be up to $800 \mathrm{mmol}$ per day. ${ }^{5,31,32}$ Data from six suddenly deceased individuals showed SCFA concentrations up to $190 \mathrm{mmol} / \mathrm{kg}$ of luminal content in the distal part of the colon. ${ }^{33}$ In the present study, SCFA concentrations of $200 \mathrm{mmol} / \mathrm{L}$ (40 mmol in a $200 \mathrm{~mL}$ solution) were administered rectally. In addition, the use of colonic SCFA mixtures containing all three SCFA is a better representation of human physiological conditions than administering single SCFA as has been done in previous studies. ${ }^{5,19}$

The pronounced effects of the SCFA mixtures on fat oxidation and energy expenditure found in the present study suggest an important role for gut-derived SCFA in whole-body energy metabolism. This might explain beneficial effects of dietary fibre(s) on body weight control and glucose homeostasis on the long term. ${ }^{5-7}$ It is important to mention that oxidation of the total amount of infused sodium acetate only contributes to a minor extent to the observed increase in fat oxidization, as we previously calculated and discussed elsewhere. ${ }^{19} \mathrm{Next}$, in a human in vivo study rectal infusions of isotopically-labelled butyrate showed that only 25\% of butyrate is oxidized within a 4 hours timeframe. ${ }^{34}$ In addition, this study showed that the rectally infused butyrate $(5 \mathrm{mmol})$ did not change whole-body respiratory 
quotient and resting energy expenditure. ${ }^{34}$ Furthermore, propionate and butyrate have a respiratory quotient of 0.86 and 0.8 , respectively. ${ }^{35}$ Together, these findings indicate that oxidation of infused SCFA mixtures are unlikely to explain the observed increase in fasting whole-body fat oxidation and resting energy expenditure in the present study.

Based on mainly rodent data, several putative other mechanisms are expected to explain these SCFA-induced increases in fat oxidation and energy expenditure. Den Besten et al. $^{17}$ showed that orally administered acetate, propionate and butyrate prevented high-fat diet induced weight gain and improved glucose metabolism in mice, interestingly without alterations in food intake and physical activity. Moreover, they observed a peroxisome proliferator-activated receptor- $\gamma$ (PPAR $\gamma$ )-dependent increase in the expression of mitochondrial uncoupling protein 2 and elevations of the AMP/ATP ratio. This led to a switch from lipid synthesis to fat $\left(\left[1-{ }^{14} \mathrm{C}\right]\right.$ palmitic acid) oxidation via an adenosine monophosphate-activated protein kinase (AMPK)-dependent mechanism in liver and adipose tissue. ${ }^{17}$ In addition, Gao and colleagues ${ }^{16}$ found that oral butyrate administration reduced adiposity and increased insulin sensitivity in obese mice, without a change in food intake, fat absorption and locomotor activity. These findings were explained by increased energy expenditure and fat oxidation via activation of AMPK and (PPARY)-coactivator (PGC)-1 $\alpha$ in the liver and the skeletal muscle. ${ }^{16}$ Along the same lines, Yashamita et al. $^{36}$ found that acetate intragastric injections lowered body weight and improved glucose homeostasis in obese rats via an increase in fat oxidation mediated by an increased AMPK activity in the skeletal muscle. ${ }^{36}$ Whether an AMPK-mediated enhanced oxidative metabolism in peripheral tissue might underlie the present findings in human remains to be established.

We found that the HA and HP mixtures increased circulating acetate concentrations and that all SCFA mixtures increased circulating butyrate concentrations during fasting conditions whilst in the postprandial state all SCFA mixtures increased propionate concentrations. Nevertheless, only the increments in acetate concentrations correlated positively with the increase in fasting fat oxidation and resting energy expenditure, suggesting that circulating acetate is the major driver of these pronounced metabolic effects in humans. Consistent with this observation, we previously observed a comparable increase in fat oxidation ( $25 \%$ ) in overweight to obese men after distal colonic administration of sodium acetate alone, when compared to a saline infusion. ${ }^{19}$ Based on the available animal data and the increased systemic acetate concentrations found in the present study, it might 
be speculated that the circulating acetate might lead to an increased oxidative capacity and a substrate switch to fat utilization in peripheral organs such as skeletal muscle, adipose tissue and liver. However, so far no human data of SCFA effects on human adipose tissue, skeletal muscle and liver oxidative metabolism are available, which therefore have a high degree of interest for future studies.

In addition, the present results indicate that all SCFA mixtures decreased fasting plasma glycerol concentrations. This is consistent with previous reports showing that single SCFA, in particular acetate, blunt whole-body lipolysis in humans. ${ }^{37-39}$ Ge et al. ${ }^{12}$ showed that treatment of rodent-derived 3T3-L1 adipocytes with acetate and propionate reduced the intracellular lipolytic activity as assessed by a decreased release of glycerol in the culture medium, ${ }^{12}$ thereby identifying these SCFA as regulators of adipose tissue metabolism. This should be confirmed using human-derived adipocyte cell lines.

The increase in energy expenditure and fat oxidation, together with a substantial increase in the satiety-stimulating gut hormone, PYY, found in the present study, indicate that elevating SCFA, in particular acetate, in the colon and in the circulation, might have important clinical implications on food intake regulation and long-term control of body weight. Furthermore, SCFA (acetate)-induced fat oxidation and/or increased oxidative capacity in skeletal muscle might improve metabolic flexibility, defined as the capacity to utilize and switch between the major fuels, lipids and glucose. ${ }^{40}$ This might result in reduced fat accumulation and improved insulin action in peripheral tissues such as skeletal muscle, liver and pancreas, thereby preventing insulin resistance.

Most luminal SCFA production occurs in the cecum and proximal part of the colon, where substrate availability is highest. ${ }^{41}$ Of interest, we found in our previous study that acetate administration in the distal rather than the proximal part of the colon evoked pronounced metabolic effects. ${ }^{19}$ We hypothesized that an increased absorption of acetate and a direct route to the systemic circulation, bypassing the liver, thereby increasing systemic acetate availability, explained these differential effects. Specific slow-fermentable acetogenic nutrients, such as fibre-acetate ester, might lead to an increased production of SCFA, in particular acetate, in the distal part of the colon, and hence be an interesting dietary approach for the control of body weight and glucose homeostasis.

In conclusion, the present study demonstrated that acute rectal administration of physiological concentrations of SCFA modulates whole-body substrate metabolism, with a pronounced increase in fasting fat oxidation and 
resting energy expenditure, which was associated with an increase in circulating acetate concentrations. In addition, these SCFA mixtures increased fasting and postprandial concentrations of the satiety-stimulating hormone PYY, and attenuated whole-body lipolysis. Whether this translates into an improved metabolic profile and may contribute to control of body weight in the long term remains to be elucidated. Together, these data indicate that increasing colonic SCFA levels may be a nutritional or therapeutic target to treat or prevent chronic metabolic diseases such as obesity and type 2 diabetes mellitus. 


\section{References}

1. Delzenne NM, Cani PD, Everard A, et al. Gut microorganisms as promising targets for the management of type 2 diabetes. Diabetologia 2015;58:2206-2217.

2. Diamant M, Blaak E, De Vos W. Do nutrient-gut-microbiota interactions play a role in human obesity, insulin resistance and type 2 diabetes? Obesity Reviews 2011;12:272-281.

3. Aron-Wisnewsky J, Clément K. The gut microbiome, diet, and links to cardiometabolic and chronic disorders. Nature Reviews Nephrology 2016;12:169181.

4. Koh A, De Vadder F, Kovatcheva-Datchary $P$, et al. From dietary fiber to host physiology: short-chain fatty acids as key bacterial metabolites. Cell 2016;165:13321345.

5. Canfora EE, Jocken JW, Blaak EE. Short-chain fatty acids in control of body weight and insulin sensitivity. Nat Rev Endocrinol 2015;11:577-591.

6. Kellow NJ, Coughlan MT, Reid CM. Metabolic benefits of dietary prebiotics in human subjects: a systematic review of randomised controlled trials. British Journal of Nutrition 2014;111:1147-1161.

7. Canfora EE, Blaak EE. The role of polydextrose in body weight control and glucose regulation. Current Opinion in Clinical Nutrition \& Metabolic Care 2015;18:395-400.

8. Tolhurst G, Heffron H, Lam YS, et al. Short-chain fatty acids stimulate glucagon-like peptide-1 secretion via the G-protein-coupled receptor FFAR2. Diabetes 2012;61:364-371.

9. Psichas A, Zac-Varghese S, Murphy K, et al. Short chain fatty acids stimulate the release of gut hormone peptide $Y Y$ from human primary enteroendocrine $L$ cells, In Proceedings of The Physiological Society, 27, PC331, 2012.

10. Bloemen JG, Venema K, van de Poll MC, et al. Short chain fatty acids exchange across the gut and liver in humans measured at surgery. Clinical nutrition 2009;28:657-661.

11. Sahuri-Arisoylu M, Brody L, Parkinson J, et al. Reprogramming of hepatic fat accumulation and'browning'of adipose tissue by the short-chain fatty acid acetate. International Journal of Obesity 2016.

12. Ge H, Li X, Weiszmann J, et al. Activation of $\mathrm{G}$ protein-coupled receptor 43 in adipocytes leads to inhibition of lipolysis and suppression of plasma free fatty acids. Endocrinology 2008;149:4519.

13. Ohira H, Fujioka $\mathrm{Y}$, Katagiri $\mathrm{C}$, et al. Butyrate Attenuates Inflammation and Lipolysis Generated by the Interaction of Adipocytes and Macrophages. Journal of atherosclerosis and thrombosis 2013.

14. Al-Lahham SaH, Roelofsen H, Priebe M, et al. Regulation of adipokine production in human adipose tissue by propionic acid. European journal of clinical investigation 2010;40:401-407.

15. Hong YH, Nishimura Y, Hishikawa D, et al. Acetate and propionate short chain fatty acids stimulate adipogenesis via GPCR43. Endocrinology 2005;146:5092.

16. Gao Z, Yin J, Zhang J, et al. Butyrate improves insulin sensitivity and increases energy expenditure in mice. Diabetes 2009;58:1509.

17. den Besten G, Bleeker A, Gerding A, et al. Short-Chain Fatty Acids protect against High-Fat Diet-Induced Obesity via a PPARy-dependent switch from lipogenesis to fat oxidation. Diabetes 2015:db141213.

18. Lin HV, Frassetto A, Kowalik Jr EJ, et al. Butyrate and Propionate Protect against Diet-Induced Obesity and Regulate Gut Hormones via Free Fatty Acid Receptor 3Independent Mechanisms. PLoS ONE 2012;7:e35240. 
19. van der Beek CM, Canfora EE, Lenaerts K, et al. Distal, but not proximal, colonic acetate infusions promote fat oxidation and improve metabolic markers in overweight men. Doctoral Thesis Emanuel Canfora 2016; Chapter 3.

20. Adriaens MP, Schoffelen PF, Westerterp KR. Intra-individual variation of basal metabolic rate and the influence of daily habitual physical activity before testing. $\mathrm{Br}$ J Nutr 2003;90:419-23.

21. Kersten S, Lichtenstein L, Steenbergen E, et al. Caloric restriction and exercise increase plasma ANGPTL4 levels in humans via elevated free fatty acids. Arteriosclerosis, thrombosis, and vascular biology 2009;29:969-974.

22. Orskov C, Rabenhoj L, Wettergren A, et al. Tissue and plasma concentrations of amidated and glycine-extended glucagon-like peptide I in humans. Diabetes 1994;43:535-9.

23. van Eijk HM, Bloemen JG, Dejong CH. Application of liquid chromatography,Äìmass spectrometry to measure short chain fatty acids in blood. Journal of Chromatography B 2009;877:719-724.

24. Weir JBV. New methods for calculating metabolic rate with special reference to protein metabolism. The Journal of physiology 1949;109:1.

25. Frayn K. Calculation of substrate oxidation rates in vivo from gaseous exchange. Journal of Applied Physiology 1983;55:628.

26. Bliss DZ, Weimer PJ, Jung H-JG, et al. In Vitro Degradation and Fermentation of Three Dietary Fiber Sources by Human Colonic Bacteria. Journal of agricultural and food chemistry 2013.

27. Timm DA, Stewart ML, Hospattankar A, et al. Wheat dextrin, psyllium, and inulin produce distinct fermentation patterns, gas volumes, and short-chain fatty acid profiles in vitro. Journal of medicinal food 2010;13:961-966.

28. Stewart M, Becker A, Slavin J, et al. Fermentability of resistant starch preparations varies in vitro. Dietary fibre: new frontiers for food and health 2010:339-349.

29. Venema K. Microbial metabolites produced by the colonic microbiota as drivers for immunomodulation in the host. The FASEB Journal 2013;27:643.12.

30. El Oufir L, Barry J, Flourie B, et al. Relationships between transit time in man and in vitro fermentation of dietary fiber by fecal bacteria. European journal of clinical nutrition 2000;54:603-609.

31. Vanhoutvin SALW, Troost FJ, Hamer HM, et al. Butyrate-induced transcriptional changes in human colonic mucosa. PLoS One 2009;4:e6759.

32. Delzenne NM, Cani PD, Neyrinck AM. Modulation of glucagon-like peptide 1 and energy metabolism by inulin and oligofructose: experimental data. The Journal of nutrition 2007;137:2547S.

33. Cummings J, Pomare E, Branch W, et al. Short chain fatty acids in human large intestine, portal, hepatic and venous blood. Gut 1987;28:1221.

34. Simpson E, Chapman M, Dawson J, et al. In vivo measurement of colonic butyrate metabolism in patients with quiescent ulcerative colitis. Gut 2000;46:73-77.

35. Ritz $\mathrm{P}$, Cloarec $\mathrm{D}$, Beylot $\mathrm{M}$, et al. Effects of colonic fermentation on respiratory gas exchanges following a glucose load in man. Metabolism 1993;42:347-352.

36. Yamashita $\mathrm{H}$, Maruta $\mathrm{H}$, Jozuka $\mathrm{M}$, et al. Effects of acetate on lipid metabolism in muscles and adipose tissues of type 2 diabetic Otsuka Long-Evans Tokushima Fatty (OLETF) rats. Bioscience, biotechnology, and biochemistry 2009;73:570-576.

37. Fernandes J, Vogt J, Wolever T. Kinetic model of acetate metabolism in healthy and hyperinsulinaemic humans. European journal of clinical nutrition 2014.

38. Crouse JR, Gerson CD, DeCarli LM, et al. Role of acetate in the reduction of plasma free fatty acids produced by ethanol in man. Journal of lipid research 1968;9:509512. 
SCFA mixtures and energy metabolism

39. Wolever T, Brighenti F, Royall D, et al. Effect of rectal infusion of short chain fatty acids in human subjects. The American journal of gastroenterology 1989;84:1027.

40. Corpeleijn E, Saris W, Blaak E. Metabolic flexibility in the development of insulin resistance and type 2 diabetes: effects of lifestyle. obesity reviews 2009;10:178-193.

41. den Besten G, van Eunen K, Groen AK, et al. The role of short-chain fatty acids in the interplay between diet, gut microbiota, and host energy metabolism. Journal of Lipid Research 2013;54:2325. 


\section{SUPPLEMENTARY RESULTS}

A

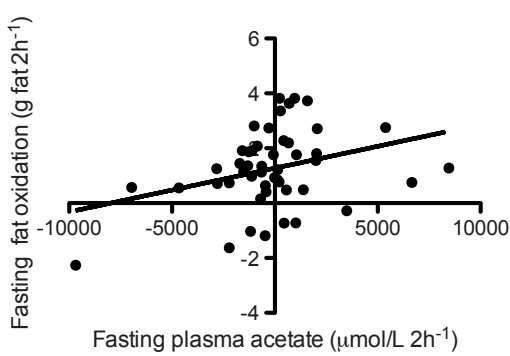

B

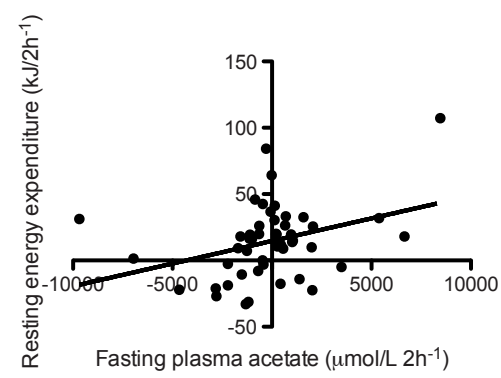

Figure S1: Relationship between increments of fasting acetate concentrations and increments of fasting fat oxidation and resting energy expenditure. A: Acetate vs. fat oxidation $r=0.328(P=.0228)$. B: Acetate vs. energy expenditure $r=0.349(P=.0149)$.

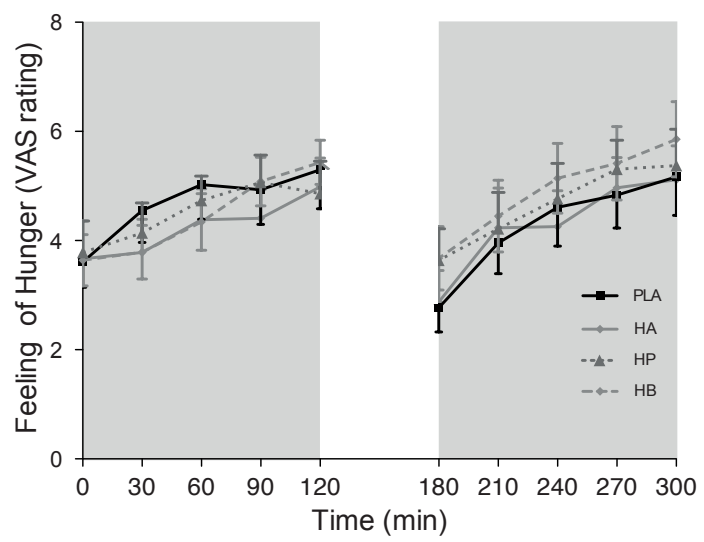

Figure S2: Fasting (t0 - t120 min) and postprandial (t180 - t300 min) VAS for feeling of hunger (as representative for VAS-scores hunger and appetite) after colonic SCFA infusions (rating $0=$ no feeling of hunger $-10=$ extreme feeling of hunger). Values are means \pm SEMs $(n=12)$. Abbreviations: HA, SCFA mixture high in acetate; HB, SCFA mixture high in butyrate; HP, SCFA mixture high in propionate; PLA, placebo. 



\section{CHAPTER 5}

Short-chain fatty acids differentially affect intracellular lipolysis in a human white adipocyte model

Running title: SCFA and intracellular lipolysis

Emanuel E. Canfora*, Johan W.E. Jocken*, Christina M. van der Beek, Yvonne P.G.

Essers, Nicole T.H. Hoebers and Ellen E. Blaak

* Shared first author

To be submitted. 
SCFA and intracellular lipolysis

\section{Abstract}

Background \& Aims: Gut-derived short-chain fatty acids (SCFA), formed by microbial fermentation of dietary fibres, are believed to be involved in the aetiology of obesity and diabetes. Previous data from our group showed that colonic infusions of physiologically relevant SCFA mixtures attenuated whole-body lipolysis in overweight men. To further study potential mechanisms involved in the antilipolytic properties of SCFA, we aimed to investigate the in vitro effects of SCFA incubations on intracellular lipolysis and signalling using a human white adipocyte model, the hMADS cells.

Methods: hMADS adipocytes were incubated with mixtures of acetate, propionate and butyrate or single SCFA (acetate, propionate and butyrate) in concentrations ranging between $1 \mu \mathrm{mol} / \mathrm{L}$ and $1 \mathrm{mmol} / \mathrm{L}$. Glycerol release and lipase activation was investigated during basal conditions and following $\beta$-adrenergic stimulation.

Results: SCFA mixtures high in acetate and propionate decreased basal glycerol release, when compared to control $(P<0.05)$, whilst mixtures high in butyrate had no effect. Also, $\beta$-ADR mediated glycerol release was not significantly altered following incubation with SCFA mixtures. Incubation with only acetate decreased basal (1 $\mu \mathrm{mol} / \mathrm{L})$ and $\beta$-adrenergically $(1 \mu \mathrm{mol} / \mathrm{L}$ and $1 \mathrm{mmol} / \mathrm{L})$ mediated glycerol release as compared to control $(P<0.05)$. In contrast, butyrate $(1 \mu \mathrm{mol} / \mathrm{L})$ slightly increased basal and $\beta$-adrenergically mediated glycerol release compared with control $(P<0.05)$, whilst propionate had no effect on lipolysis. The antilipolytic effect of acetate was accompanied by a reduced phosphorylation of hormone sensitive lipase (HSL) at serine residue 650. In addition, G-protein coupled receptor (GPR) knockdown following pertussis toxin treatment prevented the antilipolytic effect of acetate.

Conclusion: The present data indicated that acetate was mainly responsible for the antilipolytic effects of SCFA and acts via attenuation of HSL phosphorylation in a GPR-dependent manner in hMADS adipocytes. Therefore, the modulation of colonic and circulating acetate may be an important target to modulate human adipose tissue lipid metabolism. 


\section{Introduction}

Increasing evidence suggests that the human gut microbiota and its products are key players in host metabolism, body weight, and insulin sensitivity, thereby contributing to the aetiology of obesity and related disorders. ${ }^{1,2}$ The gut microbiota can ferment indigestible nutrients into short-chain fatty acids (SCFA), of which acetate, propionate and butyrate are the most abundant. ${ }^{3}$ Of note, these SCFA can be taken up by the epithelial lining of the gut and released into the blood stream. ${ }^{4}$ They may thereby act as important signalling molecules between gut microbiota and host physiology, by exerting effects on energy and substrate metabolism such as on adipogenesis and lipolysis in the adipose tissue. ${ }^{5}$

Disturbances in adipose tissue function, characterised by a reduced capacity to store lipids, seem to play a major role in the development of insulin resistance and type 2 diabetes mellitus in humans. ${ }^{6}$ Under normal healthy conditions, the adipose tissue is an important buffering organ for daily postprandial fatty acid (FA) fluxes when endogenous lipolysis is inhibited. The adipose tissue thereby prevents excessive supply of lipids to nonadipose tissues such as liver, skeletal muscle and pancreas. This buffering action may be impaired under obese insulin resistant conditions, $^{7,8}$ resulting in increased circulating lipids and ectopic fat storage in nonadipose tissues, thereby provoking disturbances in insulin signalling and substrate metabolism. ${ }^{9,10}$

SCFA may affect adipose tissue lipid buffering capacity by affecting intracellular lipolysis, the process of hydrolysis of stored triacylglycerol into one molecule of glycerol and three FA molecules, and may thereby affect circulating lipid concentrations. ${ }^{5}$ Indeed, already decades ago, a decrease in plasma free fatty acids (FFA) after a single oral acetate ingestion was observed, pointing to an antilipolytic role of acetate. ${ }^{11}$ The more recent identification of the two pertussis toxin (PTX)sensitive inhibitory $G$ (Gi) protein-coupled receptors (GPR) for SCFA, GPR41 and GPR43 in human adipose tissue, ${ }^{12}$ has led to renewed interest in the lipoytic properties of SCFA. In addition, a direct association between the SCFA/GPR signalling pathway and lipolytic activity in murine adipocytes was recently discovered. ${ }^{13}$ Treatment of differentiated murine 3T3-L1 adipocytes with acetate and propionate in a range between 0.1-0.3 mmol/L exhibited GPR43 activation and a reduction in intracellular lipolytic activity as assessed by a decreased release of glycerol in the culture medium. ${ }^{13}$ In contrast, incubation of 3T3-L1 adipocytes with supraphysiological concentrations of propionate $(20 \mathrm{mmol} / \mathrm{L})$ or butyrate $(5 \mathrm{mmol} / \mathrm{L})$ resulted in enhanced glycerol release. ${ }^{14}$ However, in murine 3T3-L1 adipocytes only 
GPR43, and not GPR41, is expressed. ${ }^{15-18}$ Therefore, it remains to be determined, whether these findings extend to human adipocytes, in which both GPR41 and GPR43 are expressed. ${ }^{12}$ Thus, further investigation on the role of SCFA in human adipocyte lipolysis is urgently warranted.

We recently observed that colonic infusions of mixtures of acetate, propionate and butyrate, in ratios and concentrations that can be reached after dietary fibre intake, attenuated whole-body lipolysis in overweight normoglycaemic men. ${ }^{19}$ Therefore, the aim of the present study was to eludicate whether an altered intracellular adipocyte lipolytic rate is responsible for the antilipolytic effect of SCFA found in vivo, as well as to further investigate underlying mechanisms. Hence, we investigated the in vitro effects of incubation with SCFA mixtures and single SCFA on intracellular lipolysis in a human white adipocyte model, the human multipotent adipose tissue-derived stem (hMADS) cells. To study whether these effects are mediated via Gi-coupled receptors, we investigated the effect of SCFA on lipase activation and performed PTX-mediated inhibtion of GPRs. 


\section{Methods}

\section{Cell culture}

hMADS cells, a validated human white adipocyte model to study lipid metabolism, ${ }^{20}$ were obtained from adult donors and differentiated into the adipogenic lineage, as described previously by Jocken et al. ${ }^{21}$. The lipolytic experiments were carried out between days 12-14 of the differentiation.

\section{Lipolysis experiment}

Free glycerol release analysis

To study effects of SCFA mixtures on the basal glycerol release, hMADS adipocytes were incubated for 6 hours with $300 \mu$ L DMEM 3 \% BSA (Sigma-Aldrich, St. Louis, United States) supplemented with or without a mixture high in acetate containing $80 \%$ acetate, $10 \%$ propionate and $10 \%$ butyrate (80:10:10), a SCFA mixture containing $60 \%$ acetate, $20 \%$ propionate and $20 \%$ butyrate (60:20:20), a mixture high in PA containing $40 \%$ acetate, $35 \%$ propionate and $25 \%$ butyrate (40:35:25) and a mixture high in BA containing $40 \%$ acetate, $25 \%$ propionate and $35 \%$ butyrate (40:25:35) in final concentrations of $1 \mathrm{mmol} / \mathrm{L}$ or $1 \mu \mathrm{mol} / \mathrm{L}$ for 6 hours.

To study effects of single SCFA on the basal (non-stimulated) glycerol release, hMADS adipocytes were incubated with $300 \mu \mathrm{L}$ DMEM 3\% BSA (Sigma-Aldrich, St. Louis, United States) supplemented with or without acetate (Merck, Darmstadt, Germany), propionate (Sigma Aldrich, St. Louis, United States) or butyrate (Sigma Aldrich, St. Louis, United States) at a final concentration of $1 \mathrm{mmol} / \mathrm{L}$ and $1 \mu \mathrm{mol} / \mathrm{L}$ concentrations for 6 hours.

To examine effects of single SCFA or SCFA mixtures on the $\beta$-ADR mediated glycerol release, 30 minutes after the initiation of SCFA incubation the non-selective $\beta$-agonist isoprenaline (ISO) was added at a final concentration of $1 \mu \mathrm{mol} / \mathrm{L}$.

After 6 hours incubation, the plates were placed on ice to stop the reactions, and subsequently $250 \mu \mathrm{L}$ supernatant was removed and directly snap-frozen in liquid nitrogen and stored at $-80{ }^{\circ} \mathrm{C}$ until analysis. The glycerol concentrations were quantified using a commercial fluorometric assay (EnzyChrome ${ }^{\mathrm{TM}}$ Adipolysis assay kit, BioAssay Systems, Hayward, United States). 
SCFA and intracellular lipolysis

Gene expression of GPR41 and GPR43 in hMADS adipocytes

To determine the GPR41 and 43 mRNA expression, total RNA was extracted from hMADS adipocytes at day 0, 2, 7, 10 and 12 using TRIzol reagent (Invitrogen) and SYBR-Green based real-time PCRs were performed using an iCyylcer (Biolegio, Nijmegen, The Netherlands; primer sequence see Table 1). Results were normalized for $18 \mathrm{~S}$ ribosomal RNA.

Table 1: Primer sequences

\begin{tabular}{lll}
\hline Gene & Forward $\left(\mathbf{5}^{\prime} \rightarrow \mathbf{3}^{\prime}\right)$ & Reverse $\left(\mathbf{3}^{\prime} \rightarrow \mathbf{5}^{\prime}\right)$ \\
\hline 18S & AGTTAGCATGCCAGAGTCTCG & TGCATGGCCGTTCTTAGTTG \\
FFAR3 (GPR41) & TTCACCACCATCTATCTCACCG & GGAACTCCAGGTAGCAGGTC \\
FFAR2 (GPR43) & CCGTGCAGTACAAGCTCTCC & CTGCTCAGTCGTGTTCAAGTATT \\
\hline
\end{tabular}

Abbreviations: FFAR, free fatty acid receptor; GPR, G-protein coupled receptor.

\section{Western blotting}

To study the effects of acetate on the protein expression and activation (phosphorylation) of the key lipolytic enzymes adipose triglyceride lipase (ATGL) and hormone-sensitive lipase (HSL), hMADS adipocytes were incubated with $300 \mu \mathrm{L}$ DMEM 3 \% BSA supplemented with or without acetate at a final concentration of 1 $\mu \mathrm{mol} / \mathrm{L}$ for one hour. In addition, $30 \mathrm{~min}$ after the start of the acetate incubation, ISO was added to the medium at a final concentration of $1 \mu \mathrm{mol} / \mathrm{L}$ to investigate the effects of acetate on the $\beta$-ADR mediated HSL phosphorylation. Following one-hour incubation, cells were washed twice with ice-cold phosphate-buffered saline (PBS), and cells were homogenized in radioimmunoprecipitation assay (RIPA) buffer supplemented with a protease and phosphatase inhibitor cocktail (Cell Signaling, Leiden, The Netherlands). $20 \mu \mathrm{g}$ solubilized proteins were separated on a Criterion TGX precast gel (Bio-Rad), transferred using the Trans Blot Turbo transfer system (Bio-Rad), and incubated with primary antibodies. The HSL antibody was a kind gift from Prof. C. Holm (Lund University, Lund, Sweden). The ATGL (No.: 2138) and the pHSL at serine residue 650 (rat SER660) (No.: 4126) antibodies were both obtained from Cell Signaling Technology, Leiden, The Netherlands. To determine the GPR41 (antibody No.: 103718, Abcam, Cambridge, UK) and 43 (antibody No.: 131003, Abcam, Cambridge, UK) protein expression, total protein was extracted from hMADS adipocytes at day $0,2,4,7,9,11$ and 14 . 
Pertussis toxin-mediated GPR knockdown

To study the involvement of GPR in the acetate-induced inhibition of the lipolytic response, we incubated hMADS adipocytes for 6 hours with acetate in a concentration of $1 \mu \mathrm{mol} / \mathrm{L}$ during basal and ISO stimulated conditions (see protocol above), with or without supplementation of PTX to the medium at a final concentration of 100 ng/mL (No.: P7208, Sigma Aldrich, St. Louis, United States).

\section{Statistical analysis}

Values are expressed as mean \pm SEM. Homogeneity of variances was tested using Levene's-test. The overall effect of single SCFA or SCFA ratios and between concentrations and ratios was analyzed using one-way analysis of variance. Post hoc testing was performed using Fisher's least significant difference adjustment for multiple testing. Statistics were performed using SPSS 22.0 for MAC (Chicago, IL, USA) and $P<0.05$ (two-sided $P$-value) was considered statistically significant. 
SCFA and intracellular lipolysis

\section{Results}

SCFA mixtures high in acetate and propionate decrease basal adipocyte glycerol release in vitro

We investigated whether the observed decrease in systemic glycerol found in our in vivo study ${ }^{19}$ is related to an attenuated adipocyte intracellular lipolysis. Therefore, we incubated hMADS adipocytes for 6 hours with $1 \mu \mathrm{mol} / \mathrm{L}$ and $1 \mathrm{mmol} / \mathrm{L}$ of SCFA mixtures. The SCFA mixtures high in acetate and propionate (80:10:10, 60:20:20 and 40:35:25) decreased the basal (non-stimulated) glycerol release, as compared to control $(P<0.05$, Figure $1 \mathrm{~A})$. The SCFA mixture high in butyrate (40:25:35) did not significantly affect basal glycerol release (Figure $1 \mathrm{~A})$. In contrast to the decreased basal lipolysis, $\beta$-ADR mediated glycerol release was not significantly affected following incubation with all SCFA mixtures in physiological concentrations ranging from $1 \mu \mathrm{mol} / \mathrm{L}$ to $1 \mathrm{mmol} / \mathrm{L}$, only a trend towards an attenuated $\beta$-ADR mediated glycerol release was found with the high acetate mixture (80:10:10) compared with control conditions $(P=0.08)$ (Figure $1 \mathrm{~B})$.

\section{Single SCFA differentially affect adipocyte glycerol release in vitro}

Subsequently, we studied whether one particular SCFA was responsible for the observed antilipolytic effect. Therefore, we incubated hMADS adipocytes for 6 hours with acetate, propionate and butyrate in concentrations of $1 \mu \mathrm{mol} / \mathrm{L}$ and 1 $\mathrm{mmol} / \mathrm{L}$. Incubation with $1 \mu \mathrm{mol} / \mathrm{L}$ acetate decreased basal glycerol release when compared to control cells and to butyrate $(P<0.05$, Figure $2 A)$. In addition, acetate blunted the $\beta$-ADR mediated glycerol release in concentrations of $1 \mathrm{mmol} / \mathrm{L}$ and 1 $\mu \mathrm{mol} / \mathrm{L}$, when compared to control $(P<0.05$, Figure $2 \mathrm{~B})$. In contrast, $1 \mu \mathrm{mol} / \mathrm{L}$ butyrate treatment slightly increased basal $(P<0.05$, Figure $2 A)$ and $\beta$-ADR mediated glycerol release $(P<0.01$, Figure $2 \mathrm{~B})$, when compared to control treated cells. Neither in the basal state nor during $\beta$-ADR stimulation, a significant difference between propionate and control treated adipocytes were observed (Figure $2 \mathrm{~A}$ and $\mathrm{B}$ ). 
A

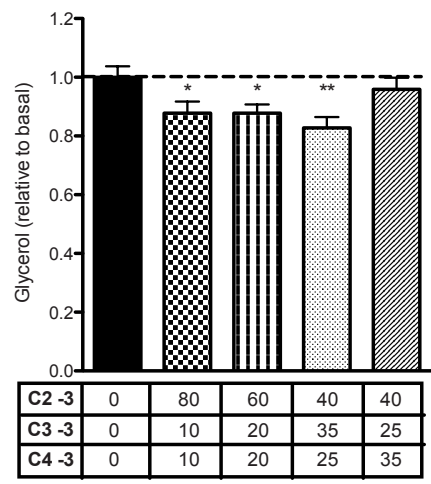

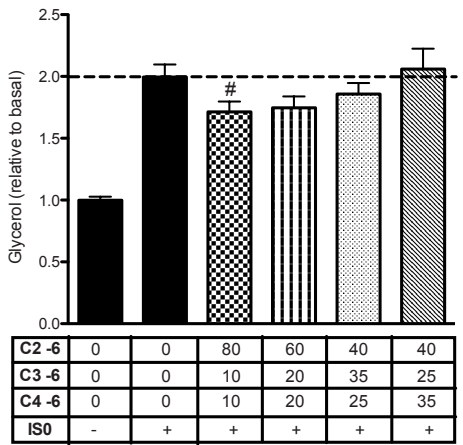

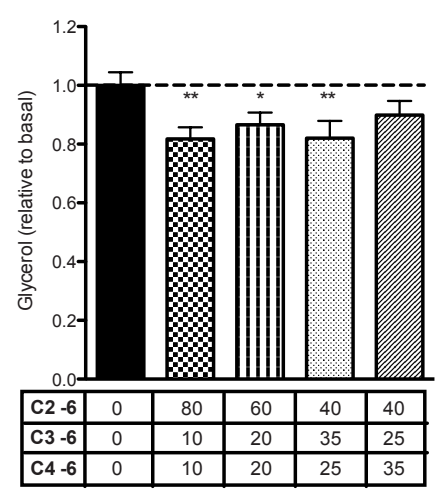

B

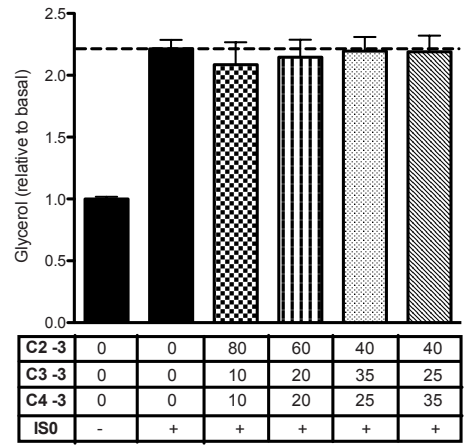

Figure 1. Effect of SCFA mixtures on basal and $\beta$-ADR stimulated glycerol release in hMADS adipocytes

A: Basal (non-stimulated) glycerol concentrations during $6 \mathrm{~h}$ incubation with $1 \mathrm{mmol} / \mathrm{L}(-3)$ or $1 \mu \mathrm{mol} / \mathrm{L}$ (-6) SCFA mixtures including acetate (C2), propionate (C3) and butyrate (C4); B: Effect of 6 h incubation with $1 \mathrm{mmol} / \mathrm{L}(-3)$ or $1 \mu \mathrm{mol} / \mathrm{L}(-6)$ SCFA mixtures including acetate (C2), propionate (C3) and butyrate (C4) on $\beta$-ADR stimulated ( $1 \mu \mathrm{mol} / \mathrm{L}$ ISO) glycerol release; Values are given as means \pm SEM ( $n=6$ independent experiments). Statistical significance compared to basal indicated as hashtag (\#) when $P<0.10$, asterisk $\left({ }^{*}\right)$ when $P<0.05$ and double asterisk $(* *)$ when $P<0.01$. 
A

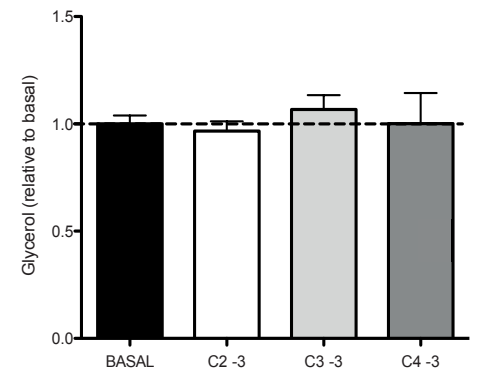

B

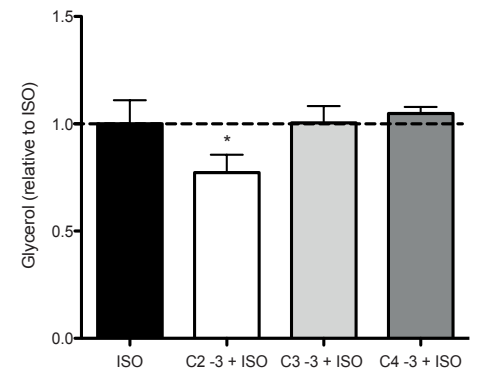

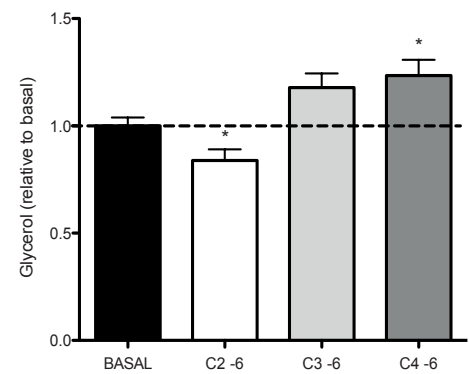

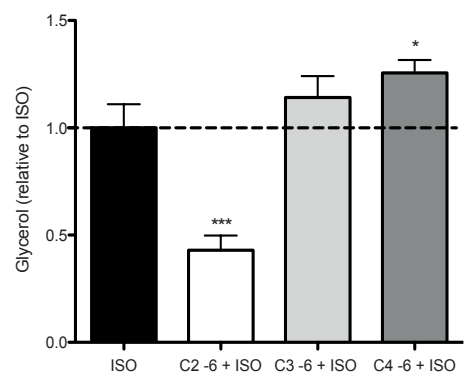

Figure 2. Effect of single SCFA on basal and $\beta$-ADR stimulated glycerol release in hMADS adipocytes A: Basal (non-stimulated) glycerol concentrations during $6 \mathrm{~h}$ incubation with $1 \mathrm{mmol} / \mathrm{L}(-3)$ or $1 \mu \mathrm{mol} / \mathrm{L}$ (-6) acetate (C2), propionate (C3) or butyrate (C4); B: Effect of $6 \mathrm{~h}$ incubation with $1 \mathrm{mmol} / \mathrm{L} \mathrm{(-3)} \mathrm{or} 1$ $\mu \mathrm{mol} / \mathrm{L}(-6)$ acetate (C2), propionate (C3) or butyrate (C4) on $\beta$-ADR stimulated ( $1 \mu \mathrm{mol} / \mathrm{L}$ ISO) glycerol release; Values are given as means $\pm \operatorname{SEM}(n=4$ independent experiments). Statistical significance as compared to basal indicated as asterisk ( $\left.{ }^{*}\right)$ when $P<0.05$ and as triple asterisk $\left({ }^{* * *}\right)$ when $P<0.001$.

\section{Acetate attenuates HSL phosphorylation in adipocytes}

Since the above data indicated that mainly acetate is the driver of the antilipolytic effect of SCFA in human adipocytes, we subsequently investigated the underlying mechanisms in more detail by quantification of key enzymes involved in intracellular lipolysis, including ATGL, HSL and phosphorylated HSL (pHSL). No significant differences of acetate on total HSL or ATGL protein content were observed (Figure 3A). As indicated in Figure 3B, treatment of hMADS adipocytes with $1 \mu \mathrm{mol} / \mathrm{L}$ acetate resulted in a $65 \%$ reduction in the relative amount of phosphorylation of HSL on the serine 650 as compared to control non-treated cells $(P=0.01$, Figure $3 B$ ). As expected, the phosphorylation of phosphorylation of HSL on the serine 650 increased by 5-6 fold in the presence of ISO, as compared to nonstimulated adipocytes (Figure $3 \mathrm{~A}$ and $\mathrm{B}$ ). However, pre-treatment of hMADS adipocytes with $1 \mu \mathrm{mol} / \mathrm{L}$ acetate and ISO resulted in a $19 \%$ reduction in the relative amount of $\mathrm{pHSL}_{(\mathrm{SER} 650)}$ compared to ISO stimulation alone $(P=0.04$, Figure $3 \mathrm{~B})$. 


\section{A}

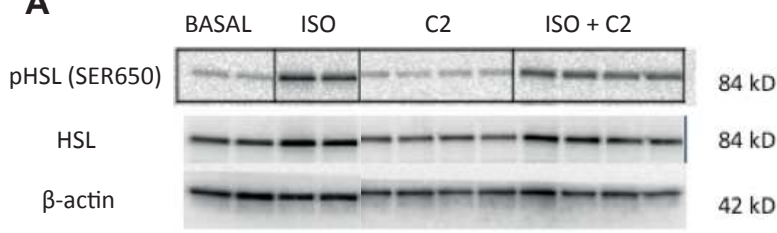

B

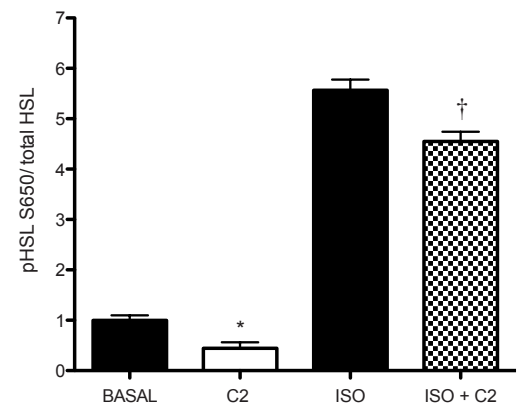

Figure 3. Acetate attenuates HSL (SER 650) phosphorylation in hMADS adipocytes

A: Representative western blot showing that $1 \mu \mathrm{mol} / \mathrm{L}$ acetate (C2) reduced the relative amount of HSL phosphorylated on serine 650 in the presence of isoprenaline (ISO). B: Quantification of western blot using ImageLab 3.0 normalized to total HSL ( $n=4$ independent experiments). Values are given as means \pm SEM. Statistical significance as compared to basal indicated as asterisk $\left({ }^{*}\right)$ when $P<0.05$; and as compared to ISO as dagger $\left({ }^{\dagger}\right)$ when $P<0.05$.

\section{PTX treatment prevents the antilipolytic effect of acetate in hMADS cells}

Finally, we investigated the involvement of inhibitory G-protein (Gi) coupled receptors (GPR) in this acetate-mediated antilipolytic effect. Both GPR41 and GPR43, the major SCFA receptors, were expressed at the RNA (Figure 4A) and protein (Figure 4B) level in our hMADS cells, and expression increased during adipogenic differentiation with a maximal expression at day 12 and 14, respectively (Figure 4).

Next, hMADS adipocytes were incubated with or without PTX, which irreversibly blocks Gi function, thereby inhibiting both GPR41 and GPR43 in our hMADS adipocytes. As expected, blocking these GPRs by PTX increased basal and $\beta$ ADR stimulated glycerol release in hMADS adipocytes (Figure 5). Of interest, PTX prevented the acetate-mediated $(1 \mu \mathrm{mol} / \mathrm{L})$ decrease in basal and $\beta$-ADR stimulated glycerol release $(P>0.05$, Figure 5$)$. 
A
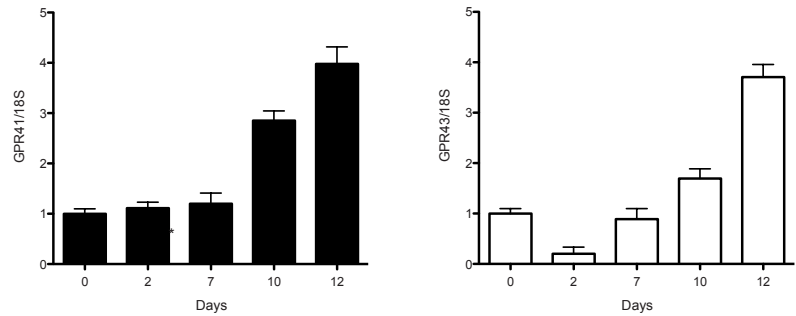

B

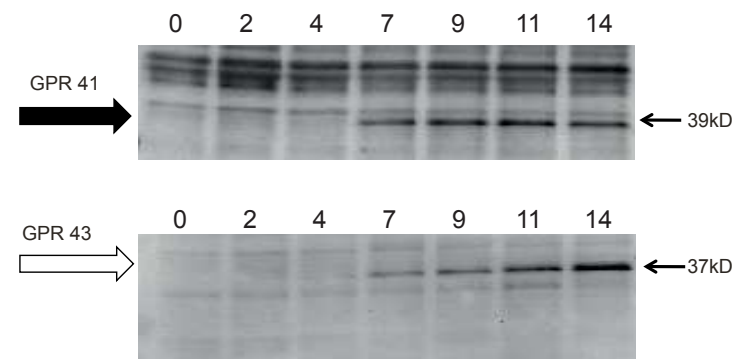

Figure 4: GPR41 and GPR43 are expressed at the RNA and protein level in hMADS adipocytes A: GPR41/43 mRNA expression during adipocyte differentiation (day 0 - 12). B: GPR43/41 protein expression during adipocyte differentiation (day 0 - 14).

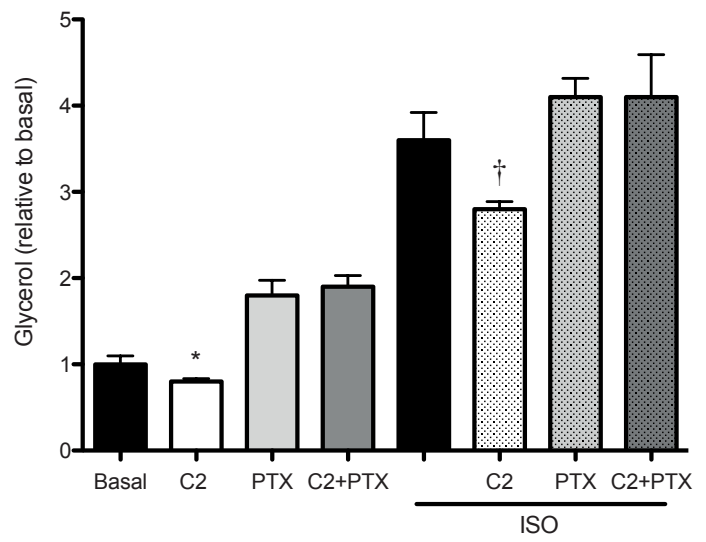

Figure 5: Pertussis toxin (PTX) abrogated acetate-induced inhibition (1 $\mu \mathrm{mol} / \mathrm{L})$ of ISO-mediated glycerol release in hMADS adipocytes

Values are given as means \pm SEM ( $n=2$ independent experiments). Statistical significance when compared to basal indicated as asterisk $\left(^{*}\right)$ when $P<0.05$; and as compared to isoprenaline (ISO) as dagger $\left({ }^{\dagger}\right)$ when $P<0.05$. 


\section{Discussion}

This study provides new insight in the effects of SCFA on human adipocyte lipolysis. We previously showed that acute colonic administration of three physiological-relevant SCFA mixtures, and subsequent elevated circulating acetate concentrations, reduced circulating glycerol concentration in overweight males, indicative of a reduced whole-body lipolysis. ${ }^{19}$ However, to further investigate whether the reduction in whole-body lipolysis was related to a putative SCFA effect on white adipocyte intracellular lipolysis, we performed several in vitro experiments using our validated hMADS adipocyte model. Our present in vitro study in hMADS adipocytes demonstrated that mainly acetate had antilipolytic effects, which was accompanied by a reduced phosphorylation of HSL (at SER650). Incubation with the GPR inhibitor PTX prevented the acetate-mediated antilipolytic effect, suggesting that this antilipolytic effect may be mediated through an acetate-GPR coupled signalling pathway (Figure 6).

This study showed, for the first time, that SCFA mixtures at physiological (1 $\mu \mathrm{mol} / \mathrm{L}$ ) and more supraphysiological ( $1 \mathrm{mmol} / \mathrm{L}$ ) concentrations attenuate intracellular lipolysis in human adipocytes. Furthermore, by subsequently incubating human adipocytes with single SCFA, we demonstrated that the intestinally and systemically most abundant SCFA acetate seems to be the main driver of this antilipolytic effect. Acetate is the most abundant circulating SCFA and is found in serum and plasma mean concentrations varying from $5 \mu \mathrm{mol} / \mathrm{L}$ up to $220 \mu \mathrm{mol} / \mathrm{L}$, depending on the nutritional status. ${ }^{4,22,23}$ Propionate and butyrate are found at much lower maximal mean concentrations of $13 \mu \mathrm{mol} / \mathrm{L}$ and $12 \mu \mathrm{mol} / \mathrm{L}$, respectively. ${ }^{4}, 22,23$ However, no human data are available reflecting SCFA concentrations that reach the adipose tissue via their capillaries. Based on the scarcely available data on circulating SCFA concentrations, an acetate to propionate to butyrate ratio of $80: 10: 10$ and $60: 20: 20$ could resemble physiologically circulating concentrations and the SCFA concentrations used in this study might be in a physiological ( $1 \mu \mathrm{mol} / \mathrm{L})$ to supraphysiological $(1 \mathrm{mmol} / \mathrm{L})$ range. 


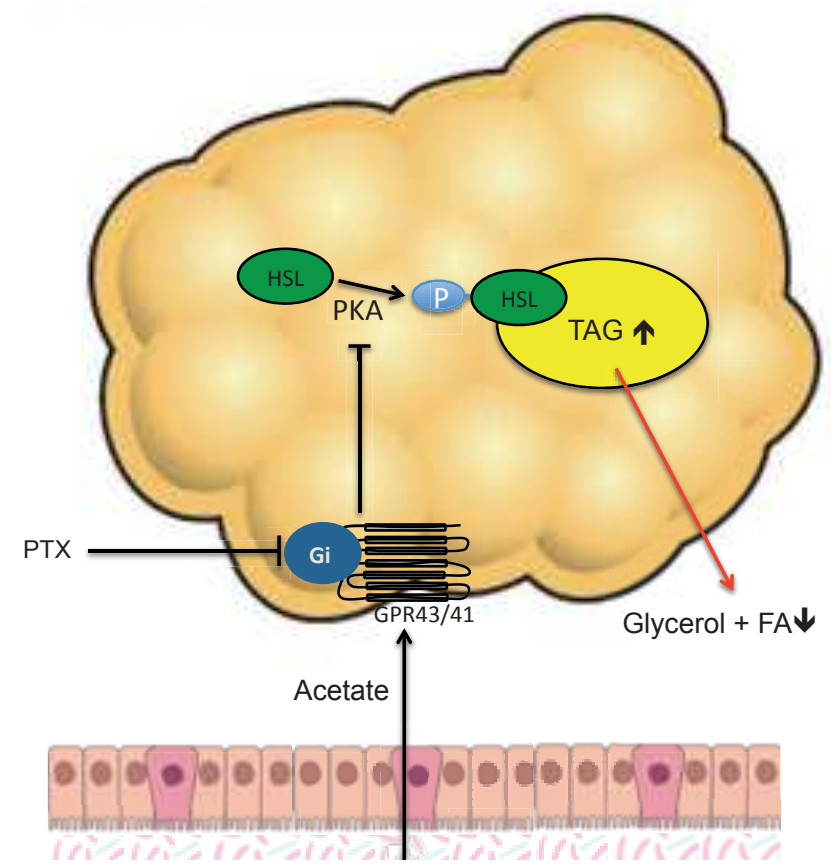

Figure 6: Proposed mechanism of the acetate-mediated antilipolytic effect in human adipocytes. The blunted FA and glycerol release during acetate incubation is accompanied by a reduced phosphorylation of $\mathrm{HSL}_{(\mathrm{SER} 650)}$, indicating a role for protein kinase A (PKA) in this antilipolytic process. The GPR inhibitor PTX prevents the acetate-mediated antilipolytic effect, indicating a role for a Gi protein coupled receptor mechanism (i.e. GPR41 and/or GPR43) in human adipocyte lipolysis.

In addition, we observed that the antilipolytic effect of acetate was accompanied by a reduced phosphorylation of HSL at the serine 650 , a major protein kinase $A$ (PKA) regulatory site. In accordance with this observation, Aberdein et al. ${ }^{24}$ demonstrated that treatment of murine 3T3-L1 adipocytes with supraphysiological concentrations ( $4 \mathrm{mmol} / \mathrm{L}$ ) of sodium acetate reduced the $\beta$-ADR stimulated nonesterified FA release and decreased HSL phosphorylation at another PKA regulatory site (serine 563). ${ }^{24}$ Ge et al. ${ }^{13}$ showed that treatment of 3T3-L1 adipocytes with acetate and propionate in a range between $0.1-0.3 \mathrm{mmol} / \mathrm{L}$ reduced the basal and $\beta$-ADR stimulated intracellular lipolytic activity as assessed by a decreased release of glycerol in the culture medium. ${ }^{13}$ In contrast to the antilipolytic effect of acetate, we observed a slightly increased basal lipolytic response after butyrate treatment in hMADS adipocytes. Comparable results were reported by Rumberger et al. ${ }^{14}$ showing an increased basal lipolytic response (glycerol release) following incubation of murine 3T3-L1 adipocytes with $5 \mathrm{mmol} / \mathrm{L}$ butyrate. ${ }^{14}$ Together, these results indicate that acetate is the main driver for the antilipolytic effects of SCFA, which is 
accompanied by an attenuated PKA-mediated HSL phosphorylation in both, murine and human adipocytes.

Finally, we observed that the antilipolytic effect of acetate was GPR dependent. We first confirmed that both, GPR41 and GPR43 transcripts and protein are expressed in our hMADS adipocyte model, and that both increased during adipogenic differentiation. Thereby, our human cell model differs to the murine 3T3L1 adipocytes used in previous studies, where only GPR43, and not GPR41, were abundant. ${ }^{15-18}$ Furthermore, we showed that the effects of acetate are abrogated with co-incubation of PTX. PTX is a well-known GPR inhibitor and irreversible inactivates Gi proteins. Thereby, these data suggest that the acetate effects were mediated via a Gi-protein receptor-PKA pathway. In line, a previous study in murine 3T3-L1 adipocytes has shown that the lipolytic effect of acetate was mediated by activation of GPR43. ${ }^{13}$ However, further investigations are warranted to elucidate whether SCFA effects on human intracellular adipocyte lipolysis are mediated mainly via GPR43 and/or 41, using specific human knockdown models.

This study has important clinical implications. If the observed results can be translated into long-term in vivo metabolic effects, increased systemic acetate availability might improve human white adipose tissue lipid buffering capacity and reduce adipose tissue lipid spillover. This could ultimately result in attenuated ectopic fat accumulation and improved insulin action in insulin sensitive tissues such as skeletal muscle, pancreas and liver, preventing insulin resistance.

In conclusion, we demonstrated that in particular the colonic and peripheral most abundant SCFA acetate plays an important role in the regulation of human adipose tissue lipolysis. The previously in vivo observed antilipolytic effect of physiologically relevant SCFA mixtures, ${ }^{19}$ all highest in acetate, was confirmed in vitro in our human adipocyte model. We found that the luminal and systemically most abundant SCFA acetate was mainly responsible for the antilipolytic response, via GPR-mediated attenuation of HSL phosphorylation in human adipocytes. Indicating that the modulation of colonic and systemic acetate might be a target to prevent or improve insulin resistance in human. Therefore, future studies should focus on increasing nutritional strategies to enhance circulating acetate availability, for example via supplementation of specific acetogenic fibres, to improve human lipid metabolism. 


\section{References}

1. Diamant M, Blaak EE, de Vos WM. Do nutrient-gut-microbiota interactions play a role in human obesity, insulin resistance and type 2 diabetes? Obes Rev 2011;12:272-81.

2. Kootte R, Vrieze A, Holleman F, et al. The therapeutic potential of manipulating gut microbiota in obesity and type 2 diabetes mellitus. Diabetes, Obesity and Metabolism 2012.

3. Canfora EE, Blaak EE. The role of polydextrose in body weight control and glucose regulation. Current Opinion in Clinical Nutrition \& Metabolic Care 2015;18:395-400.

4. Bloemen JG, Venema K, van de Poll MC, et al. Short chain fatty acids exchange across the gut and liver in humans measured at surgery. Clinical nutrition 2009;28:657-661.

5. Canfora EE, Jocken JW, Blaak EE. Short-chain fatty acids in control of body weight and insulin sensitivity. Nat Rev Endocrinol 2015;11:577-591.

6. Goossens GH. The role of adipose tissue dysfunction in the pathogenesis of obesityrelated insulin resistance. Physiology \& behavior 2008;94:206-218.

7. Mensink M, Blaak EE, van Baak MA, et al. Plasma free fatty acid uptake and oxidation are already diminished in subjects at high risk for developing type 2 diabetes. Diabetes 2001;50:2548-2554.

8. Jocken JW, Langin D, Smit E, et al. Adipose triglyceride lipase and hormone-sensitive lipase protein expression is decreased in the obese insulin-resistant state. Journal of Clinical Endocrinology \& Metabolism 2007;92:2292-2299.

9. Ravussin E, Smith SR. Increased fat intake, impaired fat oxidation, and failure of fat cell proliferation result in ectopic fat storage, insulin resistance, and type 2 diabetes mellitus. Annals of the New York Academy of Sciences 2002;967:363-378.

10. Britton KA, Fox CS. Ectopic Fat Depots and Cardiovascular Disease. Circulation 2011;124:e837-e841.

11. Crouse JR, Gerson CD, DeCarli LM, et al. Role of acetate in the reduction of plasma free fatty acids produced by ethanol in man. Journal of lipid research 1968;9:509512.

12. Xiong $\mathrm{Y}$, Miyamoto $\mathrm{N}$, Shibata $\mathrm{K}$, et al. Short-chain fatty acids stimulate leptin production in adipocytes through the $G$ protein-coupled receptor GPR41. Proceedings of the National Academy of Sciences of the United States of America 2004;101:1045.

13. Ge H, Li X, Weiszmann J, et al. Activation of $\mathrm{G}$ protein-coupled receptor 43 in adipocytes leads to inhibition of lipolysis and suppression of plasma free fatty acids. Endocrinology 2008;149:4519.

14. Rumberger JM, Arch JR, Green A. Butyrate and other Short-Chain Fatty Acids Increase the Rate of Lipolysis in 3T3-L1 Adipocytes: PeerJ PrePrints, 2014.

15. Kimura I, Ozawa K, Inoue D, et al. The gut microbiota suppresses insulin-mediated fat accumulation via the short-chain fatty acid receptor GPR43. Nature communications 2013;4:1829.

16. Inoue D, Tsujimoto G, Kimura I. Regulation of energy homeostasis by GPR41. Frontiers in Endocrinology 2014;5.

17. Hong YH, Nishimura Y, Hishikawa D, et al. Acetate and propionate short chain fatty acids stimulate adipogenesis via GPCR43. Endocrinology 2005;146:5092.

18. Zaibi MS, Stocker CJ, O'Dowd J, et al. Roles of GPR41 and GPR43 in leptin secretory responses of murine adipocytes to short chain fatty acids. FEBS letters 2010;584:2381-2386. 
19. Canfora EE, van der Beek CM, Jocken JW, et al. Colonic infusions of short-chain fatty acid mixtures promote energy metabolism in overweight men. Doctoral Thesis Emanuel Canfora 2016; Chapter 4.

20. Bezaire V, Mairal A, Ribet C, et al. Contribution of adipose triglyceride lipase and hormone-sensitive lipase to lipolysis in hMADS adipocytes. Journal of Biological Chemistry 2009;284:18282-18291.

21. Jocken J, Goossens G, Popeijus H, et al. Contribution of lipase deficiency to mitochondrial dysfunction and insulin resistance in hMADS adipocytes. International Journal of Obesity 2015.

22. Cummings J, Pomare E, Branch W, et al. Short chain fatty acids in human large intestine, portal, hepatic and venous blood. Gut 1987;28:1221.

23. Fernandes J, Vogt J, Wolever T. Kinetic model of acetate metabolism in healthy and hyperinsulinaemic humans. European journal of clinical nutrition 2014.

24. Aberdein N, Schweizer M, Ball D. Sodium acetate decreases phosphorylation of hormone sensitive lipase in isoproterenol-stimulated 3T3-L1 mature adipocytes. Adipocyte 2014;3:121. 



\title{
CHAPTER 6
}

\author{
Twelve-week supplementation of galacto- \\ oligosaccharides increased bifidobacteria in obese \\ prediabetic adults, whereas insulin sensitivity and energy \\ metabolism were not changed
}

Running title: GOS and insulin sensitivity

Emanuel E. Canfora*, Christina M. van der Beek*, Gerben D.A. Hermes, Gijs H. Goossens, Johan W. E. Jocken, Jens J. Holst, Koen Venema, Hauke Smidt, Erwin G. Zoetendal, Cornelis H. C. Dejong, Kaatje Lenaerts, Ellen E. Blaak

* Shared first author

To be submitted 


\section{Abstract}

Background \& aims: The gut microbiota may influence host lipid and glucose metabolism, satiety and chronic low-grade inflammation, thereby contributing to the aetiology of obesity and type 2 diabetes mellitus. Fermentation end products, in particular the short-chain fatty acid (SCFA) acetate, are believed to be involved in these processes. Here, we investigated the long-term effects of supplementation with galactooligosaccharides (GOS), an acetogenic fibre, on gut microbiota composition and host metabolism in humans.

Methods: Forty-four overweight/obese (BMI 28-40 kg/m²) prediabetic men and postmenopausal women completed this double-blind, placebo-controlled, parallel intervention study. The participants were randomly assigned to daily $15 \mathrm{~g}$ GOS or isocaloric placebo intake for 12 weeks. Before and after the intervention, peripheral and adipose tissue insulin sensitivity, faecal microbiota composition, plasma/faecal SCFA, energy expenditure and substrate oxidation, body composition, as well as hormonal and inflammatory responses, were determined.

Results: Supplementation of GOS to the daily diet, but not placebo, led to a marked 5fold increase in faecal Bifidobacterium spp. $(P=0.009, \mathrm{q}=0.144)$. Microbial richness or diversity were not affected. No alterations of faecal and fasting plasma SCFA concentrations, changes in systemic concentrations of gut-derived hormones, incretins, lipopolysaccharide-binding protein or other systemic inflammatory markers were observed. In addition, no significant alterations in peripheral and adipose tissue insulin sensitivity, body composition, and energy and substrate metabolism, were found.

Conclusions: Twelve-week supplementation of GOS prebiotics selectively increased faecal Bifidobacterium spp. abundance, but this did not translate into significant changes in insulin sensitivity and related host substrate and energy metabolism in overweight/obese prediabetic men and women. 


\section{Introduction}

Accumulating evidence indicates that the human gut microbiota is involved in the aetiology of obesity and type 2 diabetes mellitus. ${ }^{1-3}$ Several strategies to manipulate gut microbiota composition including faecal transplantation, antibiotic treatment, as well as supplementation of probiotics and prebiotics indicated that alterations in the microbial composition and diversity might lead to changes in insulin sensitivity and metabolic profile in humans, ${ }^{4-7}$ although data are not consistent. ${ }^{8-10}$ Importantly, however, long-term dietary intervention studies in humans, combining microbiota analysis with detailed metabolic phenotyping are scarce, and putative underlying mechanisms for beneficial effects on host metabolism remain to be fully elucidated.

Many data on prebiotic effects of dietary fibres are derived from studies with either inulin-type fructo-oligosaccharides (FOS) or galacto-oligosaccharides (GOS). ${ }^{11}$ These dietary fibres have the capacity to selectively alter the gut microbiota composition and stimulate the growth of putatively beneficial bacterial genera such as Bifidobacterium and Lactobacillus. ${ }^{11,12}$ GOS is a soluble dietary fibre derived from $\beta$ galactosidase-induced conversion of lactose. A limited number of human studies have indicated beneficial metabolic effects of GOS. ${ }^{13,14}$ Twelve-week supplementation of a GOS mixture to overweight participants improved insulin and lipid homeostasis, and attenuated low-grade systemic inflammation in these participants. ${ }^{13}$ Furthermore, dietary supplementation of a GOS mixture to healthy elderly volunteers altered gut microbiota composition and improved systemic and faecal inflammatory markers. ${ }^{14}$ However, mechanisms involved in these metabolic effects were not determined in these studies. One of the important mechanisms involved in the effects of prebiotic fibres on metabolic health is their fermentation by the gut microbiota, resulting in the formation of short-chain fatty acids (SCFA), mainly acetate, propionate and butyrate. ${ }^{15}$

We have recently demonstrated that acute infusion of acetate into the distal part of the colon increased fat oxidation and circulating concentrations of the satietystimulating hormone peptide YY (PYY) in overweight men. ${ }^{16}$ In a follow-up study, ${ }^{17}$ we have shown that rectal administration of three different SCFA mixtures (either high in acetate, propionate or butyrate) to overweight men. In that study exogenous SCFA increased fasting fat oxidation, resting energy expenditure and plasma PYY concentrations, and decreased whole-body lipolysis. ${ }^{17}$

In vitro incubation with faecal microbiota has shown that GOS is fermented by (primarily) Bifidobacterium into lactate and SCFA, mainly acetate. ${ }^{18}$ In addition, a 6week supplementation of GOS to infants increased faecal acetate concentrations and 
| GOS and insulin sensitivity

faecal abundance of Bifidobacterium. ${ }^{19}$ Therefore, we hypothesized that long-term GOS intake would beneficially modulate the gut microbiota composition and induce acetate production, leading to improved host energy and substrate metabolism and insulin sensitivity. Hence, the present study investigated the effects of 12-week GOS supplementation on peripheral insulin sensitivity in overweight and obese, prediabetic men and postmenopausal women. Secondary outcomes were effects of GOS supplementation on faecal microbiota composition, plasma and faecal SCFA concentrations, body composition, energy expenditure and substrate oxidation, circulating metabolites, hormones, inflammatory markers and adipokine concentrations. 


\section{Methods}

\section{Study participants}

Forty-six overweight and obese (body mass index, BMI $28-40 \mathrm{~kg} / \mathrm{m}^{2}$ ) Caucasian men and postmenopausal women, aged 45-70 years, with impaired fasting glucose (IFG) and/or impaired glucose tolerance (IGT) were recruited between October 2014 and October 2015 from the vicinity of Maastricht, The Netherlands. IFG was defined as fasting plasma glucose levels $\geq 5.6 \mathrm{mmol} / \mathrm{L}$. IGT was defined as plasma glucose levels between 7.8-11 mmol/L at $2 \mathrm{~h}$ after oral ingestion of $75 \mathrm{~g}$ glucose dissolved in $250 \mathrm{~mL}$ tap water (oral glucose tolerance test, OGTT). Volunteers had to be weight stable for at least 3 months prior to study participation. Exclusion criteria for participation in the study were: diabetes mellitus, gastroenterological diseases or prior abdominal surgery, cardiovascular diseases, liver or kidney malfunction, patients with a life expectancy shorter than 5 years, participants following a hypocaloric diet, or use of antibiotics, preor probiotics in the 3 months prior to start of the study or during the study period. Participants did not use $\beta$-blockers, lipid and glucose lowering-drugs, anti-oxidants or chronic corticosteroids. The study was approved by the Medical Ethical Committee of Maastricht University Medical Centre+ (MUMC+) and was conducted in accordance with the Declaration of Helsinki (revised version, October 2008, Seoul, South Korea). Written informed consent was obtained from all participants.

\section{Study design}

This study was a double-blind, placebo-controlled, randomized, parallel trial. Participants were randomly assigned to the GOS or placebo group using block randomization to stratify the participants for sex, age and BMI. Participants in the intervention group were asked to ingest $7.04 \mathrm{~g}$ of Vivinal ${ }^{\circledR}$ GOS powder (FrieslandCampina Domo, Amersfoort, the Netherlands), containing $5 \mathrm{~g}$ GOS, three times per day with their regular meals during the 12-week intervention period (Figure 1). Participants in the placebo group were asked to ingest $5.65 \mathrm{~g}$ of maltodextrin (Avebe, Veendam, the Netherlands) three times per day with their regular meals during 12 weeks. The amount of maltodextrin (269.6 kJ per day) was isocaloric to the amount of Vivinal ${ }^{\circledR}$ GOS powder product (269.6 kJ per day). GOS and maltodextrin were both provided as white powdered supplements. The products were provided in sachets and were consumed with a low fat yogurt drink (Optimel Drink Lang Lekker $200 \mathrm{~mL}$, FrieslandCampina, Amersfoort, the Netherlands). The participants were instructed to document their GOS or placebo intake in a daily diary and had to return all sachets to 
assess compliance. All participants were instructed to continue their usual physical activity and dietary regimen throughout the whole intervention period to study the isolated effect of the differential supplementation.

Primary outcome of the study was the effect of GOS on peripheral insulin sensitivity as measured by the hyperinsulinemic-euglycemic clamp method. Secondary outcomes were substrate oxidation and energy expenditure, faecal microbiota composition, faecal and plasma SCFA, circulating metabolites (glucose, triacylglycerol (TAG), free fatty acids (FFA), free glycerol) and hormones (insulin, PYY, glucagon-like peptide-1 (GLP-1), leptin), plasma inflammatory markers (tumour necrosis factor- $\alpha$ (TNF- $\alpha$ ), interleukin-6 (IL-6), interleukin-8 (IL-8), lipopolysaccharide binding protein (LBP)), body composition, BMI, body weight, dietary intake and physical activity.

Before and directly after the 12-week intervention period, participants underwent an experimental clinical investigation day (CID). The 12-week intervention started the day after the first CID. During the three days prior to CID participants recorded their dietary intake and level of physical activity. In addition, faecal samples were collected one day prior to the CID.

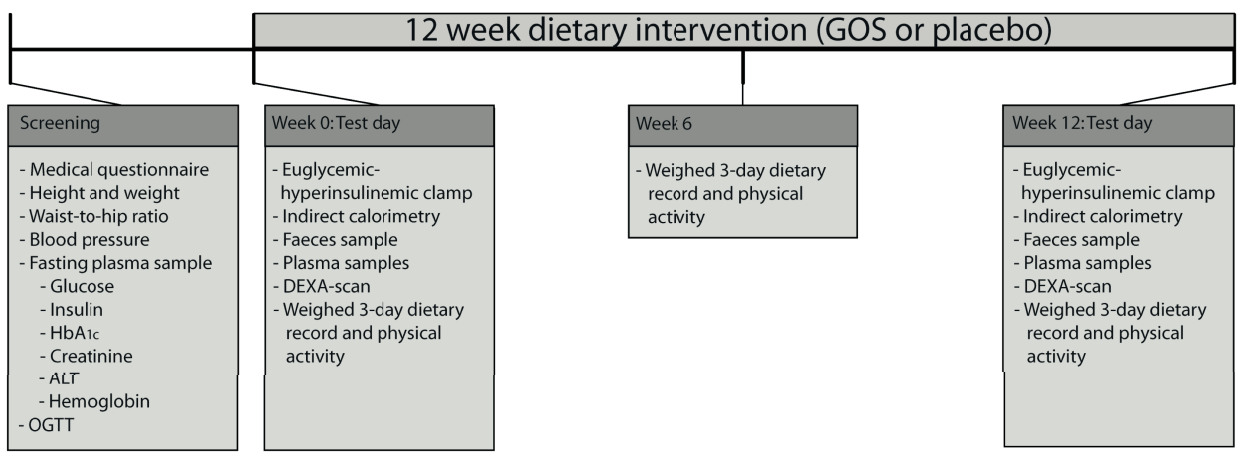

Figure 1. Outline of study design. Abbreviations: ALT, alanine transaminase, DEXA, dual energy X-ray absorptiometry-scanning; OGTT, oral glucose tolerance test; GOS, galactooligosaccharide; $\mathrm{HbA}_{1 \mathrm{c}}$, glycated haemoglobin.

\section{Dietary intake and physical activity recording}

Participants were asked to complete a three-day dietary record before the intervention period, in week 6 and in week 12 of the intervention. Before start of the intervention, participants were instructed by a dietician how to weigh and record their food and beverage intake. The volunteers were asked to include two week days and one weekend day in the three-day period. The dietary records were checked, 
discussed, in case of missing data, and analysed by an experienced dietician. Energy and nutrient intake were analysed using the Dutch Food Composition Dataset (NEVO, National Institute for Public Health and Environment, Ministry of Health, Welfare and Sport, The Hague, The Netherlands).

Self-reported level of physical activity was assessed using the Short Questionnaire to Assess Health enhancing physical activity (SQUASH). ${ }^{20}$ Participants completed the questionnaire before the intervention period and in week 6 and week 12 of the intervention period. Outcome value was the time spent (min) in light, moderate, and vigorous physical activity based on metabolic equivalent (MET), as reported before. ${ }^{20}$

\section{Clinical investigation day (CID)}

Two days prior to the CID, participants were asked to refrain from intense physical activity and alcohol consumption. In the evening before each CID, the volunteers consumed a standardized low fibre meal (62 energy\% carbohydrate, 24 energy\% protein and 14 energy\% fat). Participants came to the laboratory by car or public transport in the morning after an overnight fast $(12 \mathrm{~h})$. All procedures were carried out with the participant in a resting, half-supine position. During the CID, several measurements took place. Each CID started with a dual energy X-ray absorptiometry-scan (DEXA) to determine body composition and measurements of body weight and height. Subsequently, a one-step hyperinsulinemic-euglycemic clamp was performed to measure peripheral insulin sensitivity, combined with indirect calorimetry to measure substrate oxidation and energy expenditure during fasting and euglycemic conditions. In addition, blood samples were taken at different time points during fasting and euglycemic conditions.

\section{Body composition}

Body fat percentage, body fat and visceral fat distribution, as well as lean mass were measured before and after the intervention period by use of a DEXA scan using the 3-compartment model (Hologic BCA, VitaK, Maastricht, The Netherlands). In addition, fasting body weight (in underwear using a calibrated weight scale) and height (barefoot) were measured in order to calculate BMI. 
One step hyperinsulinemic-euglycemic clamp

A hyperinsulinemic-euglycemic clamp was performed to measure whole-body insulin-stimulated glucose rate of disappearance. Participants were placed in a semirecumbent position. First, a Teflon cannula was inserted into an antecubital vein for infusion of glucose and insulin. In order to measure blood glucose, a second Teflon cannula was inserted into a superficial dorsal hand vein for sampling of blood $(1 \mathrm{~mL}$ every $5 \mathrm{~min}$ ), which was arterialized by placing the hand into a hot-box, blowing warm air ( $50 \stackrel{\circ}{\circ}$ ). A priming dose of insulin infusion (Actrapid, Novo Nordisk, Gentofte, Denmark) was administered during the first ten $\min (\mathrm{t0}-\mathrm{t} 10 \mathrm{~min}$ ) and insulin infusion were thereafter continued at $40 \mathrm{mU} \cdot \mathrm{min}^{-1} \cdot \mathrm{m}^{2}$ body surface area during $2 \mathrm{~h} \mathrm{(t10} \mathrm{-}$ t120 min). By variable infusion of a $17.5 \%$ glucose solution, plasma concentrations were maintained at $5.0 \mathrm{mmol} / \mathrm{L}$. The mean glucose infusion rate during the final $30 \mathrm{~min}$ of euglycemia was used as an indicator of the peripheral insulin sensitivity and defined as the M-value. ${ }^{21}$ In addition, during fasting conditions ( $\mathrm{t}-30$ - t0 $\mathrm{min}$ ) and during the 30 min steady state of the clamp (t90 - t120 min), energy expenditure and substrate oxidation were measured using indirect calorimetry. Additional blood plasma samples were taken during fasting (t-5 min) and euglycemic (t90 and t120 min) conditions.

Insulin-stimulated suppression of circulating FFA was measured as an indicator of adipose tissue insulin sensitivity. Insulin-stimulated FFA suppression in \% was calculated by the formula: ((baseline FFA - insulin stimulated FFA during steady state clamp) / baseline FFA). ${ }^{22}$

\section{Indirect calorimetry}

For indirect calorimetry, an open-circuit ventilated hood system (Omnical, MUMC+, Maastricht, the Netherlands) was used. $\mathrm{CO}_{2}$ production $\left(\mathrm{VCO}_{2}\right.$ in $\left.\mathrm{L} / \mathrm{min}\right)$ and $\mathrm{O}_{2}$ consumption $\left(\mathrm{VO}_{2}\right.$ in $\mathrm{L} / \mathrm{min}$ ) were measured during two investigational time periods: a baseline measurement of $30 \mathrm{~min}$ before start of the clamp (t-30 - t0 min) and for 30 min during the steady-state of the hyperinsulinemic-euglycemic clamp (t90 - t120 $\mathrm{min})$. The equations of $\mathrm{Weir}^{23}$ and $\mathrm{Frayn}^{24}$ were used to calculate resting energy expenditure and the rate of fat and carbohydrate oxidation.

\section{Blood collection, storage and biochemical analyses}

Blood was collected into ice-cold EDTA tubes (0.2M EDTA (Sigma, Dorset, UK)) for SCFA, insulin, glucose, FFA, TAG, free glycerol, leptin, LBP, TNF- $\alpha$, IL-6, and IL-8 analyses during fasting (t-5 min) and euglycemic (t90 and t120 min) conditions. For GLP-1 analysis, blood was collected in a $2 \mathrm{~mL}$ EDTA tube containing $20 \mu \mathrm{L}$ of dipeptidyl 
peptidase-IV inhibitor (Millipore, Darmstadt, Germany). For PYY analysis, blood was collected in a $2 \mathrm{~mL}$ aprotinin tube containing $20 \mu \mathrm{L}$ of dipeptidyl peptidase-IV inhibitor. The samples were centrifuged at $3,500 \mathrm{~g}, 4{ }^{\circ} \mathrm{C}$ for $10 \mathrm{~min}$, and plasma was aliquoted and directly snap-frozen in liquid nitrogen and stored at $-80^{\circ} \mathrm{C}$ until analysis.

Plasma FFA, TAG, and glucose were measured with enzymatic assays on an automated spectrophotometer (ABX Pentra 400 autoanalyser, Horiba ABX, Montpellier, France). Plasma free glycerol was measured after precipitation with an enzymatic assay (Enzytec ${ }^{\mathrm{TM}}$ Glycerol, Roche Biopharm, Switzerland) automated on a Cobas Fara spectrophotometric autoanalyser (Roche Diagnostics, Basel, Switzerland). The concentrations of insulin, leptin and PYY were determined with commercially available radioimmunoassay (RIA) kits (Human Insulin specific RIA, Human Leptin RIA, Human PYY (3-36) RIA, Millipore Corporation, MA, USA). IL-6, IL-8 and TNF- $\alpha$ were determined with an enzyme-linked immunosorbent assay (ELISA) kit (Human Prolnflammatory II 4-Plex Ultra-Sensitive Kit, Meso Scale Diagnostics, MD, USA). Plasma samples were assayed for total GLP-1 immunoreactivity using an antiserum, which reacts equally with intact GLP-1 and the primary (N-terminally truncated) metabolite as previously described. ${ }^{25}$ For the detection of LBP, plates (Greiner Microlon 600 high binding) were coated with polyclonal anti human LBP antibodies. Diluted plasma samples (1:5000) and a standard dilution series with rLBP were added to the plate. Detection occurred with a biotinylated polyclonal rabbit anti-human LBP IgG, followed by peroxidase-conjugated streptavidin and substrate. The detection limit for the LBP assay was $200 \mathrm{pg} / \mathrm{mL}^{26}$

\section{SCFA analysis}

Faeces was collected at home within two days before the test days and stored in the subject's freezer at $-20^{\circ} \mathrm{C}$ until direct storage after arrival at the university at -80 ${ }^{\circ} \mathrm{C}$. Faecal acetate, propionate, butyrate were measured by gas chromatography-mass spectrometry (GC-MS, Medical laboratory 'Dr. Stein \& Collegae', Mönchengladbach, Germany), according to the method described by Garciá-Villalba et al. ${ }^{27}$. Deproteinisation and subsequent preparation of plasma samples for analysis of SCFA was performed as reported before. ${ }^{28}$ Analysis was performed using a liquid chromatography system combined with mass spectrometry. The detection limits for acetate, propionate and butyrate of this method were $0.1,0.05$ and $0.05 \mu \mathrm{mol} / \mathrm{L}$, respectively. 


\section{Microbiota composition}

DNA was isolated from faeces using the repeated bead beating method as previously described, ${ }^{29}$ and subsequently used for microbiota profiling using the Human Intestinal Tract Chip (HITChip), a phylogenetic microarray based on 16S rRNA gene sequences of over 1000 intestinal bacterial phylotypes. ${ }^{30}$ In short, 16S rRNA genes were amplified by PCR, followed by in vitro transcription, Cy3/Cy5 labelling and fragmentation of RNA, and hybridization. Duplicate hybridizations with a Pearson correlation $>98 \%$ were considered for further analysis, and microbiota profiles were generated by pre-processing of probe-level measurements with min-max normalization and the frozen-RPA probe summarization ${ }^{31}$ into three phylogenetic levels: order-like, genus-like ( $>90 \%$ sequence similarity), and phylotype-like ( $>98 \%$ sequence similarity). ${ }^{30}$ In the present work our analysis focused on the genus-level variation.

\section{Statistical analysis}

To detect a physiologically relevant change in peripheral insulin sensitivity of 20 $\%$, with an SD of $4 \%$, a power of $80 \%$, assuming an alpha of $0.05(\alpha)$, a number of at least 17 participants per group was necessary. Since an equivalent subject number for men and women was required, 18 participants per group (9 men and 9 women per group) were needed. Assuming a $25 \%$ dropout rate, the planned recruitment was $n=46$ participants in total.

All data are expressed as mean \pm standard error of mean (SEM). Baseline differences were evaluated using a Student's unpaired t-test. Body composition data and metabolic variables were first tested for normality using the Shapiro-Wilk test and showed a normal distribution. A two-factor repeated-measures analysis of variance (ANOVA) with time (pre, post) and intervention (GOS, placebo) as factor was applied. In case of significant timexintervention interaction, post-hoc analyses with Bonferroni correction were applied to identify significant within-intervention effects. Statistics were performed using SPSS 22.0 for Mac (Chicago, IL, USA) and $P<0.05$ (two-sided $P$ value) was considered statistically significant.

For HITChip analysis, $\log _{10}$-transformed signals were used as a proxy for bacterial logarithmic abundance. To determine which individual genus-level microbial groups were showed a significant change in abundance between intervention groups, a linear mixed model taking into account the effects of repeated measurements, treatment group, age and BMI using the Ime4 package. ${ }^{32}$ Diversity of the microbiota was quantified based on non-logarithmized HITChip oligo-level signals by inverse Simpson's index using the Vegan package. ${ }^{33,34}$ ANOVA with Tukey's Honest Significant 
post hoc analysis was applied to compare diversity between and within groups. $P$ values were corrected for multiple comparisons using the Benjamini-Hochberg procedure. Statistics were performed using R v3.1.3 software. A corrected q-value of $<0.2$ was considered as significant. 


\section{Results}

Forty-six volunteers started with the 12-week intervention period. Two women dropped out of the study due to the use of antibiotics during the study period (one for a wound infection after a bicycle fall and one for a lower respiratory tract infection, Supplemental Figure 1). Therefore, a total of 44 participants completed the study and their baseline characteristics are shown in Table 1 . No significant differences were found between groups at baseline and no adverse events were reported.

Table 1. Study participants' baseline characteristics $(n=44)$.

\begin{tabular}{llll}
\hline Variables & GOS $(\mathrm{n}=21)$ & Placebo ( $\mathrm{n}=23)$ & $P$-value \\
\hline Gender (M/F) & $11 / 10$ & $12 / 11$ & \\
IGT / IFG / IGT + IFG ( $\mathrm{n})$ & $0 / 14 / 7$ & $2 / 15 / 6$ & \\
Age, years & $59.2 \pm 1.6$ & $58.4 \pm 1.5$ & 0.716 \\
Weight, kg & $98.4 \pm 2.6$ & $96.9 \pm 2.4$ & 0.263 \\
Height, cm & $172.0 \pm 1.6$ & $173.5 \pm 1.6$ & 0.525 \\
Body mass index, kg/m ${ }^{2}$ & $33.3 \pm 0.8$ & $32.3 \pm 0.7$ & 0.321 \\
Waist-hip ratio & $1.0 \pm 0.01$ & $1.0 \pm 0.01$ & 0.899 \\
Systolic blood pressure, mmHg & $129 \pm 2$ & $127 \pm 3$ & 0.742 \\
Diastolic blood pressure, mmHg & $86 \pm 1$ & $85 \pm 2$ & 0.779 \\
Fasting glucose, mmol/L & $6.0 \pm 0.1$ & $5.8 \pm 0.1$ & 0.095 \\
OGTT 2h plasma glucose, mmol/L & $6.4 \pm 0.4$ & $7.0 \pm 0.4$ & 0.259 \\
Fasting insulin, uU/mL & $20.7 \pm 3.1$ & $19.1 \pm 2.9$ & 0.721 \\
HOMA-IR & $5.34 \pm 4.52$ & $5.10 \pm 2.66$ & 0.829 \\
HbA1c, \% & $5.6 \pm 0.1$ & $5.6 \pm 0.1$ & 0.509 \\
\hline
\end{tabular}

Values are given as mean \pm SEM. Data were analysed using a Student's unpaired t-test. Abbreviations: IFG, impaired fasting glucose; IGT, impaired glucose tolerance; HOMA-IR, homeostatic model assessment of insulin resistance; OGTT, oral glucose tolerance test.

\section{Faecal microbiota composition}

Twelve-week GOS supplementation consistently increased faecal Bifidobacterium by $5.0 \pm 0.3$ fold ( $P=0.009, \mathrm{q}=0.144$ ) (Figure $2 \mathrm{~A}$ and $2 \mathrm{~B}$ ) compared to placebo. Other taxa whose abundance was differentially impacted by the GOS intervention compared to placebo were Prevotella oralis et rel. by $1.14 \pm 0.6$ fold $(P=0.010, q=0.144)$ and Prevotella melaninogenica et rel. by $1.13 \pm 0.5$ fold $(P=0.008$, $\mathrm{q}=0.144)$, Bacteroides stercoris et rel. by $0.83 \pm 0.2$ fold $(P=0.011, q=0.144)$ and Sutterella wadsworthia et rel. by $0.85 \pm 0.1$ fold $(P=0.002, q=0.116$ (supplemental figure 2). However these taxa were all affected to a much smaller degree as compared to 
Bifidobacterium (Figure 2A) and showed a much less uniform pattern (supplemental figure 2). The overall microbial diversity and richness were unchanged between groups.

A

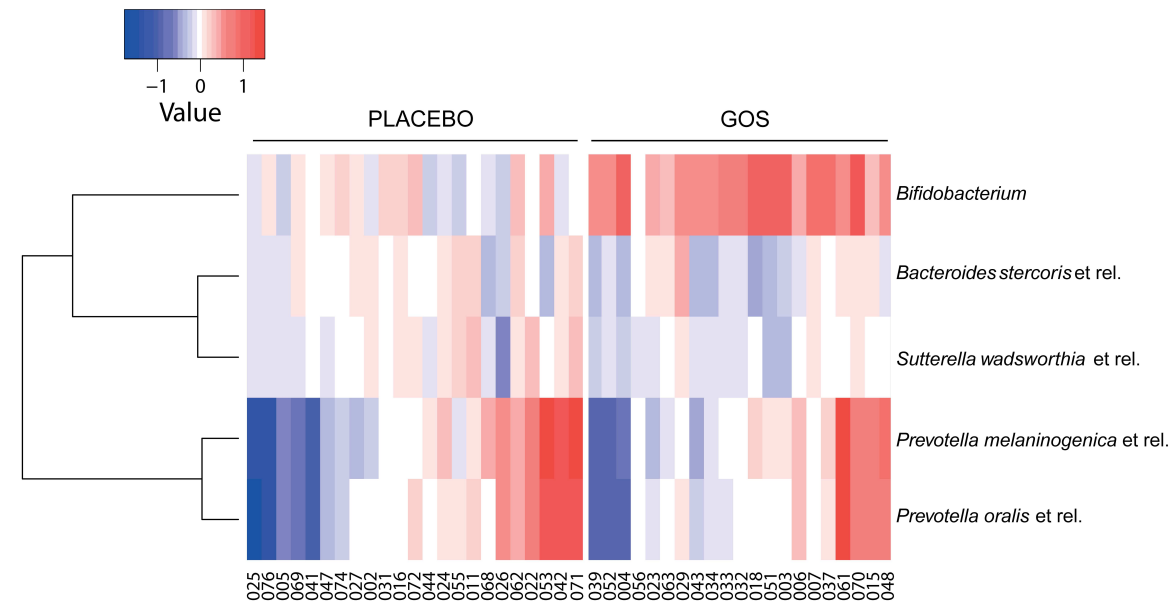

B
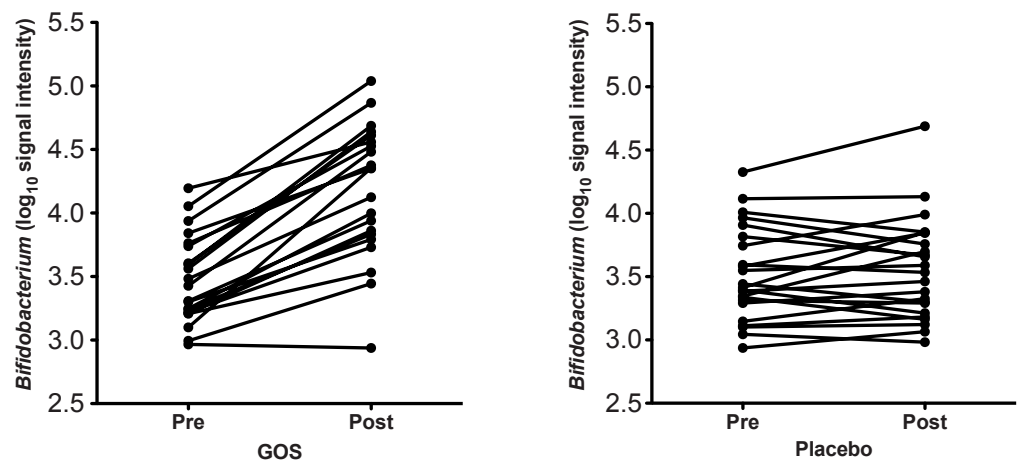

Figure 2. Gut microbiota composition before (Pre) and after (Post) GOS and placebo intervention. A: Heat map of the bacterial groups at genus-like taxonomic level, whose change in abundance was significantly different $(q<0.2)$ between GOS and placebo. Colour value shows $\log _{10}$ fold changes compared to baseline. Differences between treatments were computed using a linear mixed model taking into account the effects of repeated measurements, treatment group, age and body mass index. B: Bifidobacterium relative abundance ( $\log _{10}$ signal intensity) as individual changes for the GOS group $(n=21)$ and placebo group $(n=23)$, pre and post 12-week supplementation with GOS or placebo. Abbreviations: GOS, galacto-oligosaccharides. 


\section{Insulin sensitivity}

Peripheral insulin sensitivity as assessed by the $\mathrm{M}$-value was not altered after GOS treatment as compared with placebo (Figure 3A and 3B). The Homeostasis Model (HOMA-IR) did also not differ between treatments (Figure $3 \mathrm{C}$ ). In addition, insulinstimulated FFA suppression, a measure for adipose tissue insulin sensitivity, was not affected by GOS as compared to placebo (Figure 3D).

A

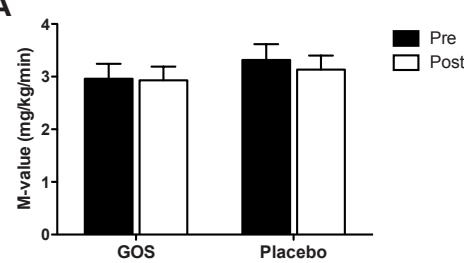

C

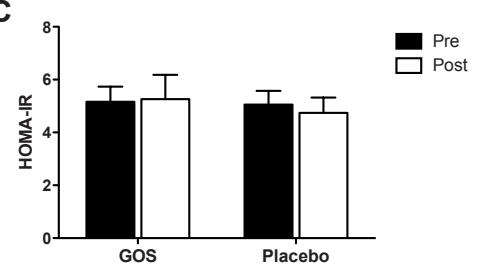

B

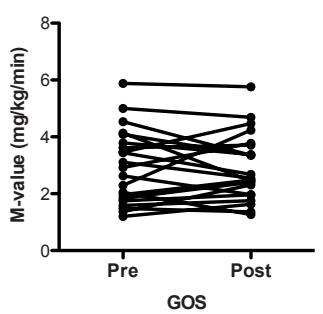

D

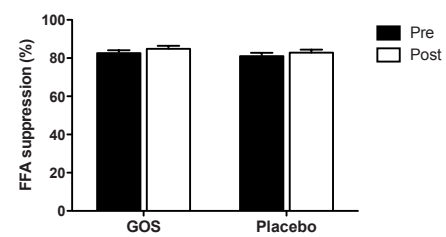

Figure 3. Insulin sensitivity before (Pre) and after (Post) GOS and placebo intervention. A: M-value given as means \pm SEM $B$ : as individual changes for the GOS group $(n=21)$ and placebo group $(n=23)$ pre and post 12-week supplementation with GOS or placebo. C: HOMA-IR and insulin-stimulated D: FFA suppression as a measure for adipose tissue insulin sensitivity pre and post 12-week supplementation with GOS or placebo. Values are given as means $\pm \operatorname{SEM}(n=44)$ and data were analysed using a two-way repeated measures ANOVA, with time (pre, post) and intervention (GOS, placebo). No significant effects were detected. Abbreviations: GOS, galacto-oligosaccharides; FFA, free fatty acids; HOMA-IR, homeostatic model assessment of insulin resistance. 


\section{Short-chain fatty acid concentrations}

Faecal and plasma acetate, propionate and butyrate concentrations did not differ significantly between intervention groups (Figure 4).
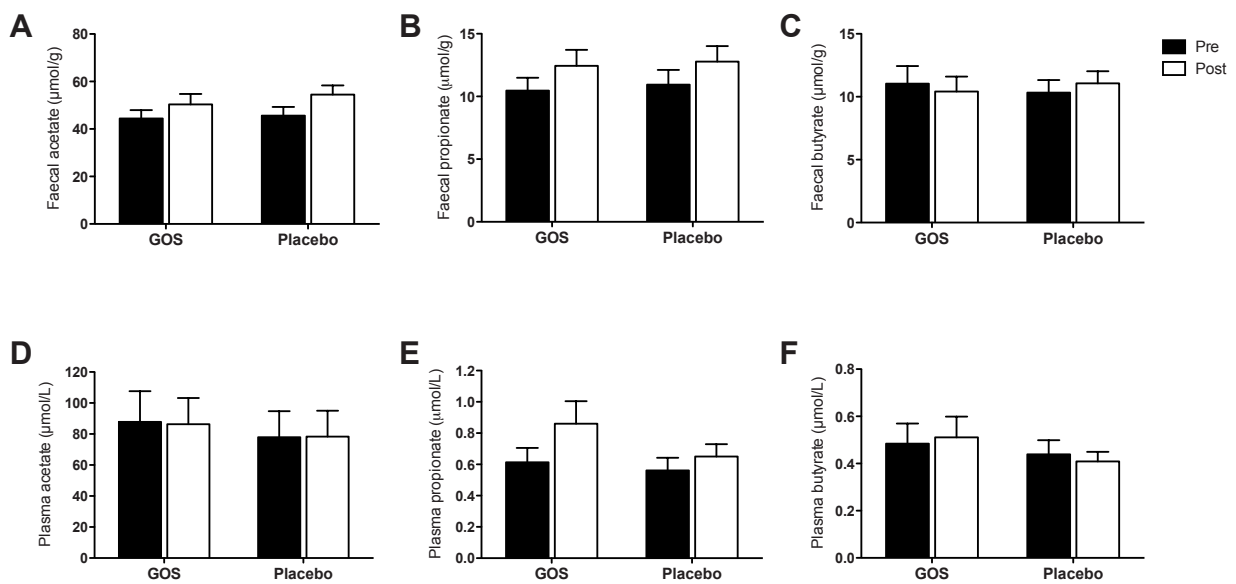

Figure 4. Faecal and plasma concentrations of short-chain fatty acids before (Pre) and after (Post) GOS and placebo intervention. A: Faecal acetate, B: propionate and C: butyrate concentrations pre and post 12-week supplementation with GOS $(n=21)$ or placebo $(n=23)$. Plasma D: acetate, E: propionate and F: butyrate concentrations pre and post 12 -week supplementation with GOS $(n=21)$ or placebo $(n=23)$. Values are given as means \pm SEM and data were analysed using a two-way repeated measures ANOVA, with time (pre, post) and intervention (GOS, placebo). No significant effects were determined. Abbreviations: GOS, galacto-oligosaccharides.

\section{Food intake and physical activity records}

Energy intake, macronutrient and micronutrient intake, assessed using selfreported 3-day food records, were not significantly different after 12 weeks GOS intervention compared to placebo (Supplementary Table 1). Groups did not differ in physical activity levels as assessed via physical activity scores (Supplementary Table 1).

\section{Body composition, BMI and body weight}

BMI, body weight, body fat percentage, body fat mass, lean mass and visceral adipose tissue mass were not significantly altered by GOS supplementation compared to placebo (Table 2). 
GOS and insulin sensitivity

Table 2: Body composition before (pre) and after (post) GOS and placebo intervention

\begin{tabular}{|c|c|c|c|c|}
\hline Variable & & $\operatorname{GOS}(n=21)$ & Placebo $(n=23)$ & $P$-value \\
\hline \multirow[t]{2}{*}{ Body mass index, $\mathrm{kg} / \mathrm{m}^{2}$} & pre & $33.3 \pm 0.8$ & $32.3 \pm 0.7$ & 0.68 \\
\hline & post & $33.7 \pm 0.7$ & $32.7 \pm 0.7$ & \\
\hline \multirow[t]{2}{*}{ Body weight, kg } & pre & $98.4 \pm 2.6$ & $96.9 \pm 2.4$ & 0.69 \\
\hline & post & $99.5 \pm 2.6$ & $98.2 \pm 2.5$ & \\
\hline \multirow[t]{2}{*}{ Body fat, \% } & pre & $36.8 \pm 0.9$ & $36.9 \pm 0.8$ & 0.17 \\
\hline & post & $37.1 \pm 0.9$ & $36.8 \pm 0.8$ & \\
\hline \multirow[t]{2}{*}{ Body fat, kg } & pre & $36.3 \pm 1.5$ & $36.0 \pm 1.4$ & 0.23 \\
\hline & post & $37.1 \pm 1.5$ & $36.3 \pm 1.4$ & \\
\hline \multirow[t]{2}{*}{ Lean mass, kg } & pre & $59.7 \pm 2.3$ & $58.9 \pm 2.0$ & 0.74 \\
\hline & post & $60.7 \pm 2.4$ & $59.7 \pm 1.9$ & \\
\hline \multirow[t]{2}{*}{ Visceral fat, g } & pre & $931.7 \pm 77.3$ & $803.7 \pm 50.9$ & 0.89 \\
\hline & post & $927.6 \pm 76.8$ & $816.8 \pm 50.1$ & \\
\hline
\end{tabular}

Values are given as means \pm SEM and data were analysed using a two-way repeated measures ANOVA, with time (pre, post) and intervention (GOS $(n=21)$, placebo $(n=23))$. No significant effects were detected. Abbreviations: GOS, galacto-oligosaccharides.

\section{Circulating metabolites, hormones and inflammatory profile}

No significant changes in fasting plasma glucose, insulin, glycerol, FFA and TAG were observed between treatments (Table 3). Likewise fasting plasma concentrations of leptin, PYY, GLP-1, and the inflammatory markers IL-6, IL-8, TNF- $\alpha$ and LBP were not significantly affected by the intervention as compared to placebo (Table 3). 
Table 3. Plasma biochemistry before (pre) and after (post) GOS and placebo intervention

\begin{tabular}{|c|c|c|c|c|c|}
\hline Variable & & & $\operatorname{GOS}(n=21)$ & Placebo $(n=23)$ & $P$-value \\
\hline \multicolumn{6}{|l|}{ Plasma metabolites } \\
\hline \multirow{2}{*}{ Glucose, $\mathrm{mmol} / \mathrm{L}$} & fasting & pre & $6.0 \pm 0.1$ & $5.8 \pm 0.1$ & 0.79 \\
\hline & & post & $6.0 \pm 0.1$ & $5.8 \pm 0.1$ & \\
\hline \multirow[t]{4}{*}{ Glycerol, $\mu \mathrm{mol} / \mathrm{L}$} & fasting & pre & $107 \pm 8$ & $99 \pm 5$ & 0.51 \\
\hline & & post & $100 \pm 6$ & $98 \pm 5$ & \\
\hline & steady-state & pre & $50.3 \pm 4.1$ & $48.6 \pm 2.8$ & 0.18 \\
\hline & & post & $46.2 \pm 3.0$ & $48.3 \pm 3.2$ & \\
\hline \multirow[t]{4}{*}{$\mathrm{TAG}, \mathrm{mmol} / \mathrm{L}$} & fasting & pre & $1.28 \pm 0.09$ & $1.17 \pm 0.93$ & 0.54 \\
\hline & & post & $1.50 \pm 0.13$ & $1.31 \pm 0.11$ & \\
\hline & steady-state & pre & $1.19 \pm 0.12$ & $1.05 \pm 0.10$ & 0.71 \\
\hline & & post & $1.40 \pm 0.13$ & $1.25 \pm 0.12$ & \\
\hline \multirow[t]{4}{*}{$\mathrm{FFA}, \mu \mathrm{mol} / \mathrm{L}$} & fasting & pre & $910 \pm 60$ & $848 \pm 43$ & 0.33 \\
\hline & & post & $805 \pm 55$ & $809 \pm 45$ & \\
\hline & steady-state & pre & $119 \pm 12$ & $105 \pm 10$ & 0.71 \\
\hline & & post & $140 \pm 13$ & $122 \pm 12$ & \\
\hline \multicolumn{6}{|l|}{ Plasma hormones } \\
\hline \multirow[t]{2}{*}{ GLP-1, pmol/L } & fasting & pre & $11.3 \pm 0.6$ & $10.6 \pm 0.5$ & 0.69 \\
\hline & & post & $10.3 \pm 0.4$ & $9.9 \pm 0.5$ & \\
\hline \multirow[t]{2}{*}{$\mathrm{PYY}, \mathrm{pg} / \mathrm{mL}$} & fasting & pre & $47.8 \pm 2.1$ & $50.8 \pm 2.3$ & 0.88 \\
\hline & & post & $50.5 \pm 2.0$ & $53.9 \pm 2.2$ & \\
\hline \multirow[t]{2}{*}{ Insulin, mU/L } & fasting & pre & $20.7 \pm 3.1$ & $19.1 \pm 2.9$ & 0.71 \\
\hline & & post & $18.9 \pm 2.0$ & $18.3 \pm 2.0$ & \\
\hline \multirow[t]{2}{*}{ Leptin, ng/mL } & fasting & pre & $31.9 \pm 4.4$ & $33.4 \pm 4.6$ & 0.36 \\
\hline & & post & $25.4 \pm 4.2$ & $28.8 \pm 4.4$ & \\
\hline \multicolumn{6}{|l|}{ Inflammatory markers } \\
\hline \multirow[t]{2}{*}{$\mathrm{LBP}, \mathrm{pg} / \mathrm{mL}$} & fasting & pre & $20.5 \pm 1.5$ & $26.4 \pm 4.0$ & 0.80 \\
\hline & & post & $21.0 \pm 1.7$ & $25.4 \pm 2.9$ & \\
\hline \multirow[t]{2}{*}{$\mathrm{IL}-6, \mathrm{pg} / \mathrm{mL}$} & fasting & pre & $0.82 \pm 0.07$ & $1.03 \pm 0.18$ & 0.59 \\
\hline & & post & $0.85 \pm 0.11$ & $0.99 \pm 0.10$ & \\
\hline \multirow[t]{2}{*}{$\mathrm{IL}-8, \mathrm{pg} / \mathrm{mL}$} & fasting & pre & $4.28 \pm 0.24$ & $3.89 \pm 0.22$ & 0.35 \\
\hline & & post & $4.32 \pm 0.28$ & $4.19 \pm 0.30$ & \\
\hline \multirow[t]{2}{*}{ TNF- $\alpha, p g / m L$} & fasting & pre & $2.35 \pm 0.14$ & $2.20 \pm 0.12$ & 0.38 \\
\hline & & post & $2.37 \pm 0.12$ & $2.32 \pm 0.10$ & \\
\hline
\end{tabular}

Values are given as means \pm SEM and data were analysed using a two-way repeated measures ANOVA, with time (pre, post) and intervention (GOS $(n=21)$, placebo $(n=23)$ ). No significant effects. Abbreviations: FFA, free fatty acids; GLP-1, glucagon-like peptide 1; GOS, galacto-oligosaccharides; LBP, lipopolysaccharide binding protein; PYY, peptide YY; TAG, plasma triacylglycerol, TNF- $\alpha$, tumour necrosis factor alpha. 


\section{Energy expenditure, fat oxidation and carbohydrate oxidation}

GOS did not affect resting energy expenditure and insulin-mediated energy expenditure as compared to placebo treatment. In line, both resting as well as insulinstimulated respiratory quotient and fasting and insulin-mediated fat and carbohydrate oxidation were not altered by GOS versus placebo (Table 4)

Table 4: Energy expenditure and substrate oxidation before (pre) and after (post) GOS and placebo intervention

\begin{tabular}{|c|c|c|c|c|c|}
\hline Variable & & & GOS $(n=21)$ & Placebo $(n=23)$ & $P$-value \\
\hline \multirow[t]{2}{*}{ Energy expenditure, $\mathrm{kJ} / \mathrm{min}$} & fasting & pre & $5.47 \pm 0.16$ & $5.30 \pm 0.13$ & 0.54 \\
\hline & & post & $5.30 \pm 0.15$ & $5.32 \pm 0.13$ & \\
\hline \multirow[t]{2}{*}{ Fat oxidation, $\mathrm{g} / \mathrm{min}$} & fasting & pre & $0.083 \pm 0.004$ & $0.082 \pm 0.003$ & 0.24 \\
\hline & & post & $0.076 \pm 0.004$ & $0.078 \pm 0.004$ & \\
\hline \multirow{2}{*}{$\begin{array}{l}\text { Carbohydrate oxidation, } \\
\text { g/min }\end{array}$} & fasting & pre & $0.081 \pm 0.007$ & $0.072 \pm 0.006$ & 0.35 \\
\hline & & post & $0.098 \pm 0.003$ & $0.084 \pm 0.010$ & \\
\hline \multirow[t]{2}{*}{ Respiratory quotient } & fasting & pre & $0.79 \pm 0.06$ & $0.78 \pm 0.01$ & 0.97 \\
\hline & & post & $0.80 \pm 0.07$ & $0.79 \pm 0.01$ & \\
\hline
\end{tabular}

Values are given as means \pm SEM and data were analysed using a two-way repeated measures ANOVA, with time (pre, post) and intervention (GOS $(n=21)$, placebo $(n=23))$. No significant effects were detected. Abbreviations: GOS, galacto-oligosaccharides. 


\section{Discussion}

In the present well-controlled human study, effects of GOS supplementation on measurements of microbiota composition, functionality (SCFA) and detailed host metabolic phenotyping were combined. We demonstrated that 12-week GOS supplementation markedly increased the abundance of faecal Bifidobacterium without significant effects on overall microbial richness or diversity. Importantly, this specific bifidogenic effect did neither translate into alterations of faecal or plasma SCFA concentrations, nor into changes in systemic concentrations of gut-derived hormones, and systemic inflammatory markers. In addition, no significant alterations in peripheral and adipose tissue insulin sensitivity, body composition, energy and substrate metabolism, and circulating metabolites were found.

GOS supplementation (15g/day) for 12 weeks increased the abundance of Bifidobacterium in faeces is in accordance with previous studies, showing bifidogenic effects of different types of GOS in infants and adults. ${ }^{13,14,19,35-37}$ However, GOS supplementation did not change metabolic deviations in the prediabetic obese participants. Dependent on substrate availability, fermentation by Bifidobacterium mainly results in the production of lactate and acetate as end products. ${ }^{38}$ Indeed, fermentation of identical type of GOS as used in the present study showed pronounced increases of acetate concentrations in the validated TNO in vitro model of the colon (TIM-2). ${ }^{18}$ Remarkably, we did not observe an increase in faecal or plasma acetate in vivo despite an average 5.0-fold increase in Bifidobacterium. Noteworthy, we measured faecal and plasma SCFA in fasted conditions and, therefore, cannot exclude that postprandial acetate concentration may have been higher in the GOS group.

Most of the GOS fermentation may have occurred in the caecum and the proximal part of the colon. ${ }^{16}$ We previously demonstrated that distal, but not proximal, colonic acetate infusions increased fat oxidation and increased circulating levels of acetate and PYY in overweight men. ${ }^{16}$ In line, we have demonstrated in overweight men that administration of SCFA mixtures into the distal colon increased circulating acetate concentrations. Interestingly, the increase in systemic acetate concentrations was positively associated with the increase in fat oxidation and energy expenditure. ${ }^{17}$ Noteworthy, Den Besten et al. $^{39}$ have indicated that a significant amount of acetate is converted to other metabolites, in particular to butyrate, in the caecum of mice via microbial cross-feeding. ${ }^{39}$ Interestingly, GOS supplementation for 3 weeks to an adult population over 50 years of age increased the production of butyrate, but not of acetate, in a three-stage in vitro fermentation model using their faecal inocula. ${ }^{40}$ Butyrate is a primary energy source for colonocytes and is mainly metabolized in the 
colon, ${ }^{15}$ which might explains why no alterations in faecal and in fasting butyrate concentrations were observed. The conversion of acetate might result in a decreased supply of acetate to the liver, where acetate is further metabolized. Thus, both the site of fermentation of GOS and the conversion of acetate into other metabolites may have led to an insufficient increase in systemic acetate concentrations to induce pronounced metabolic effects. Therefore, future research should focus on strategies to increase acetate concentrations specifically in the distal part of the colon in the longer-term. Such strategies could include the production of slow-fermentable acetogenic foods. ${ }^{41}$

The marked GOS-induced microbial changes without impact on energy and substrate metabolism, inflammatory profile and insulin sensitivity in the present study are in contrast to some, ${ }^{13-15,42}$ but not all, ${ }^{15,43}$ previous human studies using GOS or FOS. A crossover study by Vulevic et al. ${ }^{13}$ indicated that a 12-week supplementation of a GOS mixture (5.5 g per day) increased the abundance of Bifidobacterium, and decreased systemic inflammatory markers, fasting insulin, cholesterol and triglyceride concentrations in overweight participants. ${ }^{13}$ In line, the same research group supplemented this GOS mixture to healthy elderly volunteers and found a bifidogenic effect. In addition, after GOS treatment, LPS-stimulated production of IL-6, IL-1 TNF- $\alpha$ was lowered from isolated peripheral blood mononuclear cells in an ex vivo experiment. ${ }^{14}$ One of the explanations for the different metabolic outcomes between these studies and the present study might be the difference in the population, which differed with respect to age and metabolic health status.

Ageing, obesity and insulin resistance have been associated with alterations in gut microbiota composition and microbial richness and diversity, as well as with a reduction of Bifidobacterium specifically. ${ }^{44-47}$ However, there remain inconsistencies, especially between human studies, regarding the aforementioned altered features of the microbiome. ${ }^{48}$ Compared to animal experiments, the human microbiome is exposed to fundamentally different environmental factors that extend beyond the intervention alone such as heterogeneity of human (sub)population with regards to genetics, lifestyle and diet. ${ }^{49}$ Therefore, differences in the study population may explain inconsistent findings in literature. For instance we included prediabetic overweight/obese men and postmenopausal women aged between 45 and 70 years, whereas Vulevic et al. ${ }^{13,14}$ investigated either a metabolically healthy, normal weight or slightly overweight elderly population, or overweight, but more insulin sensitive and younger adults.

Indeed, when we compared the Bifidobacterium of our study population with that of healthy, lean adults using the same methodology, the baseline abundance of Bifidobacterium was markedly lower in our population, but reached after the GOS 
intervention slightly higher abundance of Bifidobacterium compared to this healthy population without treatment (unpublished data, Laboratory of Microbiology, Wageningen UR, Wageningen, The Netherlands). Amongst gut homeostasis and immune response, these differences in microbial composition could also influence fermentation rate and, therefore, the production of SCFA from GOS and associated metabolic health effects. Of note, there are strong indications that the gut microbiome of adults with obesity and insulin resistance has a lower capacity to completely ferment and breakdown complex carbohydrates as compared to the microbiome from lean and metabolically healthy individuals. ${ }^{50,51}$ Unfortunately, Vulevic et al. ${ }^{13,14}$ did not investigate plasma or faecal SCFA concentrations after GOS supplementation. We, therefore, cannot exclude that phenotype-related differences in microbial fermentation rates and subsequent increased colonic and peripheral acetate availability is the factor leading to the differences in metabolic health effects between these previously published studies using $\operatorname{GOS}^{13,14}$ and the present study. Furthermore, the metabolic imbalance and related progressed dysbiosis in our obese prediabetic population might have hampered improved metabolic effect via the altered microbial composition. ${ }^{44-47}$ Therefore, the relevance of specific gut microbiota manipulation between different metabolic phenotypes, i.e. insulin resistant versus insulin sensitive, should be investigated in more detail in future studies.

In conclusion, we demonstrated in this well-controlled study, in which participants were phenotyped in detail, that 12-week supplementation of GOS in prediabetic men and women increased the abundance of Bifidobacterium yet no alterations in plasma or faecal SCFA, peripheral insulin sensitivity, energy and substrate metabolism, and low-grade inflammation was observed. Hence, the present study implies that a considerable diet-related increase in Bifidobacterium does not significantly affect insulin sensitivity and parameters of the host substrate and energy metabolism immediately in a prediabetic population with overweight or obesity. 


\section{References}

1. Delzenne NM, Cani PD, Everard A, et al. Gut microorganisms as promising targets for the management of type 2 diabetes. Diabetologia 2015;58:2206-2217.

2. Diamant M, Blaak E, De Vos W. Do nutrient-gut-microbiota interactions play a role in human obesity, insulin resistance and type 2 diabetes? Obesity Reviews 2011;12:272281.

3. Clemente JC, Ursell LK, Parfrey LW, et al. The impact of the gut microbiota on human health: an integrative view. Cell 2012;148:1258-1270.

4. Robertson MD, Bickerton AS, Dennis AL, et al. Insulin-sensitizing effects of dietary resistant starch and effects on skeletal muscle and adipose tissue metabolism. The American journal of clinical nutrition 2005;82:559-567.

5. Vrieze A, Out C, Fuentes S, et al. Impact of oral vancomycin on gut microbiota, bile acid metabolism, and insulin sensitivity. Journal of hepatology 2014;60:824-831.

6. Vrieze A, Van Nood E, Holleman F, et al. Transfer of intestinal microbiota from lean donors increases insulin sensitivity in individuals with metabolic syndrome. Gastroenterology 2012;143:913-916. e7.

7. Hulston CJ, Churnside AA, Venables MC. Probiotic supplementation prevents high-fat, overfeeding-induced insulin resistance in human subjects. British Journal of Nutrition 2015;113:596-602.

8. Mikkelsen KH, Allin KH, Knop FK. Effect of antibiotics on gut microbiota, glucose metabolism and bodyweight regulation-a review of the literature. Diabetes, Obesity and Metabolism 2016;doi/10.1111/dom.12637.

9. Kellow NJ, Coughlan MT, Reid CM. Metabolic benefits of dietary prebiotics in human subjects: a systematic review of randomised controlled trials. British Journal of Nutrition 2014;111:1147-1161.

10. Ruan Y, Sun J, He J, et al. Effect of Probiotics on Glycemic Control: A Systematic Review and Meta-Analysis of Randomized, Controlled Trials. PloS one 2015;10:e0132121.

11. Roberfroid M, Gibson GR, Hoyles L, et al. Prebiotic effects: metabolic and health benefits. British Journal of Nutrition 2010;104:S1-S63.

12. Delzenne NM, Neyrinck AM, Cani PD. Gut microbiota and metabolic disorders: how prebiotic can work? British Journal of Nutrition 2013;109:S81-S85.

13. Vulevic J, Juric A, Tzortzis $G$, et al. A mixture of trans-galactooligosaccharides reduces markers of metabolic syndrome and modulates the fecal microbiota and immune function of overweight adults. The Journal of nutrition 2013;143:324-331.

14. Vulevic J, Drakoularakou A, Yaqoob P, et al. Modulation of the fecal microflora profile and immune function by a novel trans-galactooligosaccharide mixture (B-GOS) in healthy elderly volunteers. The American journal of clinical nutrition 2008;88:14381446.

15. Canfora EE, Jocken JW, Blaak EE. Short-chain fatty acids in control of body weight and insulin sensitivity. Nat Rev Endocrinol 2015;11:577-591.

16. van der Beek $\mathrm{CM}$, Canfora $\mathrm{EE}$, Lenaerts $\mathrm{K}$, et al. Distal, but not proximal, colonic acetate infusions promote fat oxidation and improve metabolic markers in overweight men. Doctoral Thesis Emanuel Canfora 2016; Chapter 3.

17. Canfora EE, van der Beek CM, Jocken JW, et al. Colonic infusions of short-chain fatty acid mixtures promote energy metabolism in overweight men. Doctoral Thesis Emanuel Canfora 2016; Chapter 4.

18. Maathuis AJ, van den Heuvel EG, Schoterman MH, et al. Galacto-oligosaccharides have prebiotic activity in a dynamic in vitro colon model using a 13C-labeling technique. The Journal of nutrition 2012;142:1205-1212. 
19. Holscher HD, Faust KL, Czerkies LA, et al. Effects of prebiotic-containing infant formula on gastrointestinal tolerance and fecal microbiota in a randomized controlled trial. Journal of Parenteral and Enteral Nutrition 2012;36:95S-105S.

20. Wendel-Vos GW, Schuit AJ, Saris WH, et al. Reproducibility and relative validity of the short questionnaire to assess health-enhancing physical activity. Journal of clinical epidemiology 2003;56:1163-1169.

21. DeFronzo RA, Tobin JD, Andres R. Glucose clamp technique: a method for quantifying insulin secretion and resistance. American Journal of Physiology-Gastrointestinal and Liver Physiology 1979;237:G214-G223.

22. Jaquet $D$, Gaboriau $A$, Czernichow $P$, et al. Insulin resistance early in adulthood in subjects born with intrauterine growth retardation. J Clin Endocrinol Metab 2000;85:1401-6.

23. Weir JB. New methods for calculating metabolic rate with special reference to protein metabolism. J Physiol 1949;109:1-9.

24. Frayn KN. Calculation of substrate oxidation rates in vivo from gaseous exchange. J Appl Physiol 1983;55:628-34.

25. Orskov C, Rabenhoj L, Wettergren A, et al. Tissue and plasma concentrations of amidated and glycine-extended glucagon-like peptide $\mathrm{I}$ in humans. Diabetes 1994;43:535-9.

26. Froon AH, Dentener MA, Greve JWM, et al. Lipopolysaccharide toxicity-regulating proteins in bacteremia. Journal of Infectious Diseases 1995;171:1250-1257.

27. Garcia-Villalba R, Gimenez-Bastida JA, Garcia-Conesa MT, et al. Alternative method for gas chromatography-mass spectrometry analysis of short-chain fatty acids in faecal samples. J Sep Sci 2012;35:1906-13.

28. van Eijk HM, Bloemen JG, Dejong CH. Application of liquid chromatography,äìmass spectrometry to measure short chain fatty acids in blood. Journal of Chromatography B 2009;877:719-724.

29. Salonen A, Nikkilä J, Jalanka-Tuovinen J, et al. Comparative analysis of fecal DNA extraction methods with phylogenetic microarray: effective recovery of bacterial and archaeal DNA using mechanical cell lysis. Journal of microbiological methods 2010;81:127-134.

30. Rajilić-Stojanović M, Heilig HG, Molenaar D, et al. Development and application of the human intestinal tract chip, a phylogenetic microarray: analysis of universally conserved phylotypes in the abundant microbiota of young and elderly adults. Environmental microbiology 2009;11:1736-1751.

31. Lahti L, Elo LL, Aittokallio T, et al. Probabilistic analysis of probe reliability in differential gene expression studies with short oligonucleotide arrays. IEEE/ACM Transactions on Computational Biology and Bioinformatics (TCBB) 2011;8:217-225.

32. Bates D, Maechler M, Bolker B, et al. Package 'Ime4'. convergence 2015;12:1.

33. Bates $D$, Mächler $M$, Bolker $B$, et al. Fitting linear mixed-effects models using Ime4. arXiv preprint arXiv:1406.5823 2014.

34. Oksanen J, Blanchet FG, Kindt R, et al. Package 'vegan'. Community ecology package, version 2013;2.

35. Depeint F, Tzortzis G, Vulevic J, et al. Prebiotic evaluation of a novel galactooligosaccharide mixture produced by the enzymatic activity of Bifidobacterium bifidum NCIMB 41171, in healthy humans: a randomized, double-blind, crossover, placebo-controlled intervention study. The American journal of clinical nutrition 2008;87:785-791.

36. Sierra C, Bernal M-J, Blasco J, et al. Prebiotic effect during the first year of life in healthy infants fed formula containing GOS as the only prebiotic: a multicentre, randomised, double-blind and placebo-controlled trial. European journal of nutrition 2015;54:89-99. 
37. Vulevic J, Juric A, Walton GE, et al. Influence of galacto-oligosaccharide mixture (BGOS) on gut microbiota, immune parameters and metabonomics in elderly persons. British Journal of Nutrition 2015;114:586-595.

38. Rossi M, Corradini C, Amaretti A, et al. Fermentation of fructooligosaccharides and inulin by bifidobacteria: a comparative study of pure and fecal cultures. Applied and environmental microbiology 2005;71:6150-6158.

39. den Besten $G$, Lange $K$, Havinga R, et al. Gut-derived short-chain fatty acids are vividly assimilated into host carbohydrates and lipids. American Journal of PhysiologyGastrointestinal and Liver Physiology 2013;305:G900-G910.

40. Walton $\mathrm{GE}$, van den Heuvel EG, Kosters $\mathrm{MH}$, et al. A randomised crossover study investigating the effects of galacto-oligosaccharides on the faecal microbiota in men and women over 50 years of age. British Journal of Nutrition 2012;107:1466-1475.

41. Kaur A, Rose DJ, Rumpagaporn P, et al. In Vitro Batch Fecal Fermentation Comparison of Gas and Short-Chain Fatty Acid Production Using "Slowly Fermentable" Dietary Fibers. Journal of food science 2011;76:H137-H142.

42. Parnell JA, Reimer RA. Weight loss during oligofructose supplementation is associated with decreased ghrelin and increased peptide $Y Y$ in overweight and obese adults. The American journal of clinical nutrition 2009;89:1751-1759.

43. Dewulf E, Cani P, Claus S, et al. Insight into the prebiotic concept: lessons from an exploratory, double blind intervention study with inulin-type fructans in obese women. Gut 2013;62:1112-1121.

44. O'Toole PW, Jeffery IB. Gut microbiota and aging. Science 2015;350:1214-1215.

45. Ley RE. Obesity and the human microbiome. Current opinion in gastroenterology 2010;26:5-11.

46. Tremaroli V, Bäckhed F. Functional interactions between the gut microbiota and host metabolism. Nature 2012;489:242-249.

47. Saraswati S, Sitaraman R. Aging and the human gut microbiota-from correlation to causality. Frontiers in microbiology 2013;5.

48. Walters WA, Xu Z, Knight R. Meta-analyses of human gut microbes associated with obesity and IBD. FEBS letters 2014;588:4223-4233.

49. Hermes G, Zoetendal E, Smidt H. Molecular ecological tools to decipher the role of our microbial mass in obesity. Beneficial microbes 2014;6:61-81.

50. Ridaura VK, Faith JJ, Rey FE, et al. Gut microbiota from twins discordant for obesity modulate metabolism in mice. Science 2013;341:1241214.

51. Khan MT, Nieuwdorp M, Bäckhed F. Microbial modulation of insulin sensitivity. Cell metabolism 2014;20:753-760. 


\section{SUPPLEMENTARY DATA}

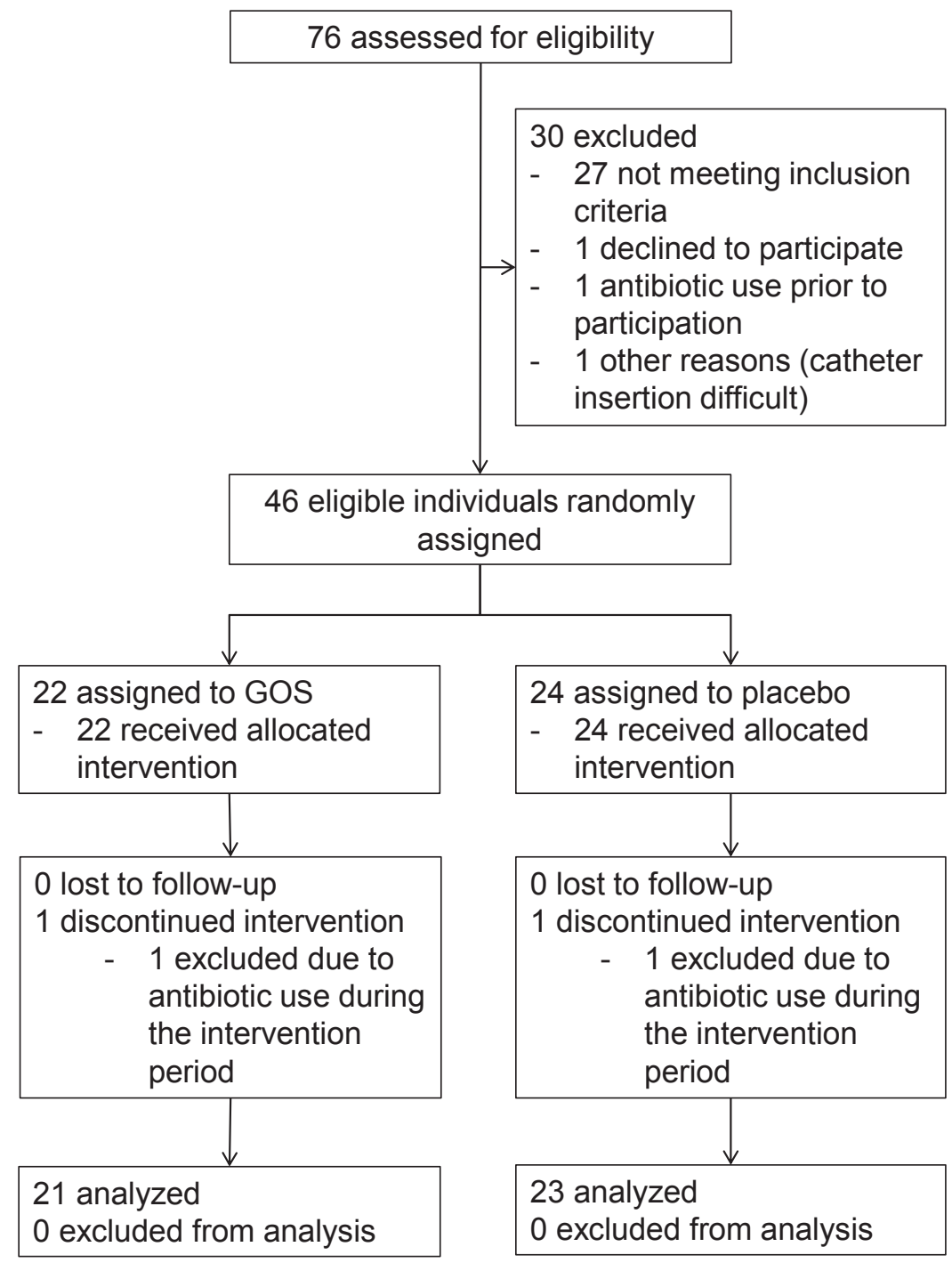

Supplementary Figure 1. Flow diagram of human participants included in this study 

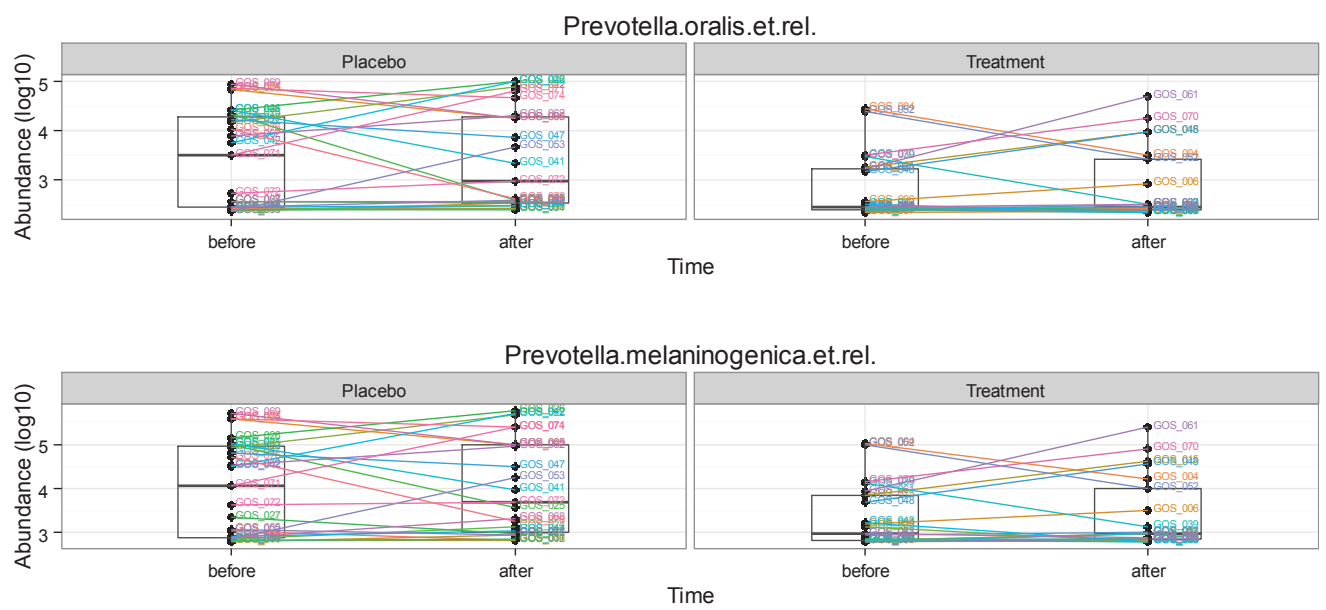

Bacteroides.stercoris.et.rel.

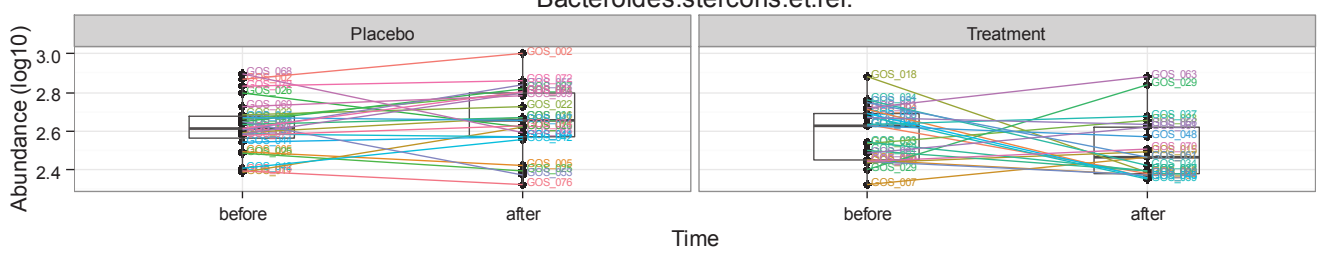

Sutterella.wadsworthia.et.rel.

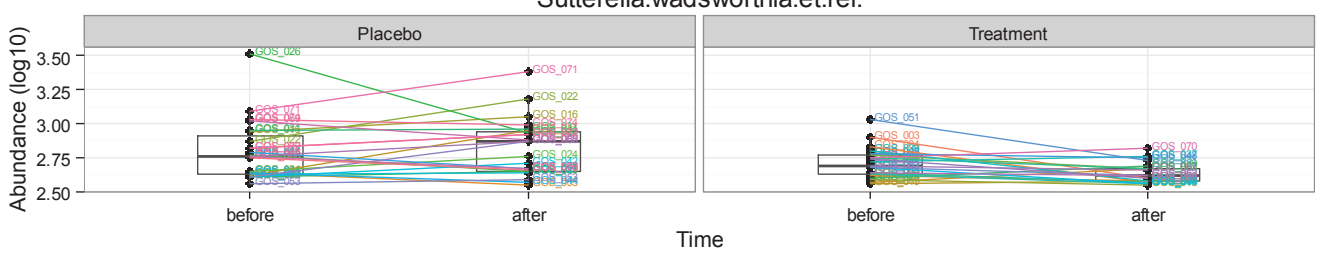

Supplementary Figure 2. Gut microbiota composition before (Pre) and after (Post) GOS and placebo intervention. Prevetoella oralis, Prevotella melaninogenica, Bacteroides stercoris, Sutterella wadsworthia relative abundance $\left(\log _{10}\right.$ signal intensity) as individual changes for the GOS group $(n=21)$ and placebo group ( $n=23)$, pre and post $12-$ week supplementation with GOS or placebo. Abbreviations: GOS, galactooligosaccharides. 
Supplementary Table 1. Food intake and physical activity scores (SQUASH) pre and post GOS and placebo intervention.

\begin{tabular}{|c|c|c|c|c|c|c|c|}
\hline \multirow[b]{2}{*}{ Time } & \multicolumn{3}{|c|}{$\operatorname{GOS}(n=21)$} & \multicolumn{3}{|c|}{ Placebo $(n=23)$} & \multirow[t]{2}{*}{$P$ - value } \\
\hline & Baseline & Week 6 & Week 12 & Baseline & Week 6 & Week 12 & \\
\hline \multirow[t]{2}{*}{ Energy intake (kcal) } & $2456 \pm$ & $2470 \pm$ & $2226 \pm$ & $2235 \pm$ & $2282 \pm$ & $2198 \pm$ & 0.513 \\
\hline & 165 & 145 & 110 & 132 & 112 & 131 & \\
\hline Fat intake (g) & $101 \pm 10$ & $83 \pm 6$ & $79 \pm 7$ & $87 \pm 7$ & $78 \pm 6$ & $78 \pm 7$ & 0.456 \\
\hline \multirow{2}{*}{$\begin{array}{l}\text { Carbohydrate intake } \\
\text { (g) }\end{array}$} & $256 \pm 20$ & $262 \pm 20$ & $247 \pm 15$ & $242 \pm 15$ & $252 \pm 14$ & $243 \pm 16$ & 0.873 \\
\hline & $104 \pm 9$ & $112 \pm 6$ & $105 \pm 4$ & $88 \pm 4$ & $97 \pm 4$ & $98 \pm 4$ & 0.589 \\
\hline \multicolumn{8}{|l|}{ Protein intake (g) } \\
\hline Meeting Dutch & 18 & 18 & 18 & 17 & 19 & 18 & 0.740 \\
\hline \multirow{2}{*}{\multicolumn{8}{|c|}{$\begin{array}{l}\text { guidelines for physical } \\
\text { activity (n) }\end{array}$}} \\
\hline & & & & & & & \\
\hline Light physical activity & $1009 \pm$ & $1188 \pm$ & $1342 \pm$ & $1342 \pm$ & $1090 \pm$ & $1414 \pm$ & 0.310 \\
\hline (min/week) & 172 & 189 & 226 & 207 & 877 & 236 & \\
\hline Moderate physical & $657 \pm 116$ & $581 \pm 73$ & $765 \pm 115$ & $703 \pm 124$ & $912 \pm$ & $744 \pm 122$ & 0.114 \\
\hline activity (min/week) & & & & & 814 & & \\
\hline $\begin{array}{l}\text { Vigorous physical } \\
\text { activity (min/week) }\end{array}$ & $53 \pm 21$ & $52 \pm 30$ & $84 \pm 36$ & $63 \pm 129$ & $75 \pm 38$ & $43 \pm 22$ & 0.223 \\
\hline
\end{tabular}

Values are given as means \pm SEM and data were analysed using a two-way repeated measures ANOVA, with time (pre, post) and intervention (GOS $(n=21)$, placebo $(n=23))$. Abbreviations: GOS, galactooligosaccharides 



\section{CHAPTER 7}

The role of polydextrose in body weight control and glucose regulation

Running title: PDX in body weight and glucose control

Emanuel E. Canfora and Ellen E. Blaak

Curr Opin Clin Nutr Metab Care (2015) 18, 395-400 


\section{Abstract}

Purpose of Review: The purpose of this Review was to highlight recent research developments on effects of the dietary fibre polydextrose (PDX) on appetite, satiety and energy intake, as well as on glucose metabolism. For, this purpose, clinically relevant human studies were reviewed and putative mechanisms and pathways were discussed.

Recent findings: A number of acute human intervention studies provide strong indications for an energy and glucose metabolism-regulating role of PDX. The effects might be mediated via a reduced gastrointestinal transit time, thereby decreasing glycaemia and insulinaemia. PDX might also alter the intestinal microbial composition, which can lead to changes in signalling in both peripheral and central pathways involved in energy metabolism and glucose homeostasis.

Summary: In acute studies, PDX seems to have inhibiting effect on energy intake and satiety, and to reduce glycaemic and insulinaemic response through effect on gastrointestinal transit time and macronutrient absorption, as well as through effects of microbial products such as short-chain fatty acids on energy and substrate metabolism. In particular, well-controlled human intervention studies are required to confirm these effects in the long term. Overall, to supplement PDX to the daily diet might be a promising approach for the management and treatment of obesity and associated metabolic disorders. 


\section{Key Points:}

- A relatively high number of short-term human intervention studies indicated beneficial effects of PDX on appetite, satiety and energy intake, as well as on glucose control.

- PDX might affect control of body weight and glucose by a decrease in gastrointestinal passage time, resulting in a delayed nutrient absorption and prolonged feeling of satiety.

- PDX might beneficially alter the colonic microbial composition, which can improve host's energy and glucose metabolism.

- The non-viscous soluble dietary fibre PDX is partly fermented by the colonic microbiota into SCFA.

- These SCFA might be strongly involved in the beneficial effects of PDX via the production of anorexic hormones, through effects on central appetite regulation and an improved inflammatory state. 
PDX in body weight and glucose control

\section{Introduction}

Dietary fibres are non-digestible food ingredients that include oligosaccharides, lignin, non-starch polysaccharides and analogous polysaccharides, which might have beneficial metabolic health effects, thereby resulting in a reduced risk for the development of obesity and type 2 diabetes mellitus (T2DM). ${ }^{1}$ Evidence is growing that an increased dietary fibre content in our daily diet might prevent weight gain and disturbances in glucose and lipid metabolism. ${ }^{2}$ Several mechanisms might explain these positive health effects First, the ability of dietary fibres to physically modify nutrient absorption could affect glycaemic and insulinaemic responses, which might, in the longer term, be related to T2DM development. ${ }^{3}$ Second, dietary fibre might alter the gut microbial composition, which might influence host's energy and substrate metabolism through local improvement of gut mucosal health, and/or by altering systemic biochemistry and/or signalling functions. $^{1}$

Dietary fibres can be classified by solubility, fermentation ability by colonic microbes and viscosity. The randomly polymerized branch-chained glucose polymer polydextrose (PDX) is nonviscous and completely soluble in water and cannot be hydrolysed by digestive enzymes, passing intact into the colon, in which it is partly fermented by the local microbiota. Studies have shown that PDX can act as a prebiotic and can beneficially modify the colonic microbial composition, which might have pronounced consequences for the host's lipid and glucose metabolism. These effects might be at least partly mediated through microbial metabolites including short-chain fatty acids (SCFA). ${ }^{4-6}$ PDX might also affect body weight and glucose control by a decrease in intestinal passage time, which results in prolonged feelings of satiety and a slower nutrient uptake, thereby improving postprandial glucose and insulin responses. ${ }^{7}$

This Review aims to provide an overview of available human studies indicating beneficial effects of PDX on body weight control, insulin sensitivity and glucose metabolism. Subsequently, putative mechanisms will be discussed in detail. 


\section{Comparative effects of polydextrose on energy intake, insulin sensitivity and glucose metabolism}

\section{Recent human studies}

Obesity develops under conditions of a positive energy balance. Any factor lowering energy intake or increasing energy expenditure would result in a negative energy homeostasis, and thus prevent the development of obesity and obesityrelated cardiometabolic disorders like T2DM.

Several human studies strongly implicate that PDX could be a useful food supplement to beneficially affect body weight control and glucose homeostasis. These trials focused on the acute or short-term effects of PDX. Hull et al. ${ }^{8}$ found a decreased feeling of hunger and a decreased energy intake when yoghurt-based drinks containing $12.5 \mathrm{~g}$ PDX were consumed $90 \mathrm{~min}$ before an ad-libitum lunch and dinner. Consistent with these observations, another acute study from Ranawana et al. ${ }^{9}$ showed that the consumption of a smoothie (containing $12 \mathrm{~g}$ of PDX) $60 \mathrm{~min}$ prior to lunch significantly reduced energy intake. Moreover, a dose-dependent decrease in energy intake was reported by Astbury et al. ${ }^{10}$, when 6.25, 12.5 and $25 \mathrm{~g}$ PDX were added to a liquid preload and consumed $90 \mathrm{~min}$ before an ad-libitum lunch. Konings et $a l^{7}{ }^{*}$ found a pronounced decrease in feeling of hunger, as determined by visual analogue scales, and an increase in whole-body fat oxidation, as well as a reduced postprandial peak glucose and insulin response when $30 \%$ of the daily carbohydrate intake was replaced by PDX at breakfast and lunch. In addition, Olli et al. $^{11} *$ showed that the supplementation of $15 \mathrm{~g}$ PDX to a high-fat meal reduced feelings of hunger, which was accompanied by increased plasma concentrations of the satiety-stimulating incretin glucagon-like peptide-1 (GLP-1).

To the author's knowledge, only two human longer-term intervention studies on PDX effects on energy homeostasis are published. An interesting study from Astbury et al. ${ }^{12 * *}$ showed a reduced total daily energy intake during experimental and free-living conditions when PDX and whey protein were incorporated in snack bars three times a day for 14 days. Interestingly, the PDX group showed reduced glucose and ghrelin concentrations and increased GLP-1 and peptide YY (PYY) responses. In another study from Costabile et al. ${ }^{5}$, patients consumed $8 \mathrm{~g}$ PDX in powder form for 21 days. The PDX group showed reduced consumption of snacks and increased intestinal butyrate-producing microbes, which have been associated 
PDX in body weight and glucose control

in several studies with improved insulin sensitivity and prevention of T2DM. ${ }^{13-15} \mathrm{~A}$ detailed overview of these human intervention studies can be found in table 1.

The above data provide indications that PDX might beneficially affect body weight control and glucose homeostasis through effects on satiety, substrate oxidation and glycaemic and insulinaemic responses. However, so far experiments were only performed in acute settings or during a relatively short intervention period (14 and 21 days), whilst long-term effects of PDX on control of body weight and glucose metabolism are missing. This clearly indicates the need to perform wellcontrolled long-term human intervention studies. In the following section putative mechanisms involved in these hypophagic and glucose-regulating effects of PDX will be discussed. 
Table 1: Recent human intervention studies investigating the effects of polydextrose on appetite, satiety, energy intake and glucose homeostasis

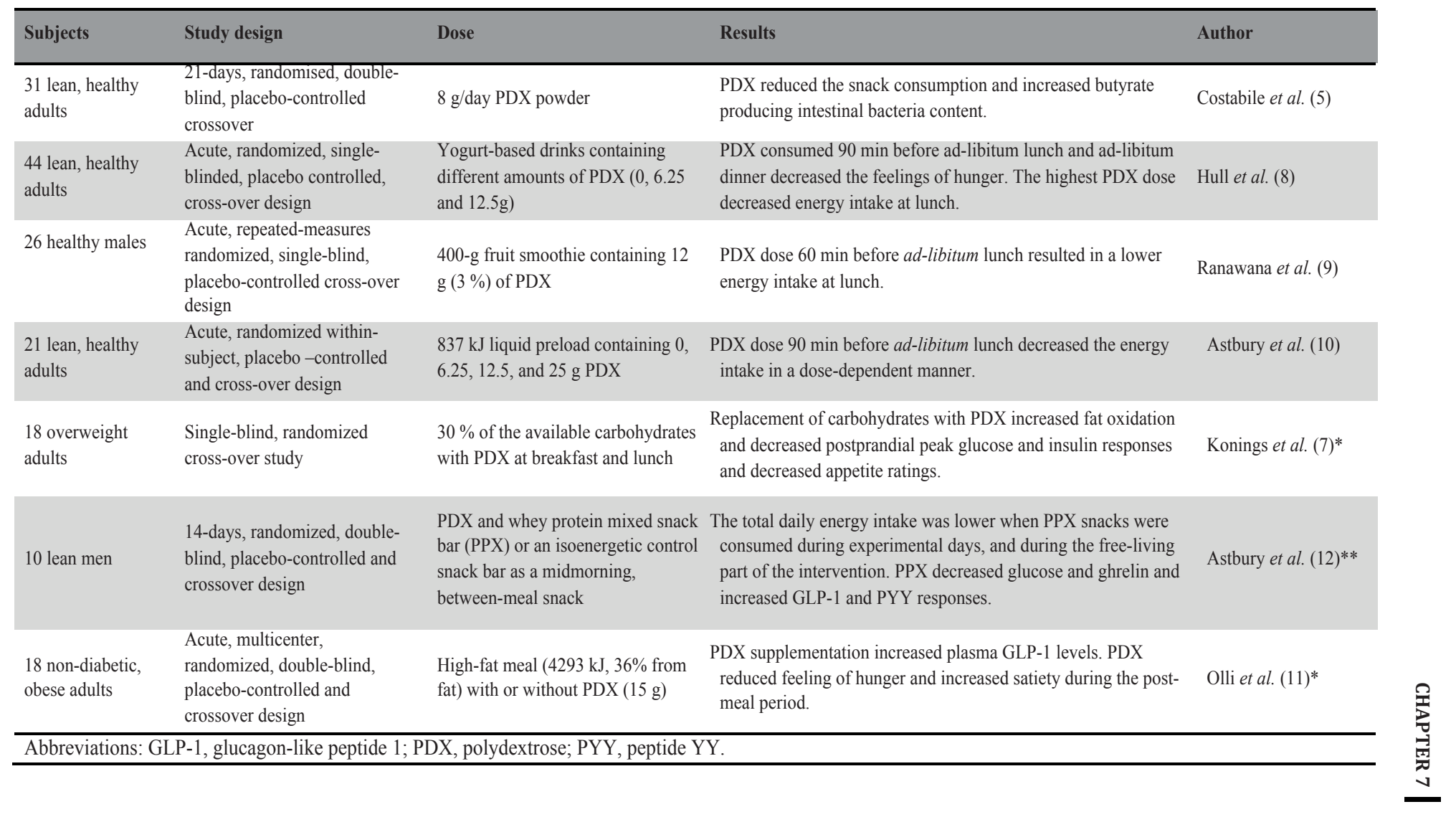


PDX in body weight and glucose control

\section{Putative mechanisms of polydextrose involved in the regulation of energy intake, insulin sensitivity and glucose metabolism}

\section{Polydextrose decreases the absorption of macronutrients}

Previously, the protective effects of soluble dietary fibres have been attributed to the ability to form viscous solutions that prolong gastric emptying, consequently attenuate the absorption of glucose and lipids and induce satiety. ${ }^{16}$ The non-viscous soluble PDX misses the physiochemical property of viscous dietary fibres to slow down gastric emptying. Therefore, other mechanisms must be involved in the effects of PDX on energy intake and glucose homeostasis described in the human studies above.

Of note, PDX was shown to shorten gastrointestinal transit time in constipated $^{17}$ and healthy subjects. ${ }^{18}$ The intestinal passage time is an important factor to determine amounts of absorbed nutrients. Decreased transit time might lead to a more gradual nutrient absorption in the proximal intestine and to prolonged feeling of satiety. The delayed nutrient uptake might reduce postprandial glucose and insulin response. ${ }^{7,12}$ These reduced glucose and insulin responses might further result in a decreased inhibition of lipolysis, higher circulating fatty acid concentrations and subsequent increased fat oxidation. In turn, an increase in postprandial fat oxidation rate might impact fat storage and satiety and can thereby beneficially affect body weight control on the long term. ${ }^{19}$ Furthermore, it might result in decreased ectopic fat accumulation, which is associated with improved insulin sensitivity and glucose metabolism. ${ }^{20}$ Reduced postprandial glycaemic and insulinaemic responses and a higher fat oxidation were shown in the acute study of Konings et al. ${ }^{7 *}$. However, in this study, it remains unclear if these effects are related to the slightly lower energetic value of the PDX diet compared with the control diet or with the PDX treatment per se. Further studies examining the effects of PDX on glucose absorption, substrate and energy utilization are needed.

\section{Polydextrose affects the intestinal microbiota}

As described above, when PDX enters the colon, it can be partly fermented by the local microbiota, thus serving as an energy source to promote their growth and survival. Recently evidence is growing rapidly that the gut microbiota might play an important role in glucose homeostasis, obesity and metabolic syndrome. ${ }^{21}$ In a human trial the bacterial DNA of faecal samples from 20 adult subjects were 
pyrosequenced before and after 21 days of PDX consumption. In this study, the content of well know producers of the SCFA butyrate, such as Faecalibacterium prausnitzii increased in number. ${ }^{4}$ Of note, these bacteria are known for their antiinflammatory property and found to be decreased in T2DM patients as compared to healthy subjects in two independent studies. ${ }^{14,15}$ However, other bacteria, such as Bifidobacterium, which are associated with a lean and metabolically healthy microbiome, ${ }^{22}$ were decreased after PDX treatment. In line, in the human crossover study of Costabile et al. ${ }^{5}$ an increase in the Eubacterium rectale-C. coccoides group, which includes important butyrate-producing microbes, such as Faecalibacterium prausnitzii and Ruminococcus intestinalis, were found after PDX consumption for three weeks. In this study no effects of the PDX treatment on Bifidobacterium were detected. ${ }^{5}$ Other human data, on the other hand, indicated that the number of Bifidobacterium was increased when PDX was consumed for three or six weeks. ${ }^{23,24}$ This discrepancy could reflect interindividual variances in initial gut microbial composition, but also showed that additional research is needed to claim PDX as a prebiotic. Overall, most evidence is supporting a PDX-induced increase in a microbial composition that favours an increased production of SCFA and an improved metabolic profile.

\section{Polydextrose increases the production of SCFA}

In vitro fermentation ${ }^{25}$ and in vivo data ${ }^{26}$ have shown that microbial PDX fermentation ends-up in the production of SCFA in particular acetate and butyrate. These SCFA might be involved in appetite regulation via the secretion of gut-derived satiety-stimulating hormones PYY and GLP-1 from L-cells in the ileum and colon. In mice, 4-week oral butyrate administration increased plasma GLP-1 and PYY concentrations. ${ }^{27}$ Moreover, a study in hyperinsulinaemic human females showed that acute rectal infusion of $200 \mathrm{mmol} / \mathrm{l}$ sodium acetate enhanced PYY plasma concentrations as compared to saline infusions. ${ }^{28}$ PYY is not only an appetite and satiety regulating hormone, ${ }^{29}$ it is also known to stimulate glucose-induced insulin secretion and insulin sensitivity. ${ }^{30}$ Furthermore, the beneficial role of GLP-1 on glucose homeostasis is well determined. It might increase insulin secretion, inhibition of glucagon production and increase pancreatic $\beta$-cell proliferation and function. ${ }^{31}$ Interestingly, as shown above, an increase in plasma levels of these gut hormones after PDX treatment was found in the study of Astbury et al. ${ }^{12 * *}$; and that was accompanied with a decrease in postprandial glucose response. 
Besides the stimulation of the production and secretion of anorectic hormones and glucose-regulating hormones, recently a novel and direct role of SCFA in the regulation of energy intake was discovered. An elegant study in mice using a PET-CT scan methodology has shown that intravenously and colonically administered

${ }^{11} \mathrm{C}$-acetate crossed the blood-brain barrier, and was taken up by the hypothalamus. Intraperitoneal injection of acetate acutely decreased food intake through appetite suppression accompanied by an increased lactate and gamma-aminobutyric acid production. ${ }^{32}$ Therefore, acetate might also be an important central regulator of satiety.

Acetate and butyrate might not only regulate energy intake; they might also increase energy utilization. It has been shown in obese mice that oral administration of sodium butyrate elicits body weight loss, via an increased energy expenditure and fat oxidation. ${ }^{33}$ In addition, oral acetate and butyrate administration to high-fat fed mice reduced body weight and improved insulin sensitivity without changing food intake or physical activity. ${ }^{34}$ Furthermore, a study showed that butyrate stimulate intestinal gluconeogenesis (IGN) via a gut-brain neural circuit. ${ }^{35}$ In wild-type mice, a butyrate-enriched diet improved glucose tolerance, insulin sensitivity and body weight control, whilst these beneficial metabolic effects were completely abolished in mice deficient in IGN. ${ }^{35}$ The induction of IGN promotes glucose release in the portal vein, which might lead through a brain-related mechanism, to decreased hepatic glucose production and increased satiety and energy expenditure. ${ }^{36}$

SCFA might also beneficially affect insulin sensitivity and glucose homeostasis via a reduction of pro-inflammatory cytokines in the long term. The immunemodulatory effects of SCFA have mainly been demonstrated in in vitro studies. Acetate and butyrate treatment decreased lipopolysaccharide (LPS)- stimulated tumour necrosis factor-alpha (TNF- $\alpha$ ) release from human neutrophils. ${ }^{37}$ In line, sodium acetate and sodium butyrate incubation of LPS-stimulated RAW264.7 macrophage-like cells reduced the production of proinflammatory cytokines and LPS-induced nuclear factor kappa-light-chain-enhancer of activated B cells (NF-KB) activation. ${ }^{38}$ Moreover, a human in vivo crossover study showed that circulating TNF$\alpha$ concentrations were reduced after acute intravenous sodium acetate $(20 \mathrm{mmol}$ in $100 \mathrm{ml}$ sterile water) and rectal sodium acetate (60 mmol in $300 \mathrm{ml}$ water) infusions, when compared to intravenous and rectal saline infusion. ${ }^{28}$ So far, no human data are present investigating the effects of PDX on intestinal or circulating inflammatory markers. Nevertheless, PDX enrichment in suckling piglets resulted in increased ileal 
SCFA concentrations and associated reductions in ileal expression of proinflammatory markers TNF $\alpha$, interleukin 1-beta (IL-1 ), and interleukin 8 (IL-8). ${ }^{39}$ Overall, there are indications that the production of SCFA is one of the links between PDX and the decreased satiety and energy intake and improved glucose homeostasis found in the human studies. However, more information is required on the direct relation between the PDX induced putative effects on appetite, satiety, energy intake and glucose metabolism and SCFA production and absorption rates. 
PDX in body weight and glucose control

\section{Conclusion}

The relatively high number of acute human intervention studies indicating beneficial effects of PDX on appetite, satiety and energy intake, tempt to draw the conclusion that PDX is a potent approach for the prevention and treatment of obesity and comorbidities. However, human long-term data are currently missing and putative mechanisms, such as changes in the gut microbiota composition and in SCFA productions, have to be studied in more detail. In addition, the effects of PDX as a glucose lowering and insulin-sensitizing agent need further investigations. Wellcontrolled and well-phenotyped human intervention studies are required to confirm these effects in the long term. These studies should focus on the long-term effects of PDX on glycaemia and insulinaemia. Furthermore, they should study alterations in gut microbiota composition, SCFA production and absorption rates, as well as gut signalling, induced by microbial products, in relation to metabolic health. These data could provide knowledge, which might be translated into novel strategies for the management and treatment of obesity and related metabolic disorders. 


\section{References}

1. Kaczmarczyk MM, Miller MJ, Freund GG. The health benefits of dietary fiber: beyond the usual suspects of type 2 diabetes mellitus, cardiovascular disease and colon cancer. Metabolism 2012;61:1058-1066.

2. Kellow NJ, Coughlan MT, Reid CM. Metabolic benefits of dietary prebiotics in human subjects: a systematic review of randomised controlled trials. British Journal of Nutrition 2014;111:1147-1161.

3. Blaak E, Antoine JM, Benton D, et al. Impact of postprandial glycaemia on health and prevention of disease. obesity reviews 2012;13:923-984.

4. Hooda S, Boler BMV, Serao MCR, et al. 454 pyrosequencing reveals a shift in fecal microbiota of healthy adult men consuming polydextrose or soluble corn fiber. The Journal of nutrition 2012;142:1259-1265.

5. Costabile A, Fava F, Röytiö H, et al. Impact of polydextrose on the faecal microbiota: a double-blind, crossover, placebo-controlled feeding study in healthy human subjects. British Journal of Nutrition 2012;108:471-481.

6. den Besten G, van Eunen K, Groen AK, et al. The role of short-chain fatty acids in the interplay between diet, gut microbiota, and host energy metabolism. Journal of Lipid Research 2013;54:2325.

7. Konings E, Schoffelen PF, Stegen J, et al. Effect of polydextrose and soluble maize fibre on energy metabolism, metabolic profile and appetite control in overweight men and women. British Journal of Nutrition 2014;111:111-121.

8. Hull $\mathrm{S}, \mathrm{Re} \mathrm{R}$, Tiihonen $\mathrm{K}$, et al. Consuming polydextrose in a mid-morning snack increases acute satiety measurements and reduces subsequent energy intake at lunch in healthy human subjects. Appetite 2012;59:706-712.

9. Ranawana V, Muller A, Henry CJK. Polydextrose: its impact on short-term food intake and subjective feelings of satiety in males-a randomized controlled crossover study. European journal of nutrition 2013;52:885-893.

10. Astbury NM, Taylor MA, Macdonald IA. Polydextrose results in a dose-dependent reduction in ad libitum energy intake at a subsequent test meal. British Journal of Nutrition 2013;110:934-942.

11. Olli K, Salli K, Alhoniemi E, et al. Postprandial effects of polydextrose on satiety hormone responses and subjective feelings of appetite in obese participants. Nutrition journal 2015;14:2.

12. Astbury NM, Taylor MA, French SJ, et al. Snacks containing whey protein and polydextrose induce a sustained reduction in daily energy intake over 2 wk under free-living conditions. The American journal of clinical nutrition 2014;99:1131-1140.

13. Vrieze $A$, Out $C$, Fuentes $S$, et al. Impact of oral vancomycin on gut microbiota, bile acid metabolism, and insulin sensitivity. Journal of hepatology 2014;60:824-831.

14. Qin J, Li Y, Cai Z, et al. A metagenome-wide association study of gut microbiota in type 2 diabetes. Nature 2012;490:55-60.

15. Karlsson FH, Tremaroli V, Nookaew I, et al. Gut metagenome in European women with normal, impaired and diabetic glucose control. Nature 2013;498:99-103.

16. Wanders A, Mars M, Borgonjen-Van Den Berg K, et al. Satiety and energy intake after single and repeated exposure to gel-forming dietary fiber: post-ingestive effects. International Journal of Obesity 2014;38:794-800.

17. Magro DO, de Oliveira LMR, Bernasconi I, et al. Effect of yogurt containing polydextrose, Lactobacillus acidophilus NCFM and Bifidobacterium lactis HN019: a randomized, double-blind, controlled study in chronic constipation. Nutrition journal 2014;13:75. 
18. Timm DA, Thomas W, Boileau TW, et al. Polydextrose and soluble corn fiber increase five-day fecal wet weight in healthy men and women. The Journal of nutrition 2013;143:473-478.

19. Astrup A. The relevance of increased fat oxidation for body-weight management: metabolic inflexibility in the predisposition to weight gain. Obesity reviews 2011;12:859-865.

20. Shulman GI. Ectopic Fat in Insulin Resistance, Dyslipidemia, and Cardiometabolic Disease. New England Journal of Medicine 2014;371:1131-1141.

21. Diamant M, Blaak E, De Vos W. Do nutrient-gut-microbiota interactions play a role in human obesity, insulin resistance and type 2 diabetes? Obesity Reviews 2011;12:272-281.

22. Million $M$, Maraninchi $M$, Henry $M$, et al. Obesity-associated gut microbiota is enriched in Lactobacillus reuteri and depleted in Bifidobacterium animalis and Methanobrevibacter smithii. International journal of obesity 2012;36:817-825.

23. Vester Boler BM, Rossoni Serao MC, Bauer LL, et al. Digestive physiological outcomes related to polydextrose and soluble maize fibre consumption by healthy adult men. British Journal of Nutrition 2011;106:1864-1871.

24. Beards E, Tuohy K, Gibson G. A human volunteer study to assess the impact of confectionery sweeteners on the gut microbiota composition. British journal of nutrition 2010;104:701-708.

25. Mäkeläinen $H$, Saarinen $M$, Stowell J, et al. Xylo-oligosaccharides and lactitol promote the growth of Bifidobacterium lactis and Lactobacillus species in pure cultures. Beneficial microbes 2010;1:139-148.

26. Fava $\mathrm{F}$, Mäkivuokko $\mathrm{H}$, Siljander-Rasi $\mathrm{H}$, et al. Effect of polydextrose on intestinal microbes and immune functions in pigs. British journal of nutrition 2007;98:123-133.

27. Lin HV, Frassetto A, Kowalik Jr EJ, et al. Butyrate and Propionate Protect against Diet-Induced Obesity and Regulate Gut Hormones via Free Fatty Acid Receptor 3Independent Mechanisms. PLoS ONE 2012;7:e35240.

28. Freeland KR, Wolever T. Acute effects of intravenous and rectal acetate on glucagonlike peptide-1, peptide $Y Y$, ghrelin, adiponectin and tumour necrosis factor-alpha. British Journal of Nutrition 2010;103:460-466.

29. De Silva A, Bloom SR. Gut hormones and appetite control: a focus on PYY and GLP-1 as therapeutic targets in obesity. Gut and liver 2012;6:10-20.

30. Manning S, Batterham RL. The role of gut hormone peptide YY in energy and glucose homeostasis: twelve years on. Annual review of physiology 2014;76:585-608.

31. Delzenne N, Blundell J, Brouns F, et al. Gastrointestinal targets of appetite regulation in humans. obesity reviews 2010;11:234-250.

32. Frost G, Sleeth ML, Sahuri-Arisoylu M, et al. The short-chain fatty acid acetate reduces appetite via a central homeostatic mechanism. Nature communications 2014;5.

33. Gao Z, Yin J, Zhang J, et al. Butyrate improves insulin sensitivity and increases energy expenditure in mice. Diabetes 2009;58:1509.

34. den Besten G, Bleeker A, Gerding A, et al. Short-Chain Fatty Acids protect against High-Fat Diet-Induced Obesity via a PPAR $\gamma$-dependent switch from lipogenesis to fat oxidation. Diabetes 2015:db141213.

35. De Vadder F, Kovatcheva-Datchary P, Goncalves D, et al. Microbiota-generated metabolites promote metabolic benefits via gut-brain neural circuits. Cell 2014;156:84-96.

36. Mithieux G, Gautier-Stein A. Intestinal glucose metabolism revisited. Diabetes research and clinical practice 2014;105:295-301. 
37. Tedelind S, Westberg F, Kjerrulf M, et al. Anti-inflammatory properties of the shortchain fatty acids acetate and propionate: a study with relevance to inflammatory bowel disease. World Journal of Gastroenterology 2007;13:2826.

38. Liu T, Li J, Liu Y, et al. Short-chain fatty acids suppress lipopolysaccharide-induced production of nitric oxide and proinflammatory cytokines through inhibition of NFKB pathway in RAW264. 7 cells. Inflammation 2012;35:1676-1684.

39. Herfel TM, Jacobi SK, Lin X, et al. Polydextrose enrichment of infant formula demonstrates prebiotic characteristics by altering intestinal microbiota, organic acid concentrations, and cytokine expression in suckling piglets. The Journal of nutrition 2011;141:2139-2145.

\section{Key references:}

Konings et al (2014) ${ }^{7 *}$ : This acute study showed that the replacement of carbohydrates with polydextrose increased fat oxidation and decreased appetite rating.

Olli et al (2015) ${ }^{11} *$ : In this acute study PDX supplementation reduced the feeling of hunger and increased satiety and plasma GLP-1 concentrations.

Astbury et al (2014) ${ }^{12 * *}$ : Key study in lean men demonstrating that the consumption of a combination of polydextrose and whey protein for 14 days reduced total daily energy intake and decreased glucose response. These effects might be explained by the increased satiety-stimulating incretins GLP-1 and PYY, which were increased in the postprandial state. 



\section{CHAPTER 8}

General discussion 
Obesity is a $21^{\text {st }}$ century pandemic and is associated with several severe metabolic disturbances and diseases, such as insulin resistance and type 2 diabetes mellitus. ${ }^{1-6}$ Obesity is characterised by a chronic positive energy balance, which leads to an excessive amount of fat mass. This might result in disturbed function of the adipose tissue and, subsequently, in the development of insulin resistance in various organs. ${ }^{7-11}$ Major factors involved in the process of obesity-induced insulin resistance are disturbances in the lipid buffering capacity of the adipose tissue, which result in lipid overflow in the circulation and ectopic fat storage in non-adipose tissues (i.e. liver, skeletal muscle and pancreas). ${ }^{9-11}$ Besides that, an impaired fat oxidation in tissues such as the skeletal muscle and liver might contribute to increased ectopic fat storage and accumulation of bioactive lipid metabolites, which may interfere with insulin signalling. ${ }^{12-14}$ In addition, obesity-induced low-grade inflammation in adipose tissue results in elevated amounts of cytokines and chemokines, which might also contribute to the development of insulin resistance. ${ }^{15-19}$

A major effort has been done to find strategies to prevent or even counteract obesity and its associated impairments in insulin sensitivity. However, the prevalence of obesity and type 2 diabetes mellitus, especially in our Western hemisphere, where up to $26 \%$ of the population suffers from obesity, raised dramatically and is expected to increase further in the coming decades. ${ }^{1}$ Consequently, improved and novel prevention and treatment strategies are urgently required.

In the last years, evidence that the gut microbiota and its products are involved in the aetiology of obesity and type 2 diabetes mellitus has been growing dramatically. ${ }^{20-26}$ One of the most promising mechanisms related to the impact of the gut microbiota on human substrate and energy metabolism is its fermentation capacity of indigestible foods, which ends up in the production of important metabolites including short-chain fatty acids (SCFA), mainly acetate, propionate and butyrate. ${ }^{27}$ Accumulating data, mostly derived from animal studies, have indicated that SCFA can beneficially affect body weight control and insulin sensitivity. ${ }^{28-34}$ Nevertheless, human data are scarce and, hence, the importance of SCFA in human energy and substrate metabolism remained to be established.

Therefore, in this thesis, we investigated the potential of SCFA to modulate whole-body substrate and energy metabolism in humans, by combining acute and longer term in vivo human intervention studies with an in vitro approach in human adipose tissue derived stem cells (hMADS) to investigate underlying mechanisms. First, the acute effects of colonic SCFA infusions in overweight men will be discussed. 
Secondly, the role of acetate, as putative major player in host physiology and metabolic health will be highlighted. Next, the outcomes of our longer-term dietary intervention study investigating the effects of the acetogenic prebiotic fibre(s) galacto-oligosaccharides (GOS) on gut microbiota composition, as well as on insulin sensitivity, substrate and energy metabolism in prediabetic adults with overweight and obesity, will be discussed. Finally, conclusions of these studies and future research directions are provided.

\section{Acute effects of colonic short-chain fatty acid infusions in overweight men}

Gut microbial-derived SCFA are believed to be involved in host metabolic health, as extensively reviewed in Chapter $\mathbf{2}$ of this thesis. Most data on the effects of SCFA on body weight control and glucose homeostasis are derived from animal studies. $^{28-36}$ These data showed that SCFA might reduce energy intake via modulating gut-derived satiety-stimulating hormones, and might affect adipose tissue function and lipid storage capacity, the inflammatory profile. In addition, SCFA might improve adipose tissue, liver and skeletal muscle oxidative capacity. ${ }^{28-36}$

Until now, there are only scarce human studies investigating the effects of SCFA on substrate and energy metabolism. In these studies SCFA are administered orally, ${ }^{37}$ intravenously, ${ }^{32,38,39}$ intragastrically $^{40}$ and rectally, ${ }^{32,41-43}$ of which the latter mode of administration reaches the distal part of the colon. However, most microbial SCFA production occurs already in the caecum and proximal part of the colon, while a smaller amount of SCFA is produced in the distal colon. ${ }^{44}$ Nevertheless, it remains unclear at which site of production, these SCFA induce metabolic effects in humans. Therefore, we first investigated in Chapter 3 whether the administration of sodium acetate in the proximal or distal part of the colon differentially affect human substrate and energy metabolism in overweight normoglycaemic men. To this end, we developed a unique endoscopic procedure, which allowed us to infuse acetate in the proximal and distal part of the colon during fasting and postprandial conditions. We demonstrated that distally, but not proximally, administered acetate modulates whole-body substrate oxidation, with a markedly increased fasting fat oxidation, a tendency towards increased systemic concentrations of acetate, increased concentrations of the satiety-stimulating hormone peptide YY (PYY), and slightly decreased plasma concentrations of the 
proinflammatory cytokine tumour necrosis factor-alpha (TNF- $\alpha$ ). Together, these data indicated that acetate administered in the distal colon might beneficially affect the metabolic profile in men.

Based on these outcomes we concluded that administration of SCFA in the distal part of the colon is an appropriate model to determine effects of gut-derived SCFA on the human substrate metabolism. Therefore, we decided to use enemas to administer physiologically relevant combinations of SCFA into the distal part of the colon in our follow-up study presented in Chapter 4. In this study, the effects of administration of three different SCFA mixtures (high in either acetate, propionate or butyrate) in the distal colon on metabolic parameters were assessed in twelve normoglycaemic men with overweight or obesity. The concentrations of SCFA in the different mixtures were based on in vitro fermentation studies of dietary fibres. Thus, all concentrations were in putatively physiological ranges that could be obtained through diet. ${ }^{45-48}$ We demonstrated that infusions of colonic SCFA mixtures markedly increase fasting fat oxidation and resting energy expenditure, which was accompanied by increased circulating acetate concentrations. In addition, all SCFA mixtures increased fasting and postprandial PYY concentrations and attenuated whole-body lipolysis and the SCFA mixture high in acetate slightly decreased concentrations of the proinflammatory cytokine interleukin-1 beta (IL-1ß).

\section{Short-chain fatty acids increase whole-body fat oxidation and energy expenditure}

The data presented in Chapter $\mathbf{3}$ and Chapter $\mathbf{4}$ showed that the infusions of sodium acetate and all three SCFA mixtures in the distal part of the colon markedly increased fat oxidation by $18-26 \%$, and increased resting energy expenditure (Chapter 4 ) by $\sim 4 \%$ as compared to saline infusions. Acetate that enters a cell can be converted to acetyl-CoA via the enzyme acetyl-CoA synthetase, which can directly enter the citric acid cycle and thereby delivering energy for the host. Therefore, it can be questioned whether the observed effects on fat oxidation and energy expenditure in our studies are due to oxidation of the administered sodium acetate per se, rather than an increased oxidation of endogenous lipids. However, if the infused sodium acetate would have been completely oxidized, this would only contribute to a minor extent to the observed increase in fat oxidization found in Chapter 3 and Chapter 4 . In brief, we based our calculation on the assumption that oxidation of sodium acetate results in a respiratory quotient of 0.5 (the oxidation of $1 \mathrm{~mol}$ sodium acetate consumes $2 \mathrm{~mol} \mathrm{O}_{2}$ and liberates $1 \mathrm{~mol} \mathrm{CO}_{2},{ }^{39,49,50}$ for detailed calculation see Chapter 3 of this thesis). Nevertheless, at least $60 \%$ of SCFA 
absorption through the colon is by simple diffusion of protonated acetate, which would yield when oxidized an RQ of 1.0 (the oxidation of $1 \mathrm{~mol}$ acetate would consume $1 \mathrm{~mol} \mathrm{O}_{2}$ and produce $1 \mathrm{~mol} \mathrm{CO}_{2}{ }^{50,51}$ ) rather than 0.5 . In addition, a kinetic study showed that only $\sim 30-50 \%$ of the rectally administered ${ }^{13} \mathrm{C}$-acetate is oxidized within 4 hours. $^{52}$ This indicates that the complete oxidation of the infused sodium acetate is a large overestimation and we rather underestimate our increments in fat oxidation.

The SCFA mixtures used in Chapter 4 were all highest in sodium acetate but also contained sodium propionate and sodium butyrate, which are well-known energy sources for colonocytes. Therefore, it can be questioned whether the infused propionate and butyrate contribute to the increases in whole-body fat oxidation found in this study. However, a human in vivo study with rectal infusions of isotopically-labelled butyrate $(5 \mathrm{mmol})$ showed that only $\sim 25 \%$ of butyrate is oxidized within a $4 \mathrm{~h}$ and did not affect whole-body $\mathrm{RQ}$ and resting energy expenditure. ${ }^{43}$ Moreover, oxidation of propionate and butyrate results in an RQ of 0.86 and 0.8 , respectively. ${ }^{51}$ Together, these data clearly indicate that direct oxidation of the infused acetate and SCFA mixtures cannot explain the increase in whole-body fasting fat oxidation and resting energy expenditure as observed in our acute studies described in Chapter $\mathbf{3}$ and Chapter $\mathbf{4}$.

Consequently, signalling mechanisms have to be involved in the demonstrated increase in whole-body fat oxidation and energy expenditure. In highfat fed mice, the oral administration of acetate, propionate and butyrate induced a peroxisome proliferator-activated receptor- $\gamma$ (PPAR $\gamma$ )-dependent increase in mitochondrial uncoupling protein 2 (UCP2) expression and increment in the AMP/ATP ratio in liver and adipose tissue. ${ }^{33}$ This led to a switch from lipid synthesis to fat oxidation (measured using $\left[1-{ }^{14} \mathrm{C}\right]$ palmitic acid) via an adenosine monophosphate-activated protein kinase (AMPK)-dependent mechanism. ${ }^{33}$ In addition, in obese mice, oral butyrate administration increased energy expenditure and fat oxidation via activation of AMPK and (PPARY)-coactivator (PGC)-1 $\alpha$ in the liver and the skeletal muscle. ${ }^{29}$ Along the same lines, intragastric injections of acetate lowered body weight and improved glucose homeostasis in obese rats via an increase in AMPK-mediated fat oxidation in the skeletal muscle. ${ }^{53}$ In the studies described in Chapter 3 and Chapter 4 no tissue biopsies were taken, therefore it remains to be determined whether AMPK-mediated oxidative mechanism in peripheral tissues might underlie the present finding of an increased whole-body fat oxidation and energy expenditure following distal SCFA administration in humans. 
Short-chain fatty acids increase peptide YY secretion

Besides an AMPK-mediated switch of fuel oxidation, also the increased circulating PYY (Chapter 3 and Chapter 4) might be involved in the increased fat oxidation. Studies performed in mice and preliminary human data suggest that an increase in circulating PYY was responsible for a shift in substrate utilization towards fat oxidation. ${ }^{54,55}$ However, the exact mechanisms behind this PYY-induced fuel switch remain unclear and need to be investigated in more detail in human.

PYY is secreted by intestinal enteroendocrine L-cells, ${ }^{56,57}$ and affects appetite and satiety by suppressing neuropeptide $Y$ and activating propiomelanocortin neurons in the hypothalic arcuate nucleus, or by delaying gastric emptying. ${ }^{58,59}$ In Chapter $\mathbf{3}$ we observed an increased plasma PYY concentration after distal, but not proximal, sodium acetate infusions. In line, a human study in six obese, hyperinsulinemic women showed that rectal infusions with sodium acetate increased plasma PYY as compared to saline infusions. ${ }^{32}$ This can be explained by the higher density of PYY-secreting L-cells, which express the SCFA receptor G-protein coupled receptor (GPR) 43, in the distal colonic epithelium than in the epithelium of the proximal colon, as observed in rodents. ${ }^{60,61}$ The increase in PYY after SCFA administration is in accordance with in vitro studies using intestinal cell lines from rodents $^{62,63}$ and humans, ${ }^{64,65}$ which showed that SCFA stimulated the secretion of PYY from L-cells in a GPR43 dependent manner.

Short-chain fatty acids attenuate whole-body and adipocyte lipolysis

In Chapter 4 of this thesis, we demonstrated that three SCFA mixtures, which differ in their content of acetate, propionate or butyrate, all attenuated whole-body lipolysis (as indicated by the suppression of plasma free glycerol concentrations). This SCFA-induced antilipolytic effect has been previously demonstrated in human in vivo studies. ${ }^{38,41,42}$ Using our in-house validated human white adipocyte model, ${ }^{66}$ the hMADS cells, as presented in Chapter 5, we extended the present knowledge by showing that acetate is mainly responsible for this antilipolytic effect of SCFA, via attenuation of hormone-sensitive lipase phosphorylation in a GPR-dependent manner. 
Short-chain fatty acids improve the inflammatory profile

Obesity and insulin resistance are characterised by systemic low-grade inflammation. In Chapter $\mathbf{3}$ and Chapter $\mathbf{4}$ of the present thesis, we demonstrated that acute infusion of sodium acetate and a SCFA mixture high in sodium acetate in the distal colon tended to attenuate the plasma concentrations of the proinflammatory cytokines TNF- $\alpha$ and IL-1 $\beta$, respectively.

Accumulating evidence derived from in vitro and animal data indicated that SCFA have immunomodulatory functions, as extensively reviewed in Chapter 2 of this thesis. To the author's knowledge, upon present, only one human in vivo study demonstrated an effect of SCFA on low-grade systemic inflammation. ${ }^{32}$ They showed that acute intravenous, but not rectal, administration of sodium acetate attenuated TNF- $\alpha$ concentrations in hyperinsulinemic women with obesity. ${ }^{32}$

\section{Acetate - a major player in host physiology and metabolic health?}

The above described acute in vivo trials (Chapter 3 and Chapter 4 ) and the in vitro experiment (Chapter 5) indicated that SCFA in acute settings pronouncedly affect human substrate and energy metabolism. We observed in both acute studies comparable increases in fat oxidation ( 18-26 \%) after distal colonic administration of sodium acetate alone (Chapter 3 ) and after all SCFA mixtures (Chapter 4). Strikingly, in Chapter 4 the increments of circulating acetate, but not of propionate and butyrate, correlated positively with the increases in fasting fat oxidation and resting energy expenditure, suggesting that systemic acetate is the major driver of these pronounced metabolic effects observed in these human studies. In agreement, with our in vivo data, in Chapter $\mathbf{5}$ we showed that mainly acetate-mediated inhibition of adipocyte lipolysis might be responsible for the whole-body antilipolytic effect of SCFA observed in Chapter 4. These whole-body and adipocyte antilipolytic effects of acetate might improve human white adipose tissue lipid buffering capacity and reduce lipid overflow. In addition, acetate-induced fat oxidation and/or increased oxidative capacity in skeletal muscle might improve metabolic flexibility, defined as the capacity to utilize and switch between the major fuels, lipids and carbohydrates. $^{67}$ Together with a reduced adipose tissue lipid spillover, this improved oxidative capacity could ultimately result in reduced accumulation of bioactive lipids and improved insulin action in peripheral tissues such as skeletal muscle and liver, thereby preventing insulin resistance. Together, with the acetate- 
induced attenuation of systemic proinflammatory cytokines, this indicates that colonic acetate administration has great potential to be a valuable strategy to improve insulin sensitivity and substrate and energy metabolism in humans.

Furthermore, elevating acetate concentrations in the distal colon and circulation might affect food intake regulation and long-term control of body weight via an increase in energy expenditure and fat oxidation, as well as with an increase in the secretion and production of the satiety-stimulating hormone PYY (Chapter $\mathbf{3}$ and Chapter 4). Nevertheless, to draw more definitive conclusions on the metabolic impact and subsequent metabolic health effects of SCFA, in particular of acetate, it is of importance to perform well controlled intervention studies that more chronically increase colonic and systemic acetate concentrations.

\section{Proof-of-concept human dietary intervention study}

To investigate longer-term effects of SCFA, in particular of acetate, on metabolic health we performed a 12-week supplementation study with 44 men and postmenopausal women with obesity and impaired glucose homeostasis (Chapter 6). In this proof-of-concept study the effect of supplementation with the acetogenic prebiotic fibre(s) GOS (15 g per day) on peripheral and adipose tissue insulin sensitivity was determined. Secondary outcome measures were faecal microbiota composition, SCFA concentrations in plasma and faeces, energy expenditure and substrate oxidation, as well as circulating proinflammatory cytokines, hormones and metabolites. In this well-controlled human study, therefore, measurements of microbiota composition, functionality (SCFA) and detailed host metabolic phenotyping were combined.

We observed a pronounced bifidogenic effect after 12-week GOS supplementation, but no effects on microbial diversity and richness. Despite the pronounced effect on acetate-producing Bifidobacterium spp., no changes in faecal or plasma fasting acetate or other SCFA were observed. In addition, 12-week GOS supplementation did not affect peripheral and adipose tissue insulin sensitivity, body composition, energy expenditure and fat oxidation, and did not alter circulating inflammatory markers, hormones or metabolites.

The fermentation of identical GOS in the validated TNO in vitro model of the colon (TIM-2), showed pronounced increases in acetate production. ${ }^{68}$ Therefore, it is surprising that we did not observe an increase in faecal or fasting plasma acetate or any acetate-related metabolic effect, in particular, since the abundance of 
Bifidobacterium spp. was increased, which are well-known acetate producers. ${ }^{69}$ Most of the GOS fermentation in our longer-term study might have occurred in the caecum and proximal colon potentially explaining the lack of metabolic effects. ${ }^{70}$ In Chapter 3, we demonstrated that distal, but not proximal, colonic acetate infusions increased fat oxidation and increased circulating levels of acetate and PYY in overweight men. In line, in Chapter 4, we have demonstrated in overweight men that administration of SCFA mixtures into the distal colon increased circulating acetate concentrations. Strikingly, the increase in systemic acetate concentrations was positively associated with the increase in fat oxidation and energy expenditure. ${ }^{71}$ Interestingly, Den Besten et al. ${ }^{72}$ have indicated that a significant amount of acetate is converted to other metabolites, in particular to butyrate, in the caecum of mice via microbial cross-feeding. ${ }^{72}$ Consequently, this might result in a decreased supply of acetate to the liver, where acetate is further metabolized. Thus, both the site of fermentation of GOS and the conversion of acetate into other metabolites may have led to an insufficient increase in systemic acetate concentrations, which might be necessary to induce pronounced metabolic effects. Therefore, future research should focus on strategies to increase acetate concentrations specifically in the distal part of the colon in the longer-term. Such strategies could include the production of slow-fermentable acetogenic foods. ${ }^{73}$

Our findings of considerable GOS-induced specific microbial changes without impact on energy and substrate metabolism, inflammatory profile and insulin sensitivity are in contrast to some, ${ }^{74,75}$ but not all, previous human studies using GOS or fructo-oligosaccharides (FOS), as reviewed in Chapter 2 of this thesis.

One of the explanations for the different metabolic outcomes between these studies $^{74,75}$ and the present study might be the difference in GOS type. The GOS supplemented in our study contained mainly $\beta-1,4$ glycosidic linkages, whereas the GOS mixture used in previous studies ${ }^{74,75}$ consist of mainly $\beta-1,3$ linkages. $A$ comparative in vitro study showed that $\beta-1,3$ GOS had a higher bifidogenic effect. ${ }^{76}$ However, we found in our study, using $\beta-1,4$ GOS, a pronounced increase in Bifidobacterium, indicating substantial microbiota manipulation but insufficient to elicit metabolic effects.

Importantly, differences in the study population may be responsible for the inconsistency. We included prediabetic overweight/obese men and postmenopausal women aged between 45 and 70 years, whereas in previous trials ${ }^{74,75}$ metabolically healthy, normal weight or slightly overweight elderly population, or overweight, but more insulin sensitive and younger adults were included. Ageing, obesity and insulin 
General discussion

resistance are associated with alterations in gut microbiota composition and microbial richness and diversity, as well as with a reduction of Bifidobacterium in particular. ${ }^{77-81}$ Of note, there are strong indications that the gut microbiome of adults with obesity and insulin resistance has a lower capacity to completely ferment and breakdown complex carbohydrates as compared to the microbiome from lean and metabolically healthy individuals. ${ }^{82,83}$ Therefore, the microbiota in our prediabetic, obese participants might have had a lower SCFA production capacity and might be more resilient to manipulations as compared to healthier groups. Hence, the relevance of specific gut microbiota manipulation between different metabolic phenotypes, i.e. insulin resistant versus insulin sensitive, should be investigated in more detail. 


\section{Conclusion and future perspectives}

This thesis focuses on the role of the SCFA acetate, propionate and butyrate, which are end products of the fermentation of complex foods by the gut microbiota, in the human substrate and energy metabolism.

We found pronounced beneficial metabolic effects of acute distal colonic SCFA administration, in particular an increase in fat oxidation, energy expenditure, circulating concentrations of the anorexogenic hormone PYY and we observed an attenuated whole-body lipolysis, probably due to GPR-dependent inhibition of adipocyte lipolysis. Nevertheless, our longer-term study did not demonstrate an increase in faecal or plasma acetate and other SCFA and could not confirm the translation of these effects to beneficial metabolic alterations in a longer-term setting.

The main outcomes of this thesis provide evidence for an important role of SCFA in human substrate and energy metabolism. However, several questions and issues should be addressed in future research:

1. Our main finding in Chapter $\mathbf{3}$ and Chapter $\mathbf{4}$ was an SCFA/acetate induced increase in fat oxidation and energy expenditure, which could not be explained by the oxidation of the infused SCFA. Therefore, signalling mechanisms have to be involved in these processes. Rodent-derived data showed that PPAR targets and AMPK are involved in a SCFA-induced increase in the oxidative capacity of peripheral tissue. ${ }^{29,33,53,84}$ This needs to be urgently addressed in human experiments. In vivo, tissue biopsies of i.e. adipose tissue and skeletal muscle should be taken to elaborate on underlying mechanisms. In addition, mechanistic cell culture studies should be performed to further detect key regulators and pathways involved in human-derived adipocyte and skeletal muscle cell models. This would deliver fundamental data for future nutritional strategies and/or the development of functional foods and nutrition-based drugs targeting specific peripheral organs in the prevention of chronic metabolic disease.

2. In Chapter 6, we did not observe an increase in concentrations of faecal or fasting plasma acetate and no changes in other SCFA. In addition, we did not observe acetate/SCFA-related beneficial metabolic effects after 12-week GOS supplementation in obese, prediabetic adults. Putative reasons, for this is the 
site of fermentation of GOS and acetate production in the colon, since we observed in Chapter 4 that distal colonic infusion resulted in a more pronounced increase in circulating acetate as compared to proximal colonic infusion. This suggests that increased distal colonic and systemic acetate concentrations are required to elicit beneficial effects on the human substrate and energy metabolism. Therefore, future research should focus on strategies to increase acetate concentrations specifically in the distal part of the colon in the longer-term. Such strategies could include the production of slowfermentable acetogenic foods and the esterification of acetate on slowfermentable nutritents. ${ }^{64,73}$

3. Besides using such strategies to increase acetate at the distal colonic site, the design of the long-term study could be extended. The volunteer number should be increased to have enough power to distinguish between sex-specific effects. Since a recent observation has been shown that besides pronounced differences in body composition and metabolism, gut microbiota composition and its impact on metabolic health might be sex-dependent. ${ }^{85}$ Furthermore, a meal test, including isotopically-labelled dietary fibre(s), should be performed. Thereby, aim to elucidate SCFA-induced changes in secretion/production of gut-derived signalling metabolites and hormones, and postprandial SCFA production rates and fluxes in relation to metabolic effects in gut, liver and peripheral tissues. In addition, functional magnetic resonance techniques to investigate the interesting effect of acetate on human central appetite regulation, as reported in rodents, ${ }^{31}$ should be included.

4. The important observation of our dietary intervention study (Chapter 6) that a daily life diet induced microbiota manipulation did not translate into pronounced metabolic effects in our obese, prediabetic population raised also further questions. Is a three month period long enough to induce sufficient changes in the microbiota composition to affect host metabolism in this population? A study in in hyperinsulinemic adults showed that only after 9 to 12 months daily intake of a high-wheat fibre cereal containing $24 \mathrm{~g}$ of soluble fibre translated into increased postprandial concentrations of plasma acetate, butyrate and glucagon like peptide- $1 .^{86}$ Or, furthermore, is the gut microbiome of our population more resilient to dietary manipulations than the microbiome 
of a more metabolically 'healthy' population? In addition, is the crosstalk between the gut microbiota and its products (i.e. SCFA signalling) and the host whole-body substrate and energy metabolism disturbed in our prediabetic, obese population? This should be further addressed by providing identical dietary interventions to phenotypic subgroups.

5. A intriguing recently published study ${ }^{25}$ indicated that a machine-learning algorithm that integrates blood parameters, dietary habits, anthropometrics, physical activity, and gut microbiome data accurately predicts personalized postprandial glycaemic response to real-life meals. ${ }^{25}$ This study suggests that an individual's gut microbiome is a major determinant of dietary health outcomes. Consequently, it provides evidence that future research regarding diet-induced manipulation of the gut microbiome and related metabolic health effects should be at the individual rather than on population level. 


\section{References}

1. Organization WHO. http://www.who.int/mediacentre/factsheets/fs311/en/, 2015.

2. $\mathrm{Ng} \mathrm{M}$, Fleming $\mathrm{T}$, Robinson $\mathrm{M}$, et al. Global, regional, and national prevalence of overweight and obesity in children and adults during 1980-2013: a systematic analysis for the Global Burden of Disease Study 2013. The Lancet 2014;384:766-781.

3. Kahn SE, Hull RL, Utzschneider KM. Mechanisms linking obesity to insulin resistance and type 2 diabetes. Nature 2006;444:840-846.

4. Bhaskaran $\mathrm{K}$, Douglas I, Forbes $\mathrm{H}$, et al. Body-mass index and risk of 22 specific cancers: a population-based cohort study of $5 \cdot 24$ million UK adults. The Lancet 2014;384:755-765.

5. Preiss K, Brennan L, Clarke D. A systematic review of variables associated with the relationship between obesity and depression. Obesity Reviews 2013;14:906-918.

6. Wormser D, Kaptoge S, Di Angelantonio E, et al. Separate and combined associations of body-mass index and abdominal adiposity with cardiovascular disease: collaborative analysis of 58 prospective studies. The Lancet 2011;377:1085-1095.

7. Krotkiewski M, Björntorp P, Sjöström L, et al. Impact of obesity on metabolism in men and women. Importance of regional adipose tissue distribution. Journal of Clinical Investigation 1983;72:1150.

8. Srdic B, Ukropina ESAKM, Breberlna KVM. Morphological Characteristics of Abdominal Adipose Tissue in Normal-Weight and Obese Women of Different Metabolic Profiles. 2010.

9. Machann J, Häring $\mathrm{H}$, Schick $\mathrm{F}$, et al. Intramyocellular lipids and insulin resistance. Diabetes, Obesity and Metabolism 2004;6:239-248.

10. Perry RJ, Samuel VT, Petersen KF, et al. The role of hepatic lipids in hepatic insulin resistance and type 2 diabetes. Nature 2014;510:84.

11. Glass CK, Olefsky JM. Inflammation and lipid signaling in the etiology of insulin resistance. Cell metabolism 2012;15:635-645.

12. Hulver MW, Berggren JR, Carper MJ, et al. Elevated stearoyl-CoA desaturase-1 expression in skeletal muscle contributes to abnormal fatty acid partitioning in obese humans. Cell metabolism 2005;2:251-261.

13. Koves TR, Ussher JR, Noland RC, et al. Mitochondrial overload and incomplete fatty acid oxidation contribute to skeletal muscle insulin resistance. Cell metabolism 2008;7:45-56.

14. Blaak EE, Hul G, Verdich C, et al. Fat oxidation before and after a high fat load in the obese insulin-resistant state. The Journal of Clinical Endocrinology \& Metabolism 2006;91:1462-1469.

15. Hotamisligil GS, Shargill NS, Spiegelman BM. Adipose expression of tumor necrosis factor-alpha: direct role in obesity-linked insulin resistance. Science 1993;259:87-91.

16. Makki K, Froguel P, Wolowczuk I. Adipose Tissue in Obesity-Related Inflammation and Insulin Resistance: Cells, Cytokines, and Chemokines. ISRN inflammation 2013;2013.

17. Wynn TA, Chawla A, Pollard JW. Macrophage biology in development, homeostasis and disease. Nature 2013;496:445-455.

18. Mraz M, Haluzik M. The role of adipose tissue immune cells in obesity and low-grade inflammation. Journal of Endocrinology 2014;222:R113-R127.

19. Goossens GH, Blaak EE, Theunissen R, et al. Expression of NLRP3 inflammasome and $T$ cell population markers in adipose tissue are associated with insulin resistance and impaired glucose metabolism in humans. Molecular immunology 2012;50:142-149.

20. Murphy KG, Dhillo WS, Bloom SR. Gut peptides in the regulation of food intake and energy homeostasis. Endocr Rev 2006;27:719-27. 
21. Diamant M, Blaak EE, de Vos WM. Do nutrient-gut-microbiota interactions play a role in human obesity, insulin resistance and type 2 diabetes? Obes Rev 2011;12:272-81.

22. Qin J, Li Y, Cai Z, et al. A metagenome-wide association study of gut microbiota in type 2 diabetes. Nature 2012;490:55-60.

23. Karlsson FH, Tremaroli V, Nookaew I, et al. Gut metagenome in European women with normal, impaired and diabetic glucose control. Nature 2013;498:99-103.

24. Santacruz A, Marcos A, Wärnberg J, et al. Interplay Between Weight Loss and Gut Microbiota Composition in Overweight Adolescents. Obesity 2009;17:1906.

25. Zeevi D, Korem T, Zmora N, et al. Personalized Nutrition by Prediction of Glycemic Responses. Cell 2015;163:1079-1094.

26. Fu J, Bonder MJ, Cenit MC, et al. The Gut Microbiome Contributes to a Substantial Proportion of the Variation in Blood Lipids. Circulation research 2015;117:817-824.

27. Canfora EE, Jocken JW, Blaak EE. Short-chain fatty acids in control of body weight and insulin sensitivity. Nat Rev Endocrinol 2015;11:577-591.

28. De Vadder F, Kovatcheva-Datchary P, Goncalves D, et al. Microbiota-generated metabolites promote metabolic benefits via gut-brain neural circuits. Cell 2014;156:84-96.

29. Gao Z, Yin J, Zhang J, et al. Butyrate improves insulin sensitivity and increases energy expenditure in mice. Diabetes 2009;58:1509.

30. Lin HV, Frassetto A, Kowalik Jr EJ, et al. Butyrate and Propionate Protect against Diet-Induced Obesity and Regulate Gut Hormones via Free Fatty Acid Receptor 3Independent Mechanisms. PLoS ONE 2012;7:e35240.

31. Frost $G$, Sleeth ML, Sahuri-Arisoylu M, et al. The short-chain fatty acid acetate reduces appetite via a central homeostatic mechanism. Nature communications 2014;5.

32. Freeland KR, Wolever T. Acute effects of intravenous and rectal acetate on glucagonlike peptide-1, peptide $Y Y$, ghrelin, adiponectin and tumour necrosis factor-alpha. British Journal of Nutrition 2010;103:460-466.

33. den Besten G, Bleeker A, Gerding A, et al. Short-Chain Fatty Acids protect against High-Fat Diet-Induced Obesity via a PPARy-dependent switch from lipogenesis to fat oxidation. Diabetes 2015:db141213.

34. Murphy $E$, Cotter $P$, Healy $S$, et al. Composition and energy harvesting capacity of the gut microbiota: relationship to diet, obesity and time in mouse models. Gut 2010;59:1635-1642.

35. Al-Lahham Sa, Roelofsen H, Rezaee F, et al. Propionic acid affects immune status and metabolism in adipose tissue from overweight subjects. European journal of clinical investigation 2012;42:357-364.

36. Al-Lahham SaH, Roelofsen $\mathrm{H}$, Priebe $\mathrm{M}$, et al. Regulation of adipokine production in human adipose tissue by propionic acid. European journal of clinical investigation 2010;40:401-407.

37. Venter CS, Vorster HH, Cummings JH. Effects of dietary propionate on carbohydrate and lipid metabolism in healthy volunteers. The American journal of gastroenterology 1990;85:549-553.

38. Fernandes J, Vogt J, Wolever TM. Intravenous acetate elicits a greater free fatty acid rebound in normal than hyperinsulinaemic humans. European journal of clinical nutrition 2012;66:1029-1034.

39. Akanji A, Bruce M, Frayn K. Effect of acetate infusion on energy expenditure and substrate oxidation rates in non-diabetic and diabetic subjects. European journal of clinical nutrition 1989;43:107-115. 
40. Laurent C, Simoneau C, Marks L, et al. Effect of acetate and propionate on fasting hepatic glucose production in humans. European journal of clinical nutrition 1995;49:484.

41. Wolever T, Spadafora P, Eshuis H. Interaction between colonic acetate and propionate in humans. The American journal of clinical nutrition 1991;53:681-687.

42. Wolever T, Brighenti F, Royall D, et al. Effect of rectal infusion of short chain fatty acids in human subjects. The American journal of gastroenterology 1989;84:1027.

43. Simpson E, Chapman M, Dawson J, et al. In vivo measurement of colonic butyrate metabolism in patients with quiescent ulcerative colitis. Gut 2000;46:73-77.

44. Cummings J, Pomare E, Branch W, et al. Short chain fatty acids in human large intestine, portal, hepatic and venous blood. Gut 1987;28:1221.

45. Kaur A, Rose DJ, Rumpagaporn P, et al. In Vitro Batch Fecal Fermentation Comparison of Gas and Short,ÄêChain Fatty Acid Production Using ,ÄúSlowly Fermentable,Äù Dietary Fibers. Journal of food science 2011;76:H137-H142.

46. Bliss DZ, Weimer PJ, Jung H-JG, et al. In Vitro Degradation and Fermentation of Three Dietary Fiber Sources by Human Colonic Bacteria. Journal of agricultural and food chemistry 2013.

47. Timm DA, Stewart ML, Hospattankar A, et al. Wheat dextrin, psyllium, and inulin produce distinct fermentation patterns, gas volumes, and short-chain fatty acid profiles in vitro. Journal of medicinal food 2010;13:961-966.

48. Stewart M, Becker A, Slavin J, et al. Fermentability of resistant starch preparations varies in vitro. Dietary fibre: new frontiers for food and health 2010:339-349.

49. Smith GI, Jeukendrup AE, Ball D. Sodium acetate induces a metabolic alkalosis but not the increase in fatty acid oxidation observed following bicarbonate ingestion in humans. The Journal of nutrition 2007;137:1750-1756.

50. Frayn K. Calculation of substrate oxidation rates in vivo from gaseous exchange. Journal of Applied Physiology 1983;55:628.

51. Ritz $\mathrm{P}$, Cloarec $D$, Beylot $\mathrm{M}$, et al. Effects of colonic fermentation on respiratory gas exchanges following a glucose load in man. Metabolism 1993;42:347-352.

52. Lifschitz $\mathrm{CH}$, Irving CS, Helge $\mathrm{H}$, et al. [13C] Acetate Oxidation in Infants After Oral Versus Rectal Administration: A Kinetic Model. Journal of pediatric gastroenterology and nutrition 1985;4:699-706.

53. Yamashita $\mathrm{H}$, Maruta $\mathrm{H}$, Jozuka $\mathrm{M}$, et al. Effects of acetate on lipid metabolism in muscles and adipose tissues of type 2 diabetic Otsuka Long-Evans Tokushima Fatty (OLETF) rats. Bioscience, biotechnology, and biochemistry 2009;73:570-576.

54. van den Hoek AM, Heijboer AC, Voshol PJ, et al. Chronic PYY3-36 treatment promotes fat oxidation and ameliorates insulin resistance in C57BL6 mice. Am J Physiol Endocrinol Metab 2007;292:E238-45.

55. Sloth B, Holst JJ, Flint A, et al. Effects of PYY1-36 and PYY3-36 on appetite, energy intake, energy expenditure, glucose and fat metabolism in obese and lean subjects. American Journal of Physiology-Endocrinology and Metabolism 2007;292:E1062E1068.

56. Theodorakis MJ, Carlson O, Michopoulos S, et al. Human duodenal enteroendocrine cells: source of both incretin peptides, GLP-1 and GIP. American Journal of Physiology-Endocrinology and Metabolism 2006;290:E550-E559.

57. Roberge JN, Brubaker PL. Regulation of intestinal proglucagon-derived peptide secretion by glucose-dependent insulinotropic peptide in a novel enteroendocrine loop. Endocrinology 1993;133:233-240.

58. De Silva A, Bloom SR. Gut hormones and appetite control: a focus on PYY and GLP-1 as therapeutic targets in obesity. Gut and liver 2012;6:10-20. 
59. Savage A, Adrian T, Carolan G, et al. Effects of peptide YY (PYY) on mouth to caecum intestinal transit time and on the rate of gastric emptying in healthy volunteers. Gut 1987;28:166-170.

60. Nilsson O, Bilchik A, Goldenring J, et al. Distribution and immunocytochemical colocalization of peptide $Y Y$ and enteroglucagon in endocrine cells of the rabbit colon. Endocrinology 1991;129:139-148.

61. Arantes R, Nogueira A. Distribution of enteroglucagon-and peptide YYimmunoreactive cells in the intestinal mucosa of germ-free and conventional mice. Cell and tissue research 1997;290:61-69.

62. Tolhurst $\mathrm{G}$, Heffron $\mathrm{H}$, Lam YS, et al. Short-chain fatty acids stimulate glucagon-like peptide-1 secretion via the G-protein-coupled receptor FFAR2. Diabetes 2012;61:364-371.

63. Psichas $A$, Sleeth $M$, Murphy $K$, et al. The short chain fatty acid propionate stimulates GLP-1 and PYY secretion via free fatty acid receptor 2 in rodents. International Journal of Obesity 2014.

64. Chambers ES, Viardot A, Psichas A, et al. Effects of targeted delivery of propionate to the human colon on appetite regulation, body weight maintenance and adiposity in overweight adults. Gut 2014:gutjnl-2014-307913.

65. Psichas A, Zac-Varghese S, Murphy $K$, et al. Short chain fatty acids stimulate the release of gut hormone peptide $Y Y$ from human primary enteroendocrine $L$ cells, In Proceedings of The Physiological Society, 27, PC331, 2012.

66. Jocken J, Goossens G, Popeijus H, et al. Contribution of lipase deficiency to mitochondrial dysfunction and insulin resistance in hMADS adipocytes. International Journal of Obesity 2015.

67. Corpeleijn E, Saris W, Blaak E. Metabolic flexibility in the development of insulin resistance and type 2 diabetes: effects of lifestyle. obesity reviews 2009;10:178-193.

68. Maathuis AJ, van den Heuvel EG, Schoterman MH, et al. Galacto-oligosaccharides have prebiotic activity in a dynamic in vitro colon model using a 13C-labeling technique. The Journal of nutrition 2012;142:1205-1212.

69. Rossi M, Corradini C, Amaretti A, et al. Fermentation of fructooligosaccharides and inulin by bifidobacteria: a comparative study of pure and fecal cultures. Applied and environmental microbiology 2005;71:6150-6158.

70. van der Beek CM, Canfora EE, Lenaerts K, et al. Distal, but not proximal, colonic acetate infusions promote fat oxidation and improve metabolic markers in overweight men. Doctoral Thesis Emanuel Canfora 2016;Chapter 3.

71. Canfora EE, van der Beek CM, Jocken JW, et al. Colonic infusions of short-chain fatty acid mixtures promote energy metabolism in overweight men. Doctoral Thesis Emanuel Canfora 2016; Chapter 4.

72. den Besten G, Lange K, Havinga R, et al. Gut-derived short-chain fatty acids are vividly assimilated into host carbohydrates and lipids. American Journal of Physiology-Gastrointestinal and Liver Physiology 2013;305:G900-G910.

73. Kaur A, Rose DJ, Rumpagaporn P, et al. In Vitro Batch Fecal Fermentation Comparison of Gas and Short-Chain Fatty Acid Production Using "Slowly Fermentable" Dietary Fibers. Journal of food science 2011;76:H137-H142.

74. Vulevic J, Drakoularakou A, Yaqoob P, et al. Modulation of the fecal microflora profile and immune function by a novel trans-galactooligosaccharide mixture (B$\mathrm{GOS}$ ) in healthy elderly volunteers. The American journal of clinical nutrition 2008;88:1438-1446.

75. Vulevic J, Juric A, Tzortzis G, et al. A mixture of trans-galactooligosaccharides reduces markers of metabolic syndrome and modulates the fecal microbiota and immune function of overweight adults. The Journal of nutrition 2013;143:324-331. 
76. Depeint F, Tzortzis G, Vulevic J, et al. Prebiotic evaluation of a novel galactooligosaccharide mixture produced by the enzymatic activity of Bifidobacterium bifidum NCIMB 41171, in healthy humans: a randomized, doubleblind, crossover, placebo-controlled intervention study. The American journal of clinical nutrition 2008;87:785-791.

77. O'Toole PW, Jeffery IB. Gut microbiota and aging. Science 2015;350:1214-1215.

78. Ley RE. Obesity and the human microbiome. Current opinion in gastroenterology 2010;26:5-11.

79. Tremaroli V, Bäckhed F. Functional interactions between the gut microbiota and host metabolism. Nature 2012;489:242-249.

80. Saraswati S, Sitaraman R. Aging and the human gut microbiota-from correlation to causality. Frontiers in microbiology 2013;5.

81. Lozupone CA, Stombaugh JI, Gordon JI, et al. Diversity, stability and resilience of the human gut microbiota. Nature 2012;489:220-230.

82. Ridaura VK, Faith JJ, Rey FE, et al. Gut microbiota from twins discordant for obesity modulate metabolism in mice. Science 2013;341:1241214.

83. Khan MT, Nieuwdorp M, Bäckhed F. Microbial modulation of insulin sensitivity. Cell metabolism 2014;20:753-760.

84. Yamashita H, Fujisawa K, Ito E, et al. Improvement of obesity and glucose tolerance by acetate in type 2 diabetic Otsuka Long-Evans Tokushima Fatty (OLETF) rats. Bioscience, biotechnology, and biochemistry 2007;71:1236-1243.

85. Most J, Goossens G, Reijnders D, et al. Gut microbiota compositon strongly correlates to peripheral insulin sensitvity in obese men but not in women. Doctoral Thesis Jasper Most 2016;Chapter 6 148-155.

86. Freeland KR, Wilson C, Wolever TM. Adaptation of colonic fermentation and glucagon-like peptide-1 secretion with increased wheat fibre intake for 1 year in hyperinsulinaemic human subjects. British journal of nutrition 2010;103:82-90. 
CHAPTER 8 

Appendices 


\section{Summary}

Accumulating evidence indicates that our gut microbiota and its products are involved in the aetiology of host metabolic disorders such as obesity and type 2 diabetes mellitus. The gut microbiota can ferment indigestible foods, which ends up in the production of important metabolites such as the short-chain fatty acids (SCFA) acetate, propionate and butyrate. Mainly animal studies have shown that SCFA are involved in the regulation of body weight and insulin sensitivity (Chapter 2 ) and may, at least in part, explain the beneficial metabolic effects of dietary fibre intake (Chapter $\mathbf{2}$ and Chapter 7). However, human data are scarce and the importance of SCFA in human energy and substrate metabolism remained to be established. Hence, in this thesis, we investigated the potential of SCFA to modulate whole-body substrate and energy metabolism and insulin sensitivity in humans, by combining acute and long term in vivo human intervention studies and an in vitro approach in human multipotent adipose tissue-derived stem (hMADS) cells to further investigate underlying mechanisms.

In Chapter $\mathbf{3}$ we investigated whether the administration of sodium acetate in the proximal or distal part of the colon differentially affect human substrate and energy metabolism. Therefore, in a randomized, double blind placebo-controlled crossover trial, six normoglycaemic overweight/obese men (BMI 25-35 kg/m ${ }^{2}$ ) underwent two experimental periods: one with distal and one with proximal colonic sodium acetate infusions. A feeding catheter was endoscopically positioned at the beginning of each period and remained in the colon for three consecutive clinical investigation days, enabling colonic acetate $(100 \mathrm{mmol} / \mathrm{L}$ or $180 \mathrm{mmol} / \mathrm{L})$ or placebo infusion during fasting conditions and after an oral glucose load (postprandial). Substrate and energy metabolism were measured using an open-circuit ventilated hood system and blood samples were repeatedly collected for $2 \mathrm{~h}$ during fasting and postprandial conditions.

We demonstrated that distally, but not proximally, administered acetate modulated whole-body substrate oxidation, with a markedly increased fasting fat oxidation ( $25 \%$ ), a tendency towards increased systemic concentrations of acetate, the satiety-stimulating hormone peptide $Y Y$ (PYY), and a tendency towards decreased systemic concentrations of the proinflammatory cytokine tumour necrosis factor-alpha (TNF- $\alpha$ ). Together, these data indicated that acetate administered in the distal colon might beneficially affect the metabolic profile in men.

Based on these outcomes, we concluded that administration of SCFA in the distal part of the colon is an appropriate model to determine effects of gut-derived 
SCFA on human substrate and energy metabolism. Therefore, we decided to use enemas to administer combinations of SCFA into the distal part of the colon in our follow-up study presented in Chapter 4. In this study, the effects of administration of three different SCFA mixtures on metabolic parameters were assessed in twelve normoglycaemic men with overweight or obesity. The concentrations and ratios of SCFA in the different mixtures were based on in vitro fermentation studies of dietary fibres, so that all concentrations were in physiological ranges that could be obtained through diet. In this randomized, double-blind, placebo-controlled, crossover study, the participants underwent four investigational days, during which SCFA mixtures (200 mmol/L) high in either acetate, propionate, butyrate or placebo were rectally administered during fasting and postprandial conditions (oral glucose load). Comparable to the study presented in Chapter 3, substrate oxidation and energy expenditure were measured using an open-circuit ventilated-hood system and blood samples were repeatedly collected for $2 \mathrm{~h}$ after colonic infusions to determine circulating metabolite and hormone concentrations during fasting and postprandial conditions. We demonstrated that infusions of colonic SCFA mixtures increased fasting fat oxidation and resting energy expenditure, which was accompanied by increased circulating acetate concentrations. In addition, all SCFA mixtures increased fasting and postprandial PYY concentrations and attenuated whole-body lipolysis. The SCFA mixture high in acetate also slightly decreased concentrations of the proinflammatory cytokine interleukin-1 beta (IL-1 $\beta$ ).

In Chapter 5, we aimed to elucidate potential mechanisms involved in the antilipolytic properties of SCFA mixtures observed in vivo (Chapter 4). Therefore, we investigated, in vitro, the effects of SCFA incubations on intracellular lipolysis and signalling using a human white adipocyte model, the hMADS cells. Differentiated hMADS cells were, therefore, incubated with mixtures of acetate, propionate and butyrate or single SCFA (acetate, propionate and butyrate) in concentrations ranging between $1 \mu \mathrm{mol} / \mathrm{L}$ and $1 \mathrm{mmol} / \mathrm{L}$. Glycerol release and lipase activation was investigated during basal conditions and $\beta$-adrenergic (maximal) stimulation. We showed that SCFA mixtures high in acetate and propionate, but not butyrate, decreased basal glycerol release. Furthermore, incubation with only acetate decreased basal and $\beta$-adrenergically mediated glycerol release. In contrast, butyrate slightly increased basal and $\beta$-adrenergically mediated glycerol release. The antilipolytic effect of acetate was accompanied by a reduced phosphorylation of hormone sensitive lipase (HSL) at serine residue 650. In addition, (inhibitory) Gprotein coupled receptor (GPR) inactivation following pertussis toxin treatment 
prevented the antilipolytic effect of acetate. Consequently, these data indicated that acetate was mainly responsible for the antilipolytic effects of SCFA in vitro and acts via attenuation of HSL phosphorylation in a GPR-dependent manner. Thus, mainly acetate might be responsible for the whole-body antilipolytic effect of SCFA mixtures observed in the human intervention study in Chapter 4.

Based on these promising outcomes of the acute studies, we questioned whether the acute effects of SCFA, in particular of acetate, would translate into longer-term effects on insulin sensitivity and substrate and energy metabolism. Therefore, we performed a 12-week dietary supplementation study with 44 men and postmenopausal women with overweight/obesity and impaired glucose homeostasis (Chapter 6). In this proof-of-concept study the effects of supplementation with the acetogenic prebiotic fibre(s) galactooligosaccharides (GOS, $15 \mathrm{~g}$ per day) on peripheral and adipose tissue insulin sensitivity were determined. Secondary outcome measures were faecal microbiota composition, SCFA concentrations in plasma and faeces, energy expenditure and substrate oxidation, as well as circulating proinflammatory cytokines, hormones and metabolites. Thus, in this well-controlled human study, measurements of microbiota composition, functionality (SCFA) and detailed host metabolic phenotyping were combined. We found that supplementation of GOS to the daily diet, but not placebo, led to a marked 5.0-fold increase in faecal acetate-producing Bifidobacterium spp. Nevertheless, we neither observed significant differences in faecal and fasting plasma SCFA concentrations, insulin sensitivity, body composition, and energy and substrate metabolism, nor significant effects on plasma hormones, metabolites and inflammatory markers.

In conclusion, we found marked beneficial metabolic effects of acute distal colonic SCFA administration, accompanied/associated with increased systemic acetate concentrations. The main findings were that colonic SCFA infusions increased fat oxidation, energy expenditure, circulating concentrations of the anorexogenic hormone PYY and attenuated whole-body lipolysis, probably due to GPR-dependent inhibition of adipocyte lipolysis. Nevertheless, our longer-term study failed to demonstrate an increase in faecal and fasting plasma SCFA following a fibrerich diet. In line, we could not detect beneficial effects on insulin sensitivity and on parameters of energy metabolism in this longer-term setting. The main outcomes of this thesis provide evidence for an important role of SCFA in human substrate and energy metabolism. However, further well-controlled long-term studies are warranted, in which the particular focus should be on enhancing SCFA, mainly acetate, in the distal colon and systemic circulation in the long term. 


\section{Samenvatting}

Er komt steeds meer bewijs voor een rol van onze darmmicrobiota en haar producten bij de etiologie van stofwisselingsziekten, zoals obesitas en type 2 diabetes mellitus. De darmmicrobiota kan onverteerbaar voedsel fermenteren, waarbij belangrijke metabolieten zoals de korte-keten vetzuren (SCFA) acetaat, propionaat en butyraat geproduceerd worden. Met name proefdierstudies hebben aangetoond dat SCFA betrokken zijn bij de regulatie van lichaamsgewicht en insulinegevoeligheid (Hoofdstuk 2) en dat ze de gunstige metabole effecten die na vezelconsumptie gevonden worden, deels kunnen verklaren (Hoofdstuk 2 en Hoofdstuk 7). Het belang van SCFA bij het energie- en substraatmetabolisme in mensen moet nog vastgesteld worden. Daarom hebben we in dit proefschrift onderzoek gedaan naar de potentie van SCFA om substraat- en energiemetabolisme en insulinegevoeligheid te moduleren in de mens, door acute en lange termijn in vivo humane interventiestudies te combineren met een in vitro benadering. Hierbij werd gebruik gemaakt van stamcellen afkomstig uit humaan vetweefsel (hMADS) ter verdere mechanistische verdieping.

In hoofdstuk 3 hebben we onderzocht of de toediening van acetaat in het proximale of distale deel van het colon resulteert in verschillende effecten op het substraat- en energiemetabolisme bij mannen met overgewicht/obesitas (BMI $25-35 \mathrm{~kg} / \mathrm{m} 2$ ). In een gerandomiseerde, dubbelblinde cross-over studie, ondergingen zes mannen twee keer een 3-daagse experimentele periode, waarbij aan het begin van elke periode een katheter endoscopisch gepositioneerd werd in de distale of proximale colon. Op 3 opeenvolgende dagen werden acetaat $(100 \mathrm{mmol} / \mathrm{L}$ of 180 $\mathrm{mmol} / \mathrm{L}$ ) of placebo via de katheter toegediend in nuchtere toestand en na inname van een glucosedrank (postprandiaal). Vetoxidatie en energiegebruik werden gemeten met behulp van een 'open-circuit ventilated hood' systeem en bloedmonsters werden verzameld gedurende nuchtere en postprandiale toestand.

Distale, maar niet proximale, toediening van acetaat verhoogde de nuchtere vetoxidatie $( \pm 25 \%)$, resulteerde in een tendens tot verhoogde systemische acetaatconcentraties, verhoogde concentraties van het verzadigings-stimulerende hormoon peptide YY (PYY), en resulteerde in een reductie van de pro-inflammatoire cytokine tumornecrosefactor-alfa (TNF- $\alpha$ ). Deze gegevens tonen aan dat acetaat, toegediend in het distale deel van het colon, het metabole profiel van mannen met overgewicht/obesitas gunstig kan beïnvloeden.

Deze resultaten tonen ook aan dat toediening van SCFA in het distale deel van het colon een geschikt model is om het effect SCFA op substraat- en 
energiemetabolisme in de mens te bepalen. Daarom hebben we besloten om in de follow-up studie gebruik te maken van klysma's om fysiologisch relevante combinaties van SCFA toe te dienen in het distale deel van het colon (hoofdstuk 4). In deze studie werden de effecten van de toediening van drie verschillende SCFAmengsels in het distale colon op energie- en substraatmetabolisme onderzocht in twaalf normoglycemische mannen met overgewicht of obesitas. De toegediende SCFA-concentraties in de verschillende mengsels werden gebaseerd op beschikbare gegevens van in vitro fermentatie van voedingsvezels, zodat deze fysiologisch relevant waren. In deze gerandomiseerde, dubbelblinde, placebo-gecontroleerde, cross-over studie ondergingen de deelnemers vier onderzoeksdagen. Hierbij werden de diverse SCFA-mengsels (200 mmol/L), hoog in acetaat, hoog in propionaat of hoog in butyraat of een placebo rectaal toegediend in nuchtere en postprandiale toestand (na consumptie van een glucosedrank). Vetoxidatie en energiegebruik werden gemeten met een 'open-circuit ventilated hood' systeem en bloedmonsters werden verzameld gedurende de hele periode om de circulerende metabolieten en hormonen te bepalen. De infusies van SCFA-mengsels in het colon verhoogden de vetoxidatie en het energiegebruik in rust, wat gepaard ging met verhoogde systemische acetaatconcentraties. Bovendien resulteerden alle SCFA-mengsels in een verhoging van PYY-concentraties tijdens gevaste en postprandiale toestand en een remming van de endogene lipolyse. Daarnaast gaf het SCFA-mengsel hoog in acetaat een lichte verlaging van het pro-inflammatoire cytokine interleukin-1 bèta (IL-1beta).

In Hoofdstuk 5 werden de mechanismen die betrokken zijn bij de antilipolytische eigenschappen van de SCFA-mengsels, zoals gevonden in Hoofdstuk 4, verder bestudeerd. Hierbij werd gebruik gemaakt van een humaan adipocytmodel met hMADS-cellen (afkomstig van subcutaan abdominaal vetweefsel). De hMADScellen werden geïncubeerd met mengsels van acetaat, propionaat en butyraat of de afzonderlijke SCFA (acetaat, propionaat en butyraat) in concentraties variërend tussen $1 \mu \mathrm{mol} / \mathrm{L}$ en $1 \mathrm{mmol} / \mathrm{L}$. Glycerolafgifte en lipase-activatie werd onder basale omstandigheden en tijdens $\beta$-adrenerge stimulatie onderzocht. SCFA-mengsels die hoog in acetaat en propionaat waren, resulteerden in een verlaagde basale glycerolafgifte, terwijl dit niet werd gevonden bij mengsel hoog in butyraat. De studies met toediening van afzonderlijke SCFA toonden aan dat met name acetaat de basale en $\beta$-adrenerg-gemedieerde glycerolafgifte verlaagde. Daarentegen resulteerde butyraat in een lichte verhoging van de basale en $\beta$-adrenerggemedieerde glycerolafgifte. Het anti-lipolytische effect van acetaat ging gepaard 
met een verlaagde fosforylering van hormoonsensitieve lipase (HSL) op serineresidue 650. G-eiwit gekoppeld receptor (GPR) 'knockdown' door toevoeging van pertussis toxine verminderde het anti-lipolytische effect van acetaat. Bovenstaande resultaten tonen aan dat acetaat voornamelijk verantwoordelijk is voor het anti-lipolytische effect van SCFA in vitro en dat deze remming werkt via een reductie van HSL-fosforylering via een GPR mechanisme. Op deze manier zou acetaat verantwoordelijk kunnen zijn voor het in vivo anti-lipolytische effect van SCFAmengsels dat werd waargenomen in Hoofdstuk 4.

De veelbelovende resultaten van de acute studies leidde tot de hypothese dat een chronische toename van acetaat in het colon of in het bloed resulteert in positieve effecten op insulinegevoeligheid en substraat- en energiemetabolisme. Daarom hebben we een 12-weken-durende voedingsinterventie uitgevoerd bij 44 mannen en postmenopauzale vrouwen met overgewicht/obesitas en een verstoorde glucosehomeostase (Hoofdstuk 6). In deze 'proof-of-concept' studie zijn de effecten van suppletie van de acetogene prebiotische vezel(s) galactooligosaccharide (GOS) (15 g per dag) op perifere insulinegevoeligheid bepaald. Secundaire uitkomstmaten waren insulinegevoeligheid in het vetweefsel, fecale microbiotasamenstelling, SCFAconcentraties in plasma en feces, energieverbruik en substraatoxidatie, evenals circulerende pro-inflammatoire cytokines, hormonen en metabolieten. We vonden dat GOS-suppletie resulteerde in een duidelijke 5-voudige verhoging van fecale Bifidobacteriën, maar de microbiële diversiteit veranderde niet. Er werden geen verschillen gevonden in fecale en plasma SCFA-concentratie, insulinegevoeligheid, lichaamssamenstelling, energie- en substraatmetabolisme, metabolieten en insuline, GLP1 en PYY of inflammatoire markers.

Concluderend tonen deze studies aan dat acute SCFA-toediening in het distale colon leidt tot gunstige metabole effecten. Dit lijkt voornamelijk gekoppeld aan verhoogde acetaatconcentraties in het distale colon en circulatie. Deze gunstige metabole effecten zijn met name een verhoogde vetoxidatie, een verhoogd energiegebruik, een verhoogde PYY-concentratie en een remming van de endogene vrijmaking van vetten (lipolyse). We vanden geen verhoogde SCFA/acetaat concentratie, waardoor we deze positieve effecten van SCFA/acetaat werden niet aangetoond in een lange termijn voedingsinterventiestudie bij een groep mensen met overgewicht/obesitas en een verstoorde glucose homeostase. GOS resulteerde in een duidelijke toename in Bifidobacteriën maar fecale en circulerende acetaatconcentraties veranderden niet. 
Samenvatting

Het huidige proefschrift toont een belangrijke rol van SCFA bij het substraaten energiemetabolisme in de mens aan. Er zijn meer goed gecontroleerde studies nodig, met een focus op een verhoging van SCFA, vooral van acetaat, in het distale colon en de systemische circulatie op de langere termijn. Dit moet bij zowel gezonde mensen als bij mensen met een hoog risico op type 2 diabetes mellitus en hart- en vaatziekten gedaan worden om hun gezondheid te verbeteren. 


\section{Zusammenfassung}

Akkumulierende Indizien zeigen, dass unsere Darmbakterien (Mikrobiota) und ihre Stoffwechselprodukte in die Ätiologie von Stoffwechselstörungen wie Obesitas und Typ-2-Diabetes-Mellitus involviert sind. Die Darmflora kann unverdaute Nahrungsbestandteile (z. B. Ballaststoffe) fermentieren. Dabei entstehen wichtige Stoffwechselprodukte wie die kurzkettigen Fettsäuren (SCFA = short-chain fatty acids) Acetat, Propionat und Butyrat. Tierexperimente zeigen, dass diese SCFA bei der Kontrolle des Körpergewichtes und der Regulierung der Insulinsensitivität (Kapitel 2) eine Rolle spielen. Dadurch sind SCFA möglicherweise auch an den positiven Stoffwechseleffekten, welche Ballaststoffen zugeschrieben werden, beteiligt (Kapitel 2 und Kapitel 7). Jedoch gibt es bislang nur wenige Humanstudien, die Effekte von SCFA auf den menschlichen Substrat- und Energiestoffwechsel untersuchen, weshalb hier noch weiterer Forschungsbedarf besteht. In der vorliegenden Doktorarbeit wird deshalb der Einfluss von SCFA auf den menschlichen Stoffwechsel und die Insulinsensitivität getestet. Zu diesem Zweck wurden humane in vivo Kurz- und Langzeitstudien mit einer in vitro Studie mit multipotenten Stammzellen aus dem Fettgewebe kombiniert.

In Kapitel $\mathbf{3}$ wird untersucht, ob Natriumacetat-Infusionen in den distalen und proximalen Dickdarm (Kolon) unterschiedliche Auswirkungen auf den menschlichen Substrat- und Energiestoffwechsel haben. Hierfür wurden in einer randomisierten, doppel-blinden Placebo-kontrollierten Cross-Over-Studie, sechs übergewichtige männliche Probanden (BMI $\left.25-35 \mathrm{~kg} / \mathrm{m}^{2}\right)$ getestet. Die Probanden durchliefen zwei experimentelle Perioden: Zunächst erhielten sie NatriumacetatInfusionen in den distalen Kolon und im weiteren Verlauf in den proximalen Kolon. Hierfür wurde jeweils am ersten Tag der experimentellen Perioden im Rahmen eines endoskopischen Eingriffs eine Sonde an der Darmmukosa befestigt. Diese Sonde blieb für die nachfolgenden drei Testtage im Kolon. Mit Hilfe dieser Sonde wurden Natriumacetat (100 mmol/L und $180 \mathrm{mmol} / \mathrm{L}$ ) beziehungsweise Placebo im nüchternen Zustand und nach einem zuckerreichen Getränk direkt in den Kolon geleitet. Während der Testtage wurden die Auswirkungen dieser Infusion auf den Substrat- und Energiestoffwechsel im nüchtern Zustand und nach dem zuckerreichen Getränk mit Hilfe der indirekten Kalorimetrie Messung und anhand von regelmäßigen Blutabnahmen untersucht.

Im Rahme dieser Studie zeigte sich, dass Natriumacetat-Infusionen in den distalen Kolon, nicht jedoch in den proximalen Kolon, die Fettsäureoxidation deutlich erhöht. Des weiteren wurde im Blutplasma eine Tendenz zu erhöhten Acetat- 
Konzentrationen festgestellt, die Konzentration des Sättigungssignals Peptid YY (PYY) war erhöht und auch eine Tendenz zur niedrigeren Konzentration des proinflammatorischen Zytokin Tumor-Nekrose-Faktor-alpha (TNF-alpha) konnte festgestellt werden. Zusammengefasst zeigen diese Daten, dass eine Erhöhung von Acetat im distalen Kolon sich vorteilhaft auf den Stoffwechsel von übergewichtigen Männern auswirken kann.

Diese Studie lässt darauf schließen, dass die Infusion von SCFA in den distalen Kolon ein geeignetes Mittel ist, um Effekte von aus dem Dickdarm kommenden SCFA auf den menschlichen Substrat- und Energiestoffwechsel zu testen. In der nachfolgenden Studie (Kapitel 4) wurden deshalb physiologisch relevante Kombination von SCFA in den distalen Kolon verabreicht. Dabei wurden die Effekte auf Stoffwechselparameter von drei verschiedenen Kombinationen von SCFA nach Verabreichung in den distalen Kolon von zwölf übergewichtigen männlichen Probanden untersucht. Die hierbei infundierten Konzentrationen und das Mengenverhältnis der SCFA können theoretisch durch balaststoffreiche Lebensmittel erreicht werden und waren dadurch im physiologischen Bereich. In dieser randomisierten, doppel-blinden Placebo-kontrollierten Cross-Over-Studie durchliefen die Probanden vier klinische Testtage. Während eines Testtages bekamen die Probanden entweder eine Kombination aus SCFA die anteilig hoch war an Acetat, Propionat oder Butyrat, an einem weiteren Testtag dann ein Placebo. Ähnlich wie in der Studie aus Kapitel $\mathbf{3}$ wurden während der Testtage nach den SCFA-Infusionen die Substratoxidation und der Energieverbrauch gemessen. Des weiteren wurden den Probanden wieder im nüchternen Zustand und nach einem zuckerhaltigem Getränk (postprandial) zwei Stunden lang regelmäßig Blut abgenommen. Die Ergebnisse zeigen, dass die SCFA-infusionen die Fettsäureoxidation und den Energieverbrauch im nüchternen Zustand erhöhen, dies ging mit erhöhten zirkulierenden Acetat-Konzentrationen einher. Des weiteren erhöhten alle SCFA-Kombinationen die PYY-Konzentration im nüchternen und postprandialen Zustand und verminderten die Ganzkörper-Lipolyse.

Im Kapitel 5 war es unser Ziel, potentielle Mechanismen die an dem antilipolytischen Effekt der SCFA-Kombinationen (Kapitel 4) beteiligt sind zu detektieren. Hierfür wurden menschliche Stammzellen genutzt, die aus dem subkutanen Fettgewebe isoliert wurden (hMADS-Zellen). Die hMADS-Zellen wurden mit Acetate, Propionat und Butyrat oder mit Kombinationen aus diesen SCFA in Konzentrationen zwischen $1 \mu \mathrm{mol} / \mathrm{L}$ und $1 \mathrm{mmol} / \mathrm{L}$ inkubiert. Daraufhin wurde die Freisetzung von Glycerin und der Lipase-Aktivität unter basalen Bedingungen und während der 
maximalen Stimulation der Lipolyse mit einem $\beta$-Adrenoreceptor Aktivator getestet. Die SCFA-Kombinationen mit hohem Anteil von Acetat und Propionat verminderten die Freisetzung von Glycerin, während die SCFA-Kombinationen mit hohem Anteil von Butyrat dies nicht zeigten. Die weiteren Experimente mit den einzelnen SCFA zeigten, dass vor allem Acetat die Glycerin-Freisetzung hemmte. Dagegen resultierte die Inkubation mit Butyrat eher in einer erhöhten Glycerin-Abgabe. Der antilipolytische Effekt von Acetat wurde bedingt durch eine verminderte Phosphorylierung der hormonsensitiven Lipase (HSL) am Serineresidue 650. Der ,Knockdown' von G-protein gekoppelten Rezeptoren (GPR) durch Zugabe von Pertussis Toxin verhinderte den anti-lipolytischen Effekt von Acetat. Zusammenfassend zeigen diese Daten, dass vor allem Acetat für den antilipolytischen Effekt der SCFA in vitro verantwortlich ist und die Hemmung der Lipolyse über eine Reduzierung der HSL-Phosphorylierung und eines GPRrelatierenden Mechanismus funktioniert. Dadurch könnte vor allem zirkulierendes Acetat für den anti-lipolytischen Effekt der in vivo in Kapitel $\mathbf{4}$ gefunden wurde verantwortlich sein.

Die vielversprechenden Resultate der Kurzzeitstudien führten zu der Hypothese, dass die chronische Erhöhung der Acetat-Konzentration im Kolon und in der Blutbahn in positiven Effekten auf die Insulin-Sensitivität und den Energie- und Substratstoffwechsel resultiert. Aus diesem Grund wurde eine 12-wöchige Ernährungsstudie mit 44 übergewichtigen, prädiabetischen männlichen und postmenopausalen weiblichen Probanden (Kapitel 6) initiiert. In dieser ,Proof-ofKonzept'-Studie wurden die Effekte der Supplementierung des acetogenen Präbiotikum Galakto-oligosaccharide (GOS, 15 Gramm pro Tag) auf die periphere Insulin-Sensitivität getestet. Sekundäre Ergebnisse waren die Insulin-Sensitivität des Fettgewebes, die Mikrobiota-Zusammenstellung, die SCFA-Konzentrationen im Stuhl sowie Blutplasma, Energieverbrauch und Substratoxidation. Des weiteren wurden zirkulierende pro-inflammatorische Zytokine, Hormone und Metaboliten im Blutplasma analysiert. Die Ergebnisse zeigen, dass 12 Wochen GOS-Einnahme zu einer deutlichen Erhöhung der Bifidobakterien führte, jedoch die Diversität der Mikrobiota nicht veränderte. Die Supplementierung von GOS resultiere nicht in signifikanten Unterschieden der Acetat-Konzentrationen und weiteren oben genannten Stoffwechselparametern.

Abschließend lässt sich auf Basis der vorliegenden Studien sagen, dass die akute SCFA-Infusion in den distalen Kolon zu positiven Stoffwechseleffekten führen kann. Dies scheint vor allem an erhöhte Konzentrationen von Acetat im distalen 
Zusammenfassung

Kolon und der Blutbahn gekoppelt zu sein. Die positiven Effekte äußern sich in einer erhöhten Fettsäureoxidation, einem Anstieg des Energieverbrauchs, erhöhter PYYKonzentration und einer Verminderung der Lipolyse. In der Langzeitstudie wurden keine erhöhten Acetat/SCFA-Konzentrationen nach Supplementierung eines Präbiotikums gefunden. Dadurch konnten die positiven Stoffwechseleffekte von Acetat/SCFA nicht in dieser Langzeit-Ernährungsstudie bei übergewichtigen, prädiabetischen Probanden nachgewiesen werden.

Die vorliegende Doktorarbeit belegt eine wichtige Rolle der SCFA in dem menschlichen Substrat- und Energiestoffwechsel. Es sind jedoch weitere Studien dringend erforderlich, die den Fokus auf eine chronische Erhöhung von SCFA, vor allem Acetat, im distalen Kolon und der Blutzirkulation legen. Diese sollten sowohl mit gesunden Probanden, als auch mit Probanden mit einem erhöhten Risiko an Typ2-Diabetes-Mellitus zu erkranken umgesetzt werden, um ihre Stoffwechselfunktion zu verbessern. 



\section{Valorisation}

The present thesis describes the potential of gut microbial-derived shortchain fatty acids (SCFA) as key players in host substrate and energy metabolism in humans. We investigated whether SCFA have beneficial effects on body weight control and insulin sensitivity via an increase in energy expenditure and fat oxidation, as well as the production of appetite-regulating hormones and inflammatory cytokines. The valorisation potential of these studies will be described in terms of societal and economic relevance and implications for specific target groups, future research and possible applications for industrial development.

The present report of the World Health Organization (WHO) indicated alarming numbers for the worldwide prevalence of obesity, indicating that more than 39\% overweight ( $>1.9$ billion adults, > 50\% in Europe) and 13\% (>600 million, > $20 \%$ in Europe) clinically obese adults. Moreover, of great concern is that more than 42 million children under the age of 5 were overweight or obese in 2013 and numbers are rising. Obesity is associated with a serious number of comorbidities such as cardiovascular disease, mental disorders (i.e. depression), certain forms of cancers, and type 2 diabetes mellitus. Overweight/obesity is thereby the fifth leading cause of death and the increasing prevalence has besides public health issues also major socio-economic consequences.

Obesity is a chronic metabolic disorder resulting from an energy imbalance, in which a long-term surplus of energy intake over energy expenditure (that is, positive energy balance) leads to the storage of excess energy as body fat. Putative mechanisms linking obesity to insulin resistance and type 2 diabetes mellitus are described in this thesis, including obesity-associated adipose dysfunction and related lipid overflow and chronic low-grade inflammation.

Preventing and counteracting this positive energy balance is getting more and more difficult for obese individuals. This is mainly driven by the increased access and exposure to energy-dense foods and the increase in sedentary lifestyle especially in our Western Hemisphere. However, in the obese state even modest weight loss might lead to considerable beneficial health effects, i.e. the US Diabetes Prevention Program indicated that every kilogram of weight loss reduced the risk of developing diabetes by $16 \%$. Therefore, the outcomes of the acute studies of this thesis - that colonic SCFA might beneficially impact body weight control via an increase of energy expenditure and fat oxidation, as well as the increase in satietystimulating hormones - is of substantial relevance for the prevention and treatment 
of obesity and related metabolic disorders. Next, we found in these studies that whole-body lipolysis and circulating pro-inflammatory markers are attenuated, and that whole-body fat oxidation is increased, which are identified as putative key factors in the pathophysiology of obesity-related insulin resistance.

Thus, SCFA were identified as important metabolites in the crosstalk of gut microbiota and peripheral tissue metabolism, indicating that modulation of SCFA metabolism through targeted diet or lifestyle interventions might contribute to the prevention of chronic metabolic disease. Increasing the effectiveness of lifestyle interventions in the prevention of obesity and related insulin resistance might significantly impact public health and health care costs. In the longer-term study, we, however, could not confirm these findings of the acute studies to more chronic beneficial metabolic health effects using a specific fibre. The reasons therefore are discussed in this thesis and the findings of this study providing several interesting leads for future strategies, which might be more effective.

The studies of this thesis are funded by TI Food and Nutrition (TIFN), a publicprivate partnership on pre-competitive research in food and nutrition. The collaboration of this project involved experts of international food industries, research institutes and universities. Thus, this thesis should been seen in the context of the TIFN Gastrointestinal Health project 'microbiota, metabolism and energy harvesting'. The overall aim of the project was to further elucidate the role of the gut microbiota, gut physiology and human energy and substrate metabolism by combining state-of-the-art human phenotyping and detailed characterization of gut microbiota composition and functionality. The specific focus was on the interaction between microbial-derived or colonically administered SCFA and liver, adipose tissue and skeletal muscle metabolism.

In this project state-of-the-art human intervention studies were performed to elucidate the significance of the gut microbiota and its products, in particular SCFA and bile acids, in body weight control and insulin sensitivity. Besides the research presented in this thesis, the project included studies investigating the knockdown of gastrointestinal microbiota by means of antibiotics, SCFA dynamics after ingestion of 13C-inulin, measurement of SCFA fluxes across gut and liver and faecal transplants from lean donors in subjects with metabolic syndrome.

All results gained within this TIFN project will be available for the public through publications in international peer-reviewed journals and via the media. The food industrial partners have contributed to the project through funding and the 
interaction and exchange of relevant knowledge and data during frequent meetings and presentations. This interaction has given leads to further studies with food products known to result in putative beneficial and targeted changes in SCFA production. In addition, the project was of great value in the translation of scientific knowledge into food products that may improve the metabolic profile and the prevention of obesity-related metabolic disorders.

The relationship between the gut microbiome and metabolic disorders is a rapidly growing area and almost on a daily basis intriguing new data have been published in the recent years. However, our understanding regarding which microbes are 'beneficial' and how these microbes interact with the host metabolism, especially in humans, is still in its infancy and researchers in this field might still be considered as frontiers. This thesis identified SCFA, the microbial products produced by their fermentation of complex non-digestible carbohydrates, as important key regulators of the crosstalk between the gut microbiota and the whole-body substrate and energy metabolism in humans. The findings are in keeping with recently published studies in SCFA-supplemented animals as well as a limited amount of human studies, in which supplementing dietary fibres demonstrated beneficially effects on metabolic health.

To conclude, the acute studies described in this thesis have shown that colonic SCFA have great potential to beneficially modulate body weight control and insulin sensitivity and maybe of importance in chronic metabolic disease. As indicated above, these findings may give leads for the development of nutritional strategies and food products modulating SCFA production in a target manner, thereby preventing obesity and obesity-related metabolic disturbances. Furthermore, this thesis also provides interesting leads for further research, such as the relevance of gut microbiota manipulation with respect to metabolic phenotypes, the colonic SCFA production sites and insight in physiologically relevant SCFA absorption rates and fluxes. 



\section{Acknowledgement, Dankwoord, Danksagung}

Het belangrijkste komt op het einde...het dankwoord. Wat heb ik tijdens mijn Aio periode prachtige mensen leren kennen en wat hebben mij aardige mensen in deze periode begeleid. Ik ben iedereen meer dan dankbaar en het ergste zou zijn als ik iemand vergeet.

Ellen, bedankt dat je me van begin het gevoel gegeven hebt dat mijn bijdrage in het project enorm belangrijk is en dat je me de vrijheid en vertrouwen gegeven hebt die ik nodig had om creatief en efficiënt te werken. Dit was ik, met mijn achtergrond en ervaring in Duitse Universiteiten, niet gewoon. Ik heb van de wetenschappelijke discussie met jouw heel erg genoten en vind het altijd indrukwekkend dat je met al jouw werk load snel op taken reageert en dingen oplost. Verder wil ik je van harte danken, dat je toch altijd weer een mogelijkheid gevonden hebt om me te motiveren, bijvoorbeeld als er frustratie kwam of als het weer te lang duurde met de analyses. En ik wil je graag bedanken, dat je wel begrip had als ik met nieuwe resultaten vol enthousiasme jouw kamer binnen stormde, en je eigenlijk helemaal geen tijd voor me had. Hartelijk bedankt voor de prettige samenwerking tot zo ver en ik kijk heel erg uit naar de volgende samenwerking.

Johan, ik wil je heel erg bedanken voor je grote inzet en ondersteuning tijdens het schrijven van mijn thesis. Het was van begin aan een plezier om met je samen te werken, wetenschappelijke dingen te bediscussiëren en ook van de gezellige praatjes in het lab maar ook op congressen heb ik genoten. Ik ben ook dankbaar voor de waardevolle tips die je mij regelmatig gegeven hebt, ook wat mijn verdere carrière betreft. Er zijn al veel mooie dingen uit onze samenwerking gekomen en ik kijk ernaar uit dat er nog veel volgt.

Kaatje, je bent iets later bij mijn promotie team gekomen - maar ik zal je belangrijke en heel nuttige input helemaal niet willen missen. Je hebt me van begin aan welkom geheten en ik heb van begin aan heel graag met jou samengewerkt. Ook was je steeds voor me bereikbaar als ik vragen of suggesties nodig had. Ik ben je ontzettend dankbaar voor je grote inzet en snelle reacties tijdens de laatste delen van mijn proefschrift en ik kijk ernaar uit om met je samen verder te werken. 
Members of the Assessment Committee, Prof. Wim Saris, Prof. Nathalie Delzenne, Prof. Albert Groen, Dr. Daisy Jonkers, Prof. Jochem Plat, as well as the members of the corona of my thesis defence, Prof. Ilja Aarts, Prof. Luc van Loon and Dr. Tanja Adams, thank you very much for your time and effort that you put in reading and reviewing this thesis.

De TI Food and Nutrition partners in het thema "Gastrointestinal Health", bedankt voor de vruchtbare samenwerking en jullie interesse, en voor nuttige suggesties en discussies tijdens onze bijeenkomsten. Thank you very much for the excellent discussions and your input in this project. Gabby, je hebt het me van begin makkelijk gemaakt om goed opgenomen te worden in het TIFN team en je had altijd een open oor voor me. A special thanks goes also to all Co-authors of the thesis' manuscripts. Thanks for the excellent collaborations, and your input and time.

Gijs, ook jij van harte bedankt voor de laatste jaren. Je was niet mijn directe begeleider, toch heb je je tijd gepakt als ik met vragen of suggesties naar je kwam. Ook was het heel gezellig met jou op de congressen en ik heb van onze praatjes genoten. Vooral wil ik je bedanken voor je geruststellende praatjes, bijvoorbeeld voor mijn presentaties of als er weer vertraging was met de studieproducten of analyses - jouw goede woorden in deze situaties hebben me erg geholpen.

Kirsten, je bent een heel belangrijke deel van dit boekje. Onze samenwerking zat van begin aan ontzettend goed. Ik denk dat ieder van ons zijn expertises prima in de uitvoering van de studies gebracht heeft en dat we daardoor een perfect team zijn geweest. Ik vond het steeds heel leuk met je samen te werken, maar ook privé hadden we het altijd heel gezellig. Ik vind het jammer dat je niet meer in Maastricht zit, maar ben blij voor je dat je je plan om MDL arts te worden in Venlo kunt realiseren. Ik wens jou en Stefan het beste en hoop dat we nog regelmatig in contact blijven.

Jasper, mein Paranimf, Dir hab ich im Besonderen zu danken. Durch Dich bin ich erst auf Maastricht aufmerksam geworden und Du hast mich vom ersten Tag in Maastricht willkommen geheißen und mir wichtige Tipps fürs studieren/arbeiten gegeben. Ganz besonders dankbar bin ich Dir natürlich, dass du mich bei Ellen vorgestellt hast. Deine Bereitschaft $z u$ helfen ist wirklich einzigartig und die ausführlichen wissenschaftlichen Diskussionen mit Dir fehlen mir. Die vier Jahre die 
wir hier zusammen in einem Buero verbracht haben werde ich nie vergessen und ich vermiss dich schon sehr. Auf der anderen Seite freue ich mich unglaublich für dich, dass du dich als Postdoc in den USA wohl fühlst und da weitere wichtige Lebens- und Berufserfahrungen sammeln kannst. Ich hoffe wir bleiben noch lange in Kontakt mein Freund!

Dorien, mijn Paranimf, ook met jou heb ik 4.5 jaar een kamer gedeeld, dezelfde dag begonnen en bijna op dezelfde dag gepromoveerd. We hebben hele mooie jaren samen gehad, en ook in mindere tijden hebben we ons steeds ondersteund en het gezellig gehad. Ik ben je dankbaar dat je van begin aan alleen Nederlands met mij gepraat hebt, mij tijdens testdagen ondersteund hebt, maar ook voor al de leuke praatjes die we samen hadden. Je was van ontzettend belang voor de sfeer van HB tijdens onze Aio periode en was altijd een van de eerste die zich gemeld hebben als er iets georganiseerd werd. Ik zal vooral de congressen en de grappige tijden niet vergeten, zoals in Lyon, Barcelona of Berlin. Ik heb van de tijd met jou genoten en kijk er naar uit om ook in de toekomst regelmatig in contact te blijven. Nu kijk ik eerst naar ons gemeenschappelijke feest uit. Sowieso wens ik jou en Jasper het beste toe in de VS en dat je goede beslissingen neemt.

Ons groep: Rudi, we kennen ons sinds de master en ik ben heel blij dat je in onze groep zit. De samenwerking met jou maar ook de privé dingen, zoals wandelen, feesten en van jouw gezelligheid geniet ik altijd. Mattea en Birgitta, jullie zijn een prima vervanger van Dorien en Jasper geworden. Ik zit heel graag met jullie op de kamer en vind het leuk hoe wij elkaar ondersteunen en geniet van de praatjes en wetenschappelijke discussies met jullie. Max, Qing, Nicole, Yvonne, Ruth, Ellen jullie zijn allemaal top collega's en ik ben blij dat ik jullie heb leren kennen en met jullie nog verder kan werken.

Tijdens de interventie studies heb ik erg leuke dagen en tijden gehad. Het uitvoeren van interventies kan uiteraard niet zonder de medewerking van gemotiveerde en enthousiaste deelnemers. Daarom wil ik graag deze mensen van harte bedanken voor hun interesse en deelname aan de studies die beschreven staan in dit proefschrift. Ook een hartelijke dank gaat uit naar mijn stagiaires Kelly, Luuk, Miranda en Nona en de diëtiste Laura die ons tijdens de interventies met grootte inzet geholpen hebben. Een bijzondere dank gaat ook naar alle analisten Jos, Joan, Wendy, Antoine, Paul, Hasibe, Loek, Hans, Dennis, Yvonne, Nicole - 
Dankwoord

bedankt voor jullie belangstelling in mijn onderzoek en de labanalyses die jullie hebben uitgevoerd voor de studies die hier beschreven staan. Zonder jullie hulp had ik dit nooit allemaal kunnen opschrijven.

Desiree, Cleo, Yolanda en Claudia. Heel erg bedankt voor jullie prettige ondersteuning en vriendelijkheid, die me heel erg geholpen hebben in HB een beetje thuis te voelen. Jullie weten wel hoe belangrijk jullie voor de groep zijn en ik vind het indrukwekkend hoe snel jullie altijd taken regelen. Desiree, voor jou een bijzonder grote dank voor de ondersteuning tijdens de laste loodjes voor mijn proefschrift.

Buurvrouwen/mannen: Stefan, Rick, Tanja, Guy, Mathijs, Jean en Jorn. Jullie hebben een hele belangrijke rol gespeeld zodat ik me in de koude kelder van begin aan een beetje thuis gevoeld heb en nu nog niet eens naar de tweede verdieping wil. Het was toch altijd prachtig met jullie over wetenschap maar ook over het leven buiten de wetenschap te discuteren. Dat jullie allen uit verschillende groepen/achtergronden komen en heel anders naar dingen kijken, was voor mij vaak heel leerzaam en belangrijk.

Mensen van HB/BW: Jos (bedankt voor al de borrels en jouw grote inzet om alle mensen van $\mathrm{HB} / \mathrm{BW}$ naar de activiteiten te brengen. Ik heb me van begin aan welkom gevoeld), Joan, Antoine, Freek, Loek, Paul (hartelijk bedankt voor al de belangrijke uitleggen), Wendy, Mark, Esther (bedankt voor leuke stage in het DDZ Düsseldorf) Jan, Joey, Dorien, Sabine, Peter, Jan-Willem (bedankt voor de leuke masterstage), Sylvie, Sophie, Marlou, Imre, Stefan, Cyril (ik zal de VLAG week nou niet vergeten - best room mate), Lex, Andi, Evelien, Pilou, Joey, Cas, Juneau, Joy, Roel, Mark, Jan, Hannah, Emmani, Marlies, Dirk en alle anderen van HB/BWs bedankt voor de leuke praatjes, samenwerking, borrels, diners en voor de gezelligheid.

Gaby, Michael, Johannes, Reni, Andre und der kleine Jonathan, Euch möchte ich auch von Herzen danken für all die Unterstützung während der letzten Jahre. Durch Euch habe ich ein zweites Zuhause fern der Heimat gefunden.

Dani, Ira, Pauline und Jona, ich bin sehr froh, dass ich Euch in meinem Leben hab. Auch wenn wir uns leider viel zu selten sehen. Die Zeit mit Euch ist für mich immer ungeheuer wertvoll und erinnert mich im Besonderen daran, dass es 
wichtigere Dinge im Leben als die Arbeit gibt. Dani, vielen Dank auch für die graphische Unterstützung.

Liebe Eltern, ich kann es gar nicht in Worte fassen, wie groß mein Dank an Euch ist. Ihr habt immer an mich geglaubt und mich bei allen Entscheidungen unterstützt und begleitet. Sicher waren meine Entscheidungen, was vor allem den Standort meiner Studien/Arbeitsplätze betrifft, nicht immer einfach für Euch. Aber Ihr habt mir niemals Steine in den Weg gelegt...dafür bin ich Euch unendlich dankbar!

Miri, Du hast während meines PhDs viel mit mir mitgemacht. Sei es, dass ich bis 2 Uhr morgens noch auf der Arbeit war, ich Testtage bedingt in der Uni schlafen musste, auf Kongressen war, frustriert darüber war, dass etwas nicht so geklappt hat wie es sollte... Du hattest jedoch immer Verständnis und hast mich noch dazu immer unglaublich unterstützt. Diesen Sommer heiraten wir - ich freue mich wahnsinnig auf weitere Abenteuer und das weitere Leben mit Dir! 



\section{Curriculum Vitae}

Emanuel Canfora was born on $19^{\text {th }}$ of May 1983 in Bietigheim-Bissingen, Germany. After an apprenticeship as a health care professional at the University Hospital Freiburg, Germany and completing secondary school at Kolping Kolleg Freiburg, Germany, he started, in 2007, a Bachelor of Science in Nutritional Science at the Technical University Munich, Germany, where he graduated in 2010. In 2011, he obtained a Master of Science degree in Physical Activity and Health at the Maastricht University, The Netherlands. In 2011, he worked as an intern at the German Diabetes Center in Dusseldorf, Germany. In September 2011, Emanuel Canfora started as a PhD candidate at the Department of Human Biology of Maastricht University Medical Centre + (MUMC+), The Netherlands, under supervision of Prof. Dr. Ellen Blaak. His research focuses on effects of gut and systemic short-chain fatty acid (SCFA) availability on parameters of control of body weight and insulin sensitivity in human in vivo studies and in human multipotent adipose-derived stem cells in vitro. He has presented his work at several national and international conferences (American Diabetes Association $74^{\text {th }}$ Scientific Sessions 2014, European Congress on Obesity 2015, European Obesity Summit 2016). During his PhD, Emanuel received five awards for abstracts and oral presentations for his in vivo and in vitro work on metabolic SCFA effects in humans. In January 2016, he received a Kootstra Talent Fellowship Grant, which enables him to continue his work on the role of gut microbial-derived SCFA in the peripheral substrate and energy metabolism. Since May 2016, Emanuel started working as Postdoctoral researcher at the Department of Human Biology at the MUMC+, The Netherlands. 
Curriculum Vitae

\section{List of Publications}

Canfora EE, Jocken JW, Blaak EE. Short-chain fatty acids in control of body weight and insulin sensitivity. Nature Reviews Endocrinology. 2015;11(10):577-91.

Canfora EE, Blaak EE. The role of polydextrose in body weight control and glucose regulation. Current Opinion in Clinical Nutrition \& Metabolic Care. 2015;18(4):395400

Van Dijk J-W, Manders R, Canfora EE, Mechelen W, Hartgens F, Stehouwer C, van Loon LJ. Exercise and 24-h glycemic control: equal effects for all type 2 diabetes patients. Med Sci Sports Exerc. 2013;45(4):628-35.

Canfora EE*, van der Beek CM*, Lenaerts K, Troost FJ, Holst JJ, Masclee AAM, Dejong $\mathrm{CHC}$, Blaak EE. Distal, not proximal colonic acetate infusions promote fat oxidation and improve metabolic parameters in overweight men. Under revision in Clinical Science. * Shared first authors

Canfora EE, van der Beek CM, Goossens GH, Jocken JW, Lenaerts K, Holst JJ, Dejong $\mathrm{CH}$, Blaak EE. Colonic infusions of short-chain fatty acids mixtures promote energy metabolism in overweight men. Submitted.

Canfora EE*, van der Beek CM*, Hermes GDA, Goossens GH, Jocken JW, Holst JJ, Venema K, Smidt H, Zoetendal EG, Dejong CH, Lenaerts K, Blaak EE. Twelve-week supplementation of galacto-oligosaccharides increased bifidobacteria in obese prediabetic adults, whereas insulin sensitivity and energy metabolism were not changed. In preparation for submission. * Shared first authors

Canfora EE*, Jocken JW*, van der Beek CM, Blaak EE. Short-chain fatty acids attenuate human in vivo and in vitro lipolysis via a decreased phosphorylation of hormone-sensitive lipase. In preparation for submission. * Shared first authors

Van der Beek CM, Canfora EE, Blaak EE, Dejong CH, Lenaerts K. Inulin enhances microbial fermentation and improves metabolic parameters in overweight males: an isotopic approach. In preparation for submission.

Jocken JW, Reijnders D, Canfora EE, Hoebers N, Goossens GH, Blaak EE. Gut microbiota manipulation and lipolysis in human adipose tissue. Submitted.

Most J, Goossens GH, Reijnders D, Canfora EE, Penders J, Blaak EE. Gut microbiota composition strongly correlates to peripheral insulin sensitivity in obese men but not in women. Submitted. 


\section{Selected oral presentations}

Oral presentation, Interorgan crosstalk session at European Obesity Summit, 11-14 June 2016, Gothenburg, Sweden

Title: Short-chain fatty acids affect intracellular lipolysis in a human adipocyte model

Elevated pitch presentation, 'best poster 2014 presentations' at the Top Institute Food and Nutrition (TIFN) Annual Conference, 21 May 2015, Unilever Research and Development, Vlaardingen, The Netherlands

TITLE: Colonic SCFA infusions promote fat oxidation and improve metabolic parameters in overweight males

Oral presentation, Organ Cross Talk session at $22^{\text {nd }}$ European Congress on Obesity, 6-9 May 2015, Prague, Czech Republic

TITLE: Colonic short chain fatty acids infusions promote fat oxidation and improve metabolic parameters in overweight males

Oral poster and pitch presentation, 'outstanding abstracts presentations' at Annual NUTRIM School of Nutrition and Translational Research in Metabolism Day, 18 December 2014, Maastricht, The Netherlands

TITLE: Colonic short chain fatty acids infusions promote fat oxidation and improve metabolic parameters in overweight males

Oral presentation, 'Best Abstracts presentations' at Annual Dutch Diabetes Research Meeting 2014, 27-28 November 2014, Oosterbeek, The Netherlands TITLE: Colonic short chain fatty acids infusions promote fat oxidation and improve metabolic parameters in overweight males

Oral presentation, new developments in obesity session at American Diabetes Association (ADA) $74^{\text {th }}$ scientific session, 13-17 June 2014, San Francisco, USA

Title: Colonic acetate infusions promote fat oxidation and improve metabolic parameters in overweight males

Poster presentation at Deutsche Gesellschaft für Gastroenterologie, Verdauungsund Stoffwechselerkrankungen (DGSV) Spring Conference, 23-24 May 2014, Berlin, Germany

Title: Colonic acetate infusions promote fat oxidation and improve metabolic parameters in overweight males

Oral presentation 'Top abstract and poster presentations' at Dutch Association for the study on obesity (NASO) Silver Jubilee Congress, 3-4 April 2014, Oosterbeek, the Netherlands

Title: Distal and proximal colonic acetate infusions differentially affect fat oxidation and improve metabolic parameters in overweight males 
Curriculum Vitae

\section{Awards and Honours}

'Kootstra Talent Fellowship Grant 2015’ for talented future postdocs, Maastricht University Medical Centre+, Maastricht, The Netherlands

'Foppe ten Hoor Award 2015' (1 ${ }^{\text {st }}$ place) for best oral presentation and discussion (3 applicants are nominated based on abstract and CV), Dutch Nutritional Science Days, 8-9 October 2015, Heeze, The Netherlands

'Poster Prize Winner 2014' (1 ${ }^{\text {st }}$ place) for best poster and elevator pitch at the Top Institute Food and Nutrition Annual Conference, 21 May 2015, Unilever Research and Development, Vlaardingen, The Netherlands

'Poster Presentation Award 2014' ( $1^{\text {st }}$ place) for outstanding abstract, best poster and poster pitch at Annual NUTRIM School of Nutrition and Translational Research in Metabolism Day, 18 December 2014, Maastricht, The Netherlands

'Best Abstract oral presentations' for best abstract at Annual Dutch Diabetes Research Meeting 2014, 27-28 November 2014, Oosterbeek, The Netherlands

'Top abstract and poster presentations' for best abstract and poster presentation at Netherlands Association for the study on obesity (NASO) Silver Jubilee Congress, 3-4 April 2014, Oosterbeek, The Netherlands 

